\title{
Inside buildings
}

Citation for published version (APA):

Palacios Temprano, J. F. (2019). Inside buildings: environment, health and performance. [Doctoral Thesis, Maastricht University]. ProefschriftMaken Maastricht. https://doi.org/10.26481/dis.20191108jp

\section{Document status and date:}

Published: 08/11/2019

DOI:

10.26481/dis.20191108jp

Document Version:

Publisher's PDF, also known as Version of record

\section{Please check the document version of this publication:}

- A submitted manuscript is the version of the article upon submission and before peer-review. There can be important differences between the submitted version and the official published version of record.

People interested in the research are advised to contact the author for the final version of the publication, or visit the DOI to the publisher's website.

- The final author version and the galley proof are versions of the publication after peer review.

- The final published version features the final layout of the paper including the volume, issue and page numbers.

Link to publication

\footnotetext{
General rights rights.

- You may freely distribute the URL identifying the publication in the public portal. please follow below link for the End User Agreement:

www.umlib.nl/taverne-license

Take down policy

If you believe that this document breaches copyright please contact us at:

repository@maastrichtuniversity.nl

providing details and we will investigate your claim.
}

Copyright and moral rights for the publications made accessible in the public portal are retained by the authors and/or other copyright owners and it is a condition of accessing publications that users recognise and abide by the legal requirements associated with these

- Users may download and print one copy of any publication from the public portal for the purpose of private study or research.

- You may not further distribute the material or use it for any profit-making activity or commercial gain

If the publication is distributed under the terms of Article $25 \mathrm{fa}$ of the Dutch Copyright Act, indicated by the "Taverne" license above, 


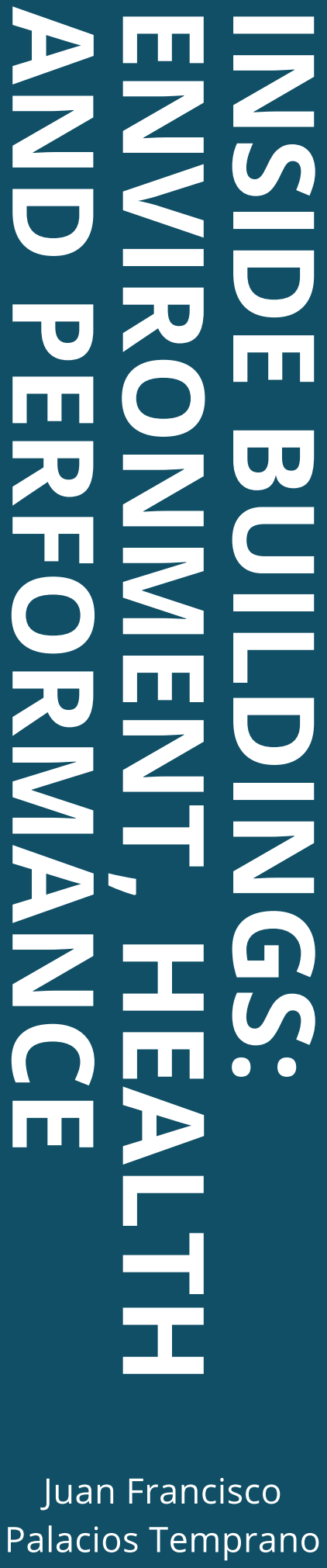




\title{
Inside Buildings:
}

\section{Environment, Health And Performance}

\author{
Juan Francisco Palacios Temprano
}




\section{ISBN}

978-94-6380-582-7

Design cover and artwork

Linda van Zijp

http://www.studiolin.nl

Printed by

ProefschriftMaken.nl

\section{Copyright (c)2019 Juan Francisco Palacios Temprano}

All rights reserved. No part of this publication may be reproduced, stored in a retrieval system, or transmitted, in any form, or by any means, electronic, mechanical, photocopying, recording or otherwise, without the prior permission in writing from the author.

This book was typeset using $\mathrm{LT}_{\mathrm{E}} \mathrm{X}$. 


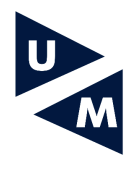

\author{
MAASTRICHT UNIVERSITY
}

\title{
Inside Buildings:
}

\section{Environment, Health And Performance}

\author{
Dissertation \\ to obtain the degree of Doctor at Maastricht University, \\ on the authority of the Rector Magnificus Prof. dr. Rianne M. Letschert \\ in accordance with the decision of the Board of Deans, \\ to be defended in public on Friday 8th November 2019 at 10:00 hours \\ by \\ Juan Francisco Palacios Temprano
}




\section{Promotor:}

Prof. Dr. Piet Eichholtz

\section{Co-Promotor:}

Dr. Nils Kok

\section{Assessment Committee:}

Prof. Dr. Jaap Bos, chairman

Dr. Joseph Gardner Allen (Harvard)

Prof. Dr. Lex Borghans

Prof. Dr. Wouter van Marken Lichtenbelt

Prof. Dr. Siqi Zheng (MIT) 
A Delia y Farruco. 



\section{Acknowledgements}

This $\mathrm{PhD}$ thesis has been a long, hilly marathon that I by no means could have completed without the support of an extraordinary group of people around me. First, I would like to thank the person that has been my academic GPS for the last four years, Piet Eichholtz, who guided me with the right questions every step of the way. Piet, you have been an amazing mentor to me, sharing with me the keys to open the door of academia, and even more importantly, teaching me how to be happy in the academic world. Defining a good route is a necessary but not sufficient condition to complete a race; you can only finish the challenge with a sufficient dose of perseverance and confidence. Over the past several years, Nils Kok has been the stamina behind this $\mathrm{PhD}$ thesis, providing me with the necessary discipline and motivation to get to the finish line.

The department of finance has been a fantastic place to run this marathon. Starting with the head, a 4x4 chair was always ready to offer advice on methods, food, swimming, hiking, and anything that has to do with nature. Jaap, "jefe," thanks for all of your time and coaching; our conversations have provided great guidance for me within and outside the office. The title of Southern European in the finance department has belonged to an incredible gentleman for several years: Paulo Rodrigues, a Portuguese with a great heart and an amazing brain, has always been ready to support me in any way at any time. My dear Portuguese, you have been a true advocate. Additionally, I have benefited from the open-door culture of the department. Peter, Stefan, Rachel, Rob, Roger, Peiran, thank you so much for being available every time I needed help while working toward my $\mathrm{PhD}$. And last but not least, I thank Francien, Carina, Els, and Cecile, the core of operations of the department, for helping all of us get our paperwork ready, and for always doing so with a smile on their faces.

Those of you who read beyond the acknowledgments will see the name of Steffen Kuenn on two of the chapters of this thesis. Both chapters have been the result of a lot of long and painful days in the office, struggling together with unmatchable datasets, remote servers, coding, and econometric books. Even in the darkest days, when (literally) nothing worked, we managed to remain positive and continue learning from the challenges. Steffen has been a fantastic teacher, co-author, and friend to me since I met him at the end of my first year. He has opened the doors 
to IZA, an amazing source of inspiration headed by Nico Pestel, who has always been a great host and great co-author. Our time together in Bonn and "a major city in West Germany" have filled my bag with knowledge, friends, and good memories.

Paul Smeets has been next to me since day one of my time in Maastricht. Paul, thanks for being one of the most inspiring people that I have ever met. You make every obstacle in the journey a challenge, every barrier a target, and every meeting together a memorable moment. As a PhD student, I benefited incredibly from Dr. Smeets's tips for presenting my work, meeting people, and writing papers. My research ideas have always welcomed a spicy and inspiring comment from you. Paultje, after being your eyes many times over the past years, I can say that I see you as an uncommon breed and someone that views the world differently. As a friend, I have always learned from your perspective on the challenges that I faced over the past few years.

During my time in Maastricht, Matthijs Korevaar has been the angel on my right shoulder. It's been a real pleasure to share my time with a person with such high ethical values, talent, and curiosity. Matthijs has always been there to provide support and feedback in my research and my personal life. Being the good climber that he is, he is an amazing person to take you down from the deeps. Over the years, we have had endless conversations during a great variety of activities; we have cooked together, cycled the hills of Limburg, danced, travelled, and more. Korevaar, I do not know where the near future will take you, but I also do not know anyone who doubts you are going to be successful.

I was lucky enough to be part of a great $\mathrm{PhD}$ cohort in the finance department, a heterogeneous group of people who created a working atmosphere that made the race a more pleasant experience. First, Mike Langen, who usually served as the mastermind behind the department's social, proposed all sorts of evening plans. Mike, thanks for all the great memories in Maastricht, Boston, and the rest of the cities that we have visited together over the last several years. Sharing a flat or hotel room with you always produced a great combination of stories, jokes, and good conversations. I could not skip Clarissa Hauptman, my nocturne buddy, with whom I shared so many night shifts in the office finishing our papers, and my dance partner in my first steps in the salsa world. Thanks to my Swiss Army knife made in Belgium: a wonderful friend, teacher, and curious researcher, always ready to fight with Stata. Manzana, you have been an amazing support during these years, a person to learn from, a friend to rely on, and a wonderful mum and daughter at the same time. Thank you for coming to my office to provide free hugs and cheer. Finally, thanks to all the $\mathrm{PhD}$ students with whom I got to share great conversations and memories: Tobias, Ehsan, Inka, Nora, Iman, Rogier Holterman, Rogier Quaedvlieg, Judy, Katrin, Frauke, Addy, Rasmus, Ulrike, Kim, Marina, and Michael.

The allocation of individuals to offices granted me with amazing office mates, each of them always ready to help any time that was needed. First, Alessandro, an Italian gentleman with 
an exquisito stomach, passionate for Fiorentina and an unlimited source of anecdotes. Matteo Bonetti, the Italian cyclist, equipped with incredible modesty, an amazing heart, and resilience for hard work. Matteo, if there is some fairness in this world and if effort pays off, even a little, you will reach all your goals. Finally, Martijn, a wonderful gentleman behind a face made for modelling. A psychologist thrown into economics, always ready to listen to any issue, give you his opinion, and a hand when it is needed.

My $\mathrm{PhD}$ journey would not have been nearly as inspirational without the long conversations with Chris Pyke and Seema Bhanghar. Chris, our conversations have always been a source of ideas, questions, and inspirational challenges since our meeting in the first year of my PhD. Seema, my Indian mum, thanks for all you have done for me over the past three years. Spending the summer of my second year in your house was one of the highlights of my time as a PhD student. Thank you for taking such great care of me and for integrating me into your family. Our long conversations and discussions, full of critical questions and advice, have opened the door to a new field of knowledge to me, and helped me understand concepts that will be key for the upcoming chapters in this thesis.

The first step of any race begins with getting to the starting line. Several people were vital for me in pursuing a career in academia, starting with Pilar, my high school teacher who shared her passion for economics with me, and guided me through my first steps in the field. I thank Enrique Llopis Agelan and Indalecio Corugedo, who gave me the opportunity to try research for the first time while I was pursuing my bachelor's degree. Piet Eichholtz once told a bunch of graduates, "Choose your first job wisely; the first boss in someone's career is crucial." I had an excellent first boss. Claudio was a great mentor who taught me numerous life lessons that have continued to guide my choices and actions. Finally, thanks to all the friends who walked with me during the previous stages of my education: my friends from primary and secondary school, Tomás, Marru, Adan who have always been there for me, in good and bad times since I was a child; Nico, the trigger of my life abroad, a source of advice, life tips and always ready for a good party; Sergio, who was next to me during my bachelor's and master's studies, sharing uncountable days at the library, good food and great trips with me.

Midway through this race, a wonderful woman tapped me on the shoulder and asked, "Do you want to dance?" Since then, we have been running together during this and multiple other challenges with big smiles on our faces. Es, you have been an amazing partner since the first mile together, running by my side, pulling me when needed, and giving me all the support, confidence, and energy needed to get this $\mathrm{PhD}$ to the final stage.

The people listed above are simply the first nodes of a network that would take me hundreds of pages to describe. Behind them are amazing families that I got the pleasure to meet over the past four years. Annemarie Kuenn-Nelen, Lian Kok, Margo Eichholtz, Omi and Bompa, and 
Ria, Wim and Mieke Smeets, thanks for opening the doors to your homes and always welcoming me with open arms on every occasion.

I am not the exception that challenges the rule. I have a wonderful family that have been always there for me. Querida familia, gracias por todo el apoyo durante este tiempo. Este doctorado es el fruto de muchos sacrificios hechos por todos vosotros durante todos estos años. Mama, papa, gracias por el cariño y la educación que me habéis dado, ninguna de las oportunidades que me ha dado la vida en estos últimos cuatro años hubiesen sido posibles sin vosotros. Fer, gracias por ser un hermano maravilloso, siempre cerca de mi pese a la distancia, siempre al otro lado del teléfono, intentando coger vuelos con el DNI caducado, y siendo la primera cara que veo cada vez que aterrizo en España. Durante todos estos años, nadie ha aprendido hacerme de rabiar como tu solo sabes, pero tampoco de motivarme y cuidarme dentro y fuera de casa como tú. Y finalmente, Leonardo, el tío pequeño, fuente de inspiración y sabiduría desde que llegaste a Madrid con un ordenador y docenas de libros debajo del brazo. Leo, esta carrera no hubiera sido posible sin todos los caminos y puentes que con tanto esfuerzo construiste en la familia mucho antes de que yo naciese.

Tot slot, een fantastische familie in Nederland waar ik me heel welkom voel. Familie ter Horst, ik kan hier veel dingen schrijven die jullie voor mij hebben gedaan. Jullie hebben gezorgd voor een familie ver van mijn oorspronkelijke huis. Deze gelukkige Spanjaard heeft altijd een plek aan tafel, een theemok naast die van jullie, een fiets om op te fietsen en een plek in de bus. De fietstochtjes, uitstapjes, etentjes en wandelingen samen waren een geweldige hulp in de laatste miles van deze $\mathrm{PhD}$ race. 


\section{Contents}

\begin{tabular}{lll}
\hline & Introduction & 3
\end{tabular}

1.1 Health Effects of Pollution And Temperature . . . . . . . . . . . . . . . . 4

1.2 Behavioral Reactions to Unsafe Environments . . . . . . . . . . . . . . . . . . 6

1.3 The Role of Indoor Environments . . . . . . . . . . . . . . . . . . . . . . . . . . 8

1.3.1 The Role of Housing as Public Health Measure . . . . . . . . . . . . 8

1.3.2 Human Performance And The Indoor Environment . . . . . . . . . . . . . 10

2 Housing Conditions And Health Outcomes 15

2.1 Literature . . . . . . . . . . . . . . . . . . . . . . . . . . . . . . . . . . . 18

2.2 Data And Descriptive Statistics . . . . . . . . . . . . . . . . . . 20

2.2 .1 Health Outcomes . . . . . . . . . . . . . . . . . . . . . 20

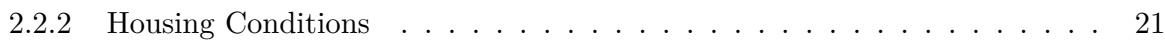

$2.2 .3 \quad$ Socio-Demographic Characteristics $\ldots \ldots \ldots \ldots \ldots \ldots . \ldots \ldots 22$

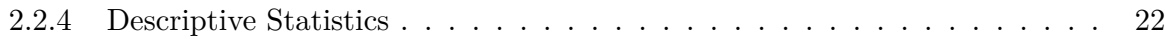

2.3 Empirical Strategy $\ldots \ldots \ldots \ldots$. . . . . . . . . . . . . . . . . . 26

2.4 Results . . . . . . . . . . . . . . . . . . . . . . . . . . . . . . . 30

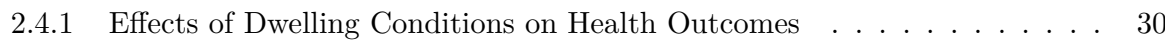

2.4 .2 Dwelling Conditions And Economic Outcomes . . . . . . . . . . . . 32

2.4 .3 Heterogenous Effects $\ldots \ldots \ldots \ldots \ldots \ldots$

2.4 .4 Robustness Checks . . . . . . . . . . . . . . . . . . . . . . . . . 37

2.4 .5 Housing Conditions and Avoidance Behavior . . . . . . . . . . . . 38

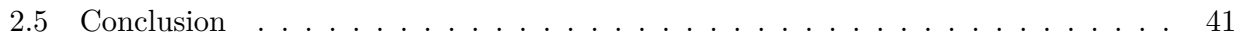

3 Health Benefits of House Renovations 43

3.1 Literature . . . . . . . . . . . . . . . . . . . . . . . . . . . . . . 45

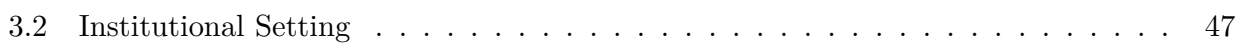

3.3 Data And Descriptive Statistics . . . . . . . . . . . . . . . . . . . . 52

3.3 .1 Dwelling Renovations . . . . . . . . . . . . . . . . . 52

3.3 .2 Individual Health And Well-Being $\ldots \ldots \ldots \ldots . \ldots \ldots$ 
$3.3 .3 \quad$ Description of Estimation Sample. . . . . . . . . . . . . . . . . 54

3.3 .4 Preferences for A Renovated Home . . . . . . . . . . . . . . . . . . 56

$3.4 \quad$ Empirical Strategy $\ldots \ldots \ldots \ldots$

3.5 Results . . . . . . . . . . . . . . . . . . . . . . . . . . . 62

3.5.1 Effects of Renovation Program . . . . . . . . . . . . . . . . 62

3.5.2 Gender Differences . . . . . . . . . . . . . . . . . . . . . . . 63

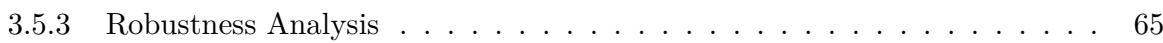

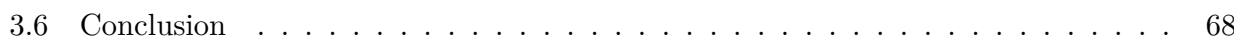

\begin{tabular}{|lll}
\hline Worker Health And IEQ at The Workplace & 71
\end{tabular}

4.1 Literature . . . . . . . . . . . . . . . . . . . . . . . . . . . . . . 73

4.2 Study Set-Up . . . . . . . . . . . . . . . . . . . . . . 74

4.2 .1 Background . . . . . . . . . . . . . . . . . . . . . 74

4.2 .2 Survey Design $\ldots \ldots \ldots \ldots \ldots \ldots$

$4.2 .3 \quad$ Descriptive Statistics $\ldots \ldots \ldots \ldots \ldots \ldots$

$4.2 .4 \quad$ Descriptive Results: Difference-in-Difference . . . . . . . . . . . . . . . . . 79

4.3 Empirical Strategy $\ldots \ldots \ldots \ldots$

4.4 Results . . . . . . . . . . . . . . . . . . . . . . . . . . . . . . . . . 83

$4.4 .1 \quad$ Regression Models Difference-in-Differences . . . . . . . . . . . . . . 83

4.4 .2 Dynamic Effects . . . . . . . . . . . . . . . . . . . . . . . 86

4.4 .3 Heterogeneous Effects . . . . . . . . . . . . . . . . . . 86

$4.4 .4 \quad$ Association between environmental conditions and health . . . . . . . . . 89

4.5 Conclusions $\ldots \ldots \ldots \ldots \ldots \ldots$

5 Indoor Air Quality And Human Cognition 101

5.1 Literature . . . . . . . . . . . . . . . . . . . . . . . 104

5.1 .1 Environment And Health . . . . . . . . . . . . . . . . . . . . 104

5.1 .2 Environment And Cognition $\ldots \ldots \ldots \ldots$. . . . . . . . . . . . . . . .

5.1 .3 Environment And Worker Performance . . . . . . . . . . . . . . . 108

5.2 Chess Tournaments: Background And Data . . . . . . . . . . . . . . . . . . . 110

5.2 .1 Tournament Setup And Chess Rating Score . . . . . . . . . . . . . . . . 110

$5.2 .2 \quad$ Move-Performance Measures $\ldots \ldots \ldots$. . . . . . . . . . . . . . . . 112

5.2 .3 Time Control . . . . . . . . . . . . . . . . . . . . . . . . . . . . . . . . . 114

5.2 .4 Measurement of Indoor Environmental Conditions . . . . . . . . . . . . . 115

$5.2 .5 \quad$ Descriptive Statistics $\ldots \ldots \ldots \ldots \ldots \ldots \ldots$

5.3 Empirical Model $\ldots \ldots \ldots \ldots \ldots$

5.4 Results . . . . . . . . . . . . . . . . . . . . . . 120 
5.4 .1 Pooled Estimation $\ldots \ldots \ldots \ldots$. . . . . . . . . . . . . . . 121

5.4 .2 Effect heterogeneity with Respect to Time Pressure . . . . . . . . . . . 121

$5.4 .3 \quad$ Effect Heterogeneity with Respect to Individual And Game Characteristics 124

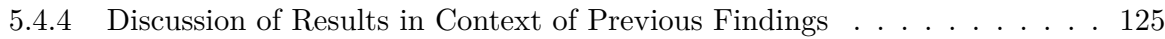

5.5 Sensitivity Analysis . . . . . . . . . . . . . . . . . . . . 127

5.5 .1 Maximum values . . . . . . . . . . . . . . . . . . . . . . . . . . . . . . . . 129

5.5 .2 Attrition $\ldots \ldots \ldots \ldots \ldots \ldots \ldots \ldots$

5.5 .3 Outdoor values . . . . . . . . . . . . . . . . . . . . . . . . . . . . . 129

5.5 .4 Other Pollutants . . . . . . . . . . . . . . . . . . . . . . . . 130

$5.5 .5 \quad$ Lagged And Lead Pollution Values . . . . . . . . . . . . . . . . . . . 130

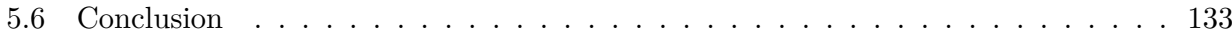

6 Classroom Environment And Pupil Performance 141

6.1 Literature . . . . . . . . . . . . . . . . . . . . . . . . . . . . . . . . . . . 142

6.1.1 The Effects of Ambient Environment on Health And Cognitive Functioning 142

6.1 .2 Existing Studies on Indoor Environmental Quality in Schools . . . . . . . 144

6.2 Methods . . . . . . . . . . . . . . . . . . . . . . . . . 146

$6.2 .1 \quad$ The Elementary Education System in The Netherlands . . . . . . . . . . 146

$6.2 .2 \quad$ Study Sample And Study Design . . . . . . . . . . . . . . . . . . . . . . 147

$6.2 .3 \quad$ Monitoring Environmental Conditions in Classrooms . . . . . . . . . . . . 148

6.2 .4 Student Performance . . . . . . . . . . . . . . . . . . . . . . . . 149

6.2 .5 Individual Characteristics . . . . . . . . . . . . . . . . . . . . . . 149

$6.2 .6 \quad$ Medical Ethical Approval $\ldots \ldots \ldots \ldots$. . . . . . . . . . . . . 150

6.3 Pilot Study $\ldots \ldots \ldots \ldots \ldots$

6.3.1 Pilot Test 1: Differences in Environmental Conditions Within and Across

Classrooms . . . . . . . . . . . . . . . . . . . 151

6.3.2 Pilot Test 2: Time-Series Variation of Sensors over The Academic Year. . 152

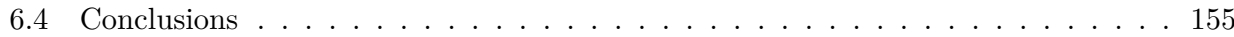

\begin{tabular}{lll}
\hline 7 & Conclusion & 163
\end{tabular}

\begin{tabular}{lll}
\hline 8 & Research Impact & 167
\end{tabular} 



\section{List of Figures}

1.1 Percentage population living in a dwelling with a leaking roof, damp walls, floors or foundation, or rot in window frames of floor in 2017 . . . . . . . . . . . . . . 9

$2.1 \quad$ Housing conditions and occupant health . . . . . . . . . . . . . . 24

2.2 Housing conditions and occupant mental and physical health over lifetime . . . . 36

3.1 Home amenities in East German dwellings over time . . . . . . . . . . . . . . 50

3.2 Percentage of households reporting a renovation in Eastern and Western Germany 51

3.3 Percentage of households reporting in a dwelling in need for partial or full renovation in Eastern and Western Germany . . . . . . . . . . . . . . . . . 51

3.4 Distribution Loan Take-up per Inhabitant Across Counties over Years of the Pro-

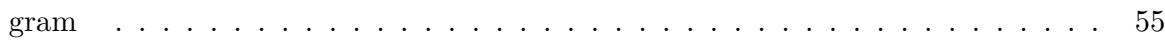

3.5 Timing of the empirical model $\ldots \ldots \ldots \ldots \ldots$. . . . . . . . . 60

4.1 Ventilation system in newly constructed building . . . . . . . . . . . . . . 75

4.2 Timing of survey waves $\ldots \ldots \ldots \ldots \ldots \ldots \ldots$

4.3 Example question about evaluating indoor air quality (translated to English) . . 77

4.4 Trends in perception of indoor environmental conditions . . . . . . . . . . . 87

4.5 Trends in sick building syndrome $(1=\mathrm{Yes}) \ldots \ldots \ldots \ldots$

$4.6 \quad$ Effect environmental problems on sick building syndrome . . . . . . . . . . . . 91

4.7 Panel A. Trends in Job Satisfaction. . . . . . . . . . . . . . . . . . . . . . . . . . . . . . 98

5.1 Player skills and average move performance . . . . . . . . . . . . . . . . 113

5.2 Distribution of total number of moves per game . . . . . . . . . . . . . 115

5.3 Indoor environmental conditions as measured on the days at the tournaments . . 116

5.4 Distribution of players' Elo rating score $\ldots \ldots$. . . . . . . . . . . 117

5.5 Impact of indoor environmental quality on performance of chess players by move level . . . . . . . . . . . . . . . . . . . . . . . . 123

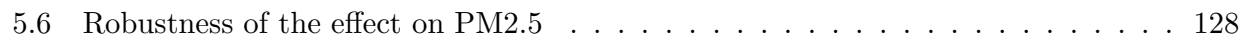

5.7 Robustness check: Inclusion of ozone $\ldots \ldots \ldots$. . . . . . . . . . . 131 
5.8 Robustness check: Lagged and lead pollution values . . . . . . . . . . . . . . . . . 132

5.9 Timing and setting of the chess tournaments $\ldots \ldots \ldots$. . . . . . . . 135

5.10 Example of players' hand-written game notation $\ldots \ldots \ldots$. . . . . . . 136

5.11 Example for sensor location . . . . . . . . . . . . . . . . . . 137

5.12 Distribution of indoor-environmental-quality measures during the tournament rounds . . . . . . . . . . . . . . . . . . . . . . . . . 138

5.13 Robustness of the effect on temperature $\ldots \ldots \ldots \ldots$. . . . . . . . 139

5.14 Robustness of the effect on CO2 $\ldots \ldots \ldots \ldots$. . . . . . . . . . 140

6.1 Current studies on IEQ and cognitive performance in children. . . . . . . . . . 146

6.2 Correlation in $\mathrm{CO}_{2}$, coarse particles and temperature within and across classrooms. . . . . . . . . . . . . . . . . . . . 152

6.3 Temperature and $\mathrm{CO}_{2}$ levels over the 2015-2016 academic year in classroom 1 of School 1 (with mechanical ventilation). . . . . . . . . . . . . . . 153

6.4 Temperature and $\mathrm{CO}_{2}$ levels over the 2015-2016 academic year in classroom 1 of School 2 (without mechanical ventilation). . . . . . . . . . . . . . . . 154

6.5 Distribution of daily CO2 peaks over the 20162017 academic year in Pilot School 1 for three scenarios in the ventilation system conditions. . . . . . . . . . . . 155

6.6 Distribution of daily CO2 peaks in Classroom 1 and Classroom 2 of Pilot School 2 before and after modification in ventilation system. . . . . . . . . . . . . 155

6.7 Average daily counts of Coarse Particles (count/L) in Classroom 1 and Classroom 2 at Pilot School 2 over the fall of the academic year 2016-2017 before and after the ventilation system is modified (January 2017). . . . . . . . . . . . . . . 161

6.8 Average daily Temperature (in C) in Classroom 1 and Classroom 2 at Pilot School 2 over the fall of the academic year 2016-2017 before and after the ventilation system is modified (January 2017). . . . . . . . . . . . . . . . . . 161 


\section{List of Tables}

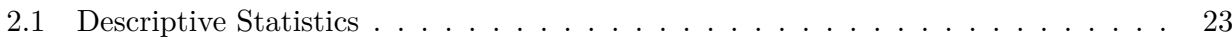

$2.2 \quad$ Household and dwelling characteristics per dwelling condition . . . . . . . . . . 25

2.3 Housing conditions and health outcomes . . . . . . . . . . . . . . . 27

2.4 Estimation results housing conditions on subjective health status . . . . . . . . 31

$2.5 \quad$ Estimation results housing condition and demand for health care . . . . . . . . 33

$2.6 \quad$ Heterogeneous effects by age group $\ldots \ldots \ldots \ldots \ldots$

$2.7 \quad$ Estimation results housing condition and health behavior $\ldots \ldots \ldots$. . . . . 38

2.8 Avoidance behavior to deficient housing condition . . . . . . . . . . . . . . 39

2.9 Years in need of renovation by ownership status . . . . . . . . . . . . . . 40

3.1 Home amenities in German dwellings at reunification in 1990 . . . . . . . . . . . 49

3.2 Descriptive statistics treated and non-treated households in the first year of the

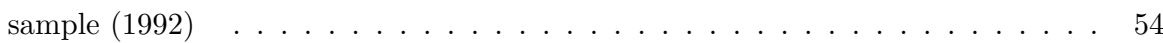

3.3 Validation treatment variable. Specification test $\ldots \ldots \ldots \ldots$. . . . . . . 57

3.4 Change in address, rent per square meter and living conditions around the reno-

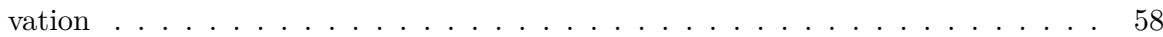

$3.5 \quad$ Effect renovations on health outcomes in years before and after renovation . . . 63

3.6 Effect renovations on health outcomes in years before and after renovation . . . 64

3.7 Labor market outcomes $\ldots \ldots \ldots$. . . . . . . . . . . . . . . . . . . 64

3.8 Effect renovation wave on objective health measures by gender . . . . . . . . 66

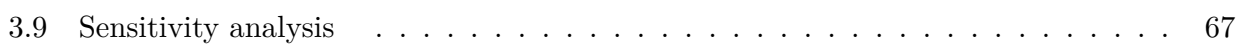

4.1 Descriptive statistics sample in first survey wave (Before the move, July 2016)] . 78

4.2 Panel A. Basic difference-in-difference . . . . . . . . . . . . . . . . . . . . 80

4.3 Estimation results difference-in-difference $\ldots \ldots \ldots \ldots$. . . . . . . . . . . . . . . 84

4.4 Heterogeneity Analysis $\ldots \ldots \ldots \ldots$. . . . . . . . . . . . . . . . . . 90

4.5 Response rate . . . . . . . . . . . . . . . . . . . . . 94

4.6 Description questions in survey $\ldots \ldots \ldots \ldots \ldots \ldots \ldots$

4.7 Heterogeneity analysis job satisfaction $\ldots \ldots \ldots \ldots$ 
4.8 Estimation results impact of indoor environmental quality on sick building syndrome 100

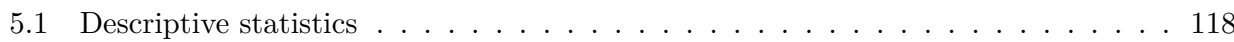

5.2 Impact of indoor environmental quality on performance of chess players . . . . . 122

5.3 Effect heterogeneity with respect to individual and game characteristics . . . . 126

6.1 Sensor characteristics $\ldots \ldots \ldots \ldots$. . . . . . . . . . . . . . . . . 148

6.2 Student performance assessments ． . . . . . . . . . . . . . . . . . . . . 149

6.3 Health outcomes . . . . . . . . . . . . . . . . . . . . . . . . . . 150

6.4 Student performance assessments $\ldots \ldots \ldots \ldots$. . . . . . . . . . . 151

6.5 Disease prevalence of children . . . . . . . . . . . . . . . . . 157

6.6 Medicine usage of children $\ldots \ldots \ldots \ldots \ldots \ldots$

6.7 Current treatments $\ldots \ldots \ldots \ldots \ldots \ldots$ 
"we shape our buildings and afterwards our buildings shape us."

Winston Churchill (1943) 



\section{Chapter 1}

\section{Introduction}

The advent of climate change, rising pollution and rapid global urbanization are exposing an unprecedented number of people to unhealthy environmental conditions. About $90 \%$ of people around the world now live in places that do not comply with the WHO Air Quality Guidelines (WHO, 2016). According to different observational records, global temperatures in the last decade (2009-2018) were an average of $0.91^{\circ} \mathrm{C}$ to $0.96^{\circ} \mathrm{C}$ warmer than the pre-industrial average EEA, 2019). This shift in the distribution of global temperatures is increasing the frequency and severity of the exposure of individuals to extreme temperatures. Heat waves are expected to become recursive events in most regions around the world, including Europe and North America (Russo et al., 2014).

The health science literature has documented the damaging effects of air pollution and extreme temperatures on health, and their massive impacts on economic costs in modern societies. Individuals spend about $90 \%$ of their time indoors, attributing a key role to buildings as a 'protective shield' towards outdoor environmental hazards. Buildings, and the adequacy of heating, cooling and insulation systems affect the extent of protection from outdoor conditions, and are thus likely to have a substantial impact on occupants. However, our current understanding on how indoor environmental conditions affect human health and performance is rather limited and either based on small-scale experiments on poor households in developing countries, or cross-sectional studies lacking causal identification.

This thesis investigates the role of indoor environmental conditions in shaping human health and performance outcomes. Chapter 1 presents an overview of the literature investigating the influence of environmental conditions on human health, and it introduces a conceptual model describing the behavioral reactions of individuals to reduce the damage of hazardous environments. Afterwards, I present a series of large quasi-experimental studies investigating the influence of indoor environmental conditions on human health and performance. The first set of studies explores the role of housing in shaping occupant health (chapters 2 and 3), where I use 
population-representative household panel datasets to investigate the impact of housing conditions on occupant health and well-being. In the second part of this dissertation, I describe the role of indoor environmental conditions on health and cognitive performance at the workplace (chapters 4, 5, 6).

\subsection{Health Effects of Pollution And Temperature}

The health science literature has documented extensively the damaging effects of air pollution and extreme temperatures on human health. Air pollution alone is estimated to be responsible for 9 million premature annual deaths, according to 2015 global estimates (Landrigan et al., 2018). In addition, a recent study based on 74 million deaths between 1985 and 2012 in 13 countries around the globe estimates that $7.7 \%$ of mortality was attributable to temperature exposure (Gasparrini et al., 2015).

The health effects of air pollution have been the scope of analysis of numerous studies over the past decades. There is a wealth of evidence showing that exposure to air pollution has detrimental consequences for human health, even at moderate levels. The inhalation of ozone or particulate matter has been associated with mortality and hospital admissions due to cardiopulmonary health problems (Brunekreef and Holgate, 2002). The respiratory system is the primary target of air pollutants. Epidemiological studies document associations between the presence of air pollutants and respiratory health morbidity, such as exacerbation of asthma or declines in lung function (for a review, see Rückerl et al., 2011). Cardiovascular systems are also vulnerable to airborne particles. For instance, exposure to high levels of ultra fine particles has been associated with the advent of ischemic heart disease and elevated blood pressure (Pope et al. 2004, Bhatnagar, 2006). Ultimately, sustained exposure to air pollution shortens lives. Quasi-experimental evidence from China estimates that a $10 \mu \mathrm{g} / \mathrm{m} 3$ increase in long term exposure to $\mathrm{PM}_{10}$ shortens life expectancy by a total of 0.64 years (Ebenstein et al. 2017). Inhalation of smaller particles (e.g. $\mathrm{PM}_{2.5}$ ) is even more harmful for human health. In a sample of more than 600 cities, Liu et al. (2019) show the increase of $10 \mu \mathrm{g} / \mathrm{m} 3$ in $P M_{2.5}$ is associated with an increases in daily all-cause mortality 1.5 times higher than a $10 \mu \mathrm{g} / \mathrm{m} 3$ in $P M_{10}$. Globally, a recent study examining all mortality causes and burden of disease in 2015 estimates that inhalation of polluted air $\left(P M_{2.5}\right)$ is the fifth most important risk mortality factor, responsible for 4.2 million deaths in the world (Cohen et al., 2017).

In addition, there is increasing evidence on mortality and morbidity attributable to hot and cold temperatures. The damaging effects of extreme temperatures generate significant burden on the cardiovascular and respiratory health systems. Epidemiological studies document significant associations between temperatures and cardiovascular diseases, such as atherosclerosis or 
pulmonary heart disease (Xiaofang et al., 2012). Global estimates indicate the existence of a significant threat of temperature on human health (Gasparrini et al., 2015). Gasparrini et al. (2015) estimate that the exposure to warm and (especially) cold temperatures are responsible of $7.71 \%$ of the total 74 million deaths considered in the study. While these estimates are mainly driven by exposure to sustained exposure to moderately cold or warm temperatures, a recent wave of studies document substantial peaks in mortality associated with the advent of extremely warm and cold days (Barreca et al., 2016, Deschênes and Greenstone, 2011, Deschenes and Moretti, 2009 ).

The impact of short term fluctuations in air pollution or temperatures on human health are present over the entire the human life cycle. Prenatal exposure to extreme temperatures or high levels of air pollution have been associated with low birth weight and infant mortality (Deschênes, Olivier, Greenstone, Michael, \& Guryan, 2017, Chay and Greenstone, 2003). The exposure in utero to these hazards has long term welfare consequences for individuals. Based on a sample of 12 million individuals born in the United States, Isen et al. (2017a) find that the exposure to an extra day with mean temperatures above $32^{\circ} \mathrm{C}$ in utero and first year of life is associated with a $0.1 \%$ reduction in adult annual earnings at age 30. Similarly, Isen et al. (2017b) use the quasi-experimental variation in county-level pollution generated by the 1970 Clean Air Act Amendments (CAAA) in the United States to provide estimates of how air pollution in the year of birth affects earnings. Isen et al. find that reduction in air pollution led to an increase in the time the individual is employed and the annual earnings at age 30 .

The student population is one of the most vulnerable groups, given the developing status of organs and immune system. In addition, children are less able to avoid exposure given their limited ability to manage their schedules and budgets. The literature shows that temperature or air pollution fluctuations have numerous consequences for the well-being of children. Besides the short term health effects, adverse environmental conditions have been associated with detrimental human capital formation. Currie et al. (2009) link attendance data from school districts in Texas to ambient air pollution in the area of elementary and middle schools, showing that high levels of air pollution (carbon monoxide) are associated with increases in school absence. In addition, there is an increasing number of studies estimating the effects of short term fluctuations in temperatures and pollution on test and learning outcomes. The evidence shows that exposure to extremely high temperatures or high levels of pollutions during both learning or testing time, harms academic performance (Goodman et al., 2018; Park, 2018; Ebenstein et al. 2016: Roth, 2018).

In addition, an increasing number of studies show the detrimental effects of environmental factors on the productivity and earnings of workers. The results show how both indoor and outdoor workers are unable to provide the same output levels when exposed to highly polluted 
or extremely hot environments (Graff Zivin and Neidell, 2012, Chang et al., 2016, 2019).

Finally, air pollution and extreme temperatures are not only affecting the length of human life, but also the quality of life of people in their last years. Older adults are considered to be highly vulnerable to environmental hazards due to the presence of pre-existing diseases in their bodies. Air pollution and extreme temperatures cause significant damages to the respiratory and cardiovascular systems of the elder population, whose pre-existing health problems tend to be exacerbated by these environmental risk factors. Mental illnesses are no exception, recent studies have associated the exposure to air pollution with cognitive decline and episodes of dementia in the elder population (Power et al., 2016; Zhang et al., 2018, Landrigan et al., 2018). The aging of the global population is likely to exacerbate the health implications of environmental risk factors.

\subsection{Behavioral Reactions to Unsafe Environments}

Individuals do not necessarily remain passive when exposed to pollution and temperature-related hazards, and typically try to minimize the harmful consequences of these risk factors. In this section, we present a model to conceptualize how individuals react to the presence of these hazards.

The total damage that an individual $i$ is suffering due to an environmental risk $s$, is a function of the dose response (DoseResponse S $_{\text {) }}$, i.e. the amount of damage created per unit of time that individual $\mathrm{i}$ is exposed to the environmental risk factor (e.g. air pollution), and the exposure time $\left(\right.$ Exposure $_{i, s}$ ) that individual $i$ is exposed to the hazard:

$$
\text { Damage }_{i, s}=\text { Exposure }_{i, s} \times \text { DoseResponse }_{s}
$$

If we consider a world where all individuals in our population of interest have the same dose response function, i.e. all individuals would suffer equally per second of exposure to the damaging environmental risk factor $s$, and therefore the only factor that mediates the total ultimate damage is the exposure $\left(\right.$ Exposure $\left._{i, s}\right)$ :

$$
\text { Exposure }_{i, s}=f\left(\text { time }_{i, s}, \text { distance }_{i, s}, \text { protection }_{i, s}\right)
$$

The exposure to environmental risk factor $s$ of individual $i$ is a function of time that the individual is exposed to the source, distance to the source, and protection against the source. The exposure time is a simply the amount of time that an individual has a positive exposure to a hazardous risk factor (e.g. air pollution or extreme temperature). The distance to the 
source describes the physical space (e.g. meters) between the individual and the source. For the case of air pollutants (e.g. $\mathrm{PM}, \mathrm{NO}_{2}$ or $\mathrm{SO}_{2}$ ), the distribution generally reaches its peak at the source of the pollutant (e.g. factory or highway) and drops with the distance to the source (for empirical evidence esimating the spacial density function around polluting sources, see for expample Currie et al., 2015: Liu et al., 2016). Finally, given an exposure time at a given distance to the source, individuals can undertake a series of protective or defensive strategies to reduce the final damage. A typical example would be wearing air masks to reduce the amount of fine particles (PM) inhaled or the use of air conditioning to avoid the exposure to extremely hot temperatures. Given an intake, individuals might also reduce health damage or suffering by the use of medication to deal with diseases produce by the source, for example, medication for asthma (Deschênes, Olivier, Greenstone, Michael, \& Guryan, 2017).

\section{Sorting}

Individuals are able to reduce total exposure to pollutants by increasing the distance to the source at any given time distance $_{i, s}$. The place of residence is the place where individuals spend most of their time, and thus determines the distance to the source. In the case of air pollution, the overwhelming majority of urban dwellers are exposed to pollutants generated by factories, power plants, and traffic. The proximity of the place residence to source of pollution has been increasingly documented to be a health risk factor for households. Quasi-experimental evidence shows exposure to the high levels of pollution experienced by residents in the neighborhood of highways or airports have detrimental consequences to respiratory or cardiovascular health (Schlenker and Walker, 2016, He et al., 2018).

When home buyers are able to assess the risk level of a place of residence, they would rationally adjust the preferences for the place and demand price compensations for any expected environmental damage attached to the dwelling. The capitalization of air quality into house prices have has the object of study of several empirical papers. In their seminal work, Chay and Greenstone (2005) exploit the air pollution reductions in US counties induced by the Clean Air Act Amendments to provide initial quasi-experimental evidence of house price changes associated to local air pollution. Similarly, Curl and Kearns (2015) documents a $11 \%$ decrease in house prices within a 0.5 mile radius of a newly opening toxic industrial plant. Evidence from China shows that urban house prices react negatively even to imported pollution from neighboring cities (Zheng and Kahn, 2013).

\section{Avoidance behavior}

Individuals can also influence the intake of environmental risks such as pollution by adjusting the time they spend expose to those hazards $\left(\right.$ time $\left._{i, s}\right)$. Thus, when rational individuals are able to decide how they spend their time, they would adjust their behavior in response to these risks and choose their activities accordingly. Evidence from California documents a significant drop in 
the visits to recreational spaces (i.e. a zoo and a park observatory) on days with pollution alerts (Graff Zivin and Neidell, 2009). Similarly, evidence based on the American Time Use Survey shows that individuals substitute outdoor by indoor leisure time to compensate for extremely high or low temperatures (Graff Zivin and Neidell, 2014). Individuals use buildings as a shield to protect themselves against (certain) hazardous environmental conditions by increasing the amount of time that they spend indoors.

\section{Protective Investments}

Finally, individuals can undertake a series of protective investments to reduce the impacts environmental risk factors $\left(\right.$ protection $_{i, s}$ ). It is not uncommon to see in the news images of Chinese individuals wearing facemasks to protect against pollution while doing their daily activities. These investments to prevent exposure can be substantial for households. Evidence from China estimates that a drop of $10 \%$ in heavy pollution days would lead to a total savings on facemasks of 187 million USD (Zhang and Mu, 2018). In addition, individuals may undertake investments to alleviate the consequences of exposure to pollution. The classical effect is the use of pharmaceutical goods to reduce the health damage or pain associated with risk factors like pollution or extreme temperatures. Deschênes, Olivier, Greenstone, Michael, \& Guryan (2017) show how a policy-driven reduction in NOx of $40 \%$ in early 2000 s in the US led to USD 800 million savings in medication in the regions where the policy was implemented. These reductions in pharmaceutical use are present in medication against respiratory symptoms and prevention and preventive medications that are taken to prevent these respiratory problems.

\subsection{The Role of Indoor Environments}

\subsubsection{The Role of Housing as Public Health Measure}

Given that individuals spend about $90 \%$ of their time indoors a key role can be attributed to buildings as a ultimate determinant of the environmental conditions that we are exposed to. Indeed the build environment has an important role as protective investment for occupants. Individuals can shape or adapt their their buildings to effectively avoid exposure to environmental hazards. The U.S. Environmental Protection Agency (1985) documents significant differences in certain pollutant concentrations between indoor and outdoor environments, up to 5 times higher concentration indoors. Building materials, furniture, inadequate heating or ventilation systems are just few examples of sources of indoor environmental hazards. However, our current understanding of how indoor environmental conditions affect occupants is still scant.

The existing evidence on how housing conditions affect our health and wellbeing is still rather scarce, mostly based on interventions in developing countries. Indoor air pollution generated by cooking stoves is a major source of mortality in developing regions of the world, such as rural 
India. A conservative estimate indicates that exposure to indoor smoke produced by solid fuels is in the top ten of leading causes of death, responsible for $3.3 \%$ of deaths in the world (WHO, 2009). An increasing number of studies attempt to measure the impact of policy programs aiming at solve housing deficiencies in developing world. The replacement of coal cooking stoves, the provision of cement floors, proper sanitation or prefabricated housing in slums are just few examples of interventions which impact on the health of the occupants have been evaluated (Cattaneo et al., 2009; Galiani et al., 2017, 2018; Devoto et al., 2012).

Policy makers in developed countries have traditionally disregarded the health consequences of investments in housing. However, a non-negligible part of the population is also exposed to deficient housing conditions. For example in Western Europe, $13.3 \%$ of households are living in dwellings with deficient maintenance (Eurostat, 2017). Figure 1.1 shows the percentage of people living in a dwelling with inadequate maintenance for all European countries. In countries like Spain, the Netherlands or the UK, the percentage of people living in deficient housing is over $10 \%$, reaching levels above $20 \%$ in countries like Portugal or Hungary. The type and magnitude of house deficiencies observed in developed regions differ significantly from those that are object of study in developing countries, challenging the extrapolation of the estimated impact of the interventions listed in the previous paragraph.

Figure 1.1: Percentage population living in a dwelling with a leaking roof, damp walls, floors or foundation, or rot in window frames of floor in 2017

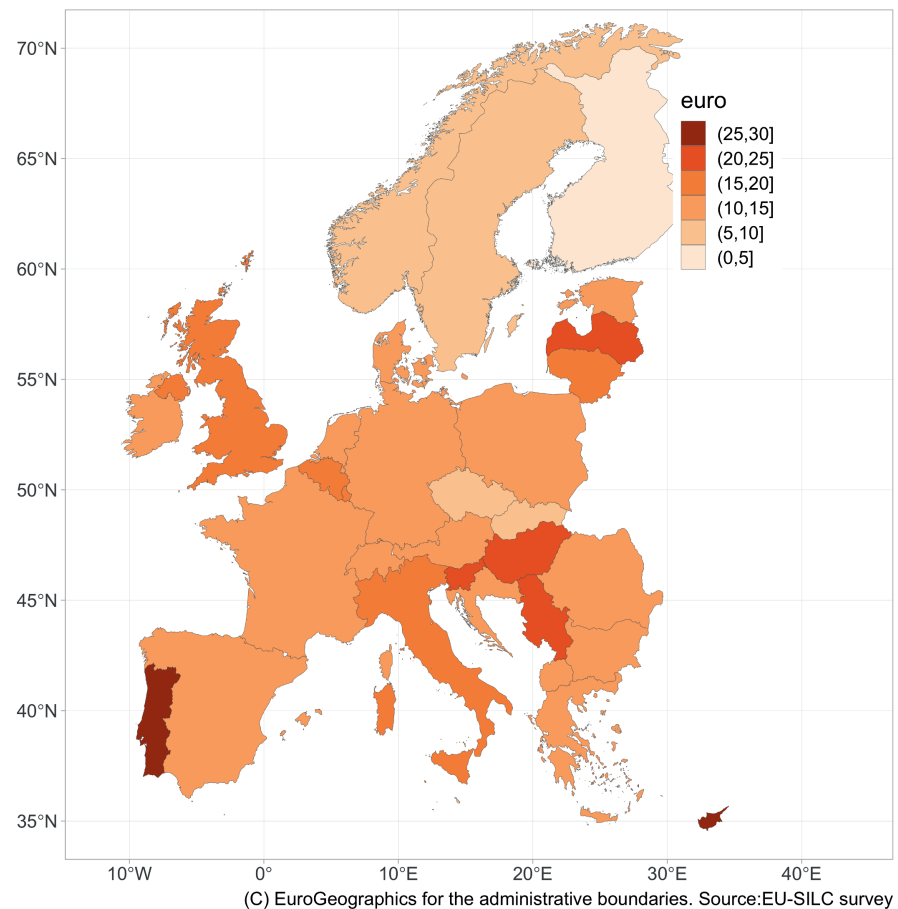


Existing studies on housing conditions and health outcomes in industrialized countries are typically based on non-experimental studies, lacking a clear causal identification (see, for example, WHO, 2007). Empirically assessing the consequences of deficient housing conditions on human health is challenging. First, large data samples with standardized measures of housing conditions and occupants' health are generally not available. Second, individuals in Western economies have a higher financial and legal capacity to select and transform the place where they live, challenging the causal claim that buildings shape the occupants, and not the reverse. In Chapter 2, I investigate the relationship between housing conditions and health, using the population-representative household panel in a developed country that collected information about housing conditions and occupants' health for the longest time span. More specifically, I use a dataset that tracks 25,000 German households over 25 years. The study estimates the impact of housing conditions on health outcomes, and the subsequent demand for healthcare services. Approximately half of these are tenants, for whom home renovation is exogenous. I document that individuals exposed to poor housing conditions report worse mental and physical health, and experience an $11 \%$ increase in doctor visit. These effects control for individual, dwelling and temporal fixed effects, and are robust to changes in socio-economic status, lifestyle choices, and neighbourhood conditions. The results of the heterogeneity analysis indicate that effects of deficient housing conditions are exacerbated by the age of individuals. When restricting our sample to individuals above 64 years old, the exposure to poor housing conditions is associated with a to $20 \%$ increase in doctor visits.

Chapter 3 then analyses the health impacts of the largest housing renovation program in an industrialized country in the last decades, not preceded by a natural disaster or war conflict. During the 1990s, the German government implemented several programs to modernize the East German housing portfolio. The largest program spent a total of $€ 40$ billion and renovated 3.6 million dwellings in East Germany. In chapter 3 I analyze the impact of the housing renovation program on the health and labor market outcomes of occupants. I use an event study approach in East Germany in the period right after the reunification, 1992-2002, exploiting the exogenous variation in the exact timing of the renovation. I find that a major renovation of a dwelling significantly improves tenants' health outcomes, with no effect on labor market prospects. More specifically, individuals in the sample reported a significantly 1.8 fewer sick-leave days in the aftermath of the renovation. I observe large gender differences, the health improvements are only present in the female subsample.

\subsubsection{Human Performance And The Indoor Environment}

Environmental conditions may also have important implications for labor supply. Recent studies show how environmental factors like temperature or pollution influence both the amount of time 
individuals allocate to work, as well as their performance in executing work-related tasks. For instance, Hanna and Oliva (2015) show an increase of 1.3 hours per week associated with a drop in $\mathrm{SO}_{2}$ levels in the area produced by a closure of a large refinery in Mexico city. Similarly, Aragón et al. (2017) document the negative impact of moderate increases in fine particles $\left(\mathrm{PM}_{2.5}\right)$ on hours worked by people in Lima. Evidence from the US shows that extremely warm days lead to a reduction in working hours, specially in industries with high exposure to outdoor climate conditions, such as the construction or forestry industry (Graff Zivin and Neidell, 2014).

The harmful effects of extreme weather conditions and pollution on labor supply go beyond a decrease in total working hours. A new wave of studies provides quasi-experimental evidence on how air pollution hinders productivity in a variety of sectors, such as agriculture, manufacturing, professional sports, call center workers, or investment brokers (Graff Zivin and Neidell, 2012 , Zhang, Xin, Xi Chen and Zhang, 2018; Fu et al., 2017; Chang et al., 2016; Lichter et al., 2017, Meyer and Pagel, 2017). Cognitive skills are key in some of these occupations. Graff Zivin and Neidell (2018) and Zhang et al. (2018) recently shown how the performance of individuals in survey-based cognitive tests is affected by the exposure to extreme temperatures and pollution.

The current evidence is mainly based on outdoor environmental data that might deviate substantially from the actual environment indoor office workers are actually exposed to. However, in today's service society the overwhelming majority of workers are indoors, giving buildings a crucial role in shaping the environment workers are exposed to while undertaking their job. Deficient building infrastructure might thus create important health care costs and productivity losses in our society.

Chapter 4 presents the results of a study estimating the impact of the environmental conditions in the workplace on the health and job satisfaction of employees, as core factors of productivity. I provide quasi-experimental evidence based on the relocation of $70 \%$ of the workforce of a municipality in the south of the Netherlands. I construct a longitudinal dataset based on individual surveys of the entire municipality workforce and include measures before and after the move. The difference-in-difference estimation results show a significant improvement in the perceived environmental conditions and health of the relocated workers. The relocation effects remain persistent in the medium term (two years after the moving date). The results from the heterogeneity analysis show the older groups of employees enjoyed larger health impacts.

Our understanding of how indoor environmental hazards affect the performance of workers in cognitive or analytical professions is still limited. In chapter 5 , I investigate how indoor environmental quality affects the performance of individuals undertaking cognitively demanding tasks under time pressure. I link measures of indoor environmental conditions to the performance of chess players at official tournaments, where players face strong incentives to exert high effort. I construct an objective outcome measure for cognitive performance by comparing the quality 
of a player's actual moves with "optimal" moves as predicted by a chess computer. The results indicate that air pollution (PM2.5) is the main driver of the probability of making meaningful errors and the magnitude of errors. I find that an increase of $10 \mu \mathrm{g} / \mathrm{m}^{3}$ raises the probability of making a meaningful error by 1.5\%-points, and 9.4\% larger errors. The impact of pollution is exacerbated by time pressure. When players approach the time control of games, an increase of $10 \mu \mathrm{g} / \mathrm{m}^{3}$, corresponding to about one standard deviation, increases the probability of making a meaningful error by 3.2\%-points, and errors are $17.3 \%$ larger. Our results have important implications for high-skilled office workers, in particular for those executing non-routine cognitive tasks, the share of which is steadily increasing in developed countries (Autor and Price, 2013).

Environmental conditions may also influence the cognitive development of children (D'Angiulli, 2018). In OECD countries, children spend 930 hours per year in a classroom, second only to time spent in their bedroom. Schools are a core infrastructure asset for modern societies. The U.S. alone invested USD 49 billion per year in school facilities from 2011 to 2013 . Yet, a recent study reports that $53 \%$ of U.S. public schools are in urgent need of repairs, renovation and/or modernizations (U.S. Department of Education, 2014), providing some indication that indoor conditions may be suboptimal in many schools. In chapter 6 using continuous sensing technology, I investigate the relationship between indoor environmental quality (IEQ) and cognitive performance of school-aged children, including health measures and socio-economic indicators as mediators in the analysis. A study protocol is presented to reliably measure IEQ in schools. I will monitor the IEQ of 280 classrooms for 5 years, covering approximately 10,000 children. Each classroom in the sample is permanently equipped with a sensor measuring air quality (carbon dioxide and coarse particles), temperature, relative humidity, light intensity, and noise levels, all at one-minute intervals. Academic performance of school-aged children is measured through standardized cognitive tests. In addition, the health status of each child is collected, together with an extensive set of socio-demographic characteristics (e.g. parental income, education, occupational status). I present the results from a pilot study monitoring eleven classrooms during an academic year show significant heterogeneity in indoor environmental conditions across classrooms and over time. I find that IEQ varies significantly both during the school year and between classroom. This reinforces the question on the effects of IEQ on cognitive performance, where IEQ should be measured in a large-sample setting with a longitudinal design.

The health aspects of the built environment are manifold but are still quite unexplored. Policy makers in developed countries are currently limited by the lack of robust evidence applicable to the national stock of housing and other real estate. This thesis provides a series of quasi-experimental estimates that allow policy makers to evaluate the impact of indoor environments on occupants. First, the dissertation provides evidence of how investments in the housing portfolio may have implications for the demand of health care and labor supply of countries. 
Second, working environments are also found to be relevant for occupants, who see their health and performance affected by the exposure to certain environmental risk factors, such as fine particles $\left(P M_{2.5}\right)$. Taken together, the dissertation contributes to widening the evaluation of investments in building infrastructure by considering the benefits of such investments in the health and performance of the occupants. 



\section{Chapter 2}

\section{Housing Conditions And Health}

\section{Outcomes*}

Increasing welfare and longevity, and the corresponding rise in the demand for health services, are confronting modern society with rapidly rising healthcare costs. Projections of these costs for 2040 are as high as 18.5 percent of U.S. GDP, 12.7 percent of German GDP, and 9.6 percent of U.K. GDP, for example (Dieleman et al. 2017). Understanding the causes of health deprivation, and providing solutions towards prevention, present an increasingly critical challenge for academia, private market participants, and policymakers.

Housing and the built environment play a major role in shaping human health. Historically, inadequate housing has fueled the spread of disease, affected individuals' physical and mental health, and increased mortality (Rosen, 2015). Slum clearance, sanitation and provision of affordable housing are just some examples of public health policies enacted in modern history to ensure healthy living conditions (Shaw, 2004). The provision of adequate housing should lead to increased human wellbeing, and subsequently lower healthcare costs. Yet, limited evidence exists to support these claims, with the current evidence mainly focused on the health effects of outdoor hazards in the area surrounding homes.

Indeed, the relationship between outdoor environmental issues and human health has been well established in the literature. Numerous studies provide quasi-experimental evidence of the causal link between environmental hazards such as extreme temperatures or air pollution and human health (for a review see Deschenes, 2014, Graff Zivin and Neidell, 2013). The literature has documented the effects of such external effects on a variety of health outcomes, including mortality rates (Deschenes and Moretti, 2009), infant mortality rates (Currie and Neidell, 2005. Luechinger, 2009), (low) birth weights (Currie et al., 2015), school absence (Currie et al., 2009),

\footnotetext{
${ }^{*}$ This chapter is co-authored with Piet Eichholtz (Maastricht University), Nils Kok (Maastricht University) and Erdal Aydin (Sabanci University)
} 
work hours (Hanna and Oliva, 2015), and respiratory and heart-related hospital admissions (Schlenker and Walker, 2016).

However, indoor environmental conditions are not merely a by-product of outdoor environmental conditions, and while there is some research concerning the impact of indoor conditions on human health, such evidence is mainly based on small-scale intervention studies and in settings not typically applicable to the average dwelling in developed economies (Cattaneo et al. 2009: Barron and Torero, 2017, Galiani et al. 2017, Imelda, 2018). Addressing this knowledge lacuna is important, given that 90 percent of an individual's time is typically spent indoors (Klepeis et al. 2001). People are working in office buildings, living in their homes, and spending leisure time in shopping malls, restaurants, the gym, etc.

Empirically assessing the consequences of deficient housing conditions on human health is challenging. First, large data samples with standardized measures of housing conditions and occupants' health are generally not available. As opposed to relying on small-scale intervention studies, this study takes a different approach to explore the impact of housing conditions on health outcomes, and the subsequent demand for healthcare. The starting point is that household panel datasets and transparent statistical models can complement evidence from the experimentbased medical literature, helping to generalize its results. In order to examine the link between housing conditions and human health, we exploit the German Socio Economic Panel (GSOEP). Starting in 1984, this dataset is, to the best of our knowledge, the longest individual-level dataset that provides information on both health and housing conditions (Wagner et al., 2007). Participants are asked to annually evaluate the conditions of their dwelling, and to complete an extensive questionnaire on subjective health status and on their demand for healthcare, objectively measured by the number of visits to a doctor and the days of sick leave.

Second, since individuals with a higher socio-economic status presumably live in better maintained dwellings and in low-poverty areas, it is difficult to separately distinguish the effect of housing conditions from the effect of variables comprising the socio-economic profile of individuals. The participation of individuals in the GSOEP over long periods of time allows researchers to observe the same individual, exposed to varying housing conditions, over the sample period. In our empirical specification, we estimate the impact of housing conditions on health outcomes with individual and dwelling-fixed effects, exploiting the changes in health outcomes associated with within individual variation in housing conditions.

Third, one of the most problematic time-varying factor is the set of characteristics of the home. A key instrument to improve housing conditions is moving to a new home. However, the potential improvement in individuals' health might well coincides with improvements in the characteristics of the neighborhood. We introduce individual-dwelling fixed effects to control for time-invariant, unobserved and idiosyncratic characteristics of participant's homes. This way, we 
exploit variations in individuals' housing conditions over time, while keeping the home address constant, avoiding potential confounding factors associated with moving to a new home (e.g. moving to a healthier home and a healthier neighborhood environment).

Last, there is the important question of self-selection into home renovation. Home owners decide themselves whether to renovate or not, but for tenants, this decision is made by a landlord and is exogenous to the tenant, so a focus on tenants addresses potential endogeneity biases. In many countries, however, the rental housing sector caters to the poorest parts of society only, compromising the external validity of the findings. Low-quality housing are likely to be low-income inhabitants who tend to be in poorer health than the population as a whole, making generalization of the findings difficult. But in Germany over the sample period considered in the analysis, home ownership was about 50 percent, among the lowest in the world. By specifically analyzing tenants in a German dataset, we minimize renovation endogeneity without compromising the external validity of our findings ${ }^{2}$

The results from the empirical analysis show that the effects of housing conditions on health outcomes are substantial. Those individuals living in dwellings with a poor indoor environment experience an 11 percent increase in demand for healthcare, as reflected in the number of visits to the doctor. The effects show substantial heterogeneity based on dwelling conditions, and hold across income groups. Moreover, the effects of poor housing conditions on medical service consumption increases with age. Results from our analysis of subjective health measures (the SF-12 questionnaire) suggest that the increase in demand for healthcare is mainly driven by a deterioration of mental health. Interestingly, we do not find a statistically significant relationship between poor housing conditions and days of sick leave from work.

Individuals can avoid or reduce their exposure to poor housing conditions by either moving or by renovating their home. We observe that individuals living in a poorly maintained home have a higher propensity to move, with remarkably similar effects for homeowners versus tenants. However, when investigating renovations, we observe evidence of underinvestment in the rental housing market due to the presence of external effects - landlords have to make investments, which benefit tenants' health rather than generating direct economic outcomes for the landlord. Owner-occupiers living in homes that need a major renovation show a likelihood of about 23 percent to renovate their home, while the likelihood of home renovation of poorly maintained rental homes is less than 5 percent, prolonging tenants' exposure to unhealthy housing conditions.

In the remainder of this paper, we first describe the existing literature assessing the impact

\footnotetext{
${ }^{2}$ Of course, this assumes that tenants have limited bargaining power over their landlords. Given that 58 percent of the German rental stock is owned by corporate and public housing companies, violation of this identifying assumption seems implausible - after all, these companies are unlikely to tailor the timing of renovation programs to the specific needs of individual tenants.
} 
of housing conditions on individuals' health. In section 3, we describe the data sources and provide some descriptive statistics. In section 4, we present the methodology, and specifically discuss issues of causality and identification. In section 5, the results of the empirical analysis are provided. The paper ends with conclusions and policy implications.

\section{$2.1 \quad$ Literature}

Economists often approach health using the theoretical model of Grossman (1972), where individuals are born with a stock of health capital that depreciates over the years and increases through different health investments, such as sports. An adult's health is the main determinant of the number of days that an individual is productive in the labor market and, in turn, able to work and to earn income. Over the past decades, scholars have made a persistent effort on the identification of different factors affecting the rate of health depreciation and the demand for health investments.

The literature on health economics has documented the relationship between different aspects of individuals' living conditions and their health status in multiple domains. In the socioeconomic domain, studies using self-reported health indicators from different countries such as the U.S., the UK, or Germany show a direct relation between household income and the health conditions of individuals (Adams et al., 2003, Contoyannis et al., 2004 Frijters et al., 2005). Long-term evidence from the often-cited field experiment Moving to Opportunity shows that participants who moved from low-income neighborhoods to less distressed areas subsequently had a measurably improved physical and mental health and well-being status (Ludwig et al., 2012).

The impact of the living environment on individuals' health is not limited to socio-economic channels. The literature has shown the detrimental effects of different environmental hazards on health outcomes. In particular, a number of studies document the relation between high levels of air pollutants (e.g. ozone or carbon monoxide) and increases in respiratory and heart-related emergency room admissions (Schlenker and Walker, 2016), low birth weight (Currie et al., 2015), and higher school absences (Currie et al. 2009).

The existing studies regarding the exposure of individuals to environmental hazards commonly rely on outdoor measurements (e.g. Currie et al., 2015, Currie, 2009, Deschênes and Greenstone, 2011). However, while the indoor conditions of homes are a function of outdoor conditions surroundings the dwelling, they are not determined by outdoor conditions alone. Individuals can take multiple actions against outdoor environmental hazards to mitigate their exposure. One of the most common examples is to adjust the heating or cooling to avoid exposure to extreme temperatures. Deschênes and Greenstone (2011) document the presence of 
such avoidance behavior under extreme temperatures in the U.S. between 1968 and 2002, where extreme outdoor temperatures systematically preceded peaks in both mortality rates and energy consumption.

Although people in developed economies spend, on average, 90 percent of their time indoors, not much is known about the impact of buildings on health outcomes. The existing knowledge regarding the impact of the indoor environment on health comes mostly from the medical literature and is based on small-scale experiments or cross-sectional surveys. An example is a pan-European housing and health survey that involves inspections of dwellings by trained surveyors $(\overline{\mathrm{WHO}}$, 2007). The results suggest that people living in homes with poor conditions (e.g. bad lighting and ventilation, presence of noise, etc.) systematically reported a higher number of mental and respiratory health problems. However, these results are solely based on cross-sectional analysis and therefore do not shed much light on the causal effects that housing conditions may have on health outcomes.

Intervention studies allow researchers to isolate biological impacts, but generalization of their results tends to be limited by small sample sizes and the unique characteristics of the participants. Indeed, reviewing the experimental medical literature studies published between 1887 and 2007 in different Western countries, Thomson et al. (2009) address the need for largesample studies using micro data, to better estimate dose-response functions and the potential for improvements of the housing stock.

A third strand of literature on indoor conditions and health outcomes is based on quasiexperimental studies that involve policy interventions in slums or developing countries, where socio-demographic characteristics differ fundamentally from those of the average household in the United States or European Union. For example, Cattaneo et al. (2009) study the effect of replacing dirt floors with cement flooring. This intervention produced significant improvements in occupants' health, measured by reductions in the number of respiratory problems and allergies. Barron and Torero (2017) explore the implications of a randomized controlled trial in El Salvador, where households were granted discount vouchers to connect to the electricity grid. The estimation results show significant drops in respiratory infections among children, associated with a decrease in $P M_{2.5}$ after connecting the dwellings to the grid. Galiani et al. (2017) report significant improvements in children's health followed by the provision of prefabricated houses to slum dwellers in Latin America. Coal cooking stoves are another major source of indoor air pollution in the developing world. Smith-Sivertsen et al. (2009) document significant improvements in lung function and a reduction in respiratory symptoms followed by the provision of upgraded cooking stoves in Guatemala, but Hanna et al. (2016) found no effects in a similar intervention in India. However, it remains an open question whether dwelling conditions also have such significant health effects when the baseline quality of housing is quite good already, 
as will likely be the case in developed countries.

\subsection{Data And Descriptive Statistics}

In order to identify the relationship between housing conditions and health outcomes, we benefit from a large, longitudinal dataset containing information on both housing conditions and occupant health status, as well as other household characteristics that are likely to affect health outcomes. The German Socio-Economic Panel (GSOEP, v31) provides a panel dataset, with annual information on individual health and housing conditions since 1984, covering more than 20,000 individuals and 11,000 households at any given time (Wagner et al., 2007). The longitudinal nature of the dataset enables us to control for unobserved individual characteristics, by focusing on the relationship between the over-time variation in housing conditions and the health situation of individuals. In addition, the survey includes extensive information on tenure choice, socio-economic and demographic characteristics of individuals, their health status, as well as detailed information about living conditions.

We use the data from all available waves for West Germany after re-unification, covering the period from 1990 through 2014 3 Our full sample includes 57,581 adults (30,151 women and 27,430 men) and a total of 24,849 households. The average duration that an individual is included in the survey is 6.48 years (standard deviation $=5.27$ ), with a maximum of 23 years.

\subsubsection{Health Outcomes}

The GSOEP provides information on several health metrics. In this paper, we focus on three different health outcomes to establish the link between housing conditions and health: (1) health status, (2) healthcare utilization, and (3) health behavior.

With respect to health status, we use the Mental and Physical Component Summary Scales. These scales are widely used in the economic literature to explore detrimental effect of different hazardous events (e.g. Eibich, 2015, Marcus, 2013; Schiele and Schmitz, 2016). The measures are constructed based on the answers of participants to the health SF-12 questionnaire. This questionnaire is included in the GSOEP every two years since 2002, and contains 12 different questions about the mental and the physical health status of respondents in the four weeks preceding the interview (e.g. "How often did you have strong physical pains in the last four weeks?"). The mental and physical scales are constructed based on factor analysis, ranging from 0 to 100 (with higher values denoting a better health status) 4

\footnotetext{
${ }^{3}$ While the GSOEP starts in 1984, the current health status is not incorporated until the beginning of our sample period.

${ }^{4} \mathrm{~A}$ detailed description of the construction of the scales is provided by Andersen et al. (2007).
} 
In addition to mental and physical health, we also include individuals' self-assessed health status over the last year (on a five-point Likert scale) 5 This question is included in the GSOEP for every wave since 1992, except for 1993. Self-assessed health measures are commonly used in empirical studies to explore the dynamics of health in a given population of interest (Contoyannis et al. 2004), or to estimate the damaging effect of different aspects of living conditions (Bilger and Carrieri, 2013; Frijters et al., 2005). We construct a measure of bad health status from this 5 -point Likert scale that takes the value of one if the individual reports being in bad or poor health, and zero otherwise.

We use the number of visits to a doctor as a quantitative measure of healthcare utilization. Participants are asked to report the number of times they visited their general practitioner in the last three months. This measure is widely used in the literature to explore the demand for healthcare (e.g. Pohlmeier and Ulrich, 1995, Winkelmann, 2004, Santos Silva and Windmeijer, 2001) The survey included this question in every wave since 1991, except for 1993 and 1994. We explore the effect of housing conditions on healthcare utilization based on two measures: (1) visiting the doctor at least once during the past three months (yes/no), and (2) the number of doctor visits in the last three months. We also explore the days on sick leave reported over the last year.

Finally, we use the body mass index (BMI) and whether people smoke as measures of health behavior. "Good health behavior" refers to the different activities undertaken by individuals to maintain or improve their health status, or to prevent illness. Typical examples include exercise, (quitting) smoking, or (healthy) nutrition. In the literature of health economics, the body mass index and smoking are often used to capture the effect of health behavior on health status (Künn-Nelen, 2016; Reinhold and Jürges, 2010).

\subsubsection{Housing Conditions}

We evaluate the condition of participants' dwellings based on self-assessment by the individuals. Each year, all survey participants are asked the following question: "How would you characterize the condition of the house in which you live? Is it in good condition, in need of partial renovation, or in need of complete renovation?". Based on the answer provided to this question, we categorized each dwelling in the sample as (1) in good condition, (2) in need of minor renovation or (3) in need of full renovation ${ }^{6}$

Out of the 56,459 survey participants for whom the information on housing conditions is

\footnotetext{
${ }^{5}$ Every year, participants are asked to assess their "current health" as: "very good", "good", "satisfactory", "poor" or "bad."

${ }^{6}$ In the original question in the GSOEP, respondents have an additional option: "Ready for demolition" However, given the low number of responses in that category we decided to omit this option in the analysis, and these observations are removed from the sample.
} 
available, 28,635 participants lived at least one year in a house in need of a minor renovation, and 4,856 participants lived at least one year in a home in need of a major renovation. Those individuals that report living in a house in need of repairs experience between two and three years of deficient housing conditions, on average. Our estimation strategy focuses on those participants that experience deficient housing conditions for a part of the period in which they appear in the survey.

\subsubsection{Socio-Demographic Characteristics}

In the analysis, we control for the following socio-demographic characteristics: age, household composition, household income, marital status, employment status (whether the individual is working or not, and whether there was a significant change in his/her occupational status in the year of the survey), education (based on number of years of education and whether the individual holds a college degree), and gender. These variables are commonly used in the literature as determinants of health outcomes, sick leave, and demand for healthcare (e.g. Adams et al., 2003 Contoyannis et al. 2004, Currie et al. 2009). In addition, we also have information about the ratio of household members to the number of rooms in the house and whether the household owns or rents the home. The latter is important for our identification strategy: while the rental housing market in some countries caters only to the poor, this is not the case in Germany. Renting a home is common in Germany, also for relatively well-off citizens. The German homeownership rate is currently just 51.9 percent, among the lowest in the world.

\subsubsection{Descriptive Statistics}

Table 2.1 provides summary statistics. The average scales on mental and physical health are very close to 50, out of a maximum scale of 100 , and the average current health status is 2.57 , on a scale of 1 to 5 . Of all participants, 25 percent report bad health. Participants report an average of 5.5 days of sick leave per year and report an average of 2.6 doctor visits in the three months preceding the survey.

Regarding dwelling conditions, 54 percent of participants always report that their home is in good condition, while 39 and 7 percent report the need for a partial or major renovation in their homes for at least one of the survey years, respectively.

We first compare average health outcomes based on different housing condition categories, using some simple visualizations. As illustrated in Figure 2.1, individuals living in homes in need of partial or full renovation systematically report poorer health status, no matter which health criterion we consider. The detrimental effect of poor housing conditions is also reflected in the physical and mental scales, as those individuals living in poor housing conditions report significantly lower values on the physical indicators and especially on the mental scale. Moreover, 
Table 2.1: Descriptive Statistics

\begin{tabular}{|c|c|c|}
\hline & Mean & Std. Dev \\
\hline \multicolumn{3}{|l|}{ Health Measures } \\
\hline MCS: Summary Scale Mental (NBS) & 50.38 & 10.03 \\
\hline PCS: Summary Scale Physical (NBS) & 49.75 & 10.02 \\
\hline Current health status & 2.57 & 0.97 \\
\hline Bad/Poor health (1=yes) & 0.25 & 0.43 \\
\hline Visits to the doctor during the last three months & 2.60 & 4.30 \\
\hline Number of days out sick (per year) & 5.51 & 20.76 \\
\hline \multicolumn{3}{|l|}{ Dwelling Characteristics } \\
\hline \multicolumn{3}{|l|}{ Housing condition } \\
\hline In good condition $(1=y e s)$ & 0.71 & 0.46 \\
\hline In need of partial renovation ( $1=$ yes $)$ & 0.27 & 0.44 \\
\hline In need of major renovation ( $1=$ yes) & 0.02 & 0.15 \\
\hline Number of years in bad condition & 3.69 & 4.75 \\
\hline Size $\left(\right.$ in $\left.\mathrm{m}^{2}\right)$ & 106.12 & 47.02 \\
\hline Number of rooms larger than $6 \mathrm{~m}^{2}$ & 4.2 & 1.91 \\
\hline Construction year & 1969 & 24.39 \\
\hline Amount of rent minus heating costs (monthly, in euros) & 467.82 & 238 \\
\hline \multicolumn{3}{|l|}{ Household Characteristics } \\
\hline Monthly household net income (in euros) & $2,713.11$ & $1,964.13$ \\
\hline Individual is a tenant or sub-tenant ( $1=$ yes $)$ & 0.48 & 0.50 \\
\hline Ratio household members per room & 0.75 & 0.44 \\
\hline \multicolumn{3}{|l|}{ Household Typology } \\
\hline 1-Pers.-HH (1=yes) & 0.15 & 0.36 \\
\hline Couple without children ( $1=$ yes $)$ & 0.30 & 0.46 \\
\hline Single parent $(1=$ yes $)$ & 0.06 & 0.25 \\
\hline Couple with children younger than 16 years ( $1=$ yes) & 0.23 & 0.42 \\
\hline Couple with children older than 16 years ( $1=$ yes) & 0.14 & 0.35 \\
\hline Couple with children younger and older than 16 years ( $1=$ yes) & 0.08 & 0.27 \\
\hline Multiple generation household (1=yes) & 0.02 & 0.14 \\
\hline \multicolumn{3}{|l|}{ Respondent Characteristics } \\
\hline Age of respondent & 46.21 & 17.41 \\
\hline Individual is working (1=yes) & 0.59 & 0.49 \\
\hline Actual work time per week (in hours) & 21.64 & 21.07 \\
\hline Amount of education or training (in years) & 11.84 & 2.73 \\
\hline Individual holds a college degree ( $1=$ yes $)$ & 0.17 & 0.38 \\
\hline
\end{tabular}

Notes: Mental scale and physical scale health variables range from 0 to 100. "Current health status" variable ranges from 1 (very good) to 5 (bad). "Satisfaction with health status" variable ranges from 0 (very unhappy) to 10 (very happy). The summary statistics displayed above consider the full sample period (from 1990 to 2014), and include 357,353 observations (and 57,581 individuals).

individuals in poorly maintained homes report a significantly higher number of visits to the doctor in the three months preceding the date of the survey, as well as more days of sick leave. Participants living in dwellings in good condition report about 2.5 doctor visits and take about five days of sick leave, compared to more than three visits and seven days of sick leave for those living in a home that needs a full renovation.

Of course, these non-parametric comparisons do not take into account the fact that not every 
Figure 2.1: Housing conditions and occupant health
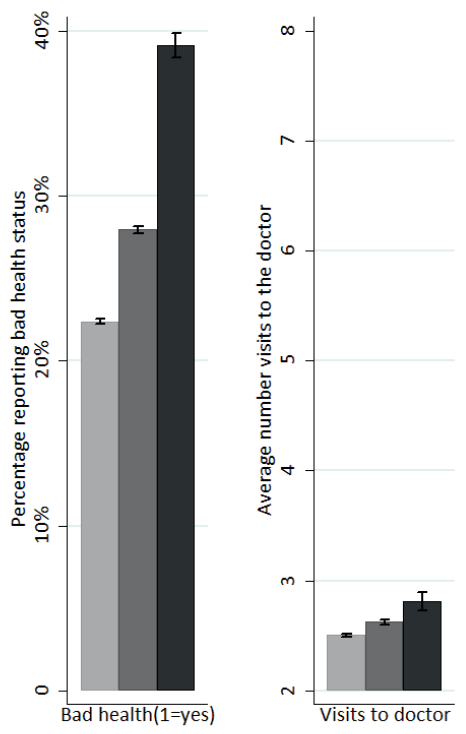
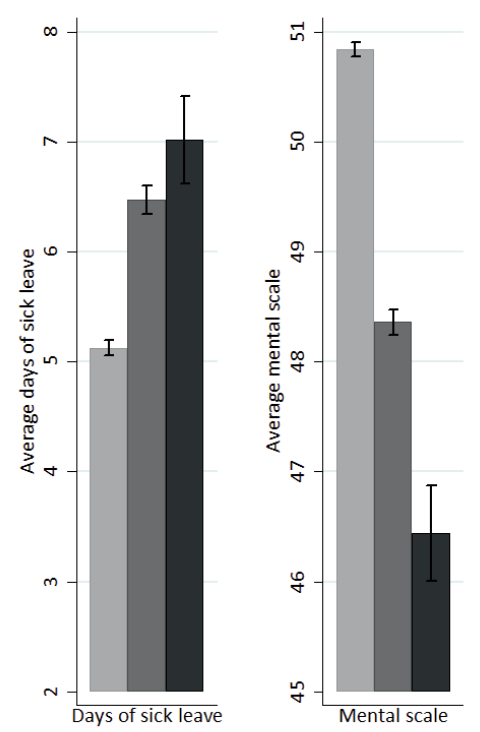

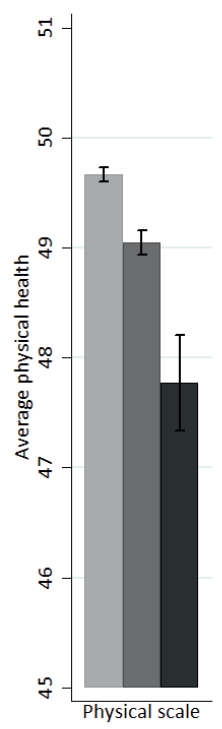

In good condition

Needs partial renovation

Needs full renovation

Notes: Figure presents the average level of health measures for different housing conditions as well as the 95 percent confidence interval. Current health ranges from 1 (very good health) to 5 (bad health). The three measures are available for all years in our sample (1990-2014). Mental and physical scales range from 0 to 100 (available for survey waves 2002, 2004, 2006, 2008, 2010, 2012 and 2014).

participant in the sample has the same probability of experiencing poor housing conditions. Table 2.2 shows systematic differences between individuals living in good housing conditions and those inhabiting homes in need of partial or full renovation. Participants living in homes with deficiencies report lower levels of income, are younger, and are more likely to be rental tenants rather than owners.

Thus, the relationship between health and housing conditions could be driven merely by socio-economic factors that determine both dwelling choice and health, which would affect our inferences regarding the association between housing conditions and health. In particular, previous empirical studies show that income is one of the main factors shaping the demand for health services (e.g. Frijters et al. 2005). Furthermore, those individuals with larger financial means are expected to inhabit better homes, so the apparent relations documented in Figure 1 might be determined by differences in socioeconomic status. Another potential confounding variable is tenure status. Poorer people are more likely to live in rental housing, which tends to be maintained poorly compared to owner-occupied housing (Pollack et al., 2004).

Table 2.3 provides further insight into the relation between health and housing conditions 


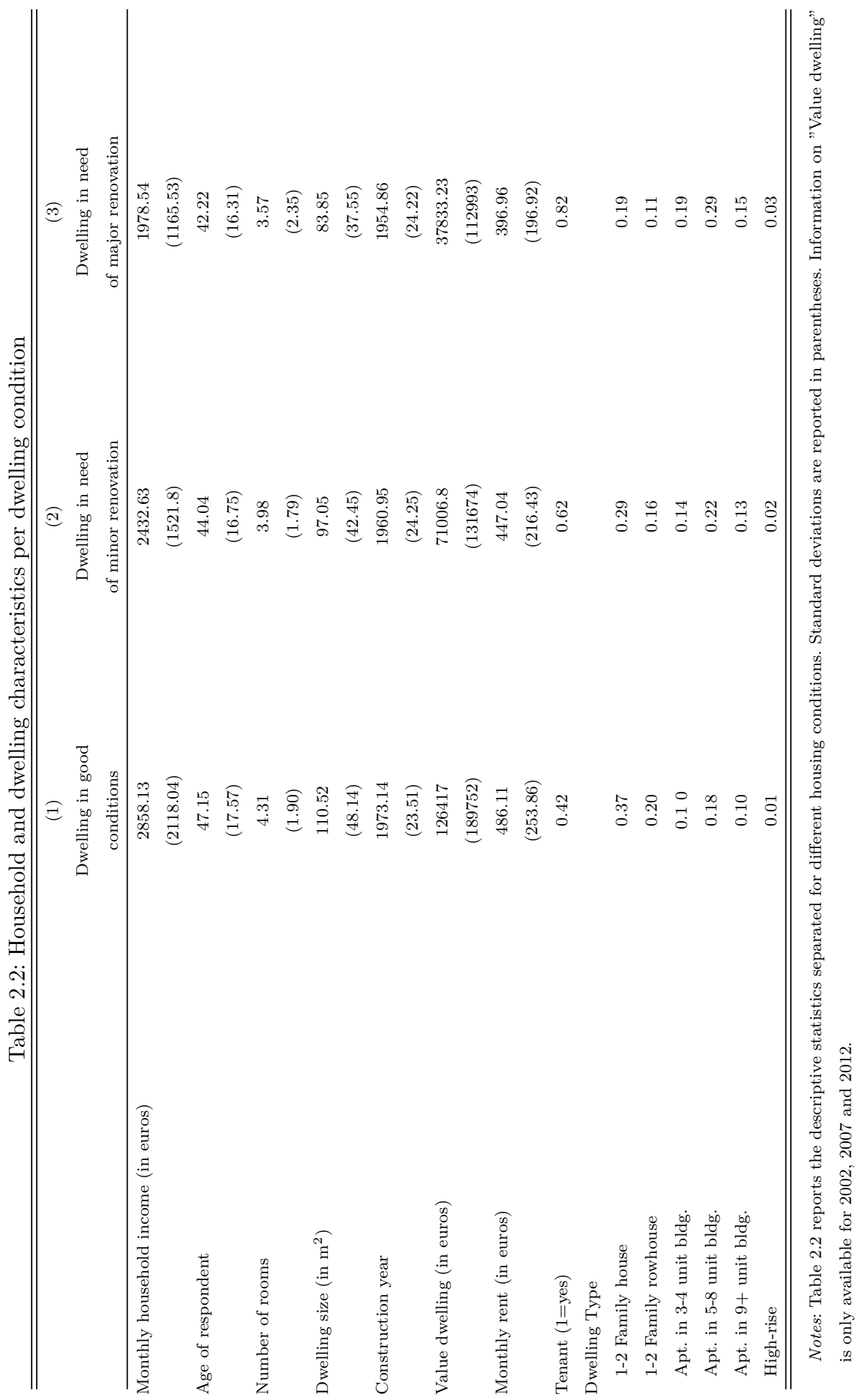


for different income and age groups, by quartile, and for owner-occupiers and tenants. Panels A through E provide the five different health indicators: bad health status, mental health scale, physical health scale, doctor visits, and days of sick leave. As expected, the statistics indicate that higher income, lower age, and homeownership are all associated with better health outcomes. However, the descriptive statistics also show that the detrimental health effect of poor housing conditions holds within almost any age or income group in the sample, and likewise for homeowners and tenants, no matter how health is measured. Interestingly, the statistics reported in Table 2.3 suggest that the relationship between poor housing quality and health status is stronger for older and lower-income respondents as compared to higher paid and younger people.

\subsection{Empirical Strategy}

The associations between housing conditions and health outcomes are manifold and complex, and an empirical analysis requires the consideration of numerous confounding factors. Investment decisions in health and individual preferences for dwellings are driven by a set of observable and unobservable household and individual characteristics. Furthermore, both are likely to be determined by some common circumstances, possibly biasing the estimated effect of housing conditions on health.

In order to identify the impact of housing conditions on individuals' health, we propose the following reduced-form empirical model:

$$
\text { Health }_{i, d, t}^{*}=\beta \text { Housing_Conditions }{ }_{d, t}+\lambda X_{i, t}+\delta Z_{d, t}+\alpha_{i}+t_{t}+\epsilon_{i, d, t}
$$

where Health $h_{i, d, t}^{*}$ denotes the health status of individual $i$, living in dwelling $d$, in year $t$. The health status of individuals will be measured by the health outcomes described in the previous section. Housing conditions $s_{, t}$ represents the conditions of the dwelling $d$ at time $t$. The vector Housing conditions $_{d, t}$ includes two dummy variables, one of them taking the value of one if the dwelling needs a partial renovation, and zero otherwise, and the other dummy taking the value of one if the dwelling is in need of a full renovation, and zero otherwise. The vectors $X_{i, t}$ and $Z_{d, t}$ include all the individual and dwelling control variables, respectively. The unobserved component of the model includes the time-invariant idiosyncratic effects, $\alpha_{i}$, time (year) fixed effects, $t_{t}$, and a normally distributed error term, $\epsilon_{i, d, t}$. Based on this model, the parameters of interest, elements of $\beta$, represent the effect of dwelling conditions on the health outcomes of individuals.

As discussed earlier, estimating the causal link between dwelling conditions and occupant health is methodologically challenging. The literature acknowledges the existence of multiple 


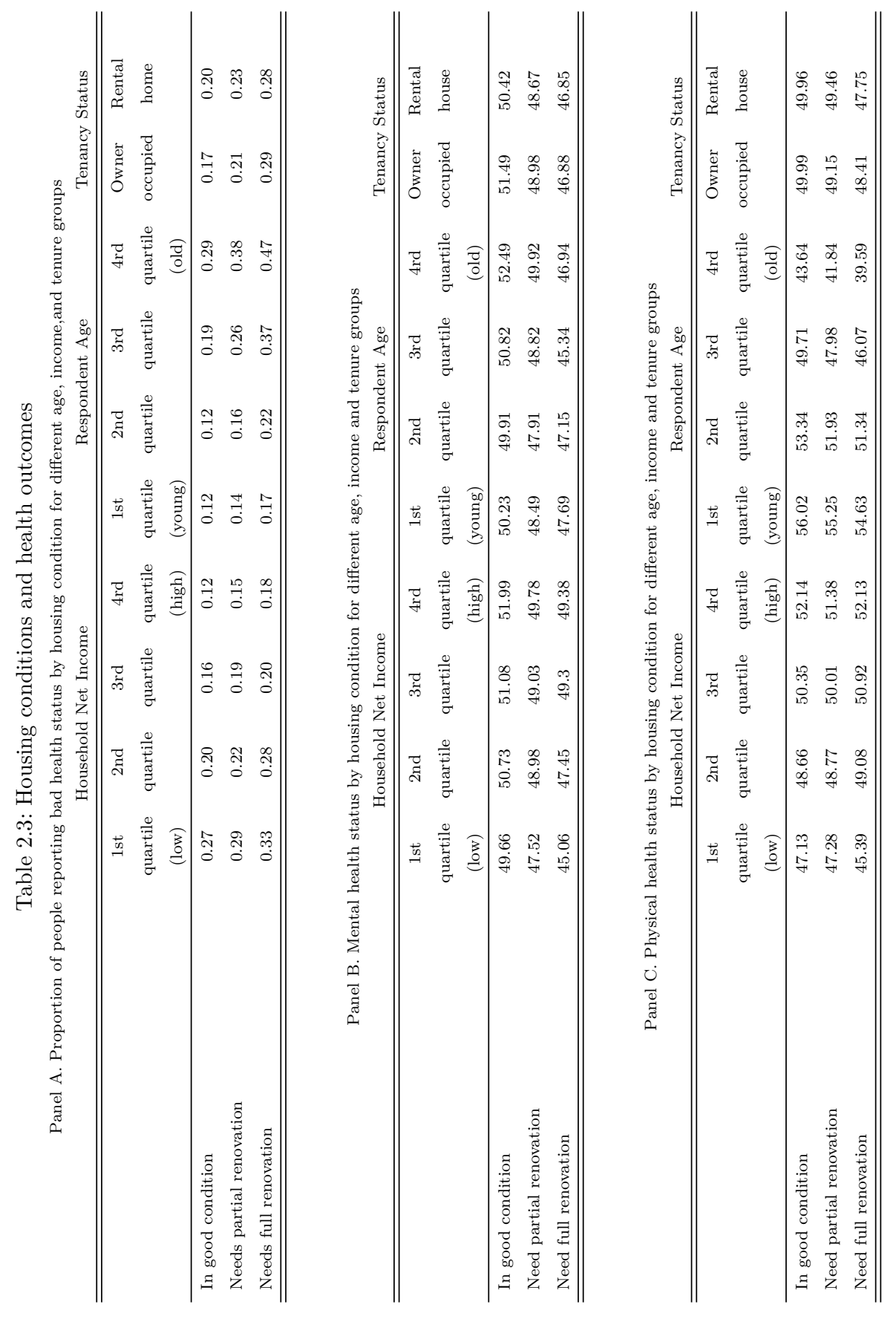




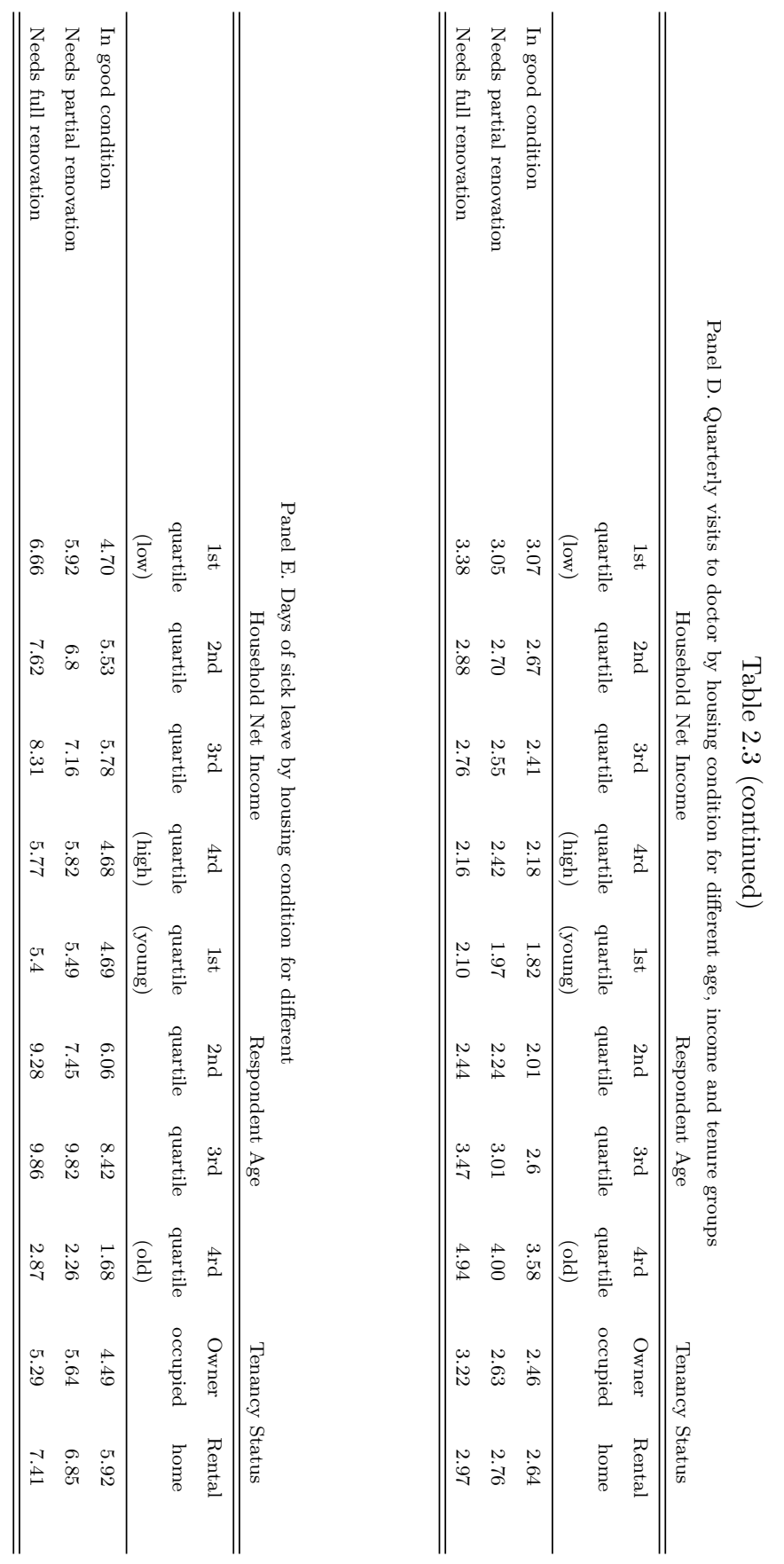


confounders, or variables affecting both the preferences of an individual for the dwelling and his investments in health. The presence of such unobserved factors hinders the proper estimation of the link between dwelling conditions and health using a cross-sectional analysis. We therefore employ the longitudinal nature of our dataset to alleviate concerns about potential endogeneity issues.

First, the over-time variation in the data allows for the estimation of fixed effects models in which the unobserved time-invariant characteristics of individuals can be properly controlled for. The individual-fixed effect approach estimates the impact of poor housing conditions on occupant health based on the variation in housing conditions over time for the same individual.

However, individual-fixed effects alone will likely not be sufficient to control for all unobservables, as the over-time variation in housing conditions can originate from either moving to a new house or from a change in the conditions of the existing dwelling. It is well established in the literature that the environmental and socio-economic conditions of the neighborhood affect human health through channels like crime or pollution (Bilger and Carrieri, 2013, Ludwig et al. 2012). In order to isolate the impact of housing conditions on health from any neighborhood confounder, we therefore implement an individual-dwelling fixed effect analysis where we exploit the variation in individuals' housing conditions within a specific dwelling. We construct an individual-dwelling identifier by combining the personal identifier of each respondent and the date the respondent moved to the current dwelling:7] So the fixed effects strategy we employ controls for both personal and dwelling time-invariant characteristics in the estimations.

A further concern in the estimations is the self-selection into home renovations. It is possible, for example, that less healthy individuals underinvest in home renovation, or that individuals facing an adverse health shock simply have less resources for home maintenance. However, that would only be an issue for homeowners, and not for tenants. In rental housing, maintenance and renovation decisions are taken by the landlord, and are exogenous to the tenant's health status 8 Our initial analysis focuses specifically on rental tenants. Germany's housing market is characterized by a relatively dominant position of rental homes, mostly owned by institutional housing providers. Indeed, approximately 50 percent of the GSOEP participants are tenants. That means home rental is not limited to the lower social strata of German society. In many other countries, renting is limited to the lower-income parts of society, involving low-quality housing and inhabitants who would likely be less healthy than the population as a whole. This

\footnotetext{
${ }^{7}$ The GSOEP contains information about the exact moving date for each respondent in the sample.

${ }^{8}$ To test whether the timing of renovation is indeed exogenous to tenants' health, we investigate whether the different aspects of health status affect the likelihood of dwelling renovation by the landlord. The results, depicted in Table A1 in the Appendix, clearly show that none of the health aspects employed in this paper (bad health status, mental health, physical health, and doctor visits) is significantly related to subsequent renovation likelihood.
} 
would make it hard to generalize the findings. Our focus on Germany addresses these concerns.

As a final check on the role of potential confounders that may simultaneously affect housing choice and health outcomes, we test for the confounding role of health behavior channels. In particular, we consider the effect of the body mass index and smoking behavior of respondents. The body mass index (BMI) is widely used as an indicator of health investments by individuals (e.g. Künn-Nelen, 2016, Reinhold and Jürges, 2010), and it is closely related to individuals' nutrition and lifestyle. Smoking is an often-used indicator of an unhealthy lifestyle choices (Cutler and Glaeser, 2005). These two measures serve as indicators of health preferences and potential changes in individuals' budget constraints, not captured by our other controls. We test whether these measures are related to housing conditions. If not, we can conclude that their role as a possible confounding factor is limited, providing more confidence in the direct relationship between housing conditions and health outcomes.

\subsection{Results}

\subsubsection{Effects of Dwelling Conditions on Health Outcomes}

We first estimate the model specified in equation (1) using pooled OLS to investigate whether housing conditions affect subjective health status, using the "bad health" perception indicator, the mental health scale, and the physical health scale as dependent variables. The OLS estimation results are reported in Table 2.4, columns 1, 4, and 7. For each of the health indicators, we document that individuals living in homes in need of renovation report a significantly deteriorated health status. The effect is significantly stronger for dwellings that need a major renovation as compared to dwellings that need a partial renovation.

We include dwelling-individual fixed effects in order to ensure that the over-time variation in health status is not influenced by unobserved characteristics of individuals, dwellings, or a change of neighborhood. The fixed-effect results are reported in columns 2, 5 and 8 of Table 2.4. We document that individuals living in a home that is in need of partial renovation are 1.1 percent more likely to report bad or poor health in a given year, and that these individuals obtained an 0.8 percent and 1.7 percent lower score on the mental and physical scales, respectively. The detrimental effect on health for those individuals living in a home in need of a major renovation is significantly stronger. Those individuals living in poorly maintained homes are 2.7 percent more likely to report a bad or poor health status, score 2.3 percent lower on the mental scale, and 3.7 percent lower on the physical scale, during those years that their homes were in need of a major renovation. The estimation results thus suggest that, on average, those who experience problems with their dwellings are less healthy. Based on all model specifications and all subjective health measures included in the analysis, exposure to homes that are anything less than well-maintained 


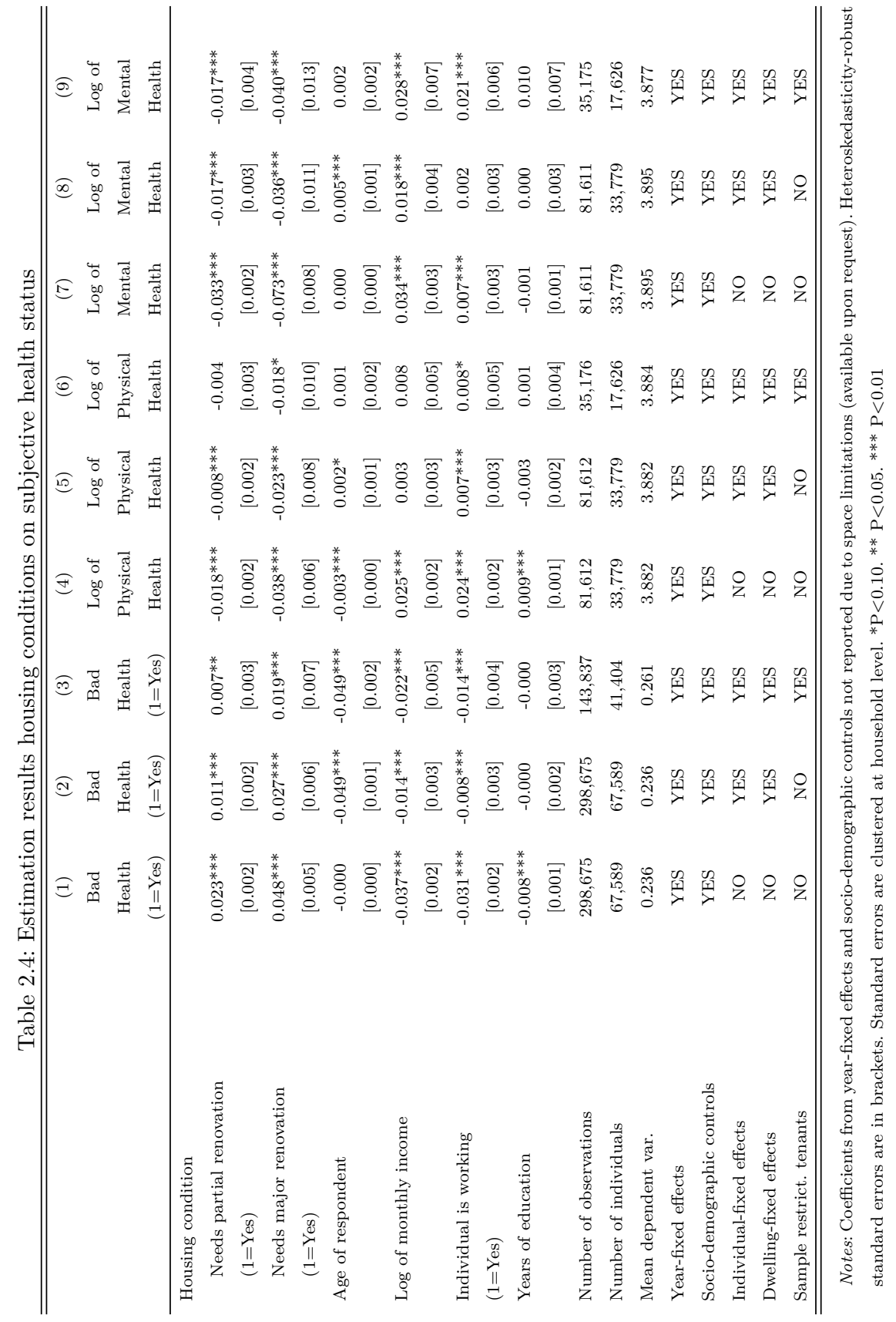


is related to deteriorated health outcomes.

In columns 3, 6 and 9 of Table 2.4 we restrict the estimation to the tenants in the sample, to address endogeneity concerns regarding the renovation decision. The empirical results stay robust, with coefficients comparable to those reported before. Tenants whose home needs renovation are less healthy, both physically and mentally.

\subsubsection{Dwelling Conditions And Economic Outcomes}

We then examine the impact of housing conditions on healthcare utilization - as measured by the number of doctor visits - and on absence from work. We investigate the impact of housing conditions and demand for healthcare on both the intensive and the extensive margin. Given the character of visits to the general practitioner, we explore the effect of housing conditions on whether an individual visits the doctor at all, as well as on the total number of visits. As before, columns 1, 4 and 7 present outcomes of the pooled OLS analysis, and columns 2, 5, and 8 show the results of the fixed-effect analysis. Columns 1,2 and 3 of Table 2.5 indicate that there is no significant effect of housing conditions on the intensive margin, i.e. the likelihood of going to the doctor in the first place. But when investigating the extensive margin, columns 4,5 and 6 of Table 2.5, the estimation results show that living in a home in need of partial renovation is associated with an increase of 4.35 percent $(0.060 / 2.612)$ in doctor visits, as compared to living in well-maintained homes. These differences are even larger for those living in a home in need of a major renovation, leading to an 11.2 percent increase in visits to the doctor in the three months preceding the survey interview, as compared to living in a dwelling that is in good condition. The results for the tenant sample, presented in column 3,6, and 9, are consistent with those in the full sample.

Table 2.5 also reports results regarding absence from work. We find some evidence of a relationship between dwelling conditions and sick leave when employing the OLS specification, but when estimating the full model that takes into account unobserved individual and dwelling specific characteristics, we find no statistically significant effect. Thus, the economic costs of poor housing conditions seem to translate mostly in an increase in demand for healthcare, as reflected by the increase in number of visits to the doctor, rather than absence from work. However, the insignificant effect on presence at work does not imply that productivity, a critical factor for employers, is unaffected by poor housing conditions.

\subsubsection{Heterogenous Effects}

This subsection further analyzes the potential heterogeneity in the impact of housing conditions on occupant health. In particular, we explore the role of age as mediating channel between 


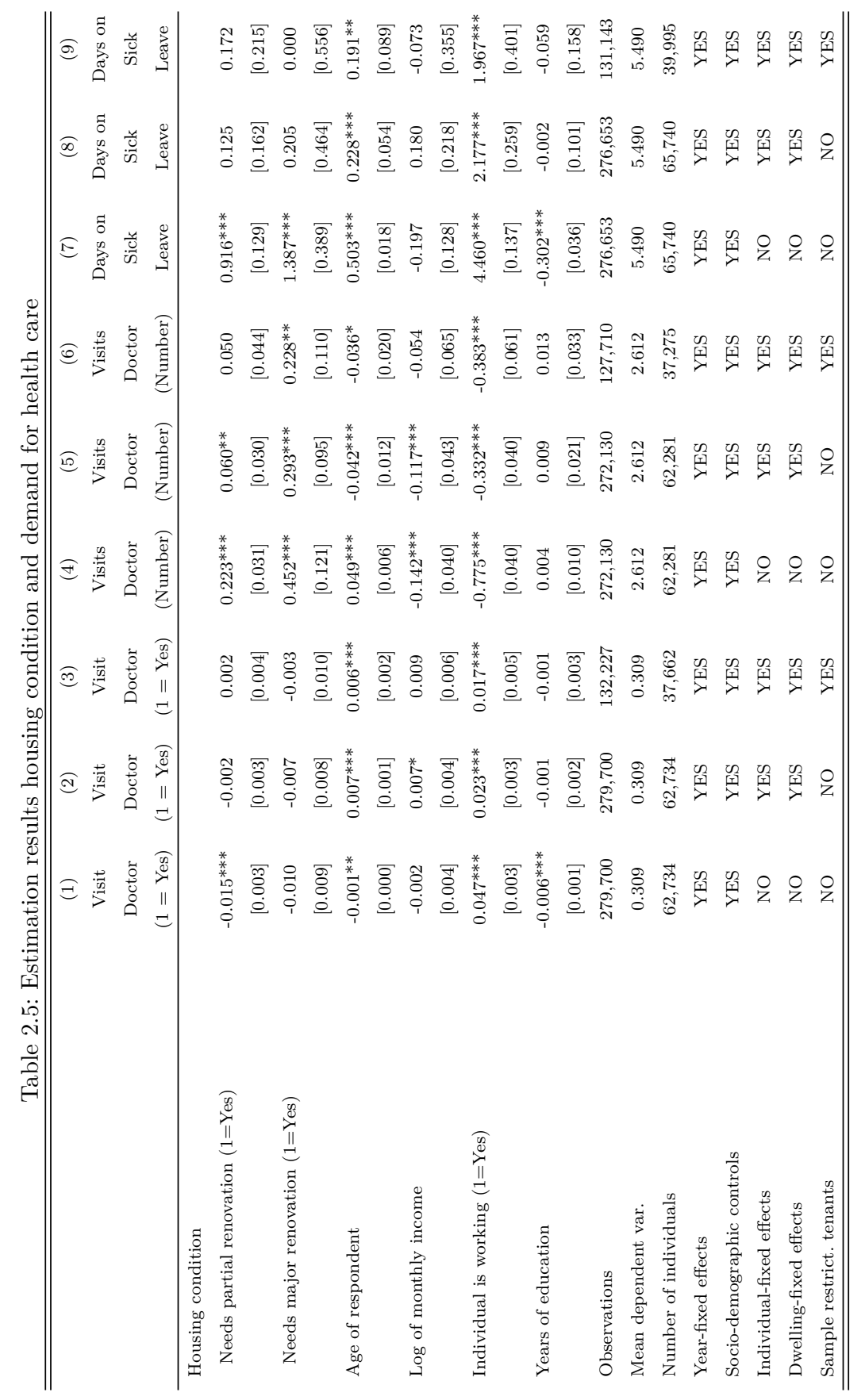


housing conditions and health outcomes 9

The differences in health status associated with housing conditions seem to be augmented over the lifetime of an individual. Tables $2.6 \mathrm{~A}$ and $2.6 \mathrm{~B}$ provide the results regarding age effects, based on the fixed-effects models. The tables show marginal effects of housing conditions on doctor visits and sick leave for five different age groups: respondents below 30 years old, 31 through 40, 41 through 50, 51 through 63, and those with an age of 64 and older. For the youngest group, we do not find a significant relationship between housing conditions and health, no matter whether we look at doctor visits or sick leave. However, for the 31-40 and 41-50 age groups, we find a marginally statistically significant (at 10 percent) effect on doctor visits when homes are in need of a major renovation: these respondents visit their doctor respectively 25 percent more often than people of the same age who reside in a home that is in good condition. The documented effect is strongest for citizens aged 64 and older: if their home needs a partial renovation, they visit the doctor 6 percent more often, increasing to 20 percent if the home needs a major renovation. So, our overall results seem to be driven by a particular group of citizens: the elderly.

For sick leave, we generally find no statistically significant results, except for the 41-50 age group. When they inhabit homes in need of a partial renovation, their sick leave is 1.34 days (24.3 percent) higher than people of the same age group who live in a home that is in a good condition. For those living in home that is in need of a major renovation, the coefficient increases to 1.75 , but is no longer statistically significant ${ }^{10}$ The fact that we do not find any effects in the older age cohorts is most likely due to low labor market participation. In the 51-63 age group, labor market participation in Germany decreases quite rapidly.

Figure 2.2 shows the conditional average scores in mental and physical health for individuals living in houses in good condition, and those living in houses that need a major renovation. The conditional means are based on the residuals of the regression of mental and physical scales on a set of socio-demographic controls (i.e. income, gender, labor status, education, and household member per room). While the differences between the two groups are relatively small in early adult life, the differences become more pronounced in later years. As the respondents get older, the health gap associated with housing conditions grows.

These findings have some implications for the interpretation of our results, and for the

\footnotetext{
${ }^{9}$ We find no evidence of heterogeneous effects in the detrimental impact of inadequate housing conditions on health outcomes relative to gender and income groups. While the descriptive statistics show that lower income groups are more likely to be exposed to poor housing conditions, the effects of deficient housing are similar for them as compared to higher income groups. Results available upon request.

${ }^{10}$ It is quite possible that this is due to relatively low statistical power: whereas we have over 15,000 observations in age group 41-50 for dwellings that need a partial renovation, we have just 1,100 observations (approximately 300 participants) in that age group for homes in need of a major renovation.
} 
Table 2.6: Heterogeneous effects by age group

Panel A. Visits to the doctor

\begin{tabular}{lccccc}
\hline \hline & $(1)$ & $(2)$ & $(3)$ & $(4)$ & $(5)$ \\
& $\begin{array}{c}\text { Doctor visits } \\
\text { Age 18-30 }\end{array}$ & $\begin{array}{c}\text { Doctor Visits } \\
\text { Age 31-40 }\end{array}$ & $\begin{array}{c}\text { Doctor Visits } \\
\text { Age 41-50 }\end{array}$ & $\begin{array}{c}\text { Doctor Visits } \\
\text { Age 51-63 }\end{array}$ & $\begin{array}{c}\text { Doctor Visits } \\
\text { Age }>64\end{array}$ \\
\hline Needs partial renovation & -0.123 & 0.043 & 0.018 & 0.146 & $0.240^{* * *}$ \\
$(1=$ Yes) & {$[0.088]$} & {$[0.103]$} & {$[0.088]$} & {$[0.100]$} & {$[0.091]$} \\
Needs for major renovation & 0.102 & $0.524^{*}$ & $0.567^{*}$ & 0.468 & $0.766^{* *}$ \\
$(1=$ Yes) & {$[0.276]$} & {$[0.316]$} & {$[0.315]$} & {$[0.355]$} & {$[0.329]$} \\
Number of observations & 27,533 & 34,838 & 36,887 & 41,911 & 46,594 \\
Number of individuals & 14,302 & 15,001 & 13,738 & 12,046 & 10,212 \\
Mean dependent var. & 1.863 & 2.051 & 2.247 & 3.111 & 3.830 \\
Individual-fixed effects & YES & YES & YES & YES & YES \\
Dwelling-fixed effects & YES & YES & YES & YES & YES \\
Year-fixed effects & YES & YES & YES & YES & YES \\
\hline \hline
\end{tabular}

Notes: Coefficients from year fixed-effects and socio-demographic controls not reported due to space limitations (available upon request). Heteroskedasticity-robust standard errors are in brackets. Standard errors are clustered at household level. ${ }^{*} \mathrm{P}<0.10$. ${ }^{* *} \mathrm{P}<0.05$. *** $\mathrm{P}<0.01$

Panel B. Days on sick leave

\begin{tabular}{lccccc}
\hline \hline & $(1)$ & $(2)$ & $(3)$ & $(4)$ & $(5)$ \\
& Days on & Days on & Days on & Days on & Days on \\
& Sick Leave & Sick Leave & Sick Leave & Sick Leave & Sick Leave \\
& Age 18-30 & Age 31-40 & Age 41-50 & Age 51-63 & Age > 64 \\
\hline Needs partial renovation & 0.122 & 0.088 & $1.344^{* *}$ & -0.812 & -0.043 \\
$(1=$ Yes) & {$[0.414]$} & {$[0.559]$} & {$[0.638]$} & {$[0.718]$} & {$[0.155]$} \\
Needs major renovation & -1.007 & 1.414 & 1.747 & -1.390 & -0.235 \\
$(1=$ Yes) & {$[1.927]$} & {$[1.495]$} & {$[1.687]$} & {$[1.890]$} & {$[0.214]$} \\
Number of observations & 29,623 & 36,933 & 38,280 & 42,886 & 47,031 \\
Number of Individuals & 15,654 & 16,442 & 14,627 & 12,510 & 10,287 \\
Mean dependent var. & 4.849 & 6.143 & 7.393 & 8.515 & 0.571 \\
Individual-fixed effects & YES & YES & YES & YES & YES \\
Dwelling-fixed effects & YES & YES & YES & YES & YES \\
Year -fixed effects & YES & YES & YES & YES & YES \\
\hline
\end{tabular}

Notes: Coefficients from year fixed-effects and socio-demographic controls not reported due to space limitations (available upon request). Heteroskedasticity-robust standard errors are in brackets. Standard errors are clustered at household level. ${ }^{*} \mathrm{P}<0.10$. ${ }^{* *} \mathrm{P}<0.05$. ${ }^{* * *} \mathrm{P}<0.01$ 
Figure 2.2: Housing conditions and occupant mental and physical health over lifetime

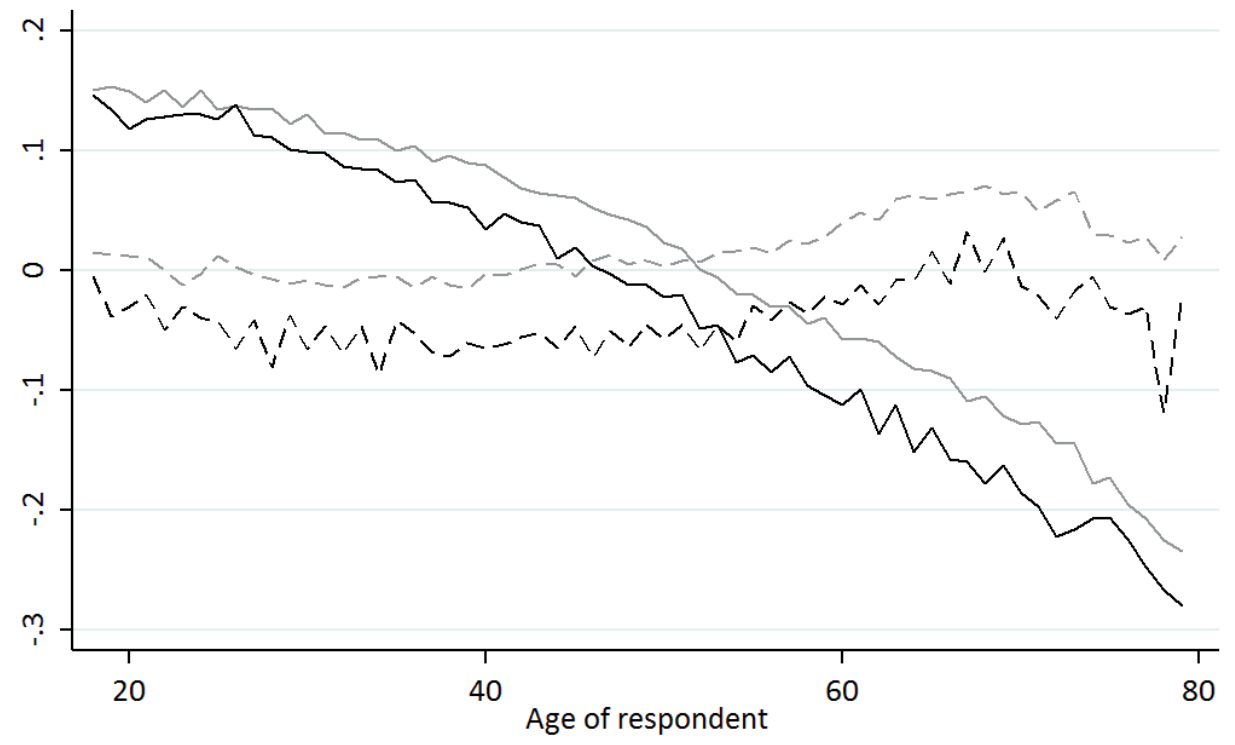

Physical scale. Good condit.

Physical scale. Needs renov.

Mental scale. Good condit.

Mental scale. Needs renov.

Notes: Figure 2.2 shows the standardized conditional mean of physical and mental scales for the sample of individuals that report living in a house in good conditions and those report living in a house in need of repairs, over the lifetime of an individual. The conditional mean is constructed from the regression controlling for gender, income, eduation and marital status. Mental and physical scales range from 0 to 100 (available for survey waves 2002, 2004, 2006, 2008, 2010, 2012 and 2014).

possible mechanism that relates housing conditions to health outcomes. First, the fact that we document effects for doctor visits, but not for sick leave, may be related to the age results reported above. Most of the overall effect seems to be driven by older citizens, who do not tend to work. So, if they fall ill due to poor housing conditions, they may go to the doctor, but they do not take sick leave.

Second, the age effect points to two possible channels between housing conditions and health outcomes. First, it is possible that citizens who are more vulnerable to external health shocks are affected, while people with a robust health are not. In that sense our result is in line with health outcomes of major heat waves, cold spells, or salmonella poisoning, which have been shown to affect older citizens disproportionately (Bind et al., 2016). But the age effect may also be determined by differences in exposure. Those individuals of 64 years and older tend not to work and are therefore likely to spend more time at home, thereby increasing their daily exposure to adverse dwelling conditions. Unfortunately, our dataset does not allow us to explore this further, given that the information about housing conditions does not provide the specific 
aspects of what makes housing conditions "poor". 11

\subsubsection{Robustness Checks}

One of the major concerns in estimating the relationship between dwelling conditions and occupant health is that the changes in housing conditions over time are accompanied with other changes in either life conditions or preferences of individuals. For instance, an individual exposed to an unexpected major negative income shock might reduce the investment in housing along with investment in health, for example by eating cheaper and less healthy food, or by cutting back on the costs associated with physical exercise, like a gym membership. It may also be possible that people who are less interested in health, and thus less willing to make health investments, are also less interested in a healthy living environment, and are thus more likely to occupy a home that is in a poor condition. If this would be the case, the findings reported in Tables 2.4 through 2.6 cannot be interpreted as causal relationships.

In order to test whether housing conditions indeed affect health status and healthcare utilization, rather than housing conditions and health status both being affected by lifestyle choices, we first estimate the effects of housing conditions on health behavioral measures. We then reestimate the relationship between housing conditions and health outcomes, including smoking as well as the body mass index of individuals as health behavior measures. If the inclusion of smoking and the body mass index in the regression would reduce or even nullify the previously established effects of poor housing conditions, that would call into question the causal relationship inferred from Tables 2.4 through 2.6. We include a dummy that reflects whether respondents smoke or not, as well as the number of cigarettes for the smokers, and we include the body mass index directly into the model.

We report estimation results for the fixed-effects models in Table 2.7. In columns (1) and (2) we provide the estimation results regarding the impact of housing conditions on occupants' body mass index and smoking behavior. The estimation results show that housing conditions have no significant impact on individuals' health behavior outcomes. The body mass index and smoking behavior of those individuals living in poorly maintained homes do not differ significantly from those individuals living in homes that are in good condition.

Columns (3), (4), (5), and (6) provide the estimation results of the fixed-effect models for health outcomes, after controlling for individuals' body mass index and smoking behavior. When comparing these coefficients with those reported in Tables 2.4 and 2.5 it is apparent that the

\footnotetext{
${ }^{11}$ Other national household panel surveys, such as those for the United Kingdom and the Netherlands, provide more specific information about exact housing conditions, including dampness, rot, black mold, and noise. Exploring these datasets may provide more insight into the mechanisms between housing conditions and health outcomes.
} 
Table 2.7: Estimation results housing condition and health behavior

\begin{tabular}{|c|c|c|c|c|c|c|}
\hline & (1) & $(2)$ & $(3)$ & $(4)$ & $(5)$ & $(6)$ \\
\hline & Body Mass & Smoke & Log of Physical & Log of Mental & Doctor & Days on \\
\hline & Index & $(1=$ Yes $)$ & Scale & Scale & Visits & Sick Leave \\
\hline \multirow[t]{2}{*}{ Needs partial renovation $(1=$ yes $)$} & 0.012 & -0.001 & $-0.009 * * *$ & $-0.018 * * *$ & $0.223^{* * *}$ & 0.355 \\
\hline & {$[0.027]$} & {$[0.005]$} & {$[0.003]$} & {$[0.003]$} & {$[0.063]$} & {$[0.359]$} \\
\hline \multirow[t]{2}{*}{ Needs major renovation $(1=$ yes $)$} & -0.018 & -0.004 & $-0.017^{* *}$ & $-0.040^{* * *}$ & $0.796^{* * *}$ & -0.344 \\
\hline & {$[0.089]$} & {$[0.011]$} & {$[0.008]$} & {$[0.011]$} & {$[0.184]$} & {$[1.155]$} \\
\hline Observations & 83,223 & 70,334 & 68,141 & 68,140 & 69,824 & 69,825 \\
\hline R-squared & 0.056 & 0.024 & 0.033 & 0.009 & 0.004 & 0.003 \\
\hline Number of Individual-Dwellings & 33,970 & 30,215 & 29,688 & 29,688 & 30,007 & 30,008 \\
\hline Mean dependent Variable & 25.69 & 0.336 & 3.883 & 3.895 & 2.612 & 5.490 \\
\hline Individual-dwelling fixed effects & YES & YES & YES & YES & YES & YES \\
\hline Health behavior controls & $\mathrm{NO}$ & $\mathrm{NO}$ & YES & YES & YES & YES \\
\hline Socio-demographic controls & YES & YES & YES & YES & YES & YES \\
\hline Year fixed-effects & YES & YES & YES & YES & YES & YES \\
\hline
\end{tabular}

Notes: Coefficients from year fixed-effects and socio-demographic controls not reported due to space limi-

tations (available upon request). Heteroskedasticity-robust standard errors are in brackets. Standard errors

are clustered at household level. Body Mass Index, mental and physical scales, and smoking are available

for survey waves 2002, 2004, 2006, 2008, 2010, 2012 and 2014 . ${ }^{*} \mathrm{P}<0.10$. ** $\mathrm{P}<0.05$. *** $\mathrm{P}<0.01$.

inclusion of the life-style variables does not significantly affect the housing condition results. For physical and mental health, the life-style variables do not make any difference for the housing condition effect, no matter whether the home is in need of a partial or a full renovation. For doctor visits, the housing condition coefficients changes, but they seem to get stronger, rather than weaker. However, this may also be caused by a sampling effect -- we can include the lifestyle controls into the regressions on bad health and doctor visits for just a quarter of the observations. For sick leave, we document no statistically significant effect. These results provide some indication that the evidence in Tables 2.4 through 2.6 are not likely to be caused by lifestyle choices that affect both housing and health investments.

\subsubsection{Housing Conditions and Avoidance Behavior}

The literature shows that individuals do not necessarily remain passive towards the hazards in their living environments. Agents tend to take multiple actions to avoid or reduce their exposure to health-detrimental environmental conditions. Evidence from the housing market shows that households are willing to pay a premium to live in neighborhoods with cleaner air, or to stay away from sources of air pollution such as toxic plants (see, for example, Chay and Greenstone, 2005: Currie et al., 2015). In addition, individuals exchange outdoor leisure for indoor leisure in order to reduce their exposure to negative external conditions, spending more time indoors in highly polluted areas or on extremely hot days (Neidell, 2009, Graff Zivin and Neidell, 2014). Similarly, studies on lead paint remediation programs provide evidence of avoidance behavior 
Table 2.8: Avoidance behavior to deficient housing condition

\begin{tabular}{|c|c|c|c|c|c|}
\hline & (1) & $(2)$ & $(3)$ & $(4)$ & $(5)$ \\
\hline & \multicolumn{2}{|c|}{ Move $t$ (1=yes) } & \multicolumn{3}{|c|}{ Renovation in Dwelling $t$ ( $1=$ yes $)$} \\
\hline & Tenant & Home-owner & $\begin{array}{c}\text { Tenant } \\
\text { (Self-Paid) }\end{array}$ & $\begin{array}{c}\text { Tenant } \\
\text { (Paid by Landlord) }\end{array}$ & Home-Owner \\
\hline \multirow[t]{2}{*}{ Needs partial renovation $t-1$} & $0.010^{* * *}$ & $0.012^{* * *}$ & $0.008^{* * *}$ & $0.030 * * *$ & $0.074^{* * *}$ \\
\hline & {$[0.002]$} & {$[0.002]$} & {$[0.002]$} & {$[0.003]$} & {$[0.007]$} \\
\hline \multirow[t]{2}{*}{ Needs major renovation $t-1$} & $0.034^{* * *}$ & $0.029^{* * *}$ & 0.005 & $0.047^{* * *}$ & $0.226^{* * *}$ \\
\hline & {$[0.005]$} & {$[0.009]$} & {$[0.005]$} & {$[0.008]$} & {$[0.026]$} \\
\hline Observations & 118,298 & 133,248 & 109,712 & 109,712 & 123,906 \\
\hline R-squared & 0.033 & 0.013 & 0.004 & 0.005 & 0.010 \\
\hline Number of individuals & 21,251 & 21,604 & 18,589 & 18,589 & 18,758 \\
\hline Mean dependent var. & 0.0232 & 0.0232 & 0.039 & 0.144 & 0.199 \\
\hline Socio-demographic controls & YES & YES & YES & YES & YES \\
\hline Year-fixed effects & YES & YES & YES & YES & YES \\
\hline Individual-fixed effects & YES & YES & YES & YES & YES \\
\hline Dwelling-fixed effects & NO & NO & YES & YES & YES \\
\hline
\end{tabular}

Notes: Coefficients from year fixed-effects and socio-demographic controls not reported due to space limitations (available upon request).

Heteroskedasticity-robust standard errors are in brackets. Standard errors are clustered at household level.

${ }^{*} \mathrm{P}<0.10$. ${ }^{* *} \mathrm{P}<0.05$. *** $\mathrm{P}<0.01$

relative to sources of indoor pollution. Individuals are willing to pay a rent or price premium to be in houses that are certified to be lead-free (Billings and Schnepel, 2017).

We explore different behavioral reactions aimed at avoiding the exposure to (poor) housing conditions. In essence, agents have two main ways to change their exposure to poor housing conditions: either through moving or through renovation. In this part of the paper, we explore how poor housing conditions affect the likelihood of either of these two actions, distinguishing between home owners and tenants.

Table 2.8 presents the estimation results. Columns (1) and (2) provide the estimates of the link between poor housing conditions and the probability of moving, with column (1) documenting the results for tenants and column (2) documenting the results for home owners. The estimates indicate that individuals in our sample indeed seem to avoid poor housing conditions by moving to a different address. Both tenants and homeowners are more likely to move in the year after reporting that their home is in need of partial or major renovation, with the likelihood of moving increasing with more detrimental housing conditions. Interestingly, the effects are almost comparable for tenants and home owners - both groups are about 1 percent more likely to move if their home needs partial renovation and are 3 percent more likely to move if it needs a major renovation. This result suggests that tenants and home owners equally dislike living in a poorly maintained home, and "vote with their feet" in a similar manner.

The other possible response to adverse housing conditions is renovating the home. Here, we 
Table 2.9: Years in need of renovation by ownership status

Years in need of renovation

\begin{tabular}{lc}
\hline Tenant (1=yes) & $1.312^{* * * *}$ \\
& {$[0.105]$} \\
Observations & 300,065 \\
Socio-demographic controls & YES \\
Dwelling controls & YES \\
Year-fixed effects & YES
\end{tabular}

Notes: Coefficients from year fixed-effects, dwelling controls and socio-demographic controls not reported due to space limitations (available upon request). Heteroskedasticity-robust standard errors are in brackets. Standard errors are clustered at household level. ${ }^{*} \mathrm{P}<0.10$. ${ }^{* *} \mathrm{P}<0.05$. ${ }^{* * *} \mathrm{P}<0.01$. The list of dwelling controls includes the size, number of rooms and year of construction in the apartment. The list of individual socio-economic controls include the monthly income, education years, whether the individual has a college degree, gender and age.

find very different results. For both tenants and home owners we observe an increased likelihood of renovation following poor housing conditions, but the extent of the effect differs substantially across the two groups. Columns (3) and (4) show estimation results for tenants, distinguishing between renovations paid by the tenant and paid by the landlord. The estimation results in column (3) indicate that tenants tend not to renovate their dwelling after they start reporting problems with the housing conditions. Landlords, however, show a higher propensity to renovate the dwellings they own when their tenants report problems with the housing conditions: the likelihood of a renovation is 3 percent higher when a partial renovation is needed, and 4.7 percent higher when a major renovation is required. But this effect is trumped by the effects observed for home owners, who are 7.4 more likely to renovate their home after reporting the need for a partial renovation, and are 22.6 percent more likely to renovate in case of the need for a major renovation.

These results point at a split incentive or external effects problem, where the agent making the investment decision is not the direct beneficiary of the investment outcomes. Home owners reap the full benefit of their renovation investments, both in increased house value (see for instance Billings and Schnepel, 2017) and in improved health and comfort. Landlords, on the other hand, only receive the benefit of increased home values following renovations, while the health benefits affect the tenants only. And if tenants would pay for the renovation, they would receive the health and comfort benefits, while their landlord would receive the increase in home value.

Standard economic theory predicts underinvestment in the latter two cases, which is aligned 
with the results presented in Table 2.8 Although tenants and homeowners similarly dislike living in poor housing conditions, as suggested by their comparable likelihood to move, tenants are much more likely to face prolonged exposure to such conditions. In Table 2.9 we provide evidence of this, showing that tenants spend 1.3 years longer in a house that needs a renovation than homeowners, thereby suffering longer from adverse indoor environmental conditions.

\subsection{Conclusion}

The predicted rise in healthcare spending is a major concern for developed economies. Environmental conditions have been shown to significantly affect public health outcomes, and over the past decades, public policy has addressed issues ranging from curbing to reducing the detrimental effects of heat waves (see Deschenes, 2014, Graff Zivin and Neidell, 2013). However, it is estimated that in developed economies, individuals spend more than 90 percent of their time indoors. Understanding the effect of indoor conditions on health outcomes is thus critical, for policymakers, private market participants, and academia alike.

This study explores whether and how the condition of homes affect the health of their inhabitants. The limited number of existing studies on the topic of housing conditions and health outcomes either fail to establish causality, or address housing conditions in poor areas, often in slums or developing countries, making the results hard to generalize to developed economies.

Using a long-running household panel dataset, the German Socioeconomic Panel (GSOEP), this paper attempts to identify a causal link between housing conditions and health outcomes. The sample includes more than 300,000 respondent/year observations for the period between 1992 and 2014, allowing for monitoring of the health outcomes of the same individual, exposed to varying housing conditions, over the sample period. Our empirical specification exploits the changes in health outcomes associated with within-individual variation in housing conditions, and focuses specifically on tenants, for whom home renovation is exogenous to health outcomes.

The results provide evidence that residents of poorly maintained dwellings report a lower subjective health status and visit the doctor 11 percent more often. Regarding doctor visits, we do not find a significant effect on the likelihood of visiting the doctor in the first place (the intensive margin), but once individuals go to the doctor, they go significantly more often when they live in a dwelling in need of renovation (the extensive margin). Regarding sick leave, we find some evidence on the salience of housing conditions, but not in the most extensive model.

These effects are stronger for dwellings that are in need of a major renovation rather than a partial renovation. The results hold across income groups, and for both owner-occupiers and tenants. Given that results remain robust after controlling for lifestyle indicators such as body mass index and smoking, we conclude that the documented effects are not caused by common 
underlying lifestyle choices, but that the causality runs from housing conditions to health outcomes.

We also investigate heterogeneity by gender and age cohorts. For gender, we find no difference in the documented effects, but the results appear to be determined mostly by the older age cohorts. For the age cohort under 31 years, we find no significant relationship between housing conditions and health, while that relationship materializes for the older age cohorts, and is especially strong for those aged 64 and over. For the latter, we document 6 percent more visits to the doctor when a home is in need of a partial renovation, increasing to 20 percent when the home is in need of a major renovation. This may explain the absence of effects for sick leave as compared to doctor visits: those individuals with an age of 64 and older tend not to work, so do not report sick for work, even if they are ill and have to go to the doctor.

Finally, we analyze avoidance behavior, by investigating the likelihood of moving and renovation when respondents report poor housing conditions. We find that tenants and homeowners are equally likely to move in the year after reporting poor housing conditions, suggesting that they equally dislike poor housing conditions. However, we also document that homeowners are almost 23 percent more likely to renovate their home under these circumstances, while that percentage is much lower for tenants, no matter whether they or their landlord pay for the renovation. This finding suggests underinvestment in home renovation in the rental market, resulting in prolonged exposure to an adverse indoor environment, likely leading to reduced health outcomes.

The results of this paper indicate that the condition of individuals' homes affects their health in a statistically and economically significant manner, especially when these individuals get older. Apart from direct, but hard-to-measure, individual welfare effects, the economic costs for society mainly materialize in higher consumption of health services rather than sick leave. These findings imply that investments in home improvement can have important positive external effects, which are currently not taken into account when evaluating such investments. As our societies grow older, these external effects will only increase, making the relevance of the building stock for health outcomes ever more important. Public policy measures aimed at maintaining and improving the condition of the building stock could have tangible effects on prevention of disease, thereby reducing the burden on the healthcare system and its finances. 


\section{Chapter 3}

\section{Health Benefits of House}

\section{Renovations:}

\section{Evidence from Eastern Germany*}

Human health and well-being are closely linked to environmental conditions. Pollution or extreme temperatures have been associated with increases in mortality rates, sick leave, school absences, and ultimately healthcare costs (for a review, see, e.g., Graff Zivin and Neidell, 2013). Whereas most of our understanding on how living environmental conditions affect health relies on outdoor measures, the average individual in industrialized countries spends over $90 \%$ of her time indoors. Indoor environmental conditions can differ dramatically from outdoor conditions. Good insulation can prevent individuals from being exposed to outdoor noise or pollution, and good insulation or heating systems can prevent individuals from being exposed to extreme temperatures. Moreover, deficient, overcrowded dwellings have fueled the spread of diseases, and the deterioration of the mental and physical health of their occupants. Slum clearance, sanitation, or provision of low-rent housing are a few examples of public health policy measures devoted to ensure healthy living standards in Western countries. Although economists and policymakers are certain the provision of decent housing should lead to increased health and well-being, the evidence on how indoor environmental conditions affect our health is rather scarce, and is mostly based on small-scale interventions and in developing countries where settings are often not applicable to the average dwelling in industrialized countries (e.g., cementing sandy floors or upgrading coal cooking stoves, see Cattaneo et al., 2009; Hanna et al., 2016).

This study contributes to this literature by providing, for the first time, evidence of a population-wide upgrade in indoor living conditions, using the largest renovation wave in modern history not preceded by a war or natural disaster. In fact, we consider the case of the

\footnotetext{
${ }^{*}$ This chapter is co-authored with Steffen Kuenn (Maastricht University and IZA).
} 
German reunification and exploit the large renovation wave in East Germany in the 90s to learn about the impact of housing quality on occupants' health and labor market outcomes in industrialized countries. At the time of reunification, the conditions of the Eastern German housing portfolio were severely deficient, partly lacking basic amenities such as indoor toilets or modern heating systems. The German Federal Ministry of Transport, Building and Housing judged the East German housing portfolio in 1990 as the oldest real estate substance within developed, industrialized countries, with $52 \%$ of the dwelling constructed before 1945 (vs. $29 \%$ in West Germany), $40 \%$ of apartment buildings massively damaged, and $11 \%$ being uninhabitable. The German government devoted significant financial resources to bring the housing portfolio in East Germany to western standards, providing subsidized loans and tax credits to the real estate industry to modernize existing dwellings and create new ones. The main program, the $K f W$-Wohnraum-Modernisierungsprogram, thus allocated a total of $€ 40$ billion and renovated 3.6 million dwellings in East Germany (about 50\% of existing dwellings). In addition, the reunification removed restrictive access to building materials and resources, which was a major cause of the poor housing conditions in the former German Democratic Republic. As a result, the significant gap in housing conditions between East and West Germany was mostly removed by the end of the 20th century. We exploit this exceptional period of renovations to generate exogenous variation in the probability of receiving a renovation to estimate the causal impact of improved housing quality on occupants' health and labor market outcomes.

We use the German Socio-Economic Panel Study (SOEP) and apply an event-study approach including individual and year fixed effects to explore the effects of reporting a major renovation of the dwelling on occupants' living conditions, health, and labour market outcomes. We restrict the analysis to tenants in East Germany in the period right after the reunification, 1992-2002, where most dwelling renovations were undertaken due to the general need for renovation of the East German housing portfolio and thanks to large governmental support. Given these sample restrictions, and conditional on the individual fixed effects, we argue that the remaining variation in the probability of receiving a renovation as a tenant is exogenous given the large renovation wave during this time period. The results of a falsification test within the event-study approach as well as other sensitivity tests (including specification tests as well as an alternative instrumental-variable [IV] strategy) support the validity of the identifying assumption.

In a first step, we show that renovations are followed by significant significant improvements in the self-assessed housing conditions. This finding is key because it (i) suggests a high consistency and reliability of the data (measurement error), and (ii) confirms a real impact of the treatment on the quality of the dwelling, which is a necessary condition in order to be able to identify impacts on health outcomes. Based on this finding, we proceed with estimating the impact on health outcomes, and find a significant improvement in objective health status of the 
tenants as reflected by a reduction in days of sick leave. The effect heterogeneity analysis shows that women drive the positive health effects. Female tenants receiving a renovation report higher subjective health as well as a reduction in hospital visits and days sick leave, whereas we find no significant effects for men. We further show for women that the reduction in days of sick leave associated with the renovation is larger in cold years. This evidence suggests women are more vulnerable with respect to housing conditions, and a major renovation apparently improves their health significantly. Finally, we do not find support that the positive health effects translate into improved labor market outcomes as suggested by the economic literature (Currie and Madrian, 1999 : Stephens and Desmond Toohey, 2018).

This paper is organized as follows: Section 3.1 summarizes the key literature related to environmental conditions on health. Section 3.2 describes the housing conditions in East Germany at the time of the reunification and explains the governmental renovation programs in the $90 \mathrm{~s}$ to modernize the East German real estate sector and its outcome. Section 5.2 presents the data used for the empirical analysis, describes the estimation sample, and defines the variables of interest. Section 3.4 explains the estimation strategy, including a discussion on the justification of the identifying assumptions. Section 5.4 presents the results, and section 5.6 concludes.

\subsection{Literature}

Environmental conditions play a crucial role in shaping human health and well-being. The increase in frequency of devastating weather events like the heat wave in Europe in 2003, which killed over 70,000 people (Herrmann et al. 2008), have raised public awareness and triggered numerous studies. Exposure to extreme temperatures generates substantial damage to human cardiovascular and respiratory systems. An increasing body of large-scale quasi-experimental studies has documented significant societal costs associated with such hazards in the form of mortality rates, demand for healthcare services, and lower life expectancy and happiness (for a review of the literature, see Graff Zivin and Neidell, 2013, Deschenes, 2014).

A wealth of evidence links thermal conditions to human morbidity and mortality. Numerous studies in the field of health science provide convincing evidence of the impact of cold and warm temperatures on respiratory and cardiovascular health. The inhalation of cold air has been associated with respiratory problems such as lung inflammation, asthma attacks, and worsening obstructive pulmonary disease (Nayha, 2002). In addition, exposure to cold environments creates a substantial burden to human cardiovascular systems, increasing the risk of cardiovascular stress, leading to ischaemic heart disease, strokes, or coronary heart disease (Nayha, 2002). Similarly, warm temperatures also generate cardiovascular, cerebrovascular, and respiratory stress in humans whose bodies require higher thermo-regulatory efforts, sending higher blood flow to 
the skin to refrigerate the body. Recent estimates from a sample of $74,225,200$ global deaths estimate the deaths attributable to cold and hot temperatures is as high as $7.71 \%$ of the total deaths considered in the study (Gasparrini et al. 2015). These estimates are mainly driven by exposure to long-term sustained exposure to warm and (especially) cold temperatures.

In addition to the detrimental effects of moderately cold or warm environments in the long term, extreme temperatures can cause serious damage to human health even after short exposures. Quasi-experimental studies provide evidence of peaks in daily mortality associated with short-term exposure to extreme temperatures. Using high-frequency data from the US, Deschênes and Greenstone (2011) finds an extra day with a mean temperature above $32 \mathrm{C}^{\circ}$ (below $\left.-7 \mathrm{C}^{\circ}\right)$ degrees leads to a $0.11 \%(0.07 \%)$ increase of in the annual age-adjusted mortality rate, relative to days with mean temperatures in the $10^{\circ}-15^{\circ} \mathrm{C}^{\circ}$ range. Given the lower mobility and greater vulnerability of their bodies, the effects are more pronounced among infants and the elderly.

In addition, extreme temperatures trigger a number of defensive behavioral reactions. Individuals or households tend not to remain passive toward these environmental threats, but take multiple actions to avoid or reduce their exposure to health-detrimental environmental conditions. Housing is a key instrument for people to protect themselves against environmental hazards. The economic literature provides evidence of changes in migration patterns or sorting associated with extreme temperature (Deschenes and Moretti, 2009). In addition, individuals trade outdoor for indoor leisure to reduce their exposure, spending even more time indoors on extremely hot days (Graff Zivin and Neidell, 2014). Ultimately, investments in the housing portfolio can protect occupants from the harming effects of extreme weather conditions. The literature provides evidence of the effectiveness of transformations in the built environment in mitigating the deadly impact of heat waves. Barreca et al. (2016) show the spread of air conditioning across US residences was associated with a remarkable decline in the number of deaths linked to extreme temperatures, helping occupants reduce the exposure.

Most of the existing literature focuses on outdoor or ambient air pollution, traditionally disregarding indoor environments. Surprisingly little is known about the indoor environmental conditions on human health and well-being. The average individual in western society spends more than $90 \%$ of her time indoors, most of it at home (Klepeis et al., 2001). The literature investigating the impacts of suboptimal thermal conditions in houses and health is scarce, and a number of methodological issues challenge its external validity. The current evidence relies on cross-sectional studies, randomized control trials in small populations with existing health problems (e.g., asthmatics), or laboratory experiments (For a recent survey of the literature, see World Health Organization, 2018). The extrapolation of results from small samples in targeted populations is challenged by the heterogeneity in dose-response functions and by the presence 
of numerous confounding variables that directly affect the health status of individuals and the chances of being exposed to pollution sources or detrimental housing conditions (Banzhaf et al. 2019 ).

In addition, recent quasi-experimental research in large samples focusing on primitive housing in developing countries shows a significant impact of improvements in the indoor environment (e.g., flooring or electrification) on occupant health and quality of life. These studies rely on existing government renovation programs to explore how upgrades in housing conditions translate into better health and cognitive outcomes of the occupants. Cattaneo et al. (2009) explore the health benefits associated with a program cementing dirty floors in rural areas of Mexico, improving the cleanness and reducing the parasites in the houses part of the program. The authors find significant improvements in the mental and physical health of the occupants (i.e., parasites or diarrhea). Similarly, an experimental study based on a lottery program assigning prefabricated houses shows significant improvements in the well-being of occupants and children's health, and reduced insecurity feelings of slummers in Latin America (Galiani et al. 2017). Finally, the reduction in fine particulate matter $\left(P M_{2.5}\right)$ generated by an electrification program in El Salvador led to significant improvements in the prevalence of acute respiratory infections among children (Barron and Torero, 2017). Although these studies provide robust evidence on the beneficial effects of house upgrades on human health and well-being, their settings are hardly applicable to the general building stock or in most developed countries.

In this paper, we aim to estimate the change in house conditions in a developed country, with starting conditions of the housing portfolio much closer to the average dwelling in western societies today. Furthermore, the housing programs explored in the existing evidence target the poorest and most disadvantaged stratus of society, challenging the external validity of the findings to other population groups. In addition, the influence of individuals' behaviour might introduce significant deviations in expected health gains (see for e.g. Hanna et al., 2016). In contrast to previous evidence, we aim to provide population representative evidence exploiting variation in indoor house conditions created by a wave in house renovations generated by a largescale governmental loan program in East Germany in the aftermath of the German reunification (1990-2000).

\subsection{Institutional Setting}

On November 9, 1989, the Berlin wall came down, and on October 3, 1990, Germany was reunited. During the time of separation, significant differences evolved in terms of the economy, institutions, infrastructure, and living conditions. East Germany experienced a massive improvement in these dimensions during the 90s, in particular due to strong financial support by West 
Germany. Although East Germany still lags significantly behind the West German economy (GDP, worker productivity, etc.) at the end of the 20th century, infrastructure and living conditions are almost equalized compared to West Germany (Sinn, 2000).

Focusing on the housing portfolio, the differences between East and West Germany were substantial at the time of the reunification. The closed planned economy in East Germany highly restricted access to building materials and resources. In addition, the capacity to maintain older buildings was limited, because the focus was on the construction of new industrialized building blocks to satisfy the high demand for dwellings in the GDR. As a result, the German Federal Ministry of Transport, Building and Housing describes the East German housing portfolio at the time of reunification as the oldest real estate substance within the developed, industrialized countries (Federal Ministry of Transport and Housing, 2000). Fifty-two percent of the dwellings were constructed before 1945 (vs. 29\% in West Germany), $40 \%$ of apartment buildings were massively damaged, and $11 \%$ were uninhabitable.

Table 3.1 provides a distribution of home amenities between East and West Germany at the time of the reunification. The numbers are based on a survey by the German Federal Association of Housing Associations and Real Estate Companies (GdW,Bundesverband deutscher Wohnungsund Immobilienunternehmen) on housing associations and municipal housing companies in 1990 (figures for West Germany refer to 1987) [2 It clearly documents the significant disparity between the East and the West German housing portfolio. Only $48 \%$ of the dwellings had access to a centralized heating system, compared to $75 \%$ in the West. Furthermore, 26\% (21\%) of the dwellings did not even have a bathtub or shower (indoor toilet), corresponding to about 800,000 $(600,000)$ dwellings. This implies sanitary issues and increases exposure time of occupants to outdoor conditions. The GdW (1990) concludes the equipment of East German dwellings lags about 20 years behind the West German standard.

A major policy goal right after the reunification focussed on equalizing living conditions in East and West Germany (Sinn, 2000) ${ }^{3}$ Therefore, the German government implemented one of the largest loan programs in history, providing significant financial means to encourage home owners to invest in their properties. The program consisted of reduced interest payments (and eased collateral conditions for public housing associations) and was implemented by the German public bank $K f W$ (Kreditanstalt für Wiederaufbau). Accordingly, the program was called the $K f W$-Wohnraum-Modernisierungsprogram, and its main aim was to incentivize the East German

\footnotetext{
${ }^{2}$ Housing associations and municipal housing companies owned 3.4 million dwellings, which corresponds to $\sim 50 \%$ of all dwellings in East Germany at this time. The numbers are likely to represent an overestimation of the actual housing conditions given that housing associations and municipal housing companies predominately own younger and modernized buildings.

${ }^{3}$ Among other reasons, a vast convergence of living conditions (in terms of wage level, housing, etc.) was supposed to reduce the East-West migration. For instance, between January 1989 and January 1992, about 870,000 East Germans migrated to West Germany, which corresponds to $5 \%$ of the entire East German population (Burda. 1993). After 1992, the internal migration decreased and stabilized at around 140,000 to 180,000 per year.
} 
Table 3.1: Home amenities in German dwellings at reunification in 1990

\begin{tabular}{lcr}
\hline \hline & West Germany & East Germany \\
& & \\
& & \\
Central heating system & 75 & 48 \\
Centralized warm water system & 55 & 36 \\
Bathtub or shower & 97 & 74 \\
Indoor toilet & 98 & 79 \\
& & \\
\hline \hline & Source: GdW Gesamtverband der deutschen Wohnungswirtschaft. \\
Note: Numbers are in percentages and based on a survey on housing asso- \\
ciations and municipal housing companies in 1990 (figures for West Ger- \\
many refer to 1987). They operate 3.4 million dwellings which corresponds \\
to $50 \%$ of all dwellings in East Germany at this time.
\end{tabular}

real estate industry to modernize their properties and hence equalize living conditions in West and East Germany $4^{4}$ Between October 1990 and January 2000, 79 billion DM (corresponds to 40 billion euro) was allocated to private and public house owners to renovate existing or create new dwellings. The majority of the budget $(71 \%)$ was used for renovations, whereas only $7 \%$ was used to build new dwellings and $22 \%$ to increase the energy efficiency of dwellings (see Reich, 2000). In total, 3.6 million dwellings have been renovated based on the program, which corresponds to about $52 \%$ of all existing dwellings in East Germany at the time of the reunification.

In addition to this main program, the German government implemented other policies to stimulate the modernization of housing in East Germany: (i) Another KfW program began in 1996, focusing specifically on the reduction of $\mathrm{CO}_{2}$ emissions and providing subsidized loans to improve heating systems and building insulation. The program covered only about $10 \%$ of the budget as the $K f W$-Wohnraum-Modernisierungsprogram. (ii) Federal states set up specific programs focusing on heritage-protected buildings, in particular in city centres. (iii) In addition to the loan programs, the federal government introduced special tax-amortization rules for the modernization and creation of dwellings. It allowed owners to deduct $50 \%$ of the expenses from taxation within the first five years. Lastly, note that next to the monetary incentives set by tax rules and loan programs, the reunification abandoned the restricted access to resources (e.g., building material) due to abolishment of the closed planned economy system in the former GDR.

As a result, the significant gap in housing conditions between East and West Germany was mostly removed by the end of the 20 th century. The GdW documents that $71 \%$ of all dwellings owned by housing associations and municipal housing companies were renovated until

\footnotetext{
${ }^{4}$ The subsidy consisted of a reduced interest rate of up to 3 percentage points below the capital market interest rate and was fixed for 10 years. The maximum amount was $400 \mathrm{Euro} / \mathrm{m}^{2}$ with a maximum maturity of 25 years. Private and public owners modernizing their dwellings (sanitary installation, doors, windows, heating, insulation, elevators, noise protection, roofs, etc.) as well as creating new dwellings were eligible.
} 
the end of 2000, whereas $24 \%$ are still in need of renovation and $5 \%$ do not need a renovation (Source: GdW Annual Statistic). Figure 3.1 shows the improvement in house amenities in East German dwellings over time. In 1998, Eastern dwellings converged to the western standard, with $78 \%$ having a centralized heating system. In terms of sanitary installments, the gap reduced significantly to $92 \%$ having a bathtub or shower in the East compared to $98 \%$ in the West (GdW, 1999).

Figure 3.1: Home amenities in East German dwellings over time

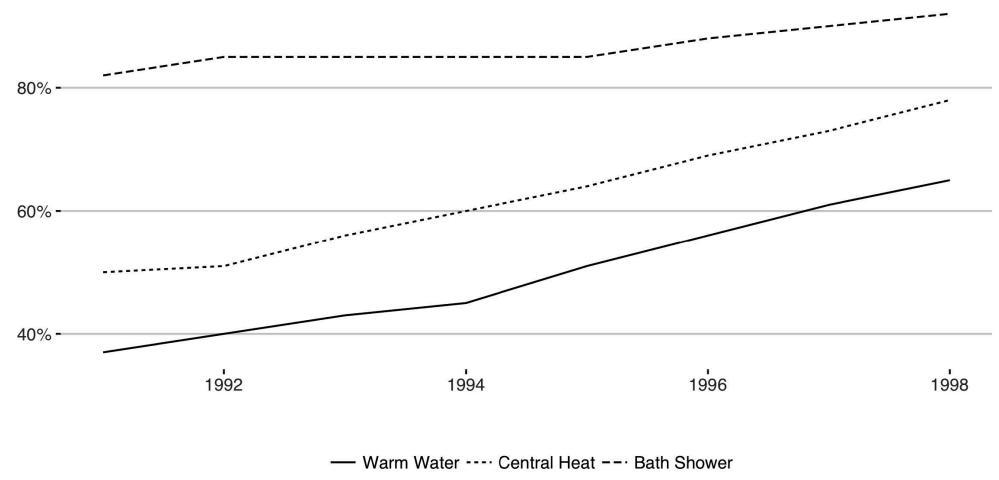

Source: $[\mathrm{GdW}](1999)$.

Note: Numbers are based on a survey on housing associations and municipal housing companies.

The massive renovation wave in the East during the 90s is also clearly visible in our sample (see section 5.2 for the data description). First, Figure 3.2 shows the share of households reporting a major renovation in their dwelling. For West Germany, we see no change. The share remains stable at around $5 \%$ over time. However, for East Germany, the share increased from initially $5 \%$ in 1991 to its peak of $20 \%$ in 1997 and then converged back to West Germany in the mid 2000s. The delayed start of the renovation wave in 1992 is mainly due to the ongoing privatization process of East German assets (including real estate) in the aftermath of the reunification (see Sinn, 1993, for a documentation of the privatization process after reunification). Ownership of real estate had to be clarified before investments took place.

Similarly, Figure 3.3 presents the percentage of households reporting problems with the conditions of their dwellings. The figure shows a significant gap between living conditions between the East and the West. In the early 90s, the differences in the proportion of households reporting their houses were in need of partial renovation between the East and the West was around 20\%, and the differences in the proportion of households reporting their houses were in need of full renovation was over $10 \%$. The renovation programs implemented in Eastern Germany managed to reduce the gap to almost zero by the beginning of the 21st century.

To sum up, during the first 10 years after reunification, East Germany experienced a massive 
Figure 3.2: Percentage of households reporting a renovation in Eastern and Western Germany

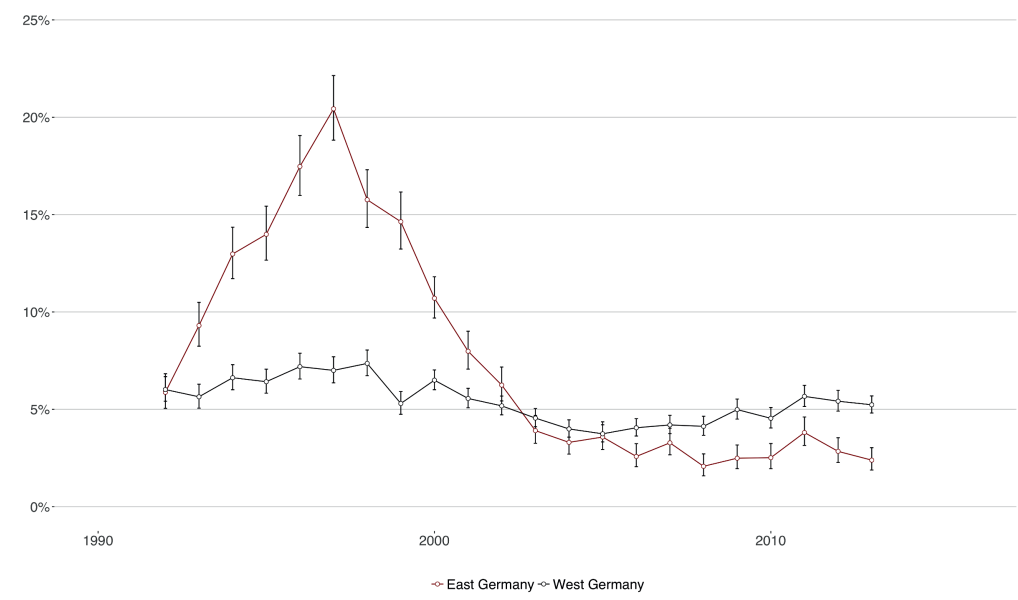

Source: SOEP, own calucations.

Figure 3.3: Percentage of households reporting in a dwelling in need for partial or full renovation in Eastern and Western Germany
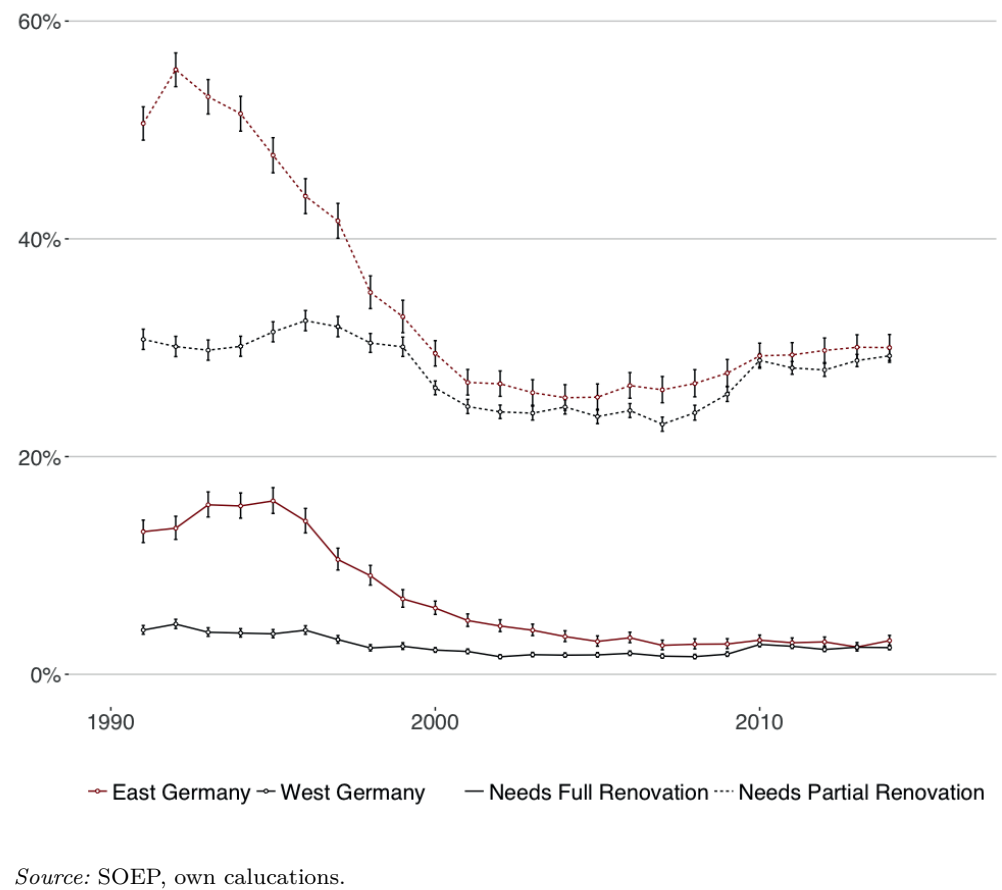

renovation wave of dwellings triggered by access to resources as well as significant governmental funding programs. To yield causal identification in the empirical strategy, we exploit this exceptional period of renovations to generate exogenous variation in the probability of receiving a 
renovation.

\subsection{Data And Descriptive Statistics}

To estimate the causal effect of a major renovation of the dwelling on occupants' health and labor market outcomes, we use the German Socio-Economic Panel (SOEP). The SOEP is a yearly population representative longitudinal study of about 11,000 households and 30,000 individuals in Germany (Wagner et al., 2007) and contains detailed information on house conditions and renovations executed in the house over the year. The SOEP also includes extensive information about respondents' health status, healthcare utilization, and socioeconomic characteristics.

The SOEP started interviewing German households in 1984, including those living in West Germany. The inclusion of those households that were living in the region of the former GDR was in 1990, before the monetary and economic reunification was executed. For the analysis, we consider the period right after the reunification, 1992-2000, when most dwelling renovations were executed as triggered by the general need for renovation of the East German housing portfolio due to the lack of maintenance before reunification and large governmental support (see section 3.2. We include only the individuals who were part of the initial sample of the SOEP in East Germany, because the sample was refreshed in 1998, after most of the renovations were executed. In addition, we exclude the period before 1992 because of the unavailability of the question on the renovation and to avoid bias due to the ongoing privatization process of the real estate industry (Sinn, 1993). We further restrict the analysis to tenants in East Germany, because for tenants, the timing and type of renovation is likely to be exogenous in this time period, given their initial choice of residence (fixed effect). Finally, we observe 3,906 tenants in East Germany, resulting in 18,170 tenant-year observations. The sample observes 4,852 respondents ( $82 \%$ ) for at least two years, making a fixed-effect strategy feasible.

\subsubsection{Dwelling Renovations}

The definition of our treatment indicator, that is, whether a household received a major renovation in a certain year, relies on a question on renovation activities that took place in their homes since the last interview. Each household has to categorize the renovation in the dwelling as at least one of the following categories: installing (1) a new kitchen, (2) bathroom, (3) heating system, (4) windows, or (5) other. 5 In addition, respondents living in rental dwellings have to report whether (1) the respondent or (2) the owner paid for the reported modernization of the dwelling. Finally, every year the individuals have to evaluate the conditions of the maintenance

\footnotetext{
${ }^{5}$ The actual wording of the question was (in German): "Haben Sie oder Ihr Vermieter seit Anfang [Jahr] eine dieser Wohnung eine oder mehrere der folgenden Modernisierungen vorgenommen? • Eine Küche eingebaut • Bad, Dusche oder WC innerhalb der Wohnung eingebaut • Zentralheizung oder Etagenheizung eingebaut • Neue Fenster eingebaut • Sonstige größere Maßnahmen "
} 
of the house where they live as (1) In good condition, (2) in need of partial renovation, (3) in need of full renovation, or (4) ready for demolition 6

Based on this information, we define a yearly binary treatment variable that takes the value of 1 if respondents report a modernization that was part of the targeted renovations in the subsidized loan programs (i.e., heating, windows, bathroom, or insulation 7 ) and was paid for by the landlord, and zero otherwise. Moreover, we create a binary outcome variable taking the value of 1 if the respondent reports that her house is in need of partial or full renovation.

\subsubsection{Individual Health And Well-Being}

The main focus of this paper is to investigate the impact of house renovations on individual health and well-being. The SOEP includes an extensive questionnaire on respondents' health status and their demand for health care, allowing us to use a range of indicators to measure the impact of the program on individuals' health. Each respondent is asked to evaluate her own current health status on a 5-point Likert scale as (1) very good, (2) good, (3) satisfactory, (4) poor, and (5) bad 8

In addition, every year participants are asked to report the number of times they visited the doctor in the three months before the date of the interview, and the number of hospital overnight stays in the year before the interview. Finally, each individual in the sample employed at the moment of the interview is asked to report the number of days he or she was on sick leave in the year before the interview.

Well-being is measured based on a series of questions in which individuals are asked to evaluate their satisfaction with life as a whole, or specific aspects of their lives on 10-point Likert scales $(1=$ not satisfied, $10=$ very satisfied $)$. In this study, we use in the analysis the questions on general life and health satisfaction.

Finally, the SOEP includes a number of variables describing the current labor market status of the survey participants. First, individuals are asked to report their current occupational status. Based on the original variable, we constructed two dummy variables: one describing whether an individual is currently unemployed and actively looking for a job (1=Yes) and another describing whether an individual is working $(1=$ Yes). Finally, we include the number of hours that the individual reported he worked the week before the interview.

\footnotetext{
${ }^{6}$ The actual wording of the question was (in German): Wie beurteilen Sie den Zustand des Hauses, in dem Sie wohnen? • In gutem Zustand • Teilweise renovierungsbedurftig • Ganz renovierungsbedurftig • Abbruchreif

${ }^{7}$ The SOEP does not ask directly for renovation regarding the insulation of the building; however, we use the category "other major parts of the apartment" as a proxy for such renovations

${ }^{8}$ The actual wording of the question was (in German): Wie wurden Sie Ihren gegenwartigen Gesundheitszustand beschreiben? • Sehr gut • Gut • Zufriedenstellend • Weniger gut • Schlecht
} 


\subsubsection{Description of Estimation Sample}

Table 3.2 shows the distribution of socio-economic characteristics among treated and non-treated households in the first year of our sample (1992), that is, before renovations part of the governmental programs took place. The table shows no significant differences in age, gender, years of education, income, household members, or construction year between the two groups before the renovation program. Similarly, we find no statistically significant differences in average health status or demand for health care between the two groups.

Table 3.2: Descriptive statistics treated and non-treated households in the first year of the sample (1992)

\begin{tabular}{lrrr}
\hline \hline & $\begin{array}{r}\text { Non Renovated } \\
(N=2152)\end{array}$ & $\begin{array}{r}\text { Renovated } \\
(N=1754)\end{array}$ & p-value \\
& & & \\
& & & \\
& & & \\
& & & \\
Individual and household characteristics & 11.97 & \\
Years of education & 1353.13 & 1329.44 & 0.27 \\
Household income (in Euro/month) & 3.05 & 2.84 & 0.00 \\
Household members & 42.27 & 42.77 & 0.40 \\
Age of respondent & 0.45 & 0.48 & 0.27 \\
Female (1=yes) & 0.60 & 0.60 & 0.61 \\
Working (1 = yes) & 781.04 & 769.71 & 0.53 \\
Labor Income (in log) & & & \\
Dwelling Characteristics & 1960.93 & 1959.25 & 0.23 \\
Construction year & 125.62 & 118.44 & 0.00 \\
Monthly rent (in $€$ ) & 0.77 & 0.78 & 0.23 \\
In need for renovation (1=yes) & & & \\
Health Outcomes & 2.36 & 2.37 & 0.62 \\
Current health (from 1 very good to 5 poor) & 7.14 & 7.86 & 0.53 \\
Days sick leave & 2.12 & 2.29 & 0.16 \\
Doctor visits last three months & 1.16 & 1.28 & 0.79 \\
Number visits hospital & & & \\
& & & \\
\hline Note: The table shows descriptive statistics for treated and non-treated individuals who are observable \\
at the beginning of our observation window in 1992. P-value is based on a t-test on equal means.
\end{tabular}

\section{Validation of Survey Measure}

In this section, we present the results of an exercise testing the validity of our main treatment variable, a survey item that describes the presence of a renovation in the house of individuals in our sample. In particular, we explore how the survey measure correlates with the total amount spent in each county per year as part of the largest governmental loan program ( $K f W$-WohnraumModernisierungsprogramm, KfW program hereafter).

We exploit the regional variation in the roll-out KfW program in East Germany in the aftermath of the German reunification (see section 3.2 for details). We have access to yearly loan take-up within the KfW program for counties in East Germany in the period 1992-2000 (Source: KfW). We construct the following intensity measure $Z_{c t}$ based on the yearly amount of 
the subsidy per inhabitant in county $c$ :

$$
Z_{c t}=\text { Subsidyct }_{\text {population }} \text { t }
$$

Figure 3.4 shows the spatio-temporal distribution of the program intensity, $Z_{c t}$. The figure shows a wide dispersion and variation in the timing of the investments over the decade across counties.

Figure 3.4: Distribution Loan Take-up per Inhabitant Across Counties over Years of the Program
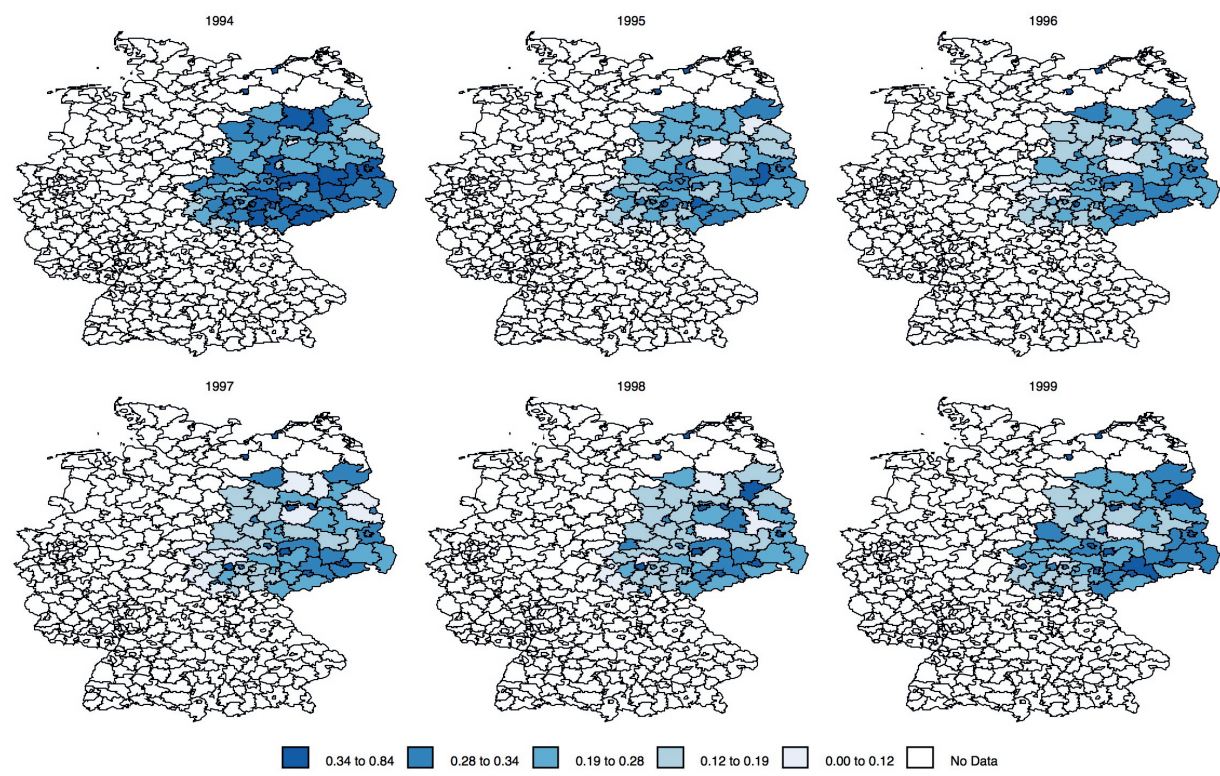

Note: Distribution of loan take-up per inhabitant in years 1992 and 1993 omitted for space limitations (available upon request).

The money per head allocated to the program in a given country in a given year $\left(Z_{c t}\right)$ is used as an explanatory variable for the individual probability of experiencing a major renovation (treatment) paid for by his landlord in his dwelling in a given year. Given the scope and impact of the program, we expect the intensity of the program to influence the individual probability of reporting a major renovation of their own dwelling. Tenants who live in a county with a relatively high loan intensity in a certain year are more likely to experience a renovation than tenants who live in a county with a low loan intensity.

We implement a fixed-effects strategy including the county fixed effects to account for the time-invariant regional discrepancies in the probability of receiving a renovation (e.g., initial status of the housing stock). Including county fixed effects controls for the initial status of the housing portfolio and takes into account potential endogenous selection of counties. Therefore, 
we use within-county variation over time to validate our treatment variable, as described by the following linear probability model:

$$
\operatorname{Renov}_{i j t}=\alpha_{1}+\gamma \ln \left(Z_{c s}\right)+\beta_{1} X_{i j t}+\eta_{j}+U_{i j t}
$$

where Renovijt indicates whether individual $i$ living in dwelling $j$ in year $t$ reports a major renovation. $X_{i j t}$ denotes individual characteristics, $\eta_{j}$ reports county fixed effects, and $Y_{i j t}$ reports the outcome variables. The set of individual characteristics $X_{i j t}$ includes the age of the respondent, the logarithm of dwelling rent, the age of individual, his gender, and ratio of household members per room. The error term $U_{i j t}$ is clustered at the county-year level.

In our regressions, we use the logarithm transformation of the per-head $Z_{c s}$ to allow for a non-linear relationship between the loan amount and the likelihood of receiving a renovation. We undertake a specification test whereby we test the temporal gap between the money allocated to the KfW program and the timing of the renovation $(t-s)$. We include the allocation of money to the program in the years after, as a falsification test.

Table 3.3 presents the results of the specification tests. The estimation results show the subsidy intensity is significantly correlated with the current likelihood of receiving a renovation and the subsidy intensity two years before. The coefficient with the largest coefficient is associated with the second lag of the subsidy. The coefficient indicates a $1 \%$ increase in the subsidy per head in a county increases the likelihood of renovation by 2.7 percentage points. Column (6) shows the results from a joint regression, confirming the strongest association is with the second lag of the subsidy intensity. The time gap between the subsidy and the completion of the renovation in the dwelling is likely due to the time needed to arrange and execute major renovation by the landlords. These results indicate the program was a significant driver of renovations in East Germany, and our survey measures is able to capture the increase in the renovation rates in the region.

In addition, the estimation results for the two leads of the subsidy intensity show a lack of correlation between the subsidy intensity in the county of residence of the individual in the following years of the renovation (columns (4) and (5) in Table 3.3). The lack of statistically significant coefficients associated with future subsidy intensity provides further supportive evidence of the validity of our treatment.

\subsubsection{Preferences for A Renovated Home}

Before discussing the identification strategy, we investigate individual preferences for upgraded housing quality. Understanding the moving pattern in our sample is important because it might affect the timing of the treatment. In fact, individuals can either receive the treatment (i) by remaining in their current dwelling and waiting until it is renovated, or (ii) by actively selecting 
Table 3.3: Validation treatment variable. Specification test

\begin{tabular}{|c|c|c|c|c|c|c|}
\hline & $\begin{array}{c}(1) \\
\text { Renovated }_{t}\end{array}$ & $\begin{array}{c}(2) \\
\text { Renovated }_{t}\end{array}$ & $\begin{array}{c}(3) \\
\text { Renovated }_{t}\end{array}$ & $\begin{array}{c}(4) \\
\text { Renovated }_{t}\end{array}$ & $\begin{array}{c}\text { (5) } \\
\text { Renovated }_{t}\end{array}$ & $\begin{array}{c}(6) \\
\text { Renovated }_{t}\end{array}$ \\
\hline \multirow[t]{2}{*}{$\ln \left(Z_{c t-2}\right)$} & $0.027^{* * *}$ & & & & & $0.037^{* *}$ \\
\hline & {$[0.012]$} & & & & & {$[0.016]$} \\
\hline \multirow{2}{*}{$\ln \left(Z_{c t-1}\right)$} & & 0.007 & & & & -.0169 \\
\hline & & {$[0.005]$} & & & & {$[0.018]$} \\
\hline \multirow[t]{2}{*}{$\ln \left(Z_{c t}\right)$} & & & $0.012^{* * *}$ & & & $0.011^{* *}$ \\
\hline & & & {$[0.005]$} & & & {$[0.005]$} \\
\hline \multirow{2}{*}{$\ln \left(Z_{c t+1}\right)$} & & & & -0.000 & & \\
\hline & & & & {$[0.006]$} & & \\
\hline \multirow[t]{2}{*}{$\ln \left(Z_{c t+2}\right)$} & & & & & -0.002 & \\
\hline & & & & & {$[0.006]$} & \\
\hline Observations & 10805 & 14175 & 16441 & 12125 & 9662 & 9257 \\
\hline Individual Controls & YES & YES & YES & YES & YES & YES \\
\hline County Fixed Effects & YES & YES & YES & YES & YES & YES \\
\hline
\end{tabular}

into the treatment. Therefore, individuals move to a different dwelling that is already renovated or is going to be renovated in the near future. The selection into treatment might be endogenous and has to be taken into account in the identification strategy.

In addition to the methodological aspect, the analysis of moving patterns is also interesting from a policy perspective. The literature has identified individual preferences for avoiding environmental health risks in the living environment (see, e.g., Chay and Greenstone, 2003). Research has shown individuals are willing to pay rent or a price premium to limit or avoid exposure to hazards such as air pollutants or lead (Billings and Schnepel, 2017). The question is whether such patterns are also visible in our sample.

To analyze individuals' changes in address, rents, and dwelling conditions around the renovation year, we estimate the following regression:

$$
Y_{i t}=\gamma_{i}+\theta_{t}+\sum_{\tau=\tau_{\min }}^{\tau_{\max }} \lambda_{\tau} \mathbb{1}\left(t=t_{0}+\tau\right)+\beta X_{i t}+V_{i t}
$$

where $i$ denotes individuals and $t$ years. We use three different outcomes: ChangeAddress $s_{i t}$, Rent $_{i t}$, and NeedsRenov ${ }_{i t}$. ChangeAddress $s_{i t}$ indicates the year individual $i$ moves to another dwelling in year $t$. In addition to observed socioeconomic characteristics $X_{i t}$ (income, age, education, working status), we include individual fixed effect $\left(\gamma_{i}\right)$ as well as year fixed effects $\left(\theta_{t}\right)$ to capture fixed unobserved individual and time characteristics. The variable of interest, $\mathbb{1}\left(t=t_{0}+\tau\right)$, is a binary variable indicating the year $t_{0}+\tau$ before or after the renovation. These effects are measured relative to the year the dwelling experiences the renovation $t_{0}(\tau=0)$, which is excluded. The main coefficient of interest, $\lambda_{\tau}$, represents the effect of experiencing a renovation event in year $t_{0}$ on the probability of moving $\tau$ years later (or previously, for $\tau<0$ ). 
Thus, the coefficients $\lambda_{\tau}$ reflect to what extent renovations influence individuals' decisions to change address. We consider a time window of three years before $\left(\tau_{\min }=-3\right)$ and after the renovation $\left(\tau_{\max }=3\right)$.

Table 3.4: Change in address, rent per square meter and living conditions around the renovation

\begin{tabular}{|c|c|c|c|c|c|c|}
\hline & $\begin{array}{c}(1) \\
\text { Change } \\
\text { Address }(1=\text { Yes })\end{array}$ & $\begin{array}{c}(2) \\
\text { Change } \\
\text { Address }(1=\text { Yes })\end{array}$ & $\begin{array}{c}(3) \\
\text { Rent } \\
\text { per sqm. }\end{array}$ & $\begin{array}{c}(4) \\
\text { Rent } \\
\text { per sqm. }\end{array}$ & $\begin{array}{c}(5) \\
\text { Needs renov. } \\
(1=\text { Yes })\end{array}$ & $\begin{array}{c}(6) \\
\text { Needs renov. } \\
(1=\text { Yes })\end{array}$ \\
\hline House Renovated $t_{t_{0}}$ & & $\begin{array}{c}0.00507 \\
(0.00494)\end{array}$ & & $\begin{array}{l}0.228^{* * *} \\
(0.0390)\end{array}$ & & $\begin{array}{c}-0.149 * * * \\
(0.0148)\end{array}$ \\
\hline Year $(1=\text { Yes })_{t_{0}+1}$ & $\begin{array}{l}-0.00977 \\
(0.00839)\end{array}$ & & $\begin{array}{c}0.268^{* * *} \\
(0.0604)\end{array}$ & & $\begin{array}{c}-0.124^{* * *} \\
(0.0199)\end{array}$ & \\
\hline Year $(1=\text { Yes })_{t_{0}+2}$ & $\begin{array}{l}-0.0180^{* *} \\
(0.00730)\end{array}$ & & $\begin{array}{r}0.246^{* * *} \\
(0.0772)\end{array}$ & & $\begin{array}{c}-0.137^{* * *} \\
(0.0222)\end{array}$ & \\
\hline Year $(1=\text { Yes })_{t_{0}+3}$ & $\begin{array}{c}-0.0114 \\
(0.00775)\end{array}$ & & $\begin{array}{c}0.142 \\
(0.0923)\end{array}$ & & $\begin{array}{c}-0.126^{* * *} \\
(0.0271)\end{array}$ & \\
\hline Year $(1=\text { Yes })_{t_{0}-1}$ & $\begin{array}{l}-0.00227 \\
(0.00717)\end{array}$ & & $\begin{array}{c}-0.329 * * * \\
(0.0578)\end{array}$ & & $\begin{array}{l}0.204^{* * *} \\
(0.0213)\end{array}$ & \\
\hline Year $(1=\text { Yes })_{t_{0}-2}$ & $\begin{array}{r}-0.000499 \\
(0.00815)\end{array}$ & & $\begin{array}{c}-0.301^{* * *} \\
(0.0653)\end{array}$ & & $\begin{array}{l}0.158^{* * *} \\
(0.0270)\end{array}$ & \\
\hline Year $(1=\text { Yes })_{t_{0}-3}$ & $\begin{array}{l}-0.00321 \\
(0.00751)\end{array}$ & & $\begin{array}{c}-0.291^{* * *} \\
(0.0760)\end{array}$ & & $\begin{array}{c}0.167^{* * *} \\
(0.0279)\end{array}$ & \\
\hline Observations & 15,491 & 18,170 & 15,057 & 17,669 & 15,347 & 18,015 \\
\hline Indivudal Fixed Effects & YES & YES & YES & YES & YES & YES \\
\hline Year Fixed Effects & YES & YES & YES & YES & YES & YES \\
\hline
\end{tabular}

Note: * /**/*** indicate statistically significance at the $10 \% / 5 \% / 1 \%$-level. Standard errors are in parentheses and clustered at the household level.

Column (1) in Table 3.4 presents the changes in the probability of changing address in the years before and after experiencing a renovation in our sample period. The table indicates no existence of a selection of individuals into renovated houses, as indicated by the lack of significant (and positive) coefficients associated with the years prior to the renovation $(\tau<0))$. In the years after the move, the results indicate a marginal reduction in the probability of changing address.

Similarly, we explore the concurrence of a renovation with a change in address, rent, or dwelling conditions using the following empirical model:

$$
Y_{i t}=\alpha_{i}+\theta_{t}+\mu \mathbb{1}\left(t=t_{0}\right)+\beta X_{i t}+V_{i t}
$$

where $\mathbb{1}\left(t=t_{0}\right)$ describes the occurrence of a renovation in the dwelling of individual $i$ in year $t$. The results presented in column (2) in Table 3.4 indicate the individuals in our sample are not significantly more likely to report changes in address the year the renovation takes place.

In addition, we investigate the changes in the rent associated with the renovation event. Here, Rent $_{i t}$ describes the rent per square meter of the dwelling where individual $i$ lives in year $t$. In column (3) of Table 3.4, we explore the changes in rent in the year of renovation. We observe a 
positive change in the renovation year. The higher willingness to pay for the dwelling happens in the renovation year, along with the lack of sorting out of renovated apartment. This suggests individuals do not select out of the renovation due to a potential increase in rents. Furthermore, individuals did not face economically significant increases in their rent after the move (0.22 euros per $\mathrm{m}^{2}$ ). Similarly, official reports indicate that due to subsidy payments to the real estate sector in the 90s in East Germany, the additional premium on the rent for modernized dwellings only amounted to 0.64 euros per $\mathrm{m}^{2}$ (Harris, 1998).

Finally, we examine whether the reported renovation indeed led to a significant improvement in living conditions. This condition must hold in order (i) to show the consistency of the data and hence the reliability of the renovation information, and (ii) to have any meaningful impact on the relevant health outcomes considered in the analysis. We estimate equation 3.3 where NeedsRenovit is defined as a dummy variable taking the value of 1 if the respondent $i$ reports that her house is in need of partial or full renovation in year $t$.

Column (4) in Table 3.4 presents the estimated change in dwelling conditions associated with the renovation, as described by the probability of assessing the current dwelling as "in need of partial" or "full renovation." In the years immediately before and after the renovation (three years after the renovation), we see a significant drop in the probability of reporting living in a house that is in need of partial or full renovation. The results indicate the perfect condition of the dwelling (no need for any renovation) sustains for up to three years after the renovation.

This evidence confirms the consistency and reliability of responses to the questions on the occurrence of renovation and housing conditions. Moreover, it shows a real impact of the treatment on the quality of the dwelling, which is a necessary condition in order to be able to identify impacts on health outcomes.

Column (5) in Table 3.4 displays the estimations of the separate coefficient in equation 3.4 The result indicates the existence of a reduction in the probability of reporting the need for a renovation in the exact year the renovation is completed.

\subsection{Empirical Strategy}

To estimate the causal impact of improved housing conditions due to a major renovation on occupants' health and labor market outcomes, we adopt an event-study approach that exploits the temporal variation in the implementation of the renovation wave in East Germany in the 90s (We adopted the event-study approach, increasingly used by different empirical studies in the economics literature, see, e.g., Lafortune et al. 2016). Our strategy assumes individuals in our sample living in dwellings non (yet) renovated in a particular year form a useful counterfactual for dwellings that did experience a renovation, after accounting for individual fixed effects and 
common time trends. The key assumption in our study is that the exact timing of the renovation cannot be altered by the tenants considered in our sample and therefore is as good as random.

The main regression model estimates the effect of a renovation on the outcome variables for the period after the renovation takes place, using the following equation:

$$
Y_{i j t}=\alpha_{i}+\theta_{t}+\lambda \mathbb{1}\left(t<t_{i j}^{*}\right)+\delta \mathbb{1}\left(t>t_{i j}^{*}\right)+\beta X_{i j t}+V_{i j t}
$$

where $i$ denotes individuals living in dwelling $j$ in year $t$, and $Y_{i j t}$ describes the outcome variables considered in the study. We discuss our particular measures in the next section. $\alpha_{i}$ and $\theta_{t}$ represent the individual and year fixed effects, respectively. The term $\mathbb{1}\left(t>t_{i j}^{*}\right)$ represents a binary variable taking the value of 1 if $t$ is larger than $t_{i j}^{*}$, which is the year before the renovation of individual $i$ 's dwelling $j$, and is set to zero the period before the renovation and for individuals whose dwellings are never renovated during the study period. Figure 3.5 illustrates the exact timing of the empirical model. The coefficient $\delta$ describes the change in the outcome following the renovation event, relative to the year $t_{i j}^{*}$, which is excluded. We consider a time window of three years before and after the renovation. $X_{i j t}$ contains a set of time-varying socioeconomic characteristics, namely, income, age (and age square), education, ratio of household members per room, occupational status, and working hours. Standard errors are clustered at the household level.

Figure 3.5: Timing of the empirical model

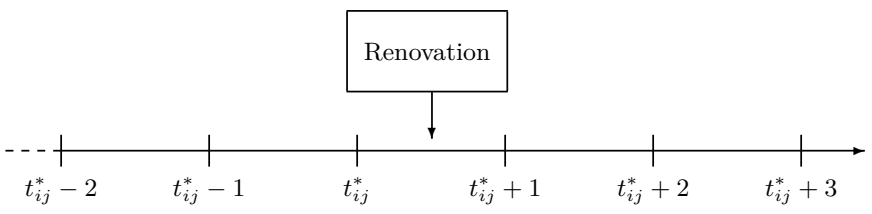

Note: The figure illustrates the exact timing of the empirical model.

Including $\mathbb{1}\left(t<t_{i j}^{*}\right)$ allows for a falsification test for our identifying assumption that the exact timing of the treatment is random. If event timing is non-random, treated individuals would differ from non-treated independent of the treatment. In this regard, $\lambda$ identifies the change in outcome variables between treated individuals in the years before treatment and nontreated individuals in these years. Therefore, $\lambda=0$ would support the validity of the identifying assumption (random timing of treatment), and exclude any anticipation effects of the treatment. In fact, we find $\lambda$ equals zero for all health and labor market outcomes.

In addition, we estimate a more flexible model in which we do not impose the functional 
form in the pre and post trends to be linear:

$$
Y_{i j t}=\alpha_{i}+\theta_{t}+\sum_{\tau=-2}^{-1} \lambda_{\tau} \mathbb{1}\left(t=t_{i j}^{*}+\tau\right)+\sum_{\tau=1}^{3} \delta_{\tau} \mathbb{1}\left(t=t_{i j}^{*}+\tau\right)+\beta X_{i j t}+V_{i j t}
$$

Equation 3.6 is identical to our main estimating equation (eq. 5.2), except that we replace the single indicator variables for the pre $\left(\mathbb{1}\left(t<t_{i j}^{*}\right)\right)$ and the post trend $\left(\mathbb{1}\left(t>t_{i j}^{*}\right)\right)$ with a set of indicators $\mathbb{1}\left(t=t_{i j}^{*}+\tau\right)$ indicating the years before and after the reference year $t_{i j}^{*}$. For instance, $t_{i j}^{*}+1$ indicates the first year right after the renovation (see Figure 3.5. The effects described by $\delta_{\tau}$ measure the effect of the renovation on outcomes $\tau$ years later, relative to the reference year $t_{i j}^{*}$ (which is excluded).

By applying a fixed-effects approach, the model controls for selection into renovation based on unobserved but fixed individual characteristics. To yield causal estimates, this approach requires that no other time-varying unobserved factors exist that are jointly correlated with the selection into renovation and outcome variables. Thus, conditional on the individual fixed effects, that is, tenants' choice of residence, the exact timing of the renovation must be exogenous. We argue this assumption is particularly plausible in our observation period given the massive renovation wave in East Germany as triggered by governmental support in the aftermath of the reunification as described in section 3.2 . The majority of dwellings were in need of renovation at the time of reunification and were renovated during the first 10 years thereafter. Figure 3.2 shows the exceptional increase in the probability of receiving a renovation in East Germany in the 90s compared to receiving one in West Germany. Research has also emphasized that the governmental financial support to renovate was paid to the owner, who actually determined the need and timing of renovation. These settings in the 90s in East Germany increase the likelihood that the exact timing of the renovation was as good as random for tenants. This assertion is supported by the estimation results where we find $\lambda$ equals zero for all health and labor market outcomes, which we interpret as a strong indication that our identifying assumption holds (see the discussion on the falsification test with equation 5.2 above).

However, potential threats to our identification strategy are still a concern, which we discuss in the following. The first point addresses the potential existence of time-variant unobserved individual characteristics. Individuals could self-select into the renovation by moving into dwellings that were planned to be renovated in the near future. Section 3.3.4 indicates a lack of significant changes in moving patterns around the renovation. However, to avoid the possibility that systematic movers bias our results, we only include in our estimation sample the years the individual was living in the exact dwelling that got renovated as part of the renovation wave.

Another concern with respect to time-variant unobserved individual characteristics might be that, for instance, tenants have power to influence the owner's renovation decision, because this power might be correlated with our outcome variables and hence bias the results. However, this 
scenario is unlikely to occur given that $91 \%$ of tenants in East Germany live in buildings with three or more apartments usually operated by larger housing associations or municipal housing companies (German Federal Statistical Office, 2003). The high ratio of tenants to home owners yields some anonymity in the relationship between tenants and owners, reducing the potential influence of tenants on the renovation decision of dwelling owners.

Third, time-varying unobserved regional factors might simultaneously affect the probability of receiving a renovation and the outcome variables. For instance, renovations in a certain region might coincide with an overall regional investment in infrastructure, for example, hospitals, roads, and public transport. We include additional time-varying regional control variables in the empirical model to show the robustness of our results in this regard (see section 5.5).

\subsection{Results}

In this section, we report the estimated effects using the empirical model as defined in equation 5.2 on several outcome variables. In a first step, we provide evidence on the health effects of the renovations as reflected by the subjective health status, days of sick leave, and the demand for health care (doctor visits, hospital overnight stay) of tenants. Second, we aim to investigate whether the health effects also translate into differences in labor market outcomes as suggested by the economic literature (Currie and Madrian, 1999; Stephens and Desmond Toohey, 2018). Third, we consider effect heterogeneity with respect to gender, and explore the role of outside weather conditions as a potential mechanism for the health effects. To test the sensitivity of our results with respect to potential violations of the underlying assumptions (in particular with respect to time-variant unobserved factors), we provide the results of several specification tests and implement an alternative IV strategy in section 35.5

\subsubsection{Effects of Renovation Program}

This section describes the main results of the analysis linking the house renovations to the occupants' health and well-being outcomes. Table 3.5 shows the estimated coefficients describing the change in health, satisfaction, and labor market outcomes before $(\hat{\lambda}$ and after $(\hat{\delta}$ the renovation event in equation 5.2 .

Columns (1) and (2) in Table 3.5 describe changes in life satisfaction and health satisfaction. The results indicate no major changes in the satisfaction of individuals around the renovation event. Column (3) in Table 3.5 describes the changes in self-assessed health status, measured by a 5 -point Likert scale $(1=$ very good, $5=$ poor $)$. The results indicate no major changes in the perceived health status of individuals. Column (4) in Table 3.5 shows the changes in the probability of individuals' reporting bad or poor health before and after the renovation of 
Table 3.5: Effect renovations on health outcomes in years before and after renovation

\begin{tabular}{|c|c|c|c|c|c|c|c|}
\hline & $\begin{array}{c}(1) \\
\text { Sat Living } \\
\text { Today }\end{array}$ & $\begin{array}{c}(2) \\
\text { Satisfaction } \\
\text { Health }\end{array}$ & $\begin{array}{c}\text { (3) } \\
\text { Current } \\
\text { Health }\end{array}$ & $\begin{array}{c}\quad(4) \\
\text { Bad } \\
\text { Health }(1=\text { Yes })\end{array}$ & $\begin{array}{c}(5) \\
\text { GP } \\
\text { Visits }\end{array}$ & $\begin{array}{c}\text { (6) } \\
\text { Hospital } \\
\text { Visits }\end{array}$ & $\begin{array}{c}\text { (7) } \\
\text { Days on } \\
\text { Sick Leave }\end{array}$ \\
\hline Post Renovation ( $1=$ Yes) & $\begin{array}{l}-0.0539 \\
(0.0508)\end{array}$ & $\begin{array}{l}-0.0276 \\
(0.0504)\end{array}$ & $\begin{array}{l}0.00557 \\
(0.0230)\end{array}$ & $\begin{array}{l}-0.00219 \\
(0.0106)\end{array}$ & $\begin{array}{l}-0.0844 \\
(0.120)\end{array}$ & $\begin{array}{l}-0.00739 \\
(0.0539)\end{array}$ & $\begin{array}{c}-1.834^{* *} \\
(0.840)\end{array}$ \\
\hline Pre Renovation ( $1=$ Yes) & $\begin{array}{l}-0.0258 \\
(0.0661)\end{array}$ & $\begin{array}{l}-0.0144 \\
(0.0637)\end{array}$ & $\begin{array}{l}0.00747 \\
(0.0276)\end{array}$ & $\begin{array}{l}-0.0117 \\
(0.0133)\end{array}$ & $\begin{array}{l}-0.177 \\
(0.156)\end{array}$ & $\begin{array}{c}-0.104 \\
(0.0741)\end{array}$ & $\begin{array}{l}-0.340 \\
(0.929)\end{array}$ \\
\hline Observations & 14,858 & 14,860 & 13,165 & 13,165 & 10,891 & 12,456 & 12,608 \\
\hline Individual FE & YES & YES & YES & YES & YES & YES & YES \\
\hline Year FE & YES & YES & YES & YES & YES & YES & YES \\
\hline Controls YES & YES & YES & YES & YES & YES & YES & YES \\
\hline
\end{tabular}

Note: $* / * * / * * *$ indicate statistically significance at the $10 \% / 5 \% / 1 \%$-level. Standard errors are in parentheses and clustered at the household level.

their dwellings. The renovation event was not followed by a significant drop in the probability of reporting bad or poor health in the next three years.

Column (5), (6), and (7) in Table 3.5 show the effect of renovations on doctor visits, hospital visits, and days of sick leave, respectively. The table suggests that whereas the number of hospital visits and hospital visits were not affected, the number of sick-leave days dropped significantly in the years immediately after the renovation event. In particular, individuals in our sample reported a significantly 1.8 fewer sick-leave days in the years after the renovation. Table 3.6 shows the estimated coefficients for $\lambda_{\tau}$ and $\delta_{\tau}$ based on equation 3.6, measuring the changes in health outcomes around the renovation event. The results are similar to those presented in Table 3.5, except that the significant effect on sick-leave days disappears.

Finally, Table 3.7 presents the estimated impact of the house renovation on individuals' labor market outcomes. The results indicate the absence of significant effects on the individuals' probability of being employed, the number of hours worked, and the probability of being unemployed.

In sum, we observe that individuals reported significantly fewer days of sick leave in the years immediately after their houses were renovated. The results indicate the individuals did not experience significant changes in their contract type or their current labor market status. The changes experienced in the house amenities did not affect the probability of being employed, unemployed, or the hours that individuals worked during the week.

\subsubsection{Gender Differences}

In this section, we study whether the house renovations affected women and men differently. The renovations improved the housing insulation and heating systems. Recent studies in the 
Table 3.6: Effect renovations on health outcomes in years before and after renovation

\begin{tabular}{|c|c|c|c|c|c|c|}
\hline & $\begin{array}{c}\text { (1) } \\
\text { Sat Living } \\
\text { Today }\end{array}$ & $\begin{array}{c}(2) \\
\text { Satisfaction } \\
\text { Health }\end{array}$ & $\begin{array}{c}(3) \\
\text { Current } \\
\text { Health }\end{array}$ & $\begin{array}{c}(4) \\
\text { GP } \\
\text { Visits }\end{array}$ & $\begin{array}{c}(5) \\
\text { Hospital } \\
\text { Visits }\end{array}$ & $\begin{array}{c}\text { (6) } \\
\text { Days on } \\
\text { Sick Leave }\end{array}$ \\
\hline Year $t^{*}+1(1=$ Yes $)$ & $\begin{array}{l}-0.0123 \\
(0.0528)\end{array}$ & $\begin{array}{c}0.0232 \\
(0.0544)\end{array}$ & $\begin{array}{l}0.00139 \\
(0.0234)\end{array}$ & $\begin{array}{c}0.127 \\
(0.143)\end{array}$ & $\begin{array}{l}-0.0314 \\
(0.0552)\end{array}$ & $\begin{array}{l}-0.609 \\
(0.909)\end{array}$ \\
\hline Year $t^{*}+2(1=$ Yes $)$ & $\begin{array}{l}-0.0315 \\
(0.0613)\end{array}$ & $\begin{array}{l}-0.0211 \\
(0.0679)\end{array}$ & $\begin{array}{l}0.00578 \\
(0.0280)\end{array}$ & $\begin{array}{c}0.142 \\
(0.187)\end{array}$ & $\begin{array}{l}-0.0747 \\
(0.0722)\end{array}$ & $\begin{array}{l}-0.697 \\
(0.905)\end{array}$ \\
\hline Year $t^{*}+3(1=$ Yes $)$ & $\begin{array}{l}-0.0955 \\
(0.0778)\end{array}$ & $\begin{array}{l}0.00675 \\
(0.0816)\end{array}$ & $\begin{array}{c}0.0546 \\
(0.0332)\end{array}$ & $\begin{array}{r}-0.0407 \\
(0.163)\end{array}$ & $\begin{array}{c}0.0648 \\
(0.0966)\end{array}$ & $\begin{array}{c}0.111 \\
(1.139)\end{array}$ \\
\hline Year $t^{*}-1(1=$ Yes $)$ & $\begin{array}{c}-0.00306 \\
(0.0712)\end{array}$ & $\begin{array}{l}-0.0351 \\
(0.0654)\end{array}$ & $\begin{array}{c}0.0291 \\
(0.0299)\end{array}$ & $\begin{array}{r}-0.0968 \\
(0.171)\end{array}$ & $\begin{array}{l}-0.0889 \\
(0.0739)\end{array}$ & $\begin{array}{c}0.196 \\
(0.905)\end{array}$ \\
\hline Year $t^{*}-2(1=$ Yes $)$ & $\begin{array}{c}-0.00974 \\
(0.0853)\end{array}$ & $\begin{array}{c}0.0325 \\
(0.0895)\end{array}$ & $\begin{array}{l}-0.0326 \\
(0.0371)\end{array}$ & $\begin{array}{r}-0.0263 \\
(0.172)\end{array}$ & $\begin{array}{l}-0.158 \\
(0.121)\end{array}$ & $\begin{array}{c}0.761 \\
(1.200)\end{array}$ \\
\hline Observations & 14,858 & 14,860 & 13,165 & 11,452 & 13,014 & 13,169 \\
\hline Year FE & YES & YES & YES & YES & YES & YES \\
\hline Controls YES & YES & YES & YES & YES & YES & YES \\
\hline Indivudal FE & YES & YES & YES & YES & YES & YES \\
\hline
\end{tabular}

Table 3.7: Labor market outcomes

\begin{tabular}{lccc}
\hline \hline & $\begin{array}{c}(1) \\
\text { Working } \\
(1=\text { Yes })\end{array}$ & $\begin{array}{c}(2) \\
\text { Hours Work } \\
\text { per Week }\end{array}$ & $\begin{array}{c}(3) \\
\text { Unemployed } \\
(1=\text { Yes })\end{array}$ \\
\hline & & & \\
Post Renovation $(1=$ Yes $)$ & 0.0140 & 0.484 & -0.00710 \\
& $(0.0118)$ & $(0.495)$ & $(0.0129)$ \\
Pre Renovation $(1=$ Yes $)$ & 0.000771 & 0.491 & -0.00919 \\
& $(0.0143)$ & $(0.625)$ & $(0.0156)$ \\
Observations & & & \\
Controls & 12,889 & 12,605 & 8,874 \\
Year FE & YES & YES & YES \\
Controls YES & YES & YES & YES \\
Indivudal FE & YES & YES & YES \\
\hline \hline \multicolumn{2}{l}{ Note: * $/ * * / * * *$ indicate statistically significance at the $10 \% / 5 \% / 1 \%-$} \\
level. Standard errors are in parentheses and clustered at the household \\
level.
\end{tabular}

science literature indicate the presence of significant differences in thermal comfort between men and women (e.g., Kingma and Van Marken Lichtenbelt, 2015). Many field studies show that women tend to express higher levels of discomfort in low temperatures than men (for a review of the literature, see Karjalainen, 2012). Deschenes and Moretti (2009) find striking differences in extreme-weather mortality across genders. The authors find the impact of cold weather on 
mortality is significantly larger for females than for males. Recent lab experimental evidence indicates these differences might have implications for workers through impairments in cognitive performance. Chang and Id (2019) find women perform better in verbal and numeric tasks at experimentally manipulated higher temperatures, whereas the reverse pattern is observed for men.

Table 3.8 shows the differences in the estimated parameters from equation 3.6 for the subsample of women and men separately. Columns (1) and (2) in Table 3.8 present the differences in living conditions around the renovation event for men and women separately. The estimated coefficients of the changes in living conditions in the years before and after the renovation (i.e., $\left.\lambda_{\tau}\right)$ are not significantly different for men and women. However, the differences between men and women become salient when focusing on the health outcomes. Columns (5) and (7) show coefficients describing changes in visits to the hospital and the reported days on sick leave in the years before and after the renovation event in the men subsample. The results indicate no significant changes for men in their annual number of visits to the hospital or days on sick leave are associated with the renovation event. On the other hand, column (6) in Table 3.8 shows a significant drop for women in visits to the hospital in the years following the housing renovation. In particular, we observe a drop of 0.175 visits in the first year and 0.191 in the second year after the renovation, relative to the year before the renovation took place. Similarly, column (8) in Table 3.8 shows the number of days on sick leave the first year after the renovation drops by 1.6, relative to the year before the renovation took place.

In sum, the results presented in this section indicate the health improvements are only present in the female subsample and not in the male subsample. The results also indicate a decrease in the magnitude and significance of the coefficients after year 2 .

\subsubsection{Robustness Analysis}

Using an individual fixed-effects strategy to estimate causal treatment effects requires the assumption that the endogenous selection into treatment (renovation) is based on unobserved but fixed individual characteristics. In section 3.4 , we argue this assumption is valid in our case due to the large-scale renovation wave in East Germany after reunification (see section 3.2). Although the baseline empirical model controls for time-varying individual characteristics such as income, age, education, ratio of household members per room, and working status, other time-varying but unobserved factors may exist that are jointly correlated with the treatment and outcome variables, resulting in biased fixed-effects results. For instance, (although unlikely) tenants' power to influence owners' decision to renovate might alter over time, or regional confounding factors such as parallel investments in health infrastructure may coincide with treatment probabilities. The existence of such factors would violate the identifying assumption. To test the sensitivity of 
Table 3.8: Effect renovation wave on objective health measures by gender

\begin{tabular}{lcccccccc}
\hline \hline & $(1)$ & $(2)$ & $(3)$ & $(4)$ & $(5)$ & $(6)$ & $(7)$ & $(8)$ \\
& Needs & Needs & Doctor & Doctor & Hospital & Hospital & Days on & Days on \\
& Renov. $(1=$ Yes $)$ & Renov. $(1=$ Yes $)$ & Visits & Visits & Visits & Visits & Sick Leave & Sick Leave \\
& Male & Female & male & Female & Male & Female & Male & Female \\
\hline & & & & & & & & \\
Year t $(1=$ Yes $)$ & $-0.054^{* *}$ & $-0.065^{* * *}$ & 0.152 & 0.075 & 0.115 & $-0.175^{* *}$ & 0.623 & $-1.608^{*}$ \\
& $(0.0229)$ & $(0.021)$ & $(0.203)$ & $(0.191)$ & $(0.075)$ & $(0.078)$ & $(1.625)$ & $(0.920)$ \\
Year t+1 (1=Yes) & $-0.071^{* * *}$ & $-0.068^{* * *}$ & 0.179 & 0.067 & 0.046 & $-0.191^{*}$ & -0.734 & -0.558 \\
& $(0.0273)$ & $(0.023)$ & $(0.189)$ & $(0.296)$ & $(0.0807)$ & $(0.102)$ & $(1.385)$ & $(1.193)$ \\
Year t+2 (1=Yes) & -0.043 & -0.040 & 0.162 & -0.239 & 0.120 & -0.003 & 0.438 & -0.123 \\
& $(0.0332)$ & $(0.027)$ & $(0.201)$ & $(0.233)$ & $(0.101)$ & $(0.150)$ & $-1,772$ & $(1.664)$ \\
Year t-2 (1=Yes) & $0.161^{* * *}$ & $0.182^{* * *}$ & 0.109 & -0.264 & -0.135 & -0.027 & -1.395 & 1.673 \\
Year t-3 (1=Yes) & $(0.0263)$ & $(0.022)$ & $(0.261)$ & $(0.223)$ & $(0.0882)$ & $(0.112)$ & $(0.992)$ & $(1.446)$ \\
& $0.106^{* * *}$ & $0.115^{* * *}$ & $0.371^{*}$ & -0.338 & -0.139 & -0.146 & -0.363 & 1.752 \\
Observations & $(0.0327)$ & $(0.029)$ & $(0.210)$ & $(0.293)$ & $(0.151)$ & $(0.179)$ & $(1.429)$ & $(1.789)$ \\
Controls & 6,913 & 7,865 & 5,348 & 6,104 & 6,096 & 6,918 & 6,159 & 7,010 \\
Year FE & YES & YES & YES & YES & YES & YES & YES & YES \\
Controls YES & YES & YES & YES & YES & YES & YES & YES & YES \\
\hline \hline
\end{tabular}

Note: $* / * * / * * *$ indicate statistically significance at the $10 \% / 5 \% / 1 \%$-level. Standard errors are in parentheses and clustered at the household level.

our results with respect to time-varying but unobserved confounding factors, we (i) additionally include time-varying regional control variables in our empirical model, and (ii) re-estimate our results using an alternative IV approach. In addition to overcoming the issue of time-varying unobserved factors, the IV strategy addresses another typical concern with fixed-effects analysis, which is the sensitivity with respect to measurement error due to self-reporting of the treatment variable (see Appendix 3.6 for the full specification of the IV). Although, we already provide evidence suggesting consistency and reliability of the data in section 3.3 .4 , the IV strategy provides additional proof of whether measurement error significantly affects the results. Both strategies suggest our findings are robust.

\section{Time-Varying Regional Characteristics}

In a first step, we test the sensitivity of our results with respect to the existence of regional time-varying unobserved factors jointly correlated with the treatment and the outcome variables. Therefore, we include additional regional control variables $W_{c t}$ in our main regression model (see equation 5.2. The regional indicators are measured on a yearly basis for each county $c 9^{9}$ Given that we are concerned about parallel regional developments that might be jointly correlated with the treatment indicator and the outcome variables, such as investment programs in health infrastructure and environmental or economic regional development, we include the following

\footnotetext{
${ }^{9}$ East Germany consists of 77 counties based on the regional classification in 2012 (which we apply in our empirical analysis).
} 
control variables: population density, immigration and emigration rates, access to health facilities (regional density of general practitioners and hospitals), tax revenues, unemployment rate and labour market participation, and sales in the construction sector. Unfortunately, the regional indicators are only available from 1995 onwards, restricting the observation window from 1995 to 2002 (which is the main reason we do not include $W_{c t}$ in the main regression analysis).

Table 3.9: Sensitivity analysis

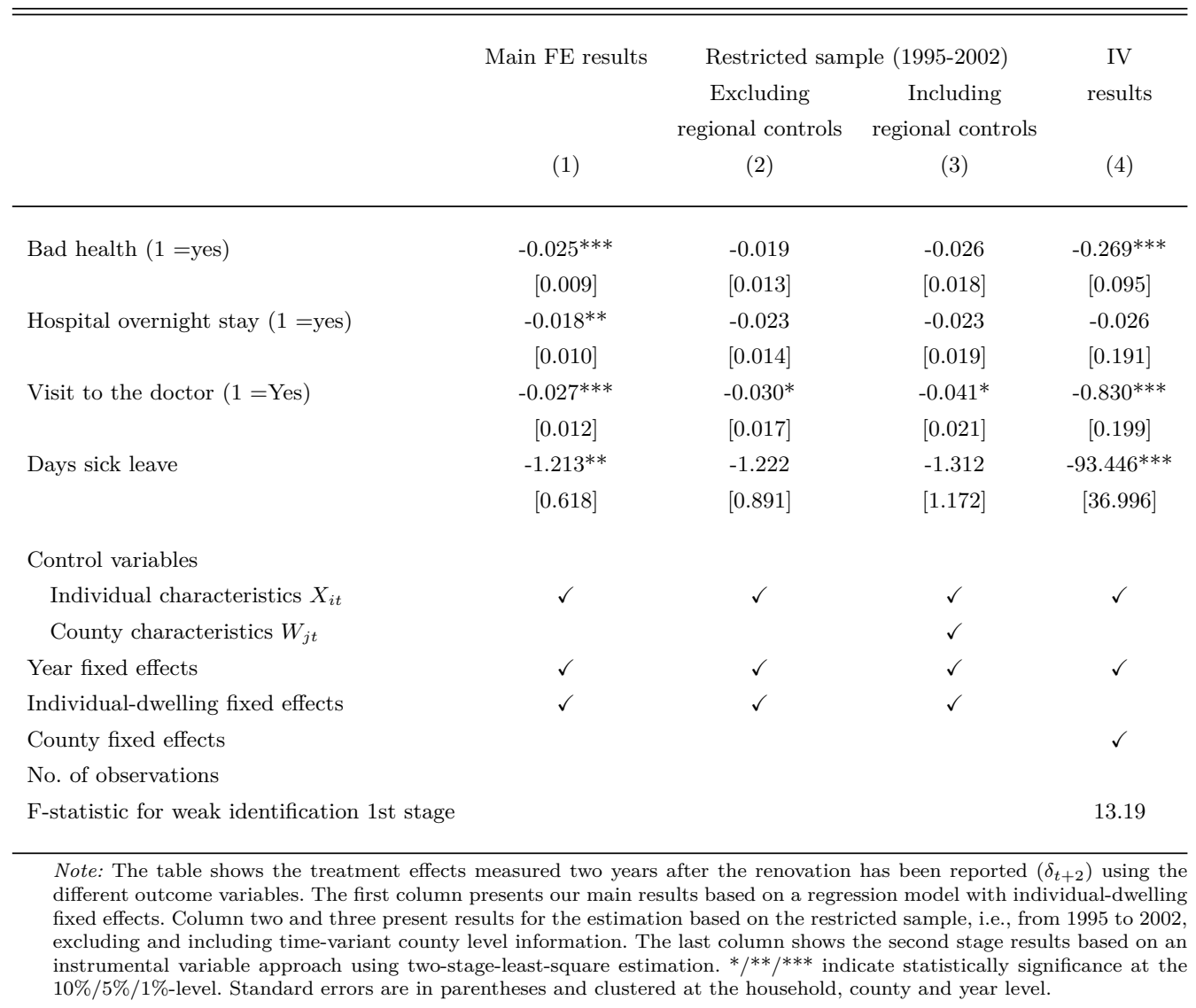

First results indicate the robustness of our main results, which makes us confident that timevariant regional unobserved confounding factors do not play a major role and, more importantly, are not inducing a bias in our main results.

Table 3.9 summarizes the results of the sensitivity analysis by showing the treatment effects measured two years after the renovation $\left(\delta_{t+2}\right)$ for different outcome variables. In the first column, we show our main results as already reported in the previous section. The second and third columns contain the estimation results using the restricted sample, namely, 1995 - 2002, due to the limited availability of the regional information. Because doing so results in a decreasing number of observations, we re-estimate our main results using the restricted sample including 
only the years for which we have information of regional controls (column (2)) and including regional information (column (3)) in order to judge whether differences are due to statistical power or bias.

When comparing results in columns (1) and (2) in Table 3.9, we can see the coefficients change little once the sample is restricted. However, statistical significance disappears for most of the coefficients, which is attributable to the loss of observations. If we now compare the results in column (2) (excluding regional information) to column (3) (including regional information), results hardly change. This finding makes us confident that time-variant regional unobserved confounding factors do not play a major role and, more importantly, are not inducing a bias in our main results.

\subsection{Conclusion}

We study the massive renovation wave in East Germany in the aftermath of the German reunification to contribute population-representative evidence on the impact of improved housing conditions on occupants' health and labor market outcomes in industrialized countries.

We use individual household panel data (SOEP) to explore the effect of the program on individual living conditions and health outcomes of Eastern Germans. Applying an event-study approach including individual and year fixed effects, we observe a significant improvement in housing conditions and objective health status of the tenants as reflected by a reduction in days of sick leave.

In addition, we show the positive health effects associated with a renovation are driven by women. Female tenants receiving a renovation report higher subjective health as well as a reduction in hospital visits and days of. sick leave, whereas we find no significant effects for men. We further show for women that the reduction in days of sick leave associated with the renovation is larger in cold years. Therefore, women seem to be more vulnerable with respect to housing conditions, and a major renovation apparently improves their health significantly. Finally, we find no indication that the positive health effects translate into improved labor market outcomes. Sensitivity tests confirm the robustness of our results with respect to the underlying assumptions. 


\section{Appendix 3A. Instrumental Variable Specification}

The instrumental variable approach exploits regional variation in the roll-out of the largest governmental loan program ( $K f W$-Wohnraum-Modernisierungsprogramm, KfW program hereafter) in East Germany in the aftermath of the German reunification (see Section 3.2 for details). This variation is used as an instrumental variable for the individual probability to experience a major renovation (treatment). In order to identify the effects of this intervention, we take advantage of the regional variability in the implementation of the program. We have access to yearly loan take-up within the KfW program for counties in East Germany in the period 1992-2000 (Source: KfW). Based on this information, we construct the instrument $Z_{c t}$ as the yearly amount of the subsidy per inhabitant in county $c$ :

$$
Z_{c t}=\text { Subsidyct }_{\text {population }} \text { t }
$$

Given the scope and impact of the program, we argue that the instrument affects the individual probability to report a major renovation of their own dwelling. Tenants who live in a county with a relatively high loan intensity in a certain year are more likely to experience a renovation compared to tenants living in a county with a low intensity. The first stage results strongly support the relevance of the instrument. Furthermore, we do include county fixed effects in order to take potential endogenous selection of counties into account. Therefore, we use within county variation over time to identify the causal parameters. In such a setting, we argue that the exact timing of the renovation can be assumed to be exogenous to the tenant. Assuming validity of the instrument, we estimate the causal local average treatment effect $\delta$ using the two-stage least squares estimator (2-SLS, e.g. Angrist and Krueger, 1991):

$$
\begin{aligned}
\text { Renov }_{i j t} & =\alpha_{1}+\gamma_{1} Z_{c t-2}+\gamma_{2} Z_{c t-2}^{2}+\beta_{1} X_{i j t}+\eta_{j}+U_{i j t} \\
Y_{i j t} & =\alpha_{2}+\text { Renov }_{i j t}+\beta_{2} X_{i j t}+\eta_{j}+V_{i j t}
\end{aligned}
$$

where Renovijt indicates whether individual $i$ living in dwelling $j$ at year $t$ reports a major renovation or not. $X_{i j t}$ denotes individual characteristics, $\eta_{j}$ county fixed effects and $Y_{i j t}$ the outcome variables. The instrument $Z_{c t-2}$ is used with two lags because of the time gap between loan approval and actual implementation of the renovation. In addition to the level of the instrument, we include a squared term $Z_{c t-2}^{2}$ to allow for a non-linear relationship between the instrument and the treatment indicator. 



\section{Chapter 4}

\section{Worker Health And Environmental Conditions at The Workplace}

Workers represent a critical input factor for the modern firm. To improve our understanding of the effects of workplace environmental conditions on human performance, we estimate the impact of a major upgrade in office-building infrastructure on employees' health and job satisfaction. Economists have devoted significant effort exploring the relationship between health and labor market performance of individuals. Early work by Grossman (1972) provided the theoretical foundation for the role of health in labor markets. For workers, health is a key factor of individuals' supply of labor, determining the total amount of time they are able to spend producing. On the firm side, companies bear substantial costs in the form of both absenteeism and presenteeism, that is, productivity losses due to workers not being able to work at full capacity (Hemp, 2004). Stewart et al. (2003) estimate in a sample of 28,902 working adults in the US that $13 \%$ of the total workforce experienced a loss in productive time due to common pain conditions such as headaches or back problems. The authors estimate a loss of $\$ 61.2$ billion per year in pain-related productive time.

The link between employee well-being and firm performance has also been the subject of numerous studies. The recruitment and retention of skilled employees is critical for the competitive advantage and value of firms, especially in knowledge-based industries such as technology (Edmans, 2012). Employee satisfaction is essential for the retention of key workers (Mitchell et al. 2001), whose transfer to another company would bring their knowledge and skills to a competitor, weakening the position of the current company. In addition, employee well-being and satisfaction have recently been related to direct productivity benefits. In the manufacturing industry, Böckerman and Ilmakunnas (2012) provide plant-level evidence on the effect of job satisfaction on productivity, showing a one-standard-deviation increase in job satisfaction leads to an increase in value-added per hour worked of $6.6 \%$. Recent evidence from the lab shows a direct

\footnotetext{
${ }^{*}$ This chapter is co-authored with Piet Eichholtz (Maastricht University) and Nils Kok (Maastricht University).
} 
link between satisfaction and productivity. Oswald et al. (2015), by experimentally manipulating the levels of short-term happiness with a comedy clip or memories of recent life events, saw a $12 \%$ increase in individual productivity, measured by the amount of arithmetic tasks executed by the participants.

Much attention has been devoted to understanding the role of material conditions on people's happiness and well-being. Cattaneo et al. (2009) find that upgrading dirt floors to cement floors increased happiness and reduced symptoms of depression among poor individuals in Mexico. Devoto et al. (2012) show that connecting households to piped water improved households' wellbeing in Morocco. Evidence from the Moving To Opportunity (MTO) experiment in the US shows significant improvements in subjective well-being 15 years after being relocated to a less distressed neighborhood environment (Ludwig et al., 2012).

Moreover, the economics literature has given much attention to the effect of (material) workplace conditions on employee health and well-being, as critical factors in human performance. Our study is based on the quasi-experimental variation created by the relocation of $70 \%$ of the workforce of a large municipality in the Netherlands $(\mathrm{N}=1,200)$. Using survey data, we show significant long-term benefits in the working conditions and health of employees, but not in employee satisfaction. We evaluate changes in (1) employee-perceived environmental conditions in their workplace, (2) health outcomes, and (3) job satisfaction following their relocation to a new office building designed to enhance indoor environmental quality. 2 We develop a unique dataset monitoring the perceived working conditions, health, and job satisfaction of more than 600 municipality workers up to two years after the relocation. In total, we surveyed the employees four times, once before the move and three times after the move. We employ a traditional difference-in-differences (DiD) approach to estimate the impact of the move on perceived working conditions and employee health. The results indicate the relocation led to significant improvements in perceive working conditions and health. However, these improvements did not translate into better general job satisfaction.

The literature documents significant discrepancies between the short- and long-term reported impacts of individuals associated with material upgrades in their lives due to hedonic adaptation, a psychological process that attenuates the long-term impact in conditions. For instance, individuals even adapt to serious chronic health conditions (i.e., disabilities), exhibiting high levels of happiness or life satisfaction close to the baseline level again in the long term (Loewenstein and Ubel, 2008). A recent study by Galiani et al. (2018) shows this adaptation also appears to exist when evaluating the impact of major building infrastructure improvements. Two years after the intervention, Galiani et al. found the beneficiaries of the program reported well-being

\footnotetext{
${ }^{2}$ Around $70 \%$ of the subjects were relocated; the remaining $30 \%$ stayed in their original workplaces over the entire study period.
} 
levels identical to the baseline levels before the intervention.

In a second step of the study, we decompose the estimates of the three surveys administered in the two years after the moving date, to investigate the discrepancy between short- and longterm effects. The estimates of health and perceived environmental quality show a persistence over time. On the other hand, none of the job-satisfaction measures deviate significantly from the baseline in the long term.

The remainder of our paper is organized as follows. In the next section, we discuss the literature investigating the link between environmental conditions in offices and employee health. In section 4.2, we provide a description of the relocation event and the study design used in the study, and we also explain the construction of our health and environmental-quality surveybased indicators. In section 4.3 , we present our empirical strategy. The results are presented in section 4.4, and section 4.5 concludes.

\subsection{Literature}

The effect of indoor environmental quality (IEQ) on measures of employee health, well-being, and productivity has been the focus of a large number of studies in the public health, architecture, and engineering literature (for a recent review of the literature, see Ghaffarianhoseini et al., 2018). The exposure to deficient indoor environmental conditions at work has been associated with health problems, causing nuisance among employees. Usually known as the sick-building syndrome, health problems include eye, nose, or throat irritation, headache, or fatigue associated with the regular occupation of a building with detrimental environmental conditions (Fisk et al. 2009 ).

The literature provides evidence on the harmful effects of multiple environmental factors in the workplace. Poor indoor air quality in the form of high levels of $\mathrm{CO}_{2}$ or pollutants has been linked to the prevalence of absenteeism, sick-building symptoms (Fisk et al., 2009), and cognitive performance of workers (Allen et al., 2016, MacNaughton et al., 2016). Inadequate thermal conditions in the form of suboptimal temperatures or relative humidity have been linked to the prevalence of increased heart rate, respiratory problems, sick-building syndrome, and reduced cognitive performance (Lan et al., 2011, Seppänen et al., 2006). Noise is also a risk factor commonly found in workplaces. The exposure to unhealthy decibel levels leads to cardiovascular disease, stress, and sleep disruption, ultimately harming employees' cognitive performance and labor productivity (Dean, 2017). Finally, light quality has been linked to eye-irritation problems and changes in the circadian rhythm of adults (Cedeño-Laurent et al. 2018).

Most of our understanding about the impact of indoor environmental factors on employees is based on occupant surveys. Recent reviews of the literature from MacNaughton et al. (2015) and 
Altomonte and Schiavon (2013) provide a comprehensive overview of the literature investigating the benefits for occupants located in so-called "green" environmentally certified buildings. In both reviews, the results from the majority of the surveyed studies indicate that individuals in "green" buildings evaluate better their perceived health and the environmental conditions at their workplace. These studies are based on cross-sectional comparisons of the reported values of participants working in "green" buildings against the answers from those working in conventional buildings. The validity of the results therefore relies on strong assumptions about the differences between employers and employees in "green" and non-"green" buildings. These studies rely on assuming an absence of selection bias, which would arise when the health and working conditions of occupants in sustainable buildings might differ from the health and working conditions of those working in conventional buildings, beyond the building infrastructure.

Singh et al. (2010) is the only study in the field that is based on a longitudinal design. The authors followed a group of 262 individuals who moved from a conventional to a sustainable building in Michigan. The authors found the study participants reported a significant improvement in the perceived environmental conditions at their workplace after the move, a reduction in the number of hours absent from work due to health reasons, and a higher perception of individual productivity. However, the study has some limitations. First, the post- and pre-surveys were implemented in different seasons, where the presence of allergies and other diseases might differ, as well as the impact of outdoor climate conditions on the indoor environment. In addition, the study lacked a control group, serving as a benchmark for changes in the general health status in the organization over time. Finally, some of the participants in the study were asked to fill in the questionnaire retrospectively, after the move took place.

\subsection{Study Set-Up}

\subsubsection{Background}

In 2016, Venlo, a municipality in the southeast of the Netherlands, inaugurated a second, newly constructed office building. The construction costs of the building were $€ 34.5$ million. The new municipality building was built following green and sustainable principles: In addition to glass and concrete, the north wall of the building is covered with vegetation, and includes a green wall of 2,000 $\mathrm{m}^{2}$. Green or living walls allow plants to grow from the vertical structure. The installation of green walls has been associated with an improvement in outdoor and indoor air quality, transforming carbon dioxide (CO2) into oxygen, and filtering fine particles from outdoor sources of pollution (Perini and Rosasco, 2013). In addition, the plants serve as natural insulation against heat, cold, and sound (Cuce, 2016). The building is also equipped with state-of-the-art natural ventilation technology. The air enters the building at the top, where it is oxygenated by 
plants and brought to the bottom of the building, from where the purified air then circulates naturally throughout the building using physical principles rather than mechanical ventilation systems (see Figure 4.1 for a description of the ventilation system).

Figure 4.1: Ventilation system in newly constructed building

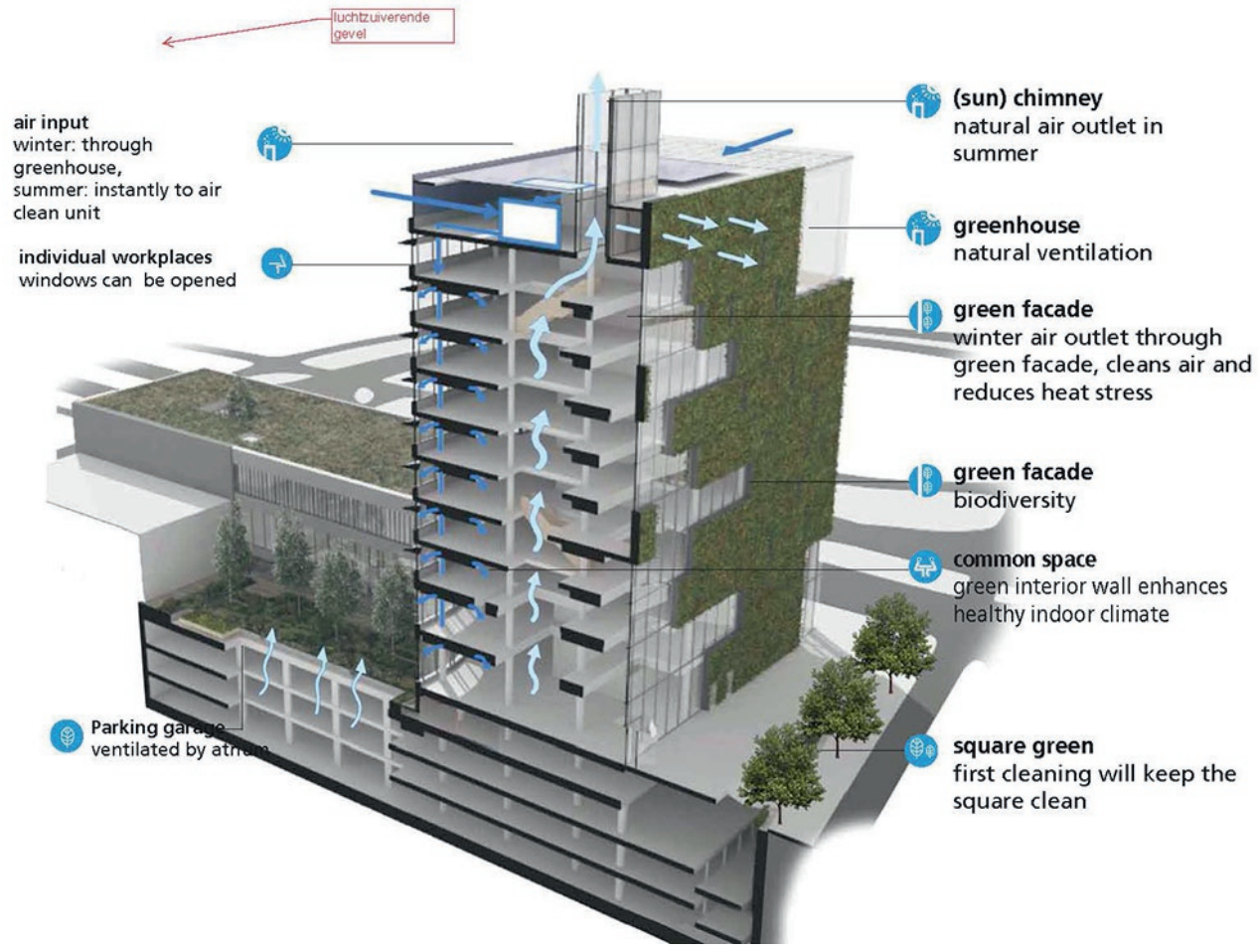

Source: https://www.royalhaskoningdhv.com/en-gb/projects/new-municipal-office-venlo-nl/5931

In the summer of $2016,70 \%$ of the 1,461 workers of the municipality were moved to a newly constructed office building within the same city ${ }^{3}$ Office space in the previous workplaces was organized in enclosed private offices that several people shared. In the new building, the office space follows an open office layout. Open offices tend to generate noise complaints among occupants, who can be distracted by high levels of noise and loss of privacy (Kim and de Dear, 2013). The selection of movers was quasi-random, through selection of teams rather than individuals. In addition to significant changes in indoor conditions, the organizational office layout also changed.

\subsubsection{Survey Design}

We received permission from the municipality to a send survey to all of its employees, asking them to complete it via email. 4 The survey included anonymized individual identifiers, allowing us

\footnotetext{
${ }^{3}$ Estimates are based on the number of individuals with an active corporate email list in the summer 2016 .

${ }^{4}$ See Appendix 4.5 for the text of the invitation sent to the employees.
} 
to build a longitudinal dataset that tracks the responses from the same employee over multiple survey waves. Our sample includes the survey responses of the treatment group, individuals relocated to the new "green" building, and those of the control group, comprising those employees who were not relocated to the new building.

The surveys span both the period before and after the relocation. Figure 4.2 describes the timeline of the four surveys contained in our data. We first sent a questionnaire to all employees one month before the relocation took place, serving as the baseline survey in the analysis. After the relocation, we surveyed all employees three times-those individuals that were relocated as well as those who remained in their original workplace during the entire sample period.

Figure 4.2: Timing of survey waves

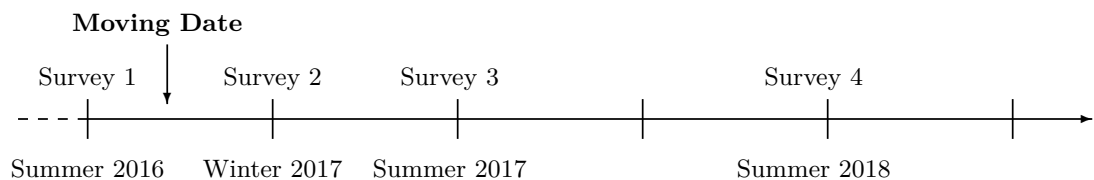

Note: The figure illustrates the exact timing of each survey wave. The first survey $(\mathrm{k}=0)$ took place before
the moving date (August 2016). The second $(\mathrm{k}=1)$, third $(\mathrm{k}=2)$ and fourth $(\mathrm{k}=3)$ took place after the
relocated group moved to the new building, in respectively January 2017, July 2017 and October 2018 .

The survey includes the module developed by the Center for the Built Environment (CBE) at the University of California, Berkeley, to monitor the perceived environmental conditions of occupants in their workplaces (Zagreus et al., 2004). Since the early 2000s, the CBE survey has been extensively used to evaluate the performance of buildings globally. The core questions in the survey assess occupant (dis)satisfaction and comfort with indoor environmental quality (IEQ) issues including indoor air quality, thermal comfort, lighting, and acoustics.

Figure 4.3 shows an example of the two types of questions used in the main analysis to assess changes in perceived environmental conditions. First, we asked participants to rate their satisfaction with different aspects of the environment on a 7-point scale ranging from "very satisfied" to "very dissatisfied," with a neutral midpoint. In a second set of questions, we asked participants to rate each IEQ dimension on 7-point scales ranging from "support" to "interferes in" their ability to get their work done.

The survey includes two questions about the health status of individuals. First, we examine changes in the health status of workers based on the prevalence of sick-building-syndrome symptoms. This concept is widely examined in the building science and public health literature and refers to "a collection of non-specific symptoms including eye, nose and throat irritation, mental fatigue, headaches, nausea, dizziness and skin irritations, which seem to be linked with 
Figure 4.3: Example question about evaluating indoor air quality (translated to English)

\section{Maastricht University}

\section{How satisfied are you with the air quality at your workplace?}

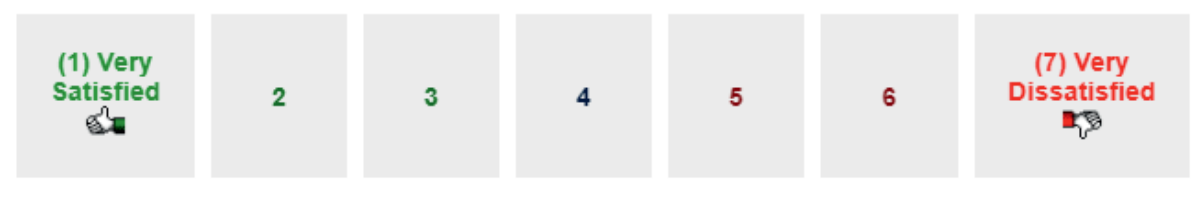

In general: does the air quality at your workplace support or hinder your work?

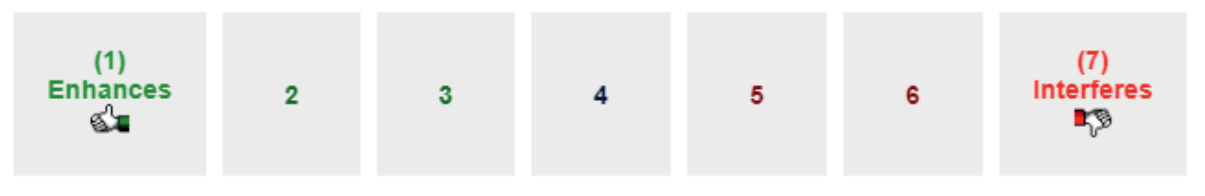

Full survey (in Dutch) available here: https://maastrichtuniversity.eu.qualtrics.com/jfe/form/SV_0e4EEdnROnzIyGh

occupancy of certain workplaces" (WHO, 1983). The survey includes a question asking whether the subject suffers from syndrome symptoms ("Do you regularly have symptoms (e.g. tiredness, headache, eye irritation, nasal congestion, dry throat, dry skin) that disappear when you leave the building - when you are at work?"). In addition, we collected self-stated sick-leave data based on the number of days missed due to health reasons in the year before the survey ("How many days were you unable to work this year due to illness?")!5

We measure the job satisfaction of employees based on a series of Likert scales, where respondents rated the frequency with which they experienced job-related emotions (see Panel B Table 4.2 for the complete list of questions). The frequency of the scales ranges from "Daily" to "Never," and includes the options "A few times a week," "Once a week," "Few times a month," "Once a month," and "Few times a year or less."

Finally, the survey includes questions about basic demographic characteristics of respondents (i.e., age and gender) and some details of the employee's employment contract (i.e., working hours, and years in the current organization). In addition, the survey includes a series of questions that ask participants to grade their (dis)satisfaction with the layout, and furniture and equipment

\footnotetext{
${ }^{5}$ Respondents were asked to choose between the following options to report the number of sick days: I did not report sick this year, (2) 1 day, (2) 2-5 days, (3) 5-10 days, and (4) more than 10 days.
} 
in their workplace, based on the same scales that are used to grade the perceived environmental conditions in the workplace. We created dummies from the original scales that take the value of 1 if the original scale is "Daily," "A few times a week," or "Once a week," and zero otherwise.

\subsubsection{Descriptive Statistics}

The response rate of the surveys ranged between $35 \%$ and $40 \%$ (see Appendix Table 4.5). In the first wave, we gathered 573 valid answers, 585 in the second wave, 569 in the third, and 530 in the fourth. The median completion time of the survey was 11 minutes. We observe no differences in response time between relocated (treated) and non-relocated (control) employees, suggesting no differences in attention or effort between the two groups (but, of course, our goal is not to empirically assess such differences).

Table 4.1 shows the demographic characteristics of the relocated and non-relocated workers in wave 1 . The non-relocated employees were younger, on average, than those in the relocated group, as reflected by the higher percentage of individuals below 31 years old (19\% vs. 10\%). The gender ratio does not differ between two employee groups.

Table 4.1: Descriptive statistics sample in first survey wave (Before the move, July 2016)

\begin{tabular}{|c|c|c|c|}
\hline & Non-Relocated $(\mathrm{N}=247)$ & Relocated $(\mathrm{N}=326)$ & Diff. \\
\hline \multicolumn{4}{|l|}{ Age } \\
\hline Below 31 Years Old (1=Yes) & 0.19 & 0.10 & $0.09^{* *}$ \\
\hline 31-50 Year Old $(1=$ Yes $)$ & 0.34 & 0.45 & $-0.11^{* *}$ \\
\hline 50 Years Old or Older ( $1=$ Yes $)$ & 0.47 & 0.45 & 0.02 \\
\hline \multicolumn{4}{|l|}{ Gender } \\
\hline Female $(1=$ Yes $)$ & 0.46 & 0.50 & -0.04 \\
\hline \multicolumn{4}{|l|}{ Health } \\
\hline Sick Building Syndrome (1=Yes) & 0.44 & 0.42 & 0.03 \\
\hline No Days on Sick Leave (1=yes) & 0.53 & 0.53 & -0.01 \\
\hline \multicolumn{4}{|l|}{ Time Working for The Company } \\
\hline Less than 1 Year & 0.23 & 0.12 & $0.11^{* * *}$ \\
\hline 1-2 Years & 0.38 & 0.24 & $0.14^{* * *}$ \\
\hline 3-5 Years & 0.16 & 0.27 & $-0.11^{* *}$ \\
\hline More than 5 Years & 0.23 & 0.37 & $-0.14^{* * *}$ \\
\hline \multicolumn{4}{|l|}{ Working Hours per Week } \\
\hline Less than 10 Hours & 0.06 & 0.03 & 0.03 \\
\hline 11-30 Hours & 0.41 & 0.49 & -0.08 \\
\hline More than 30 Hours & 0.53 & 0.48 & 0.05 \\
\hline
\end{tabular}

${ }^{*} \mathrm{p}<0.05,{ }^{* *} \mathrm{p}<0.01, * * * \mathrm{p}<0.001$

Looking at the current contract characteristics of the two groups of employees, we find the 
non-relocated individuals were less experienced than those in the relocated group (as reflected in the age difference between the groups). The total working hours does not differ significantly between the treatment and control group.

\subsubsection{Descriptive Results: Difference-in-Difference}

Table 4.2 presents the results of basic DiD comparisons tests. The numbers in column (1) describe the average dissatisfaction scales and health outcomes reported by subjects who were relocated to the sustainable building in the first survey $(k=0)$, the baseline survey. The second column displays the scales reported by the group of employees who were not relocated to the sustainable building, before the relocation $(k=0)$. The scales displayed in columns $(1)$ and $(2)$ indicate employees were the most dissatisfied with air quality and noise levels in the workplace. Column (3) displays the difference between the average scales between those relocated and those not relocated, together with the significance level for the t-test of the difference in means. The results indicate that in the initial baseline survey, before the move took place, the group of individuals who were going to be relocated were less satisfied with the air quality and light quality, on average, than were those employees who were not going to be relocated-as represented by the higher values reported in the corresponding scales. In addition, the relocated individuals had a baseline satisfaction higher for the space available and visual privacy in the workplace, but were less satisfied with the furniture. Finally, we observe no significant differences between the two groups of employees in health outcomes in the baseline survey.

Columns (4) to (6) in Table 4.2 show the average responses of the relocated and non-relocated samples after the moving date. Column (4) shows a substantial drop in air-quality, temperature, and light-quality dissatisfaction for the relocated employees, compared to those in the baseline (column (1)). In the group whose workplace remained unchanged, the answers after the move (column (5)) are comparable in magnitude to those before the move (column (2)). When comparing the answers between the treated and the control sample, we observe a reversion from the situation before the move. The relocated group shows significantly lower dissatisfaction in air quality, temperature, and light quality than the non-relocated group. The relocated individuals also show an average improvement in the health status, as reflected in the drop of the proportion of people reporting sick-building-syndrome symptoms. We do not observe any differences in the probability of missing work days due to illness.

Table 4.2 Panel B shows the descriptive statistics for the job-satisfaction questions. We observe no significant differences in job satisfaction between relocated and non-relocated employees either before or after the move to the new building. We also do not observe a significant change in job satisfaction in any specification considered in this study 6

\footnotetext{
${ }^{6}$ We include the remaining results of the analysis of the impacts on job satisfaction in Appendix 4.5
} 


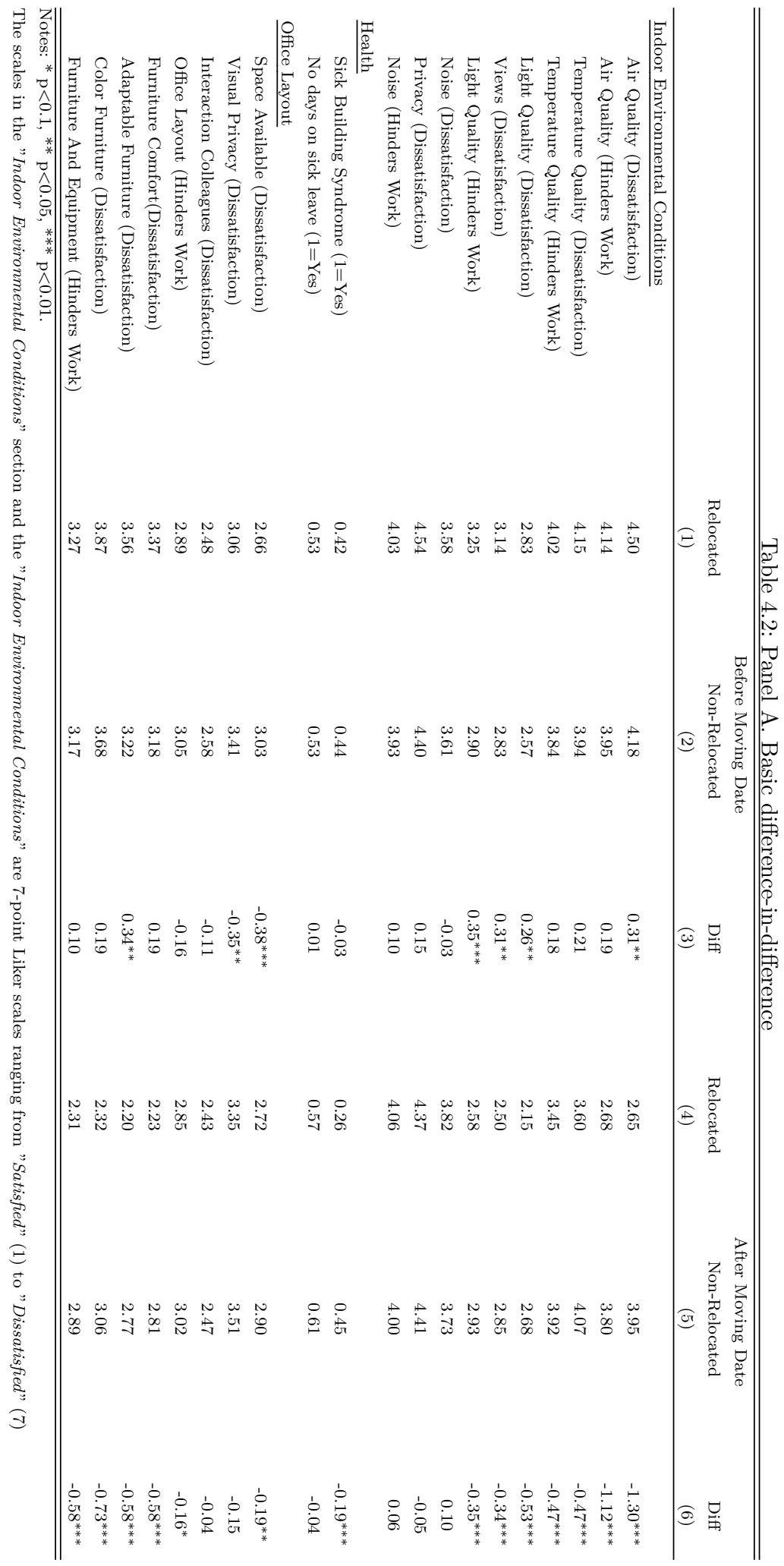




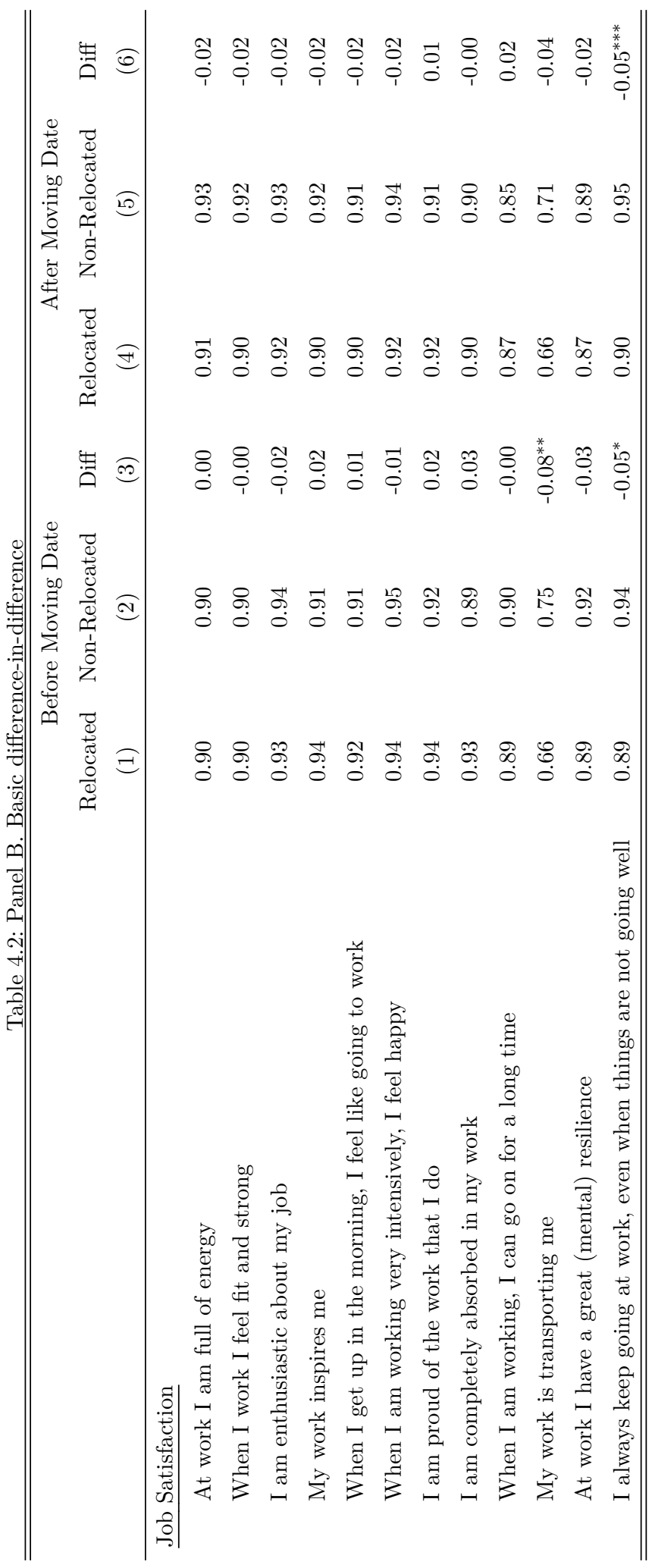




\subsection{Empirical Strategy}

We use DiD models to estimate the impact of the improvement in building conditions on workers' perceived working conditions and health status. The basic DiD model takes the following form:

$$
Y_{i t}=\alpha+\beta \text { Relocated }_{i}+\lambda \text { AfterMove }_{t}+\delta \text { Relocated }^{*} \text { AfterMove }_{i t}+\epsilon_{i t}
$$

where $Y_{i t}$ includes the set of outcome variables describing the perceived working conditions, health status, and job satisfaction of individual $i$ at time $t$. We include the scales describing the perceived noise, temperature, light, and air quality in the workplace. We consider two health outcomes in the analysis: a dummy variable indicating the individual suffers from sic- building syndrome and a dummy variable indicating the individual missed work in the previous year due to illness. In addition, we include the set of job-satisfaction questions described in the previous

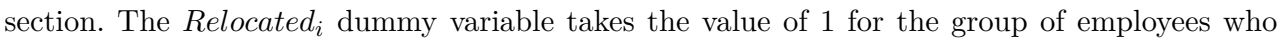
were relocated to the new building. The AfterMove $t$ takes the value of 1 for the survey waves after the moving date, and zero otherwise. Our prime parameter of interest is $\delta$, describing the average change in the outcomes $\left(Y_{i t}\right)$ after the move for the employees who relocated to the new building. $\epsilon_{i t}$ is the error term, which might be correlated within individuals. Therefore, we cluster standard errors at the individual level.

$$
Y_{i t}=\mu_{i}+\tau_{t}+\delta \text { Relocated } * \text { AfterMove } i t+\beta X_{i t}+\epsilon_{i t}
$$

Our DiD research design relies on the assumption that the characteristics of workers who were relocated to the new building changed over time in a way that is comparable to those who were not relocated. To alleviate concerns of potential biases in our results, we estimate our parameter of interest in a regression model with a rich set of fixed effects and time-varying control variables (Equation 4.2. First, we replace Relocated R $_{i}$ with a set of individual fixed effects $\left(\mu_{i}\right)$ to reduce biases resulting from differences between the movers and non-movers. In addition, we replace the indicator for the post-treatment period (AfterMove $)_{t}$ with a set of time dummy variables $\tau_{t}$ for each survey wave, thereby non-parametrically adjusting for possible shocks in the city or employer that coincide with the move (e.g., pollution reduction in the city). Finally, we include a set of individual time-varying controls, $X_{i t}$. The set of controls includes the average working hours per week and the reported scales rating the Office Layout (See Table 4.6 for the full list of scales in this category). 7

Finally, we use an event-study analysis to capture dynamic effects of the new building on the workers. Equation 4.3 estimates the effects of the relocation separately by year:

$$
Y_{i t}=\mu_{i}+\tau_{t}+\sum_{k=1}^{K} \delta_{k} \text { Relocated } * \text { AfterMove } e_{i t}^{k}+\beta X_{i t}+\epsilon_{i t}
$$

\footnotetext{
${ }^{7}$ We include two dummy variables indicating the individual works "Less than 10 hours" or "11-30 hours," leaving the category "More than 30 hours" as reference.
} 
Here, the coefficient $\delta_{k}$ describes the effect of working in the newly constructed office $k$ periods after the moving date. Thus, Relocated $*$ After Move $_{i t}^{k}$ is an indicator for being $k$ time periods relative to the moving date. The reference category is $k=0$; hence, the post-treatment effects are relative to the year immediately before the treated individuals were relocated to the new building.

In a final step, we estimate to what extent the changes in each of the environmental scales with respect to their baseline level translate into changes in health status with respect to the baseline:

$$
\text { Health }_{i t}-\text { Health }_{i b}=\tau_{t}+\Theta_{s}\left(I E Q_{i t s}-I E Q_{i b s}\right)+\beta\left(X_{i t}-X_{i b}\right)+u_{i t}-u_{i b}
$$

where Health $_{i t}$ takes the value of 1 if individual $i$ reports sick-building-syndrome symptoms at time $\mathrm{t}$, and zero otherwise. Health $h_{i b}$ takes the value of 1 if individual i reports sick-buildingsyndrome symptoms in the baseline survey. Health $h_{i t}-$ Healt $_{i b}$ describes the difference between individual i's probability of stating sick-building-syndrome status at time $t$ and in the baseline survey $b$. Similarly, $I E Q_{i t s}-I E Q_{i b s}$ describes the changes in the values reported in the environmental scale $s$ for individual $i$ at time $t$, with respect to his answers in the baseline survey $b$. The coefficients of interest, $\Theta_{s}$, describe how changes in environmental scale $s$ translate into changes in the probability of reporting sick-building-syndrome symptoms. In addition, we include the changes in a set of control variables $X_{i t}-X_{i b}$-building quality. Error terms are clustered again at the individual level.

\subsection{Results}

\subsubsection{Regression Models Difference-in-Differences}

In this section, we report the estimated coefficients and standard errors of the coefficients associated with the $\mathrm{DiD}$ variable in equation 4.1 and 4.2 . Table 4.3 provides the estimation results, where each row displays the estimated DiD coefficient $(\hat{\delta})$ in 4.1 and 4.2 for a different outcome. Each column provides a different specification of the model, introducing in a stepwise fashion different sets of fixed effects and time-varying control variables. Column (1) shows the estimated DiD coefficients of equation 4.1. The estimation results indicate the relocation of workers was associated with a significant decrease in the level of dissatisfaction of perceived environmental quality in all measures, except for noise and privacy. The highest impact associated with the relocation was on the air-quality dimension, where the dissatisfaction scale dropped 1.6 points on a 7 -point scale. In relative terms, when compared to the average value of these scales in the baseline survey for the relocated group, the relocation to the new building improved employee satisfaction with the air quality by $35 \%$ (1.61/4.50). Similarly, the relocated employees attached a $31 \%(1.31 / 4.14)$ lower value to the scale evaluating whether air quality hinders work. 


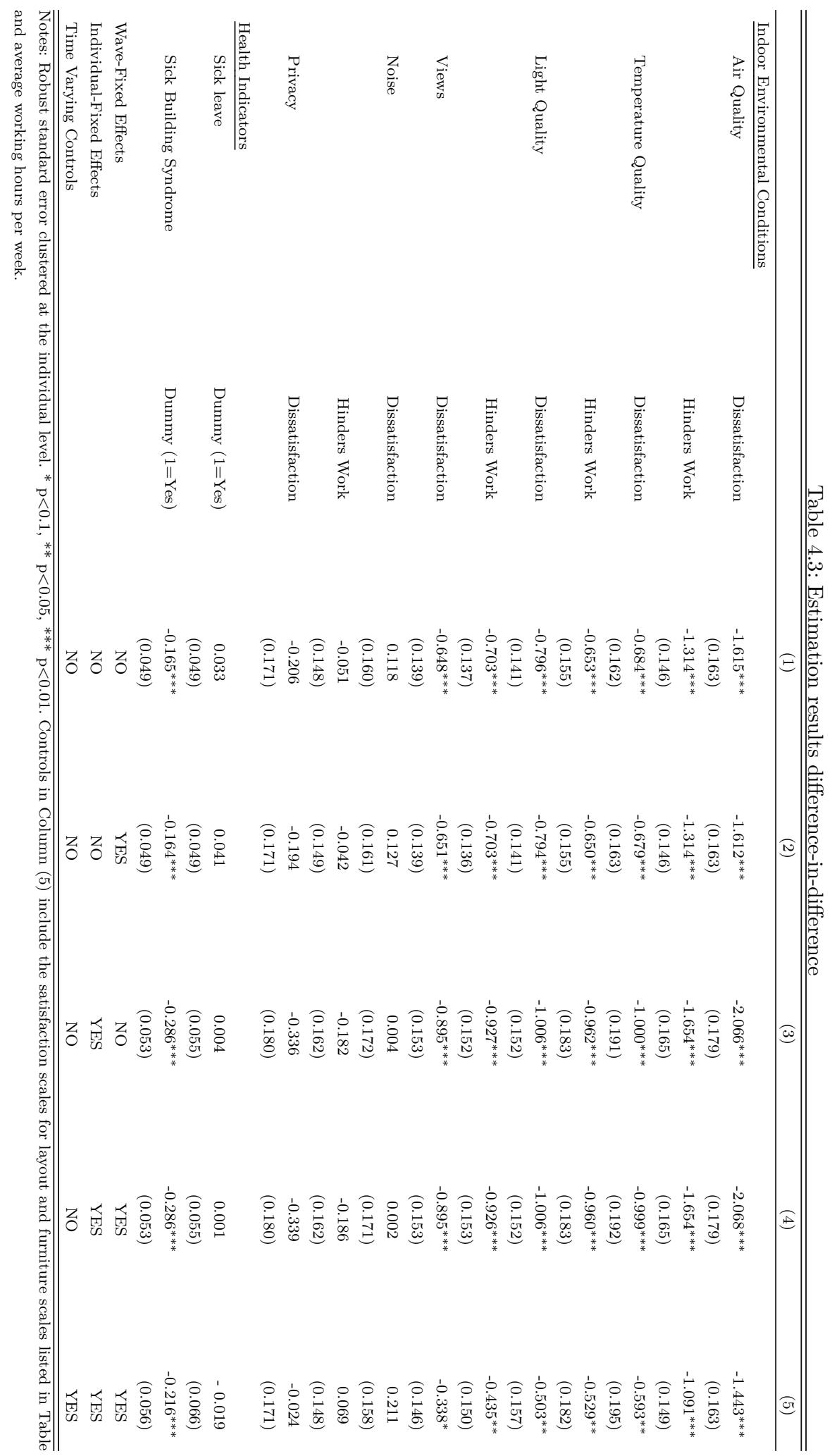


Columns (2) to (5) provide insights into the robustness of the results across different specifications of equation 4.2 . The estimates remain significant with the inclusion of time, individual fixed effects, and time-varying controls 8 The relocation of workers to the sustainable building also generated significant improvements in the perception of light quality and temperature. The absolute and relative improvement in the scales of these two parameters is smaller than the changes observed for the air-quality dimension. Temperature dissatisfaction among relocated workers dropped, on average, by $0.68 \%-17 \%$ compared to the average value of the relocated group before the move. Similarly, the relocation reduced dissatisfaction with the light quality in the building by $0.80 \%-28 \%$ compared to the average value of the relocated group before the move.

The estimates displayed in columns (2) to (5) show the stability of the estimates, supporting the robustness of the results across specifications. The estimation results show no significant improvement in any of the scales in the acoustic-quality dimension. This indicates finding the noise-satisfaction level remained constant after the move from an enclosed office to an open office, and therefore that the open-office environment did not generate significant nuisance for employees, which was an initial concern of the employer. In addition, the heterogeneity in reported satisfaction across dimensions supports the independence of the scales, and implies our results are not driven by the overall relocation itself, but rather by the characteristics of the new building.

We also observe significant improvement in the health of individuals. Although we observe no changes in absence due to illness, we observe significant changes in the health status of individuals. Column (1) of Table 4.2 shows the relocation of employees to the new building reduced the percentage of workers suffering from sick-building syndrome by $16.5 \%$. The results from the more flexible specifications (Columns (2) to (5)) indicate the inclusion of a richer set of fixed effects and individual controls increased the estimated coefficient. The most conservative estimation including time-varying controls, individual and time fixed effects (column (5)), shows a decrease of $21.6 \%$ in the prevalence of sick-building syndrome among the relocated workers after the move. The relocation of workers, generates a substantial drop in the prevalence of sick leave syndrome symptoms when compared to the baseline probability of reporting sick building syndrome symptoms among the relocated employees, by $42 \% .9$

\footnotetext{
${ }^{8}$ In column (5), we include changes in working hours, perceived quality of furniture, and layout as time-varying controls.

${ }^{9}$ The baseline probability of reporting sick-building-syndrome symptoms for the treatment group is reported in column (1) in Table 4.1
} 


\subsubsection{Dynamic Effects}

In this section, we test for the existence of a possible rebound in the improvement of perceived satisfaction and health experienced by the relocated employees. Evidence from psychology and behavioral economics shows that individuals tend to adapt, in the medium term, to changes in their physical or material conditions (e.g., Kahneman and Deaton, 2010). Thus, the estimated changes in the subjective assessments presented in the previous section might be biased by an overreaction of individuals in the short term. In addition, the potential material depreciation of the new building might also distort the results.

Figure 4.4 shows the coefficients $\left(\hat{\delta_{k}}\right)$ describing the changes in responses across survey waves (k) with respect to the baseline survey for the relocated (blue) and non-relocated employees (gray), together with their associated confidence intervals. Our surveys are taken from six months to two years after the relocation. In addition, the three surveys cover both the cold and warm seasons (see Figure 3.5 for the exact timeline of the surveys).

Overall, we observe stability in the coefficients describing the indoor environmental-dissatisfaction scales. For the group of employees who stayed in their initial workplaces, we observe no changes in reported scales or prevalence of sick-building syndrome over time. For the transferred group, we observe that the initial decrease in dissatisfaction with the indoor environmental quality in the workplace persisted over time. Thus, we observe no rebound in the initial perceived benefits toward the initial levels, suggesting the results are not caused by the move itself, but by the indoor environmental quality of the building. These results also support the hypothesis that no drop occurred in the quality of the building over time.

Figure 4.5 presents the changes in health status over time. In line with the improvement in the perceived indoor environmental quality, we find no evidence of a rebound in the estimated changes in the health status of the employees. The estimation results indicate the initial drop in the prevalence of sick-building syndrome, symptoms remained at the initial level $\left(\delta_{k=1}=0.210\right)$. 10

\subsubsection{Heterogeneous Effects}

In this section, we study whether some subgroups are more sensitive to indoor environmental conditions than others. First, we explore gender differences. The current indoor climate regula-

\footnotetext{
${ }^{10}$ Figure 4.7 in Appendix 4.5 presents the changes in job satisfaction over time. We observe no deviations to the baseline responses to any question in the block of satisfaction questions except for the item "I am proud of the work that I do". In the first survey after the move $(k=1)$, the relocated group showed a significantly higher frequency that they felt proud of their work. By contrast, in the group of employees who were not relocated, we observe a drop in the frequency with which the average respondent felt proud of his or her work. In the following surveys $(k>1)$, the differences with respect to the baseline frequencies and between the two groups of employees disappear.
} 
Figure 4.4: Trends in perception of indoor environmental conditions

Air Quality (Dissatisfaction)

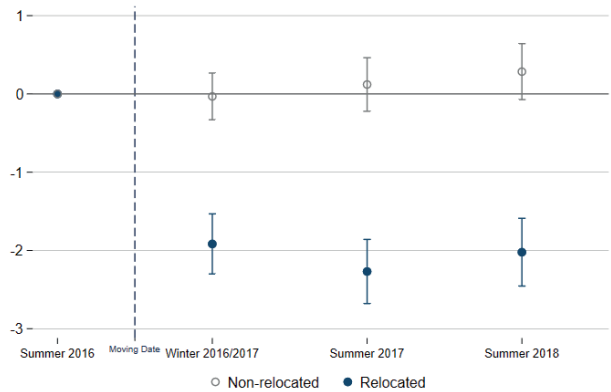

Temperature (Dissatisfaction)

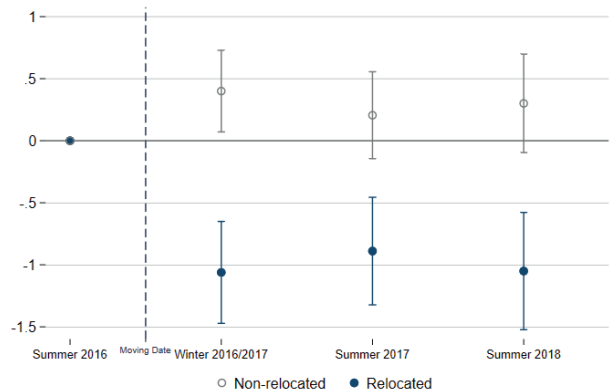

Light (Dissatisfaction)

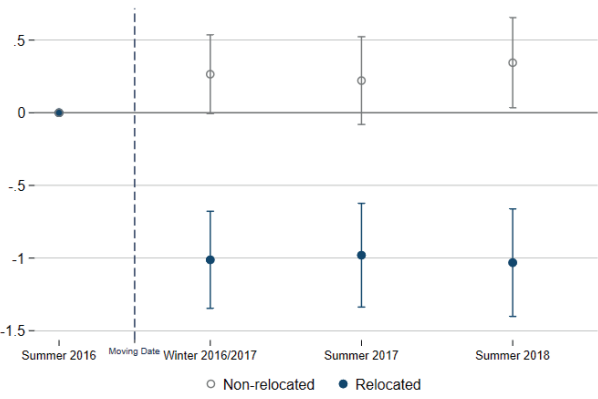

Noise (Dissatisfaction)

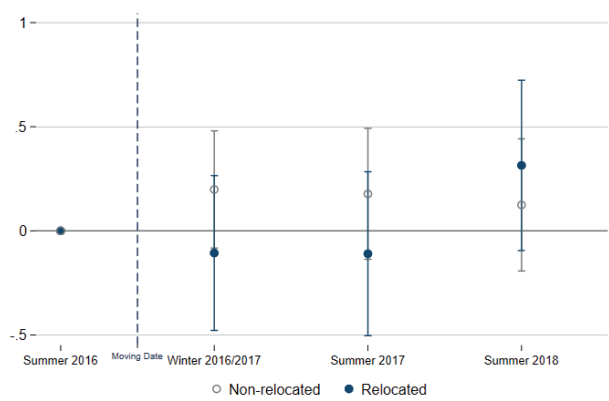

Air Quality (Hinders Work)

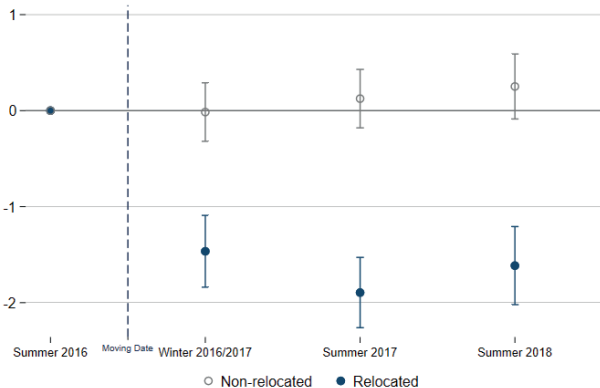

Temperature (Hinders Work)

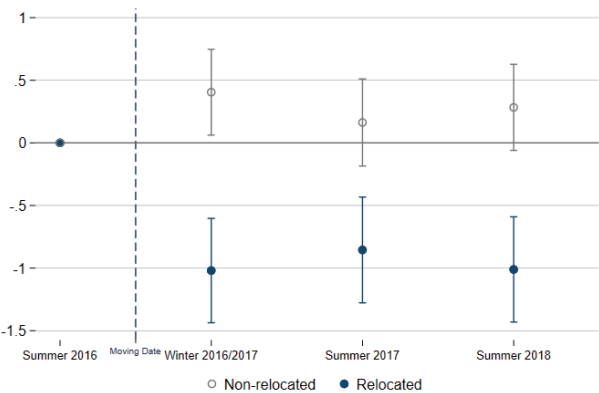

Light (Hinders Work)

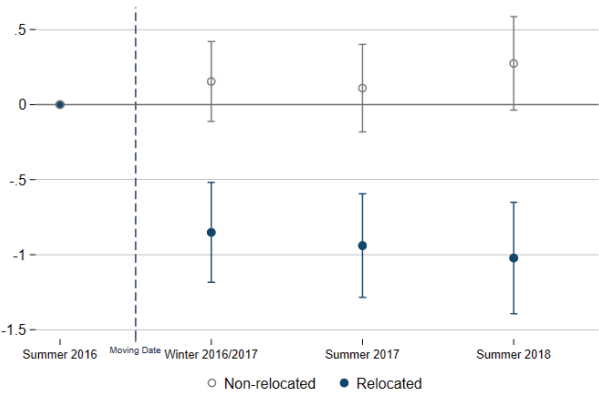

Noise (Hinders Work)

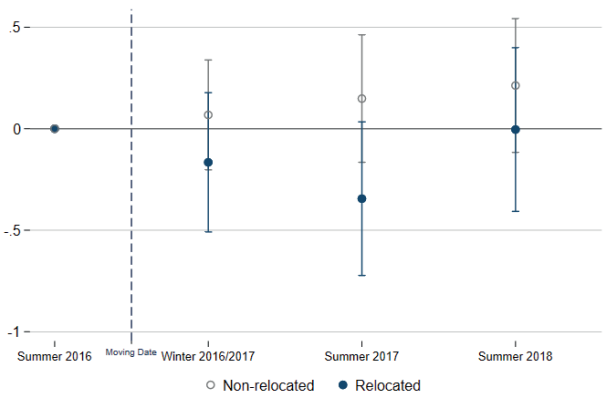

Note: The figures show the estimated coefficient of the time dummies describing the survey times before $(=0)$ and after the moving date. The dots represent the point estimates and the bars the $95 \%$ confidence intervals. All regressions include the time varying controls, individual and survey wave fixed effects. The vertical, dashed gray line indicates the moving date. 
Figure 4.5: Trends in sick building syndrome $(1=$ Yes $)$

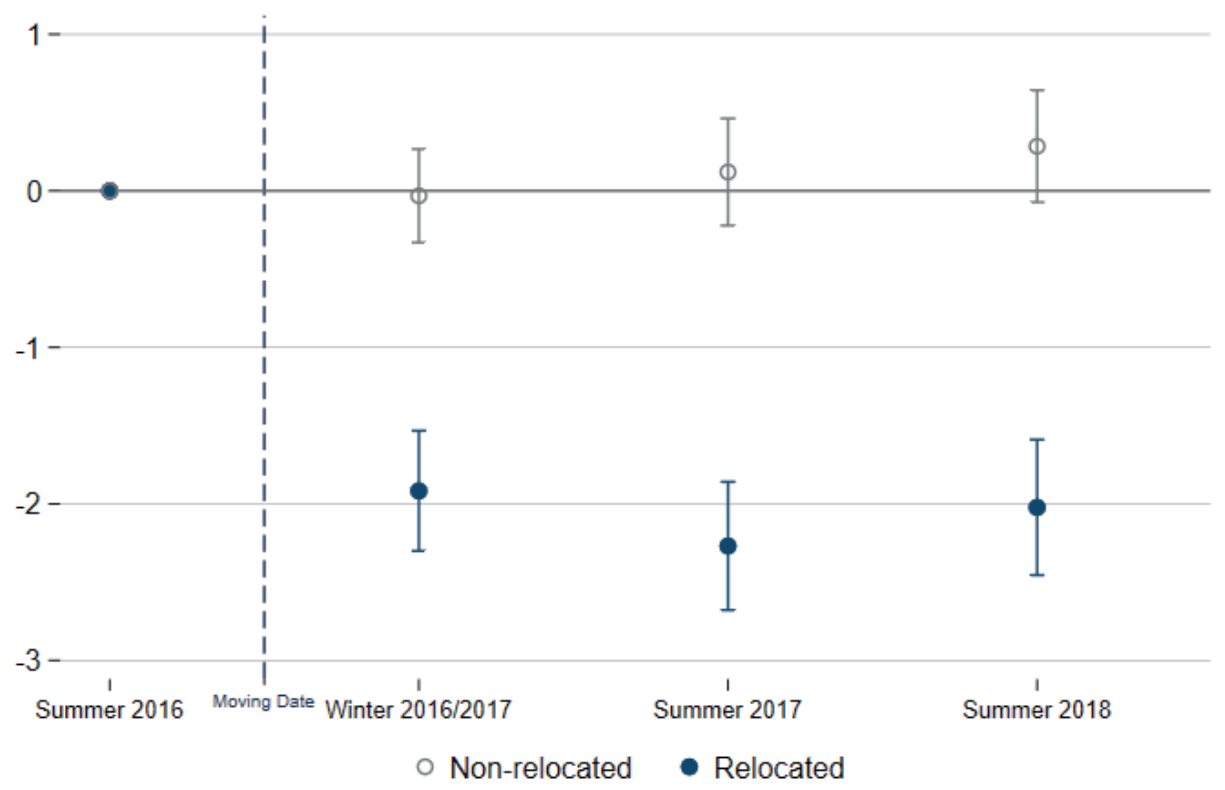

Note: The figure shows the estimated coefficient of the time dummies describing the survey times before $(=0)$ and after the moving date. The dots represent the point estimates and the bars the $95 \%$ confidence intervals. The vertical, dashed gray line indicates the moving date. The set of control variables include the average hours worked per week and the layout scales (See Table 4.6 for the full list). The estimation results are also presented in 4.8 in the Appendix. 
tions in office buildings tend to be based on a thermal comfort model developed in the 1960s. That model optimizes the environmental conditions to satisfy an average male. A recent study in biophysics indicates the existing model significantly miscalculates the metabolic rate of female thermal demand (Kingma and Van Marken Lichtenbelt, 2015). This is line with the many field studies showing females express more dissatisfaction than males with low temperatures (for a review of the literature, see Karjalainen, 2012). Recent experimental evidence indicates these differences have implications for cognitive performance. Chang and Id (2019) find women perform better in verbal and numeric tasks at experimentally manipulated higher temperatures, whereas the reverse pattern is observed for men.

In addition, the presence of pre-existing diseases in the respiratory or cardiovascular systems among older population groups might exacerbate the health impacts of certain hazards in the indoor environment (e.g., indoor pollutants) (Li et al. 2018). For the analysis of the differences across demographic groups, we therefore stratify our sample by gender and age.

Table 4.4 presents the results of the heterogeneity analysis. The first two columns display the results for the two gender subsamples, and the last three columns show the estimates for the three age groups in our sample. We observe no significant discrepancies in responses to scales in the noise, air, and light-quality dimensions across gender or age groups. However, the results for thermal dissatisfaction indicate the drops in dissatisfaction rates associated with the new building are present only among male employees. Relocated women did not significantly adjust their ratings after being transferred to the new building. Similarly, we observe significant changes in thermal dissatisfaction among the older employees only (beyond 30 years old).

When focusing on the health measures, we find the relocation of workers to the new building generated similar drops in the prevalence of sick-building-syndrome symptoms in female and male employees. The estimates suggest the impact of the relocation becomes more significant with the age of employees. We observe significant drops only in the probability of reporting sick-building syndrome among the oldest group of employees (over 50 years old). The coefficient associated with the group of workers between 30 and 50 years old is marginally significant (i.e., at the $10 \%$ level).

\subsubsection{Association between environmental conditions and health}

The relocation to a new building involves significant changes in a variety of factors regarding the workplace of employees. We analyze how the changes in the different indoor environmentalconditions dimensions contributed to the drop in the prevalence of sick-building-syndrome symptoms, with respect to the initial situation just before the moving date.

Figure 4.6 presents the estimated coefficients $\Theta_{s}$ of equation 4.4 , describing the association between the probability of reporting sick-building-syndrome symptoms and each of the four 


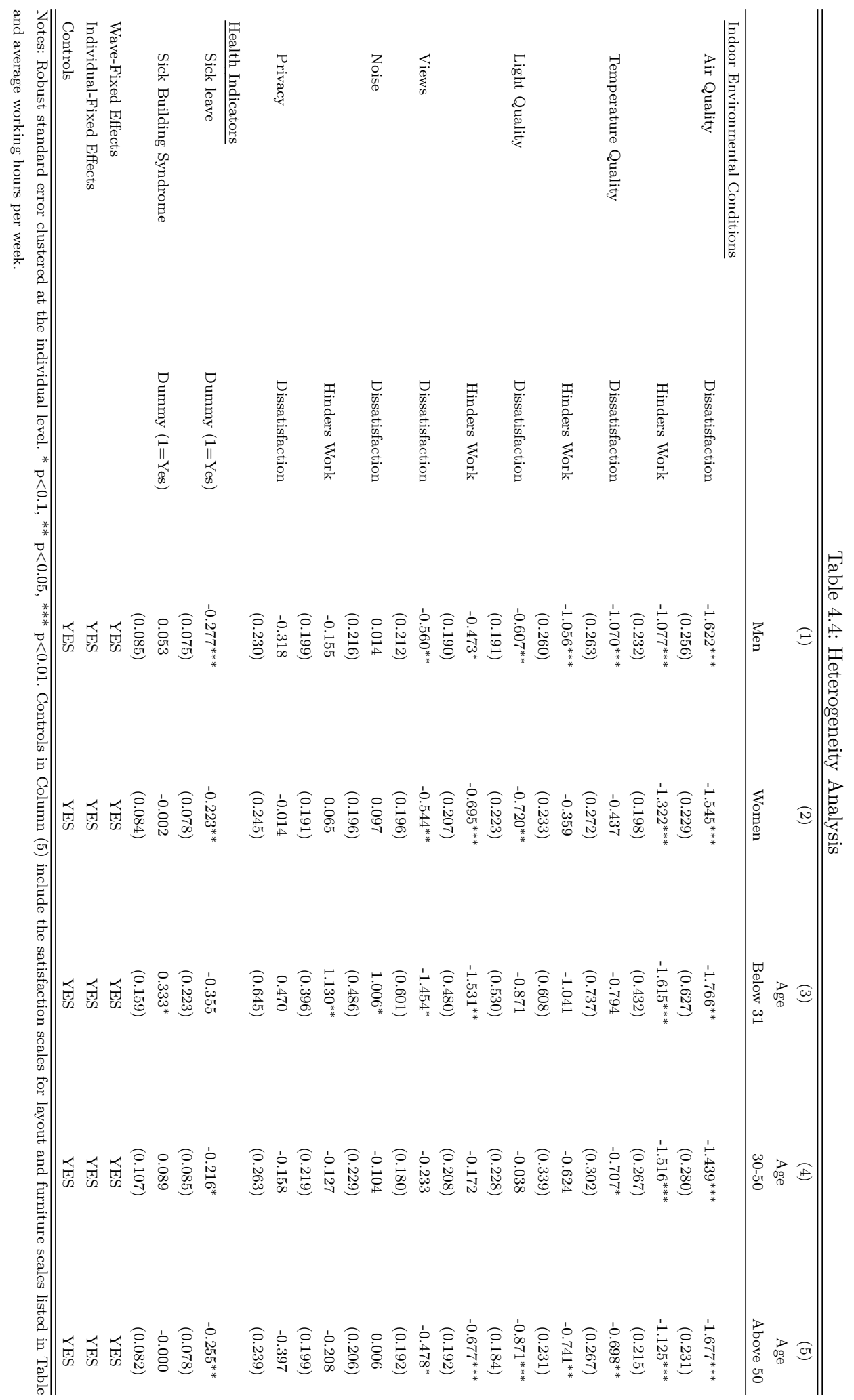


Figure 4.6: Effect environmental problems on sick building syndrome

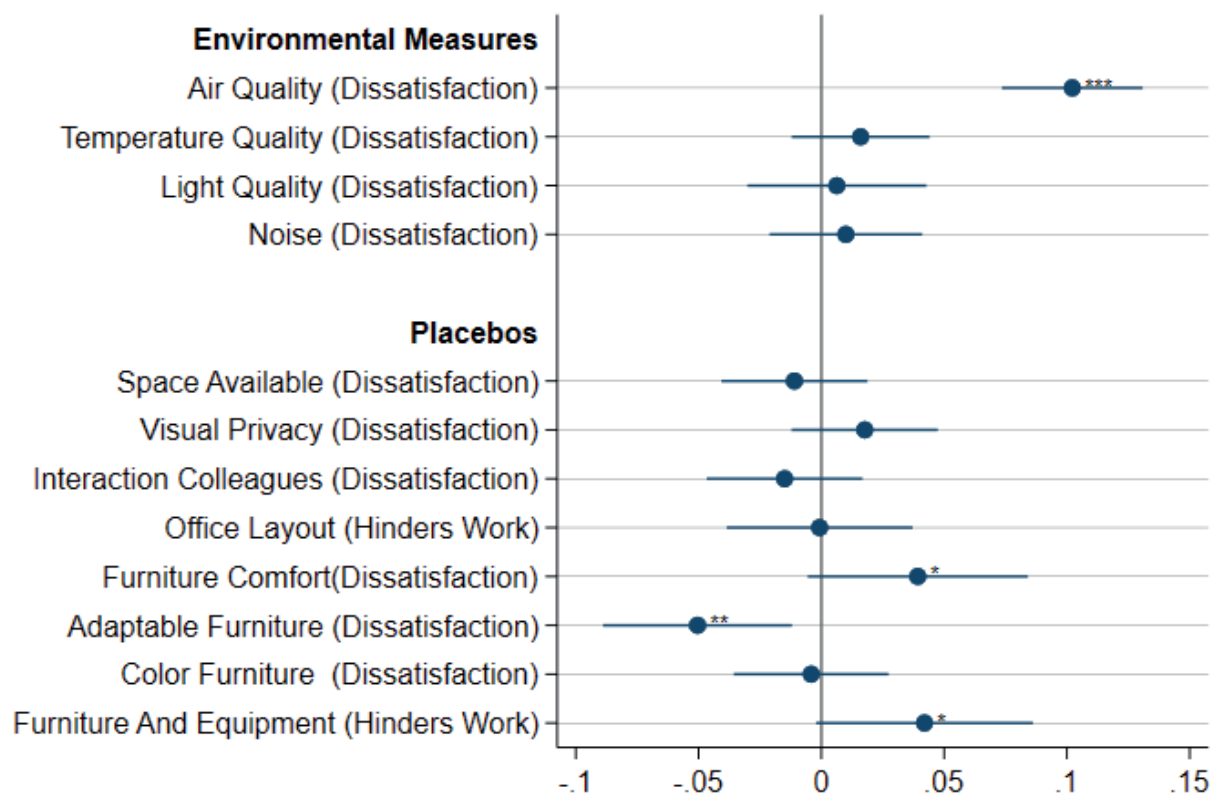

Note: The figure shows the point estimates of and confidence intervals associated with each ot the elements of vector $\Theta$ in Equation 4.4 The dots represent the point estimates and the bars the $95 \%$ confidence intervals. All regressions include time varying controls (contract type), individual and survey-wave fixed effects. ${ }^{*} \mathrm{p}<0.1,{ }^{* *} \mathrm{p}<0.05, * * * \mathrm{p}<0.01$.

factors related to the indoor environmental conditions in the workplace (i.e., elements of $\Theta$ ). The estimation results indicate poor air quality is, on average, the only significant contributor to the prevalence of sick-building-syndrome symptoms. The presence of perceived deficient air quality is associated with an increase of about 10 percentage points in the odds of reporting sick-building syndrome in our sample.

We also include a series of furniture-quality factors as regressors in the empirical model, as placebos to construct a falsification test. The absence of significant coefficients associated with these factors supports the hypothesis that the health improvements displayed in this study are mainly driven by an improvement in environmental conditions in the workplace and not by a general building-quality improvement.

\subsection{Conclusions}

Human health is a critical factor for the generation of output by workers. Companies bear substantial costs associated with absenteeism and presenteeism among their employees (Hemp, 2004 Stewart et al. 2003). In addition, increasing evidence shows job satisfaction translates into higher productivity for workers and ultimately higher value for companies (Edmans, 2012).

This study investigates the impact of the indoor environmental conditions in the workplace 
on the health and job satisfaction of employees, as core factors of productivity. We provide quasi-experimental evidence based on the relocation of $70 \%$ of the workforce of a municipality in the south of the Netherlands. We construct a longitudinal dataset based on individual surveys of the entire municipal workforce and include measures before and after the relocation.

The estimation results show a significant improvement in the perceived indoor environmental conditions and health of the relocated workers. We find the largest improvements in perceived air quality of the workplace, reducing the level of dissatisfaction by 1.62 points on a 7 -point Likert scale. In addition, we observe significant improvements in the health status of individuals. In particular, we observe a 0.22 -percentage-point reduction in the prevalence of sick-building syndrome. Finally, we observe no significant changes in job-satisfaction scales associated with the relocation event. The decomposition of effects over time indicates the estimated changes remained persistent in the medium term (two years after the moving date).

The results of the heterogeneity analysis show the existence of differences among workers. The relocation to the new building had significant effects on men and not women. On the contrary, the relocation led to a drop in sick-building syndrome that was similar in magnitude between men and women. The analysis of different age subsamples indicates increasing benefits with age. Older individuals benefited the most from the move in terms of perceived environmental quality and health status.

Of course, the analysis in this paper is restricted by the availability of data. First, the analysis relies on self-reported data of participants' sick leave, based on a categorical variable. Ideally, the analysis would include administrative data of sick leave with the exact number of sick days in the year (or months) preceding the survey. Similarly, the changes in environmental conditions are based on the perceived environmental conditions of workers in their workplaces. Ideally, we would rely on sensor data to objectively document changes in indoor environmental quality. Advances in indoor sensor technology should make such data available in the near future. The differences in characteristics between the respondents of the survey and non-respondents are not observed, and therefore in the current version we rely on the assumption that the sample of respondents do not differ from the sample of non-respondents.

The results in this paper add to a significant body of research that is mostly based on engineering measures or on cross-sectional analysis. The quality of indoor environmental conditions may have significant economic implications-our service society depends on buildings in order for workers to be productive. Our findings show that variation in different dimensions of indoor environmental quality affect perceived health outcomes, which may have implications not just on worker productivity, but also on the cost of absenteeism. 


\section{Appendix $4 \mathrm{~A}$}

\section{Dutch (original)}

Maastricht University en de gemeente Venlo nodigen $u$ uit om deel te nemen aan een onderzoek over werkplek beleving en kwaliteit. Dat doen we door middel van een enquete over uw werkplek en het gebouw waarin die zich bevindt.

De enquete gaat over uw huidige werkplek. Over een paar maanden zullen we $u$ opnieuw vragen om de vragenlijst in te vullen, of $u$ nu gaat verhuizen naar het nieuwe stadskantoor of niet. De informatie wordt gebruikt om gebouwen en werkplekken te verbeteren, niet alleen in Venlo, maar ook in de rest van Nederland en daarbuiten. Het invullen van de vragenlijst duurt ongeveer tien minuten. We danken u heel hartelijk voor uw hulp!

\section{English (translated)}

Maastricht University and the municipality of Venlo invite you to participate in a study on workplace experience and quality. We do this by means of a survey about your workplace and the building in which it is located.

The survey is about your current workplace. In a few months we will ask you again to complete the questionnaire, whether you are moving to the new city office or not. The information is used to improve buildings and workplaces, not only in Venlo, but also in the rest of the Netherlands and beyond. It takes approximately ten minutes to complete the questionnaire. We thank you very much for your help! 
Appendix $4 \mathrm{~B}$

Table 4.5: Response rate

\begin{tabular}{lccc}
\hline Survey wave & Total Employees & Valid surveys & Response rate \\
\hline 1 (Summer 2016) & 1461 & 589 & $40.31 \%$ \\
2 (Winter 2017) & 1461 & 596 & $40.79 \%$ \\
3 (Summer 2017) & 1550 & 584 & $37.67 \%$ \\
4 (Summer 2018) & 1525 & 537 & $35.25 \%$ \\
\hline
\end{tabular}




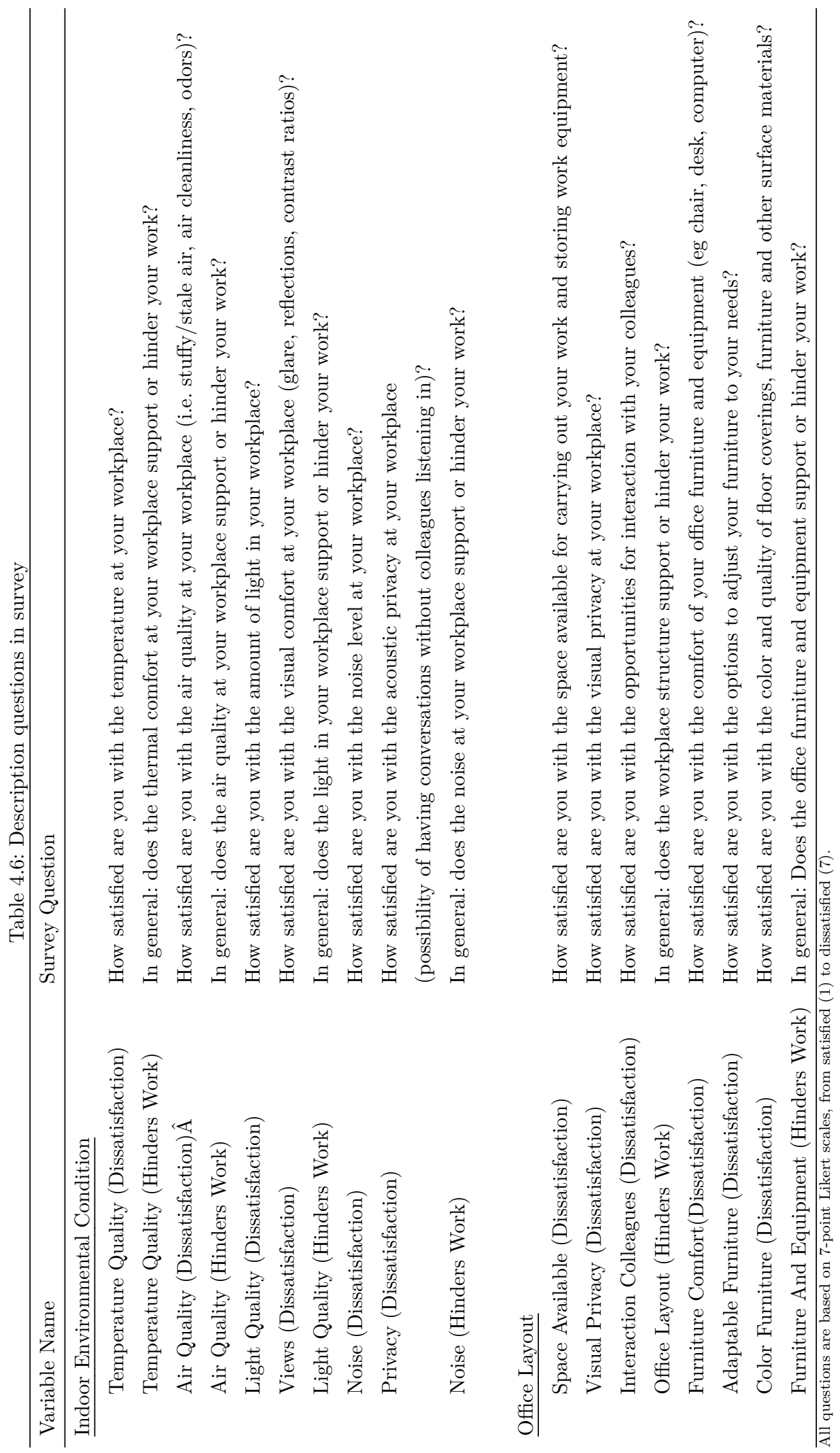




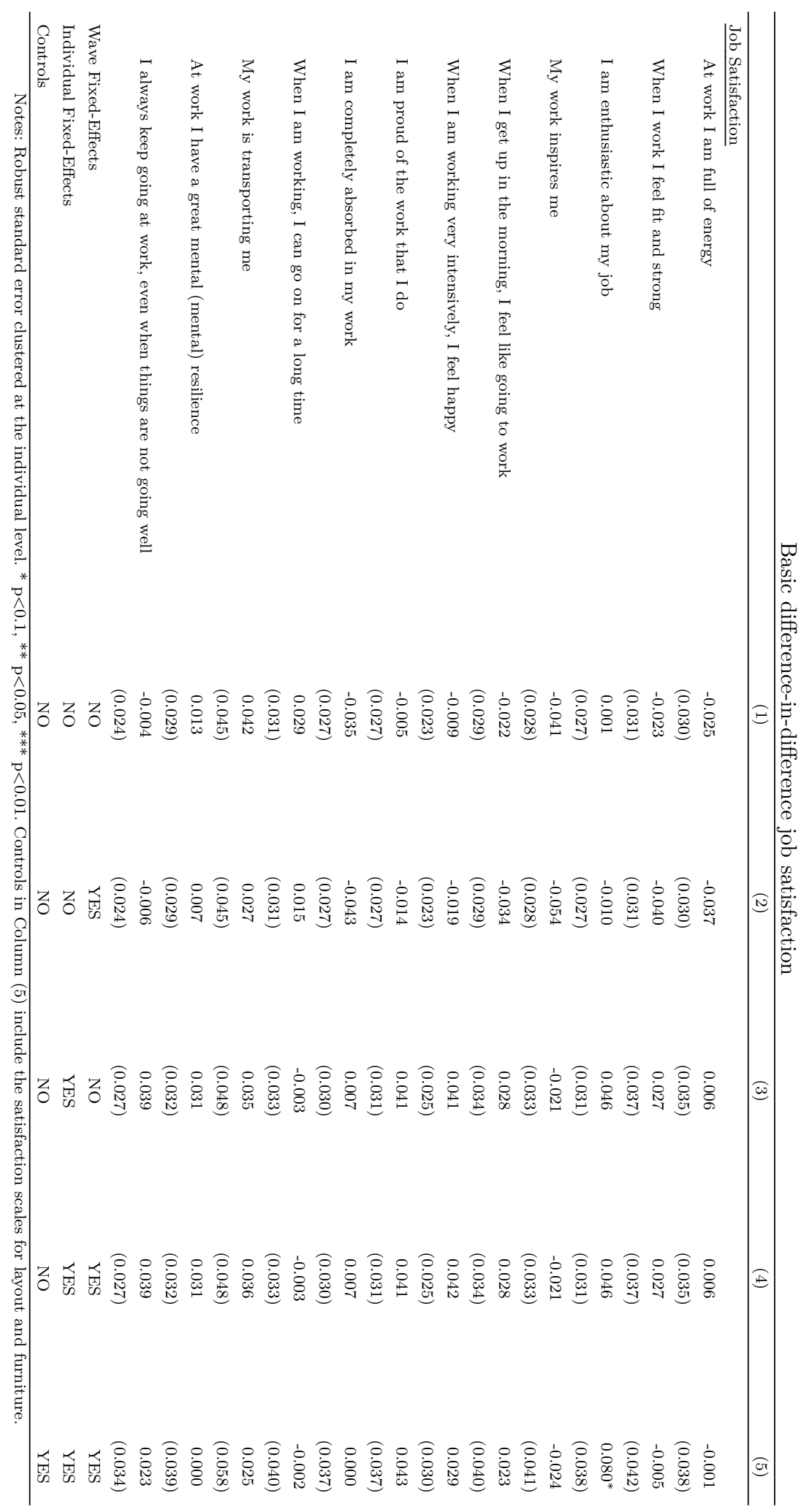




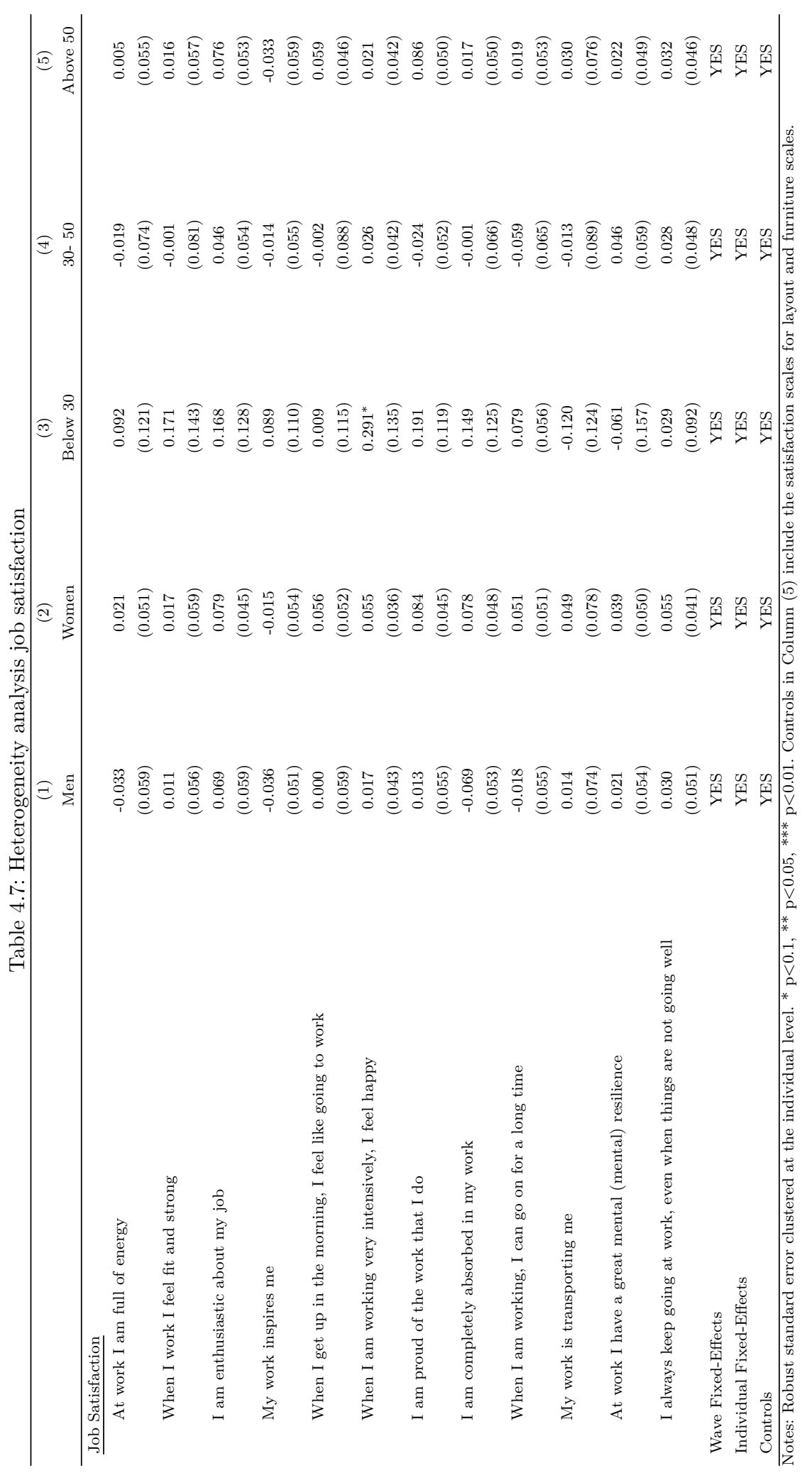


Figure 4.7: Panel A. Trends in Job Satisfaction

At work I am full of energy

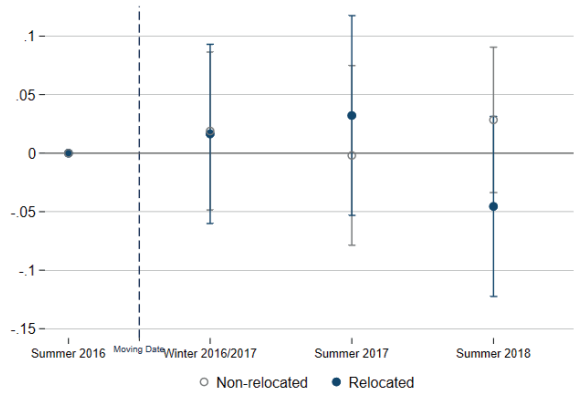

I am enthusiastic about my job

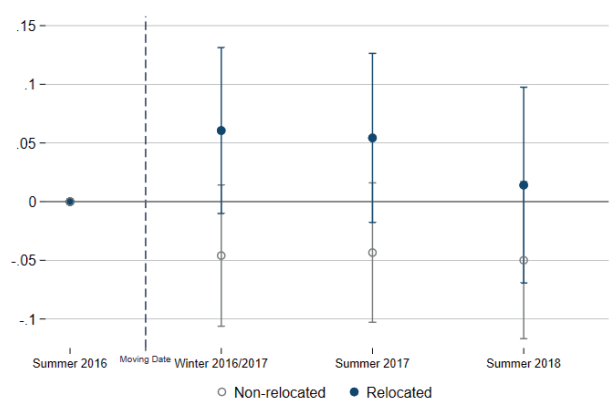

When I get up in the morning, I feel like going to work

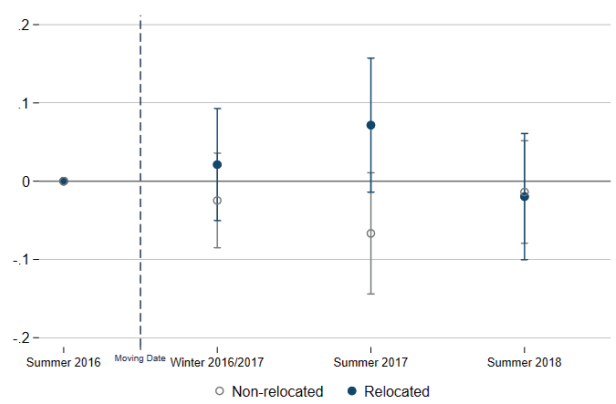

When I work I feel fit and strong

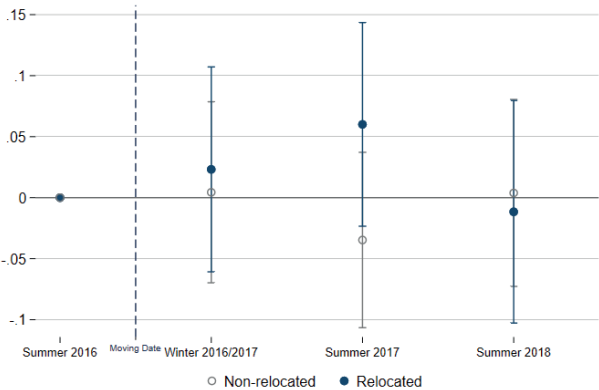

My work inspires me

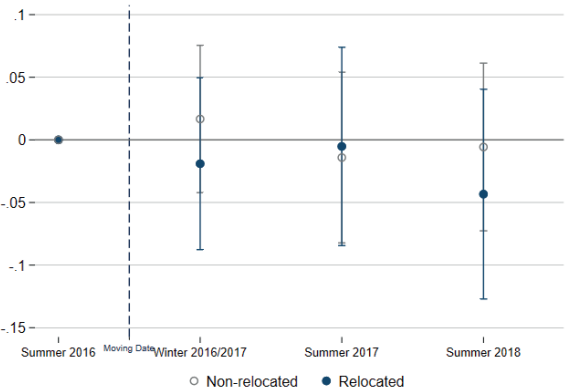

When I am working very intensively, I feel happy

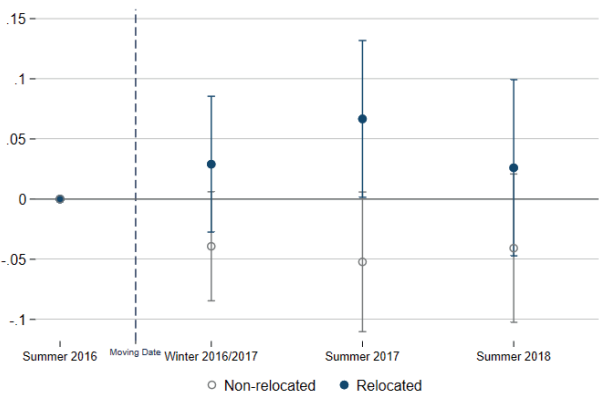

Note: The figure shows the estimated coefficient of the time dummies describing the survey times before $(=0)$ and after the moving date. The dots represent the point estimates and the bars the $95 \%$ confidence intervals. All regressions include the Elo score individual fixed effects. The vertical, dashed gray line indicates the moving date. 
Table 4.7Panel B.Trends in Job Satisfaction

I am proud of the work that I do

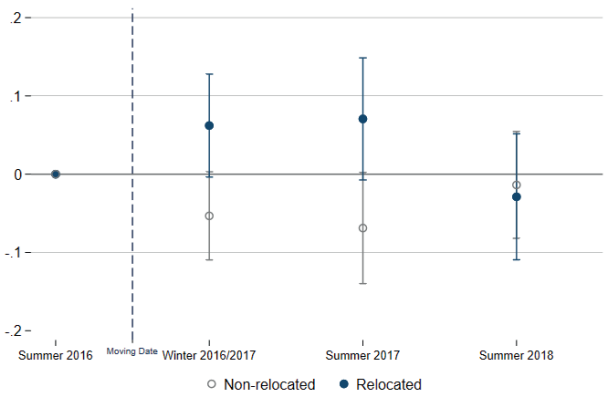

I am proud of the work that I do

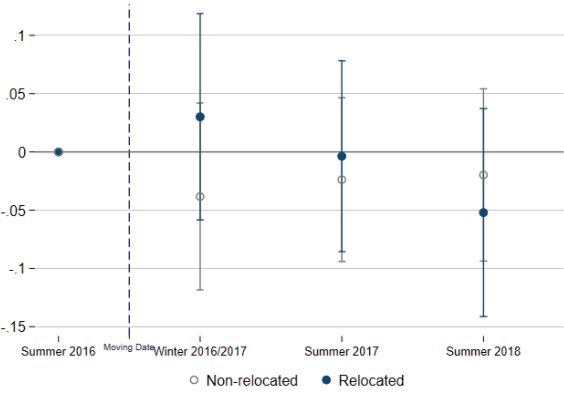

At work I have a great mental (mental) resilience

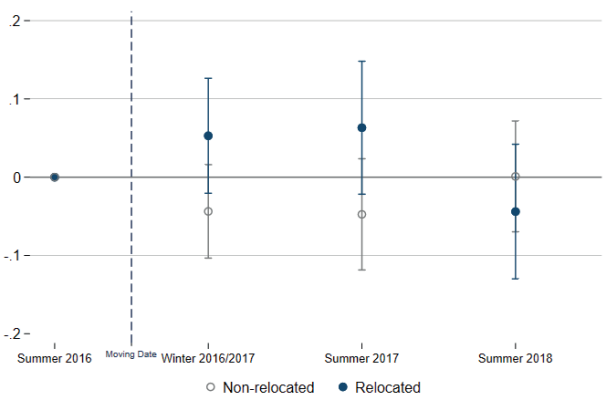

I am completely absorbed in my work

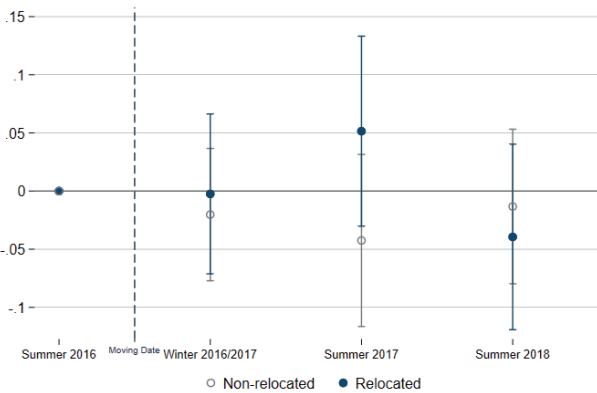

My work is transporting me

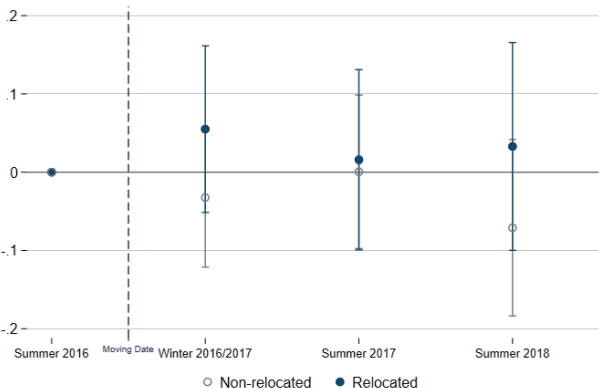

I always keep going at work, even when things are not going well

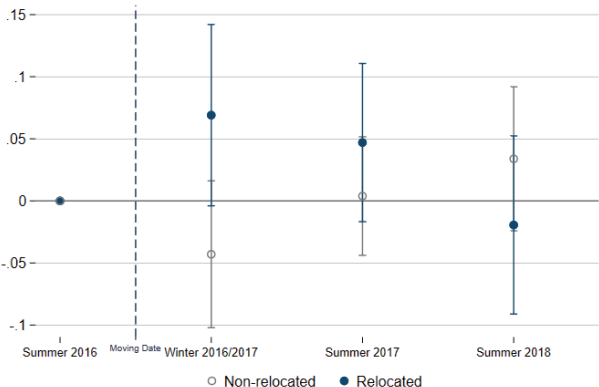

Note: The figure shows the estimated coefficient of the time dummies describing the survey times before $(=0)$ and after the moving date. The dots represent the point estimates and the bars the $95 \%$ confidence intervals. All regressions include the Elo score individual fixed effects. The vertical, dashed gray line indicates the moving date. 
Table 4.8: Estimation results impact of indoor environmental quality on sick building syndrome

Air Quality (Dissatisfaction)

$0.102^{* * *}$

\begin{tabular}{lc} 
& $(0.015)$ \\
Temperature Quality (Dissatisfaction) & 0.016 \\
Light Quality (Dissatisfaction) & $(0.014)$ \\
& 0.006 \\
Noise (Dissatisfaction) & $(0.019)$ \\
& 0.010 \\
Space Available (Dissatisfaction) & $(0.016)$ \\
& -0.011 \\
Visual Privacy (Dissatisfaction) & $(0.015)$ \\
Interaction Colleagues (Dissatisfaction) & 0.018 \\
Office Layout (Hinders Work) & $(0.015)$ \\
& -0.015 \\
Furniture Comfort(Dissatisfaction) & $(0.016)$ \\
Adaptable Furniture (Dissatisfaction) & -0.001 \\
Color Furniture (Dissatisfaction) & $(0.019)$ \\
Furniture And Equipment (Hinders Work) & $0.039^{*}$ \\
& $(0.023)$ \\
& $-0.050^{* *}$ \\
& $(0.020)$ \\
& -0.004 \\
& $(0.016)$ \\
& 1,279 \\
& 0.243 \\
\hline
\end{tabular}

Notes: The table shows the point estimates of and standard errors associated with each ot the elements of vector $\Theta$ in Equation 4.4 All regressions include time varying controls (contract type), individual and survey-wave fixed effects. ${ }^{*} \mathrm{p}<0.1,{ }^{* *} \mathrm{p}<0.05,{ }^{* * *} \mathrm{p}<0.01$. Standard errors are clustered at the individual level. 


\section{Chapter 5}

\section{Indoor Air Quality And Human Cognition买}

Air pollution alone is estimated to be responsible for nine million premature deaths annually (Landrigan et al. 2018). While the literature has extensively documented the detrimental effects of air pollution on the respiratory and cardiovascular systems, a growing body of evidence suggests that exposure to air pollutants may also have harmful effects on the human brain and cognitive functioning (Underwood, 2017). The physiological effects are substantial and may have significant consequences for individual performance in cognitive tasks and human capital formation.

This paper examines the causal impact of indoor air quality on the cognitive performance of individuals using data from chess tournaments. Chess provides an ideal setting to study the relationship between detrimental environmental conditions and individuals' cognition. Chess is a complex and cognitively demanding activity, where individuals face strong incentives to exert high effort and have to perform under time pressure. The quality of cognitive performance can be objectively evaluated using predictions by a chess computers as a benchmark for the quality of strategic decision making. In addition, our setting allows us to measure indoor air quality and unambiguously assign individual exposure to air quality resembling moderate conditions typically faced indoors in Western economies ${ }^{2}$

In this study, we use panel data on the performance of chess players obtained from two official tournaments held in Germany in 2017 and 2018. Each tournament comprises seven rounds over a period of eight weeks. Overall, we have detailed information on more than 20,000 moves made by 102 players in more than 400 games. Players' skills range from beginner's to advanced

\footnotetext{
${ }^{*}$ This chapter is co-authored with Steffen Kuenn (Maastricht University and IZA) and Nico Pestel (IZA)

${ }^{2}$ The exposure of building occupants to extreme temperatures or pollutants is likely to deviate substantially from outdoor levels. In addition to the intermediation of air conditioning or heating for temperatures, the U.S. Environmental Protection Agency (EPA) documents significant differences in certain pollutant concentrations between indoors and outdoors.
} 
levels. All players have strong incentives to perform well throughout the tournament as their accomplishments during the tournament count for their chess rating score, which is a matter of prestige among chess players and has implications for future competitions. In addition, there are pecuniary incentives as the tournament organizers award monetary prizes.

We make use of a chess computer program to analyze the quality of each individual move of a game. In fact, the chess engine provides an evaluation of a player's actual move as the relative advantage to win the game as well as to the relative advantage that would be achieved by making the move deemed optimal according to the algorithm. In addition, the chess engine annotates moves of particular low quality, so-called strategic mistakes or blunders. In our empirical analysis, we construct two outcome variables based on the output of the chess computer: (i) a binary indicator for a move being annotated as a "meaningful error", and (ii) the magnitude of the error measured by the difference between the relative advantage of the actual and optimal move.

Our identification strategy exploits the fact that we observe the performance of the same individual playing multiple games in the exact same venue, at the same time of the day but under varying indoor environmental conditions which are beyond the control of the players. In order to accurately assign players' exposure to air quality, we installed sensors inside the tournament venue continuously measuring the concentration of fine particulate matter with a diameter smaller than 2.5 micrometers (PM2.5), which may penetrate deep into the lungs and brains, as well as the levels of temperature and the concentration of carbon dioxide (CO2). On average, players' exposures last for about three hours, which is sufficient to uncover an effect of the environmental conditions on cognitive performance ${ }^{3}$

Overall, we find that indoor air pollution significantly deteriorates cognitive performance. Exploiting within-player variation in environmental conditions and controlling for year, round, and move fixed effects, and a set of control variables, we find that an increase in particulate pollution (PM2.5) of ten micrograms per cubic meter $\left(10 \mu \mathrm{g} / \mathrm{m}^{3}\right)$, about one standard deviation in the sample, leads to a 1.5 percentage point increase in the probability of making a meaningful error, corresponding to an increase of $18.8 \%$ relative to the sample mean. Further, for the magnitude of the error we find that an increase of $10 \mu \mathrm{g} / \mathrm{m}^{3}$ in PM2.5 concentration leads to $9.4 \%$ larger errors. The results are similar in magnitude to existing estimates within the literature. We do not find any significant effects of temperature and $\mathrm{CO} 2$ on our error measures.

In addition, we exploit the fact that the tournament rules set a time restriction to evaluate effect heterogeneity with respect to time pressure. Each player has to complete the first 40 moves

\footnotetext{
${ }^{3}$ Exposure time in our study is similar to the average exposure in epidemiological studies exploring the effect of CO2 or temperature on cognition (e.g. Satish et al. 2012). Levels of CO2 concentration range between 1,000 and over 2,250 ppm, temperature between 22 and 29 degrees Celsius (72 and 84 degrees Fahrenheit) and fine particulate pollution between 12 and $58 \mu \mathrm{g} / \mathrm{m}^{3}$.
} 
within a time limit of 110 minutes per player. This implies that move decisions shortly before move 40 can be assumed to be made under relative time pressure, compared to other phases of the game. We split the overall sample by move intervals within the game and find that the negative impact of air pollution on cognitive performance is substantially exacerbated if decisions need to be made under time pressure. Approaching the time control within a game (moves 3140), an increase of $10 \mu \mathrm{g} / \mathrm{m}^{3}$ in PM2.5 increases the probability of making a meaningful error by 3.2 percentage points (equivalent to a $29.6 \%$ increase compared to the sample mean), with the errors being $17.3 \%$ larger. Again, we find no effects for temperature and CO2. A sensitivity analysis with respect to potentially selective sample attrition as well as the implementation of several specification tests support the robustness of the results.

This paper makes the following contributions to the literature. We complement the growing economics literature on productivity losses resulting from working in detrimental environments characterized by extreme temperatures or air pollution. A Most of the existing quasi-experimental evidence is based on routine manual occupations, such as agriculture or factory workers (Graff Zivin and Neidell, 2012, Chang et al., 2016), where individual output is easy to quantify. Our understanding of how environmental hazards affect the performance of workers in cognitive or analytical professions, where the value added of a worker tends to be much harder to quantify, is still limited. Previous studies in the field use measures such as quantity rates (e.g., number of calls handled per hour (Chang et al., 2019) $)$, judges' decision time (Kahn and Li, 2019) or uptime (percent of time in a day that a trader is at his desk trading (Meyer and Pagel, 2017)) to measure the added value of a worker. Little is known about how the final quality of the tasks or decisions undertaken by cognitive workers is affected by adverse environmental conditions. The paper by Archsmith et al. (2018), studying the propensity of professional baseball umpires to make incorrect calls, is currently the only exception. The results of our paper contribute to this literature by examining a setting where individuals are confronted with highly demanding cognitive tasks involving complex and strategic decision making under time pressure and with strong incentives to perform well. For the first time we show that detrimental effects of pollution on cognition are exacerbated if decisions are taken under time pressure. Therefore, our findings are likely to have strong implications for high-skilled office workers, in particular for those executing non-routine cognitive tasks. The roles of these tasks are gaining more and more importance in developed labor markets and are mainly represented in professional, managerial, technical, and creative occupations (Autor and Price, 2013).

Finally, the setting of this paper allows us to study the impact on cognitive performance

\footnotetext{
${ }^{4}$ In addition, recent work documents significant drops in performance when testing days coincide with high levels of air pollution (Ebenstein et al. 2016) or extremely high temperatures (Park 2018).
} 
caused by individuals' exposure to indoor environmental conditions. 5 Importantly, the levels of indoor air quality we observe are rather moderate and our results are not driven by extreme levels of air pollution frequently observed in countries like China or India. In addition, since the variation of indoor air pollution is largely driven by outdoor emission sources (e.g., traffic and industrial activity) our results have important implications for environmental policy-making. Quantifying the benefits of improving air quality by regulating emissions from traffic or industrial activity has to expand beyond major health impacts that result in hospitalizations or death and additionally take into account more subtle effects on labor productivity and human capital accumulation (Graff Zivin and Neidell, 2018).

The remainder of our paper is organized as follows. In the next section, we discuss the literature linking environmental conditions to human health and (cognitive) performance. In section 5.2 we provide a description of the game of chess and its use by the scientific literature to understand human behavior and performance. In this section, we also explain the construction of our performance measure and the estimation sample. In section 5.3 , we present our empirical strategy. The results are presented and discussed in section 5.4 and robustness checks are shown in section 5.5. Section 5.6 concludes.

\section{$5.1 \quad$ Literature}

\subsubsection{Environment And Health}

For decades, the health science literature has linked exposure to high levels of air pollution or extreme temperatures with respiratory and cardiovascular mortality and morbidity. Air pollution alone is estimated to be responsible for 9 million premature annual deaths, according to 2015 global estimates (Landrigan et al. 2018). Similarly, a recent study based on 74 million deaths between 1985 and 2012 in 13 countries around the globe estimates that $7.7 \%$ of mortality was attributable to temperature exposures (Gasparrini et al., 2015). The health cost of hazardous environments goes beyond mortality. Quasi-experimental evidence shows how exposure to air pollution leads to an increase in direct medical costs, such as increases in hospitalizations and pharmaceutical expenses by individuals (Schlenker and Walker, 2016; Deschênes, Olivier, Greenstone, Michael, \& Guryan, 2017).

The health effects of air pollution have been the scope of the analysis of numerous studies over the past decades. A wealth of evidence suggests exposure to air pollution has detrimental consequences for human health, even at moderate levels. The inhalation of ozone or particulate matter has been associated with mortality and hospital admissions due to cardiopulmonary

\footnotetext{
${ }^{5}$ See Roth (2018) for a similar setting studying the effect of indoor air quality on exam scores outcomes of UK university students.
} 
health problems (Brunekreef and Holgate, 2002). The respiratory system is the primary target of air pollutants. Epidemiological studies document associations between the presence of air pollutants and respiratory health morbidity, such as exacerbation of asthma or declines in lung function (for a review, see Rückerl et al., 2011). Cardiovascular systems are also vulnerable to airborne particles. For instance, exposure to high levels of ultra fine particles has been associated with the advent of ischemic heart disease or elevated blood pressure (Pope et al., 2004, Bhatnagar, 2006).

In addition, evidence on the mortality and morbidity attributable to hot and cold temperatures is increasing. The damaging effects of extreme temperatures generate important burdens for the cardiovascular and respiratory health systems. Epidemiological studies document significant links between temperatures and cardiovascular diseases such as atherosclerosis or pulmonary heart disease (Xiaofang et al. 2012). Global estimates indicate the existence of a significant burden of temperature on human health. Gasparrini et al. (2015) estimate the exposure to warm and (specially) cold temperatures is responsible for $7.71 \%$ of the total $74,225,200$ deaths considered in the study. Although these estimates are mainly driven by exposure to sustained exposure to cold or warm temperatures, a recent wave of studies document substantial peaks in mortality associated with the advent of extremely warm and cold days (Barreca et al., 2016, Deschênes and Greenstone, 2011; Deschenes and Moretti, 2009).

Children and older adults tend to be the most vulnerable to air pollution or extreme temperatures. However, these hazards also have important implications for the working population: the economic literature has documented significant drops in the labor supply associated with both, temperatures and air pollution. The exposure to adverse environmental conditions has detrimental effects on the total time that workers supply. Hanna and Oliva (2015) shows, following the closure of a large refinery in Mexico City, an increase of 1.3 worker hours per week in the area surrounding the refinery. Similarly, (Aragón et al., 2017) document the negative impact of moderate increases in fine particles (PM2.5) on hours worked by people in Lima. Similarly, evidence from the US shows extremely warm days lead to a reduction in working hours, specially in industries with high exposure to outdoor climate conditions, such as the construction or forestry industry (Graff Zivin and Neidell, 2014). The authors find that on days with maximum temperatures above $30^{\circ} \mathrm{C}$, workers in these industries reduce the time allocated to labor by one hour.

\subsubsection{Environment And Cognition}

Increasing evidence supports the hypothesis that environmental factors affect the human brain and cognition. The health science literature has provided convincing evidence on the detrimental links between poor air quality or thermal conditions and brain health and cognition. The eco- 
nomics literature suggest the cognitive impairment linked to these factors ultimately hampers academic achievement and human-capital formation.

A growing body of evidence in the area of epidemiology and toxicology suggests exposure to air pollution can harm the brain and hinder cognition via different channels. The inhalation of particles smaller than 200 nanometers can reach the brain, causing inflammatory reactions and ultimately impairing cognition (Underwood, 2017, Kumar, 2018). In adults, exposure to air pollution has been associated with depression, mood disorders, and ischemic strokes due to artery atherosclerosis or small vessel occlusion (Calderon-Garciduenas et al., 2015). Epidemiological studies have related long-term exposure to air pollution to the risk of dementia and cognitive decline in adult populations (Power et al. 2016$)$. Finally, exposure to air pollutants such as carbon monoxide have been associated with a drop in the capacity of hemoglobin to transport oxygen, reducing oxygen availability to the brain and hindering concentration (Bernstein et al. 2004 ).

The consequences of pollution on cognition might be substantial even in the short term. Evidence from high-stake examinations in Israel shows the same student performs worse when the ambient levels of PM2.5 are higher during the exam day (Ebenstein et al., 2016). This finding is consistent with recent evidence linking the level of indoor PM10 to test scores of thousands of university students across multiple subjects in London. (Roth, 2018). Roth explores withinstudent variation in test performance under different levels of fine particles in the classrooms. The author finds significant substantial drops in grades when individuals take the exam in high-pollution days. The damaging effects of air pollution on human cognition seem to intensify with age. Zhang, Xin, Xi Chen and Zhang (2018) explore the effect of PM2.5 on survey-based test scores in verbal and numerical cognitive tasks in a representative sample of the Chinese population. The authors find the negative effects of pollution become more pronounced with age (specially for men).

Indoors, the main indicator used in the literature to measure the air quality in a room is the level of carbon dioxide $(\mathrm{CO} 2)$. Humans are the main source of $\mathrm{CO} 2$, which is produced when breathing. The levels of $\mathrm{CO} 2$ in a room are mainly determined by the number of occupants and the ventilation rate in the room (rate at which the indoor air is exchanged with outdoor air). The inhalation of high levels of CO2 has been linked to fysiological and physiological symptoms such as dizziness, headache, or fatigue (Stankovic et al., 2016). Experimental evidence from the lab shows exposure to moderate levels of $\mathrm{CO} 2$ impairs cognitive functioning of humans. In these studies, a group of individuals are asked to stay in a room where the levels of $\mathrm{CO} 2$ have been artificially manipulated for several hours, and undertake a series of cognitive tests. The results of the studies indicate that even at moderate levels of CO2 (e.g. 1,500 ppm), individuals performed significantly worse in cognitive tasks (Satish et al., 2012, Allen et al., 2016). In both studies, the 
experimentally induced high levels of $\mathrm{CO} 2$ in the room mainly affect the cognitive domain of strategic thinking. A quasi-experimental study exploring the impact of a renovation program of ventilation systems in a sample of 65 US school buildings documents significant improvements in standardized test scores and passing rates (Stafford, 2015).

Finally, the literature also provides strong evidence on how exposure to extreme temperatures impairs cognitive function of humans. Recent experimental evidence based on functional magnetic resonance imaging (fMRI) shows alterations of brain blood flow upon exposure to heat stress (Liu et al. 2013). These alterations tend to impair individuals' ability to undertake complex tasks. In addition, the authors test a series of behavioral measures and find that high temperatures $\left(50^{\circ} \mathrm{C}\right)$ impairs the executive function of individuals, but not the alerting and orienting functions. The results from a meta-analysis of the literature suggests heat stress affects only complex (cognitive) tasks, such as working-memory tasks, sustained attention, or tracking (Taylor et al., 2015). On the other hand, the cognitive studies in the area tend to show no significant effects of heat stress on simple cognitive tasks, such simple arithmetic tasks. Finally, a recent observational study using a series of cognitive tests suggest the reaction time of individuals increases with exposure to high temperatures. Cedeño Laurent et al. (2018) show that during a heat wave, participants that lived in air-conditioned houses have a $13 \%$ lower reaction time than their peers living in houses without air conditioning.

The impact of heat stress on cognition also translates into a reduction in test scores. Graff Zivin et al. (2018) analyze the effect of weather on cognitive performance of children using cognitive-assessment data from the National Longitudinal Survey of Youth. The authors find that daily changes in temperatures lead to substantial decreases in cognitive performance on math beyond 26 degrees Celsius, taking 21 degrees Celsius as the reference point. Given the voluntary character of the tests used as outcome in the study, the reduction in test scores is not purely the result of reduced cognitive performance, but a combination of a drop in cognitive abilities of participants and effort. Park (2018) links the scores of high-stake examinations in NYC to the ambient temperatures on the test day. Using the within student variation in exam temperatures across tests, Park finds that hot temperatures during exams results in reduced exam scores. Also, that this transitory shock in temperatures has long-term consequences, as reflected by the significant reduction in the likelihood of passing a subject at the end of the academic year. Recent evidence from a large sample of US exam scores shows high temperatures have been also associated with an impairment of learning (Goodman et al., 2018).

Cognitive ability has been considered an important factor in understanding how people perform and learn in strategic decision-making (for a review, see Rustichini, 2015). In a sample of 1,000 trainees, Burks et al. (2009) find that cognitive skills are a good predictor of strategic behavior. In particular, the authors find that individuals with high cognitive skills have signif- 
icantly more accurate predictions of the behavior of the participants in a Prisioner's Dilemma game. In their seminal work, Gill and Prowse (2016) test in a large experiment whether cognitive ability influences individuals' ability to play a Nash equilibrium in a repeated game. The authors find that the individuals with higher cognitive skills perform better at the strategic game. In particular, in a p beauty contest game, more cognitively able participants choose strategies closer to the Nash equilibrium and learned faster than less cognitively able individuals.

\subsubsection{Environment And Worker Performance}

The harming effects of extreme weather conditions and pollution on labor supply go beyond drops in total working hours. Evidence from the manufacturing sector shows significant drops in the productivity of factories in periods with high pollution or high temperatures (Zhang, Xin, Xi Chen and Zhang, 2018, Fu et al., 2017). Similarly, a recent series of studies using daily productivity measures provides additional evidence on the harming effects of environmental conditions on workers' ability to exert high productivity levels. The studies focusing on manual routine occupations, such as agriculture workers or pear packers, show a reduction in performance of workers when exposed to high levels of pollution (Graff Zivin and Neidell, 2012; Chang et al. 2016). These drops in productivity are also present in highly skilled, highly trained workers physical workers. Lichter et al. (2017) analyze the changes in the performance of professional soccer players associated with pollution in a sample of German first-league matches. The results show that variations in pollution across matches lead to changes in performance in soccer players. In particular, the number of passes per game that each player executes is reduced when the match takes place on a high-pollution day.

Physically demanding occupations are rely considerably on the respiratory and cardiovascular health of workers, which are heavily impaired by pollution and temperature. However, the results from a new series of studies suggest the productivity of office workers is not exempt from these hazards. Chang et al. (2016) explore how air pollution affects daily worker productivity of two call centers in China. The results indicate the number of daily calls handled by a worker decreases linearly with the level of local air pollution. The drops in daily productivity are not driven by the ability of the employees to handle the calls, but from an increase in the amount of time spent on breaks. Similarly, Meyer and Pagel (2017) link the daily trading activity of 103,000 private investors in Germany to contemporaneous levels of air pollution. The authors find that when investors are working on high-pollution days, they sit down less at their workplace, log in less often, and trade less in their brokerage accounts. Finally, a recent study examines the exposure to pollution and extreme temperatures of 135,924 judges in 9.7 million criminal and civil cases $($ Kahn and Li, 2019). The authors show that exposure to high-pollution days leads to an increase in their total decision deliberation time period per case. 
The evidence exploring the impact of extreme temperatures on worker performance relies mainly on call centers and lab studies where participants are asked to undertake several simulated office tasks (e.g., text processing). In a meta-review of the empirical literature, Seppänen et al. (2006); Seppänen and Fisk (2004) find the performance of participants tend to follow an inverted U-shape curve with the maximum at 21-24 degrees Celsius. Based on the meta-analysis of the studies, the authors estimate a $8.90 \%$ drop in individual performance associated with exposures to temperatures beyond 30 degrees Celsius The current evidence on how (indoor) environmental conditions (e.g., CO2 or temperature) affect the productivity of adult office workers is generally based on simulated office tasks that might well differ from real office settings. Individuals might undertake a series of behavioral responses (e.g., turn on a fan) to reduce the disutility produced by exerting high effort in high-temperature or highly polluted environments (Heal and Park, 2016). One of the likely reactions to adverse environments is the reduction of effort. As described above, evidence suggests a reduction in working hours or an increase in the time taken for breaks during the working days associated with pollution. Against this background, the estimates of the harming effects of extreme temperatures or poor air quality on performance from the lab studies where participants are not compensated by outcomes (but just by participating in the experiment) are likely to be a combination of a drop in pure cognitive performance and effort.

In sum, an increasing number of quasi-experimental studies provide evidence on the harming effects of pollution or temperature on worker productivity. Most of the current evidence relies on samples of manual routine jobs, such as agricultural or manufacturing workers. These occupations are usually physically demanding and therefore rely more heavily on the cardiovascular and respiratory systems than the tasks undertaken by office workers. The existing evidence on workers' productivity in cognitive professions uses piece rates or uptime as outcome variables (e.g., number of units produced or frequency and duration of times logged into a work station), but it is silent about the quality (or value) of the tasks undertaken by the subjects. The lab studies in the field complement the current field studies by looking at office-simulated tasks. However, the lack of incentives of participants makes differentiating between how much of the drop in performance comes from the drop in the ability of individuals to execute the task and how much from the drop in the effort in executing the task difficult.

This study deviates from the existing studies by exploring the effect of environmental conditions on cognitively demanding tasks in a setting where performance is remunerated, and thus the participants have clear incentives to exert high effort. In addition, this study is the first to investigate the impact on the quality of the produced outcome (cognitive performance) and not workers' availability to execute the task. 


\subsection{Chess Tournaments: Background And Data}

In this paper, we use data from chess tournaments to study the impact of indoor environmental conditions on cognitive performance. Chess is a two-player strategic board game in which players alternately make moves with pieces on the chess board ${ }^{6}$ A player wins the game if (i) the player checkmates the opponent's king, (ii) the opponent resigns, or (iii) - in a game with time restrictions - the player runs out of time. In addition, the players can agree upon a draw at any time during the game.

Chess is a very complex, strategic, and computational activity, and has been heavily deployed by cognitive psychologists for investigating different strategic and cognitive aspects of human thinking, such as perception, memory, and problem solving (e.g. Charness, 1992). Burgoyne et al. (2016) provide empirical proof for the relationship between chess skills and general cognitive skills such as fluid reasoning, comprehension knowledge, short-term memory, and processing speed. In recent years, economists started using chess to analyze human behavior due its computational nature and the cognitive power of chess players (see, e.g., Palacios-Huerta and Volij, 2009: Gerdes and Gränsmark, 2010, Levitt et al., 2011, Backhus et al., 2016).

The data used in this paper come from two amateur chess tournaments in Germany. We received access to data on players' characteristics as well as the list of all moves of each individual tournament game. Throughout the tournaments, we measured indoor environmental conditions at the venue.

\subsubsection{Tournament Setup And Chess Rating Score}

The tournaments were organized by an amateur chess club in a major city in West Germany in May-June 2017 and April-May 2018 as the club's main event of the year 7 Each tournament comprises seven rounds over an eight-week period with each round taking place on a Monday night starting at 6:00pm local time and lasting until the last game is over 8 Figure 5.9 in the Appendix illustrates the timing of the tournaments. Registration for the tournament was open to any amateur chess player on a first-come, first-served basis conditional on paying the participation fee of 30 euros. The total number of participants was limited to about 80 players per tournament 9 The tournament format follows the "Swiss system," a non-eliminating tournament format commonly applied in chess competitions. In each round, players gain one point for a win,

\footnotetext{
${ }^{6}$ For details on the game of chess see the chess handbook as provided by the World Chess Federation (FIDE): https://www.fide.com/fide/handbook.html?id=171view=article

'Further activities are participation in regional championship competitions, smaller-scale internal tournaments and regular training meetings.

${ }^{8}$ The weekly tournament rounds were paused for one week due to the public holidays Whit Monday (in 2017) and Easter Monday (in 2018).

${ }^{9}$ Most participants are from the same city or from the surrounding region.
} 
0.5 for a draw, and zero for a defeat. The winner of the tournament is the player with the highest aggregate points earned in all rounds. The assignment of fixtures is based on players' pre-tournament chess rating scores indicating their strength as well as their performance during the tournament 10

In general, chess rating scores are calculated based on the performance in games against other players. Winning (losing) a game results in an improvement (a decline) in the rating score, whereby the change in the rating score is larger in absolute terms for "unexpected" outcomes, for example, when a player with a much higher score than the opponent loses the game. The rating score applied for the assignment of fixtures in the tournaments is the German chess federation's rating score $D W Z$ (Deutsche Wertungszahl) ${ }^{11}$ This score is equivalent to the international Elo rating system as used by the world chess federation FIDE, also for assigning titles like "International Master" or "Grandmaster." We use the internationally acknowledged term Elo rating score instead of $D W Z$ in the remainder of the paper.

After each tournament in our sample, all game outcomes are submitted to the chess federation for a recalculation of players' rating scores based on their results ${ }^{12}$ Hence, all players participating in the tournaments have an incentive to perform well throughout all tournament rounds in order to improve their rating score, which is a matter of prestige among chess players and which determines fixtures in future competitions. In addition, pecuniary incentives are offered. The winner of the tournament receives a cash prize of 400 euros. The participants ranked 2nd to 4 th receive prizes of 300,150 , and 100 euros respectively, and extra prizes are awarded for the best-ranked players among the youth, the senior, and the female players (70 euros each), as well as for the best team (60 euros).

\footnotetext{
${ }^{10}$ Before the first round, all players are ranked based on their rating score. The ranking is then divided into the upper and lower half of the score distribution. In the first round, the highest-ranked player of the upper half (i.e., the player with the highest score overall) plays against the highest-ranked player of the bottom half (i.e., the player just below the median score) and so on. After round one, fixtures are assigned in the same way, but separately among the groups of players equal on points earned during the tournament. This implies that, by construction, the difference in rating scores between opponents is relatively high in the first round and typically becomes smaller in subsequent rounds because players with a higher score are more likely to win, especially when the difference is large.

${ }^{11}$ The $D W Z$ rating system works as follows: Chess player $i$ is assigned a cardinal rating score $Z_{i, g}$ reflecting the player's strength before game $g$ against opponent $j$. The outcome of game $g$ determines the change in the score between games $g$ and $g+1$ according to the following formula: $Z_{i, g+1}=Z_{i, g}+\alpha_{i, g}\left[y_{i, g}-E\left(y_{i, g} \mid \Delta Z_{i j, g}\right)\right]$, where the actual outcome for player $i$ in game $g$ is $y_{i, g} \in\{1,0.5,0\}$ for win, draw, or defeat, ereas the expected outcome is defined as $E\left(y_{i, g} \mid \Delta Z_{i j, g}\right)=\frac{1}{1+10^{\left(-\Delta Z_{i j, g} / 400\right)}}$ based on the difference between players' scores, $\Delta Z_{i j, g}=Z_{i, g}-Z_{j, g}$, as well as a factor $\alpha_{i, g}$ depending on player $i$ 's score level, experience, and age. See https://www.schachbund. de/dwz.html for details.

${ }^{i 2}$ The club has to pay a fee for the recalculation of participating players' scores, which is less expensive for the German $D W Z$ score than for the international Elo score, which is why the organizers decided to "only" apply the $D W Z$ score
} 


\subsubsection{Move-Performance Measures}

We measure the performance of players in each tournament round based on the quality of players' moves within the game. A chess game $g$ comprises $M_{g}$ moves, with two plies per move $m \in\left\{1, \ldots, M_{g}\right\}$, where the player with the white pieces moves first. For any given stage of the game, the relative (dis)advantage for each player is evaluated by the so-called pawn metric $C_{g m}$ based on the remaining pieces and their position on the board. Although it plays no formal role in the game, the pawn metric is useful to players and is essential to evaluate positions in chess software ${ }^{13}$ The sign of this metric indicates which player is in the better position (i.e., is more likely to win the game) with $C_{g m}>0\left(C_{g m}<0\right)$, indicating advantage for white (black). For example, a pawn metric of -1 is interpreted as the player with the black pieces having an advantage equivalent to one extra pawn on the board relative to the opponent.

For each tournament game, we have information on the evolution of the game based on players' hand-written notation (see Figure 5.10 in the appendix for an example), which has been digitized by the tournament organizers ${ }^{14}$ We use the chess engine Stockfish to assess the quality of each move in the tournaments ${ }^{15}$ In theory, for each move, a particular move option optimizes the pawn metric given the situation on the chess board. Figuring out the best possible move is essentially a computational task for the human player. Therefore, we compare the pawn metric resulting from player $i$ 's actual move $m$ in game $g$ with the metric that would result from the computer's optimally suggested move. The pawn-metric difference between the human player and the computer can be viewed as an error:

$$
\text { Error }_{i g m}=\left|C_{\text {igm }}^{\text {computer }}-C_{\text {igm }}^{\text {player }}\right|
$$

In the empirical analysis, we look at player-move specific errors as an outcome variable that may be affected by disadvantageous environmental conditions to which the players are exposed. We remove the first 14 moves of each game, which can be assumed to represent the opening game for which players usually have an established plan and are hence less affected by environmental conditions (Backhus et al. 2016). Furthermore, Expression (5.1) can take negative values when, at a given point in the game, the player makes a move that is evaluated to be better than the one proposed by the computer. This is a very rare event and because we are mainly interested

\footnotetext{
${ }^{13}$ The metric values the remaining pieces on the board relative to a pawn, determining how valuable a piece is strategically. For example, knights and bishops are typically valued three times a pawn while the queen is valued at nine times a pawn. In addition, the value of a piece on the board differs depending on its position. See https://chess.fandom.com/wiki/Centipawn for details.

${ }^{14}$ Both players are obliged to document the evolution of moves and have to hand in the hand-written notation to the tournament organizer immediately after the game is completed. This notation is then submitted to the chess federation for the recalculation of players' rating scores.

${ }^{15}$ In fact, we use the chess engine Stockfish 9 64-bits with a current Elo rating score of 3548 (http://ccrl. chessdom.com/ccrl/404/). The highest Elo rating score by a human is 2882, achieved in 2014 by the current chess world champion Magnus Carlsen.
} 
in the errors associated with the environmental conditions, and therefore the positive side of the error distribution, we redefine negative cases as zero ( $0.7 \%$ of the sample). Panel A in Figure 5.1 displays the relationship between the average error per player and her ELO rating score, showing a clear negative relationship between the two. A statistically significant and negative correlation also exists between a player's $E L O$ rating score and her mean error $(\rho=-0.54, p-$ value $=0.00)$.

Figure 5.1: Player skills and average move performance

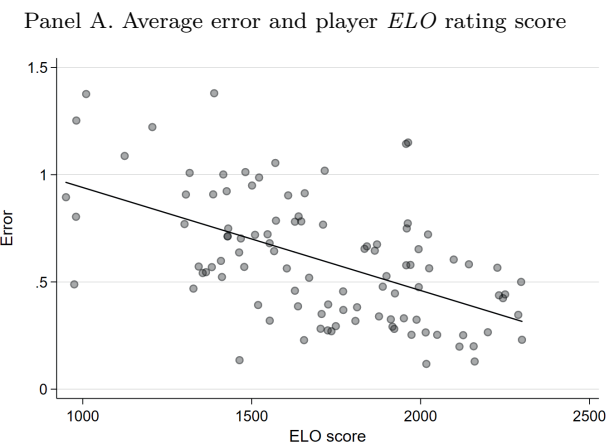

Panel B. Average number of meaningful errors and player ELO rating score

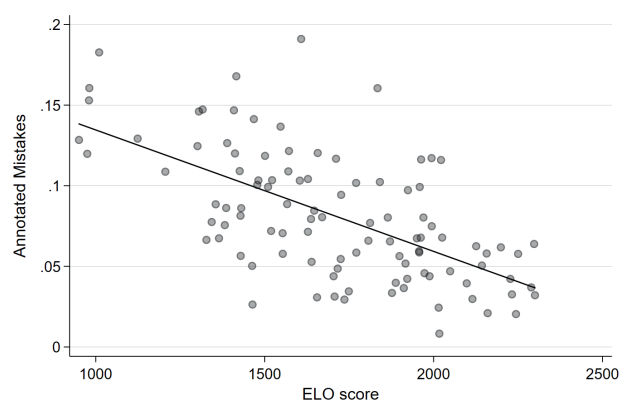

Note: Each dot in the figures represents a player, the figures display the average error of a player (Panel A) or the average number of annotated errors (Panel B) in the vertical axis, and the average ELO rating score of the player over the two tournaments in the sample in the horizontal axis. The error measure is defined in equation 5.1 The annotated errors are defined as the sum of moves labeled as mistakes and blunders. The Pearson correlation between the error measure [annotated error] and the ELO rating score is $-0.54(\mathrm{p}$-value $=0.00) \quad[-0.62(\mathrm{p}$-value $=0.00)]$. The correlation between the player average of the two move-performance measures is $0.72(\mathrm{p}$-value $=0.00)$.

In addition to the continuous error measure, we explore the probability of an individual making a meaningful error based on the annotations of the chess engine. This is particularly important because not every positive error has a significant meaning for the game. For instance, some errors are minor without real consequences for the remainder of the game, or sometimes players create positive errors on purpose when they follow a risky strategy or try to force errors in the opponent. Chess engines are able to classify a certain move as a "meaningful error" based on the status of the game, the skill of the player, and the magnitude of the Error ${ }_{i g m}$. In particular, 
chess engines annotate a move $m$ as "meaningful error" if the engine considers move $m$ to be poor and should not be played weakening the chances of the player to consolidate her position or win the game. Given her skill level (ELO rating score), the player should be able to realize the move should not be played. The chess engine annotates two types of meaningful errors: (1) strategic mistakes and (2) tactical mistakes or blunders. The annotation of a move considered a strategic mistake describes a move that results in a loss of tempo or material for the player. These errors are considered strategic and not tactical. Blunders are severe errors that overlook a tactic from the opponent and usually result in an immediate loss in position, with a substantial drop in the chances of the player winning or drawing the game. The chess engine detects and annotates these errors. Panel B in Figure 5.1 displays the relationship between the average number of moves annotated as errors per player and the player's ELO rating score, showing a clear negative relationship between the two. The correlation between the average number of annotated meaningful errors per player (the sum of strategic mistakes and blunders) and her $E L O$ rating score is $-0.62(\mathrm{p}$-value $=0.00)$.

\subsubsection{Time Control}

In each game, players face a time constraint (time control): Each player is allotted 90 minutes for the first 40 moves plus 30 seconds per completed move, resulting in a total time budget of 110 minutes for the first 40 moves. The time limit is allotted to each player individually and enforced by chess clocks. In each round, the tournament organizer announces the start for all games taking place in the same venue at the same time. If a player does not complete 40 moves within the time limit, he loses the game.

This measure gives each player a time budget to allocate to each move in the game, implying players are likely be under time pressure when they approach the 40th move and the time budget is reaching zero. To prevent losing the game altogether, a player then has to make move decisions more quickly, potentially within seconds, which makes them more prone to making lower-quality moves. Figure 5.2 shows the distribution of the total number of moves for all the games in our sample. The histogram shows peaks in the number of games finished around the move constraint (40 moves), suggesting that the imposed time constraint is binding, increasing the probability of ending a game right after the 40th move.

In the empirical analysis, we exploit this feature of the tournament set-up to test whether the indoor environmental conditions during a game increases the effect of air quality or temperature on the probability of making errors when approaching the last move of the time control (move 40). 
Figure 5.2: Distribution of total number of moves per game

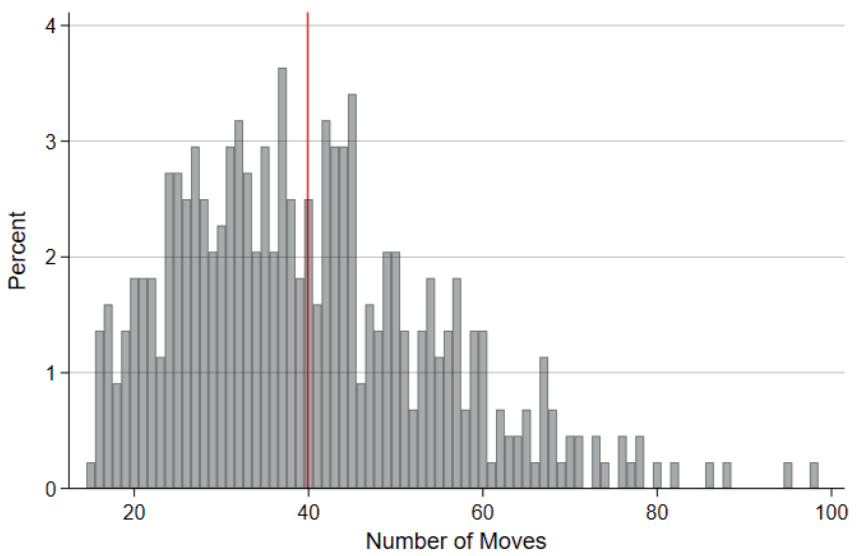

\subsubsection{Measurement of Indoor Environmental Conditions}

During both editions of the tournament, the organizers granted us permission to measure indoor environmental conditions throughout all tournament rounds inside the venue, a large church community hall in a residential area. The sensors were installed before the start of each tournament round and removed after the last game was finished. The players were informed that the measurement was being undertaken for scientific purposes. However, the players were not informed about the exact purpose of the study, namely, studying the effect of indoor environmental conditions on chess players' performance 116

Our measures of air quality (carbon dioxide, $\mathrm{CO} 2$, and fine particulate matter, PM2.5) and temperature were gathered from three real-time web-connected sensors located inside the tournament venue (see Figure 5.11 in the appendix for an example) ${ }^{17}$ The sensors measure the parameters of interest every minute and upload the measurements to a cloud server where the researchers can access the data in real time.

Figure 5.3 shows the distribution of the three parameters of interest over the seven rounds across the two editions of the tournament (2017 and 2018). The levels of CO2 range between 1,000 and over 2,250 ppm. These levels are above critical thresholds presented in the literature as detrimental for human cognition, for example, 1,000 or 1,500 ppm (Allen et al., 2016). The temperature levels during the tournament are between 22 and 29 degrees Celsius. Although these temperature levels are moderate, they are far from the temperature levels the literature considers as optimal for performance, namely, 21-24 degrees Celsius (Seppänen et al., 2006).

\footnotetext{
${ }^{16}$ Just before the start of the first rounds, the main organizer of the tournaments informed all players about the presence of the sensors and that they should not be touched. In addition, we put signs next to each sensor explaining that the device was measuring indoor environmental conditions and should not be moved.

${ }^{17}$ We used two Foobot sensors and one Netatmo indoor sensor.
} 
Finally, the average level in our sample for PM2.5 is $25.9 \mu \mathrm{g} / \mathrm{m}^{3}$, similar to the European target of $25 \mu \mathrm{g} / \mathrm{m}^{3}$ set by the European Environmental Agency (EEA, 2018).

Figure 5.3: Indoor environmental conditions as measured on the days at the tournaments
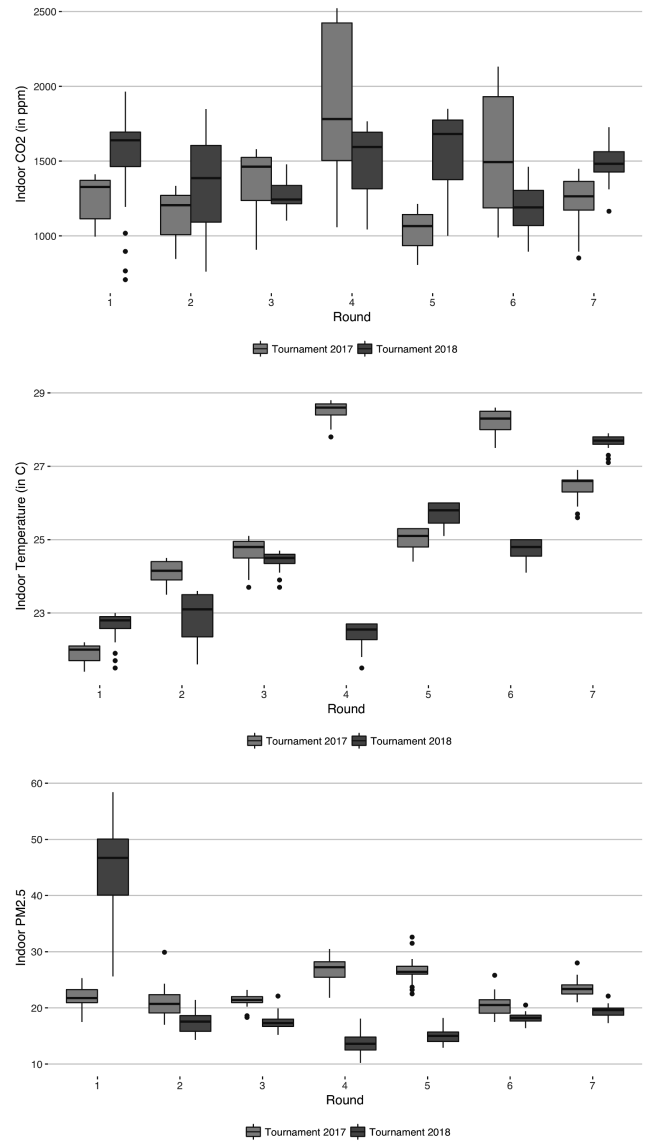

Note: The figures show the distribution of $\mathrm{CO} 2$ concentration, temperature, and fine particulate matters (PM2.5) as measured during the days (rounds) at the chess tournaments.

Note that important differences exists in the measurements of these parameters for the same rounds between the two years. In addition, no clear trend appears in the changes of the parameters between the years, but the changes in temperature or air quality between years are seemingly random. These differences are crucial for our estimation strategy, based on withinplayer and round variation of errors.

\subsubsection{Descriptive Statistics}

Our data follow 102 players over a maximum of 14 matches. A total of 44 players participate in the two editions of the tournament. Table 5.1 shows summary statistics for player skills and 
demographic characteristics of the participants. Our sample is mainly composed of adult men who were, on average 54 years old, with a wide range of levels of expertise. The least experienced player has only two official matches in her records and the most experienced player played 273 matches. The players also differ in their skills levels, according to the Elo rating score attached to their records. The Elo rating score of the most skilled player was more than twice as large as the Elo rating score of the least skilled player. In addition, Figure 5.4 shows the entire distribution of the Elo rating score of the players in the observed tournaments, and compares the scores with the official ranks within the chess association FIDE. As the figure shows, we observe a wide range of skill levels ranging from beginners (novices) to advanced players (FIDE masters). In addition, the figure shows the Elo score of the chess engine Stockfish clearly dominating any human player.

Focusing on the game-specific characteristics (Panel B in Table 5.1), we can see that games in our sample last around three hours on average. This length is similar to the average exposure time in epidemiological studies exploring the effect of $\mathrm{CO} 2$ or temperature on cognition (e.g. Satish et al. 2012). In our study, the average game duration is sufficiently long to expect the exposure time of participants is sufficient to uncover an effect of the environmental conditions on their cognitive abilities. The average length of the games in our sample is around the 40-moves threshold (see Figure 5.2 for the full distribution of moves). About $20 \%$ of games finished in a draw.

Figure 5.4: Distribution of players' Elo rating score

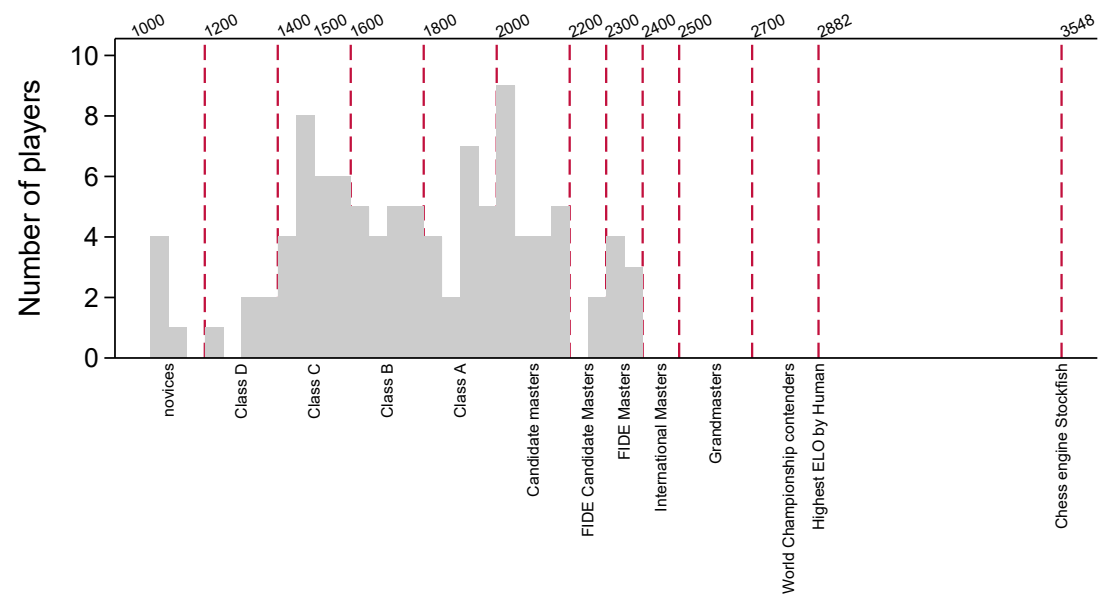

ELO score

Note: The players' Elo score is calculated by adding 100 to the players' DWZ score in order to make the scores comparable to the FIDE system. 
Table 5.1: Descriptive statistics

\begin{tabular}{|c|c|c|c|c|c|}
\hline & $\begin{array}{l}\mathrm{N} \\
(1)\end{array}$ & $\begin{array}{c}\text { mean } \\
(2)\end{array}$ & $\begin{array}{l}\text { sd } \\
(3)\end{array}$ & $\begin{array}{l}\min \\
(4)\end{array}$ & $\begin{array}{c}\max \\
(5)\end{array}$ \\
\hline \multicolumn{6}{|l|}{ A. Player characteristics } \\
\hline$E L O$ rating score & 102 & 1,681 & 329.1 & 950.3 & 2,289 \\
\hline Number of official matches played & 101 & 80.83 & 64.12 & 2 & 273 \\
\hline Age (in years) & 102 & 53.71 & 16.63 & 18 & 89 \\
\hline Female & 102 & 0.0386 & 0.192 & 0 & 1 \\
\hline \multicolumn{6}{|l|}{ B. Game-specific characteristics } \\
\hline Total number of moves & 418 & 38.94 & 14.70 & 15 & 98 \\
\hline Total duration (in minutes) & 413 & 171.50 & 54.62 & 43 & 310 \\
\hline Draw game & 418 & 0.20 & & & \\
\hline \multicolumn{6}{|l|}{ Player-opponent difference in } \\
\hline$E L O$ rating score & 418 & 3.51 & 357.60 & $-1,265$ & 814 \\
\hline Experience (in \#games) & 398 & 67.24 & 53.36 & 0 & 271 \\
\hline Age (in years) & 418 & 18.13 & 14.24 & 0 & 66 \\
\hline \multicolumn{6}{|l|}{ C. Move-specific characteristics } \\
\hline Meaningful error & 20,408 & 0.08 & & & \\
\hline Error if $>0$ & 8,600 & 1.43 & 4.61 & 0.01 & 59.22 \\
\hline \multicolumn{6}{|c|}{ D. Environmental measures (round level) ${ }^{a}$ ) } \\
\hline CO2 (in ppm) & 14 & 1,549 & 326.60 & 1,179 & 2,393 \\
\hline Temperature (in C ) & 14 & 25.17 & 2.12 & 22.10 & 28.75 \\
\hline PM2.5 (in $\mu g / m 3)$ & 14 & 22.38 & 9.15 & 14.03 & 51.05 \\
\hline
\end{tabular}

a) Environmental measures are mean values of the prevailing conditions as measured during second hour of the tournament round.

Finally, the distribution of our outcome measures is shown in Panel C of Table 5.1. A total of $8 \%$ of the moves are annotated as meaningful errors. Moreover, $42 \%$ of the moves are considered suboptimal (positive error), with an average error rate of 1.43 pawns. Panel D in Table 5.1 shows the distribution of the indoor-environmental-quality variables within the estimation sample.

\subsection{Empirical Model}

Our goal is to estimate the effect of environmental conditions on the quality of the decisions undertaken by chess players. Our study setting has a number of features that allow us to identify the effect of environmental stressors on cognitive performance. First, players are executing the 
same (cognitive) tasks repeatedly in the same venue, the same day of the week, and at the same time of the day. In addition, the selection of opponents for each of the games is exogenously determined by the tournament organizer, following official rules in chess. Thus, participants have no control over the environmental conditions that they are exposed to during their games nor the opponents they play in a given round.

Second, we have objective measures of individual cognitive performance. In particular, we are able to evaluate each move in our sample of games. The chess engine is able to detect meaningful errors in the moves undertaken by the players. In addition, we build a continuous measure of the magnitude of the error by comparing the advantage reached with the actual move of the player with the maximum (pawn) advantage that a player could reach if she would undertake the best possible move (see equation 5.1). The evaluation of the move quality is specific to the player's move and is not influenced in any way by the opponent.

Third, the high frequency of our outcome measures allows for the decomposition of the impact of environmental measures over different stages of the game. In particular, it allows us to test for differences in the magnitude of the impact as the time budget of players disappears over the course of the game.

Finally, all players in our sample face strong incentives to exert high effort and make optimal decisions, because the performance in each game of the tournaments counts for their chess rating score. Therefore, the incentive structure in our setting deviates from the structure in non-incentivized lab experiments or survey-based studies in which participants' payoffs are not determined by their performance in the proposed tasks. By contrast, our participants are highly motivated to perform to the best of their abilities.

We follow a fixed-effect strategy and estimate the following linear probability model:

$$
Y_{i j t r m}=\alpha+\delta I E Q_{t r}+\beta X_{i j t}+\eta_{i}+\gamma_{t}+\lambda_{r}+\theta_{m}+V_{i j t r m}
$$

where $Y_{i j t r m}$ is the outcome variable measured in a game between player $i$ and opponent $j$ at move $m$, round $r$, and year $t$. We consider two main outcome variables to capture the frequency and the magnitude of errors, namely, MeaningfulError ${ }_{i j t r m}$ and $\ln \left(\right.$ Error $\left._{i j t r m}\right)$. Meaning fulError $_{i j t r m}$ is defined as a binary variable taking the value of 1 if move $m$, in round $r$, in year $t$, undertaken by player $i$ against opponent $j$ is annotated as a meaningful error. We consider meaningful errors those moves annotated by the chess engine as strategic mistakes and blunders. We focus on annotated errors, instead of using the Prob(error $>0)$, because not every positive error has a significant meaning for the game (see section 5.2 .2 for details). $\ln$ (Error $_{i j t r m}$ ) describes the natural magnitude of the error for individual $i$, playing against opponent $j$ in year $t$, round $r$ and move $m$, describing the difference in the pawn metric between the computer's proposal and the player's move (see equation 5.1 for a detailed description of the variable). 
We include a set of time-varying controls, (i) describing the differences in skills between opponents in a given game, (ii) the points earned over the tournament by the player, and (iii) the initial advantage of the player before executing the move, pawn metric $C_{i g m-1}^{\text {player }}$. We describe the differences in skills between the opponents with the variable EloDiff $f_{i j t}$ that denotes the player-opponent difference in terms of the $E L O$ rating score to control for initial performance differences among the two players, measured at the beginning of the tournament. We include the level variable EloDiff $f_{i j t}$ as well as its squared term. $\eta_{i}, \gamma_{t}, \lambda_{r}$, and $\theta_{m}$ are individual, year, round and move fixed effects, respectively.

$I E Q_{t r}$ includes three available indoor environmental measures: (i) $\mathrm{CO} 2$ concentration, (ii) temperature, and (iii) fine particulate matter (PM2.5). All measures are included as the mean value of the prevailing conditions as measured during the second hour of the tournament rounds $(\mathrm{N}=14)$. Figure 5.12 in the Appendix shows the distribution of the measures during the tournaments rounds. Whereas temperature and PM2.5 are relatively stable during the tournament rounds, $\mathrm{CO} 2$ concentration varies with the number of people in the room, namely, increasing (decreasing) at the start (end) of the tournament. Therefore, we decided to take the mean within the second hour of the tournament (as indicated by the dashed lines in Figure 5.12 to avoid lower values at the beginning/end of the tournament polluting the measure ${ }^{18}$ Finally, the error term $V_{i j t r m}$ is clustered at the game level to allow for arbitrary correlation within the games in our sample.

The parameter of interest is denoted by $\delta$, which measures the impact of prevailing indoor environmental quality $I E Q_{t r}$ on the outcome variable. In such a setting, the main identifying assumption is that pollution, temperature, and $\mathrm{CO} 2$ are assigned as good as randomly after including the rich set of fixed effects. Thus, we identify the parameter of interest by observing identical individuals playing against different opponents under varying indoor environmental conditions across tournament editions (years) of the same round of the tournament.

\subsection{Results}

We present the results on the impact of environmental conditions on the performance of chess players in two stages: In a first step, the results based on the pooled sample are presented in section 5.4.1. where we estimate equation (5.2) using all moves in the games of the sample. In the second step, we split the sample into subsamples based on the status of a game, namely, the move number, in order to investigate effect heterogeneity with respect to time pressure. Players have a total of 110 minutes for the first 40 moves, inducing higher time pressure once they approach the 40th move than at the beginning of the match. The results for different moves

\footnotetext{
${ }^{18}$ The replacement of our main regressors by the daily maximum values of these parameters does not change the results in sign and magnitude; see section 5.5 .1
} 
levels are presented in section 5.4 .2 Finally, we analysis the effect heterogeneity with respect to individual characteristics in section 5.4.3, and provide a discussion of our findings in the context of previous findings in section 5.4.4.

\subsubsection{Pooled Estimation}

Table 5.2 presents the estimated coefficients $\hat{\delta}$ associated with environmental parameters in equation 5.2 using all moves in our sample. Panel A presents the estimation results using the probability of making a meaningful error as the outcome variable. Panel B shows the results for the magnitude of the error $(\ln ($ error $))$. The columns in each of the panels display the estimates for a different set of fixed effects, starting with no fixed effects, and then stepwise including individual, year, round, and move-number fixed effects. All regressions include all environmental variables together with the set of control variables.

With respect to the probability of making a meaningful error and focussing on the most conservative specification (5) including the full set of fixed effects, we find no evidence for an effect of temperature or the concentration of $\mathrm{CO} 2$ in the room. The results indicate only the level of PM2.5 affects the probability of making a meaningful error. The significance and magnitude of the estimate even increases with the inclusion of additional fixed effects. The results of our main specification (5) indicate a $10 \mu \mathrm{g} / \mathrm{m}^{3}$ increase in PM2.5 raises the probability of a player making a meaningful error by 1.5 percentage points in a given move of a game. This effect is equivalent to an $18.8 \%$ increase given the average probability of making a meaningful error in our sample of $8.0 \%$ (see Panel C in Table 5.1.

In Panel B in Table 5.2, we present the analysis of the magnitude of those errors. The results are similar to Panel A. Although we do not find any significant effects for CO2 and temperature, the results show a significant impact of fine particles (PM2.5) on the magnitude of the error. For our main specification (5), we find that a $10 \mu \mathrm{g} / \mathrm{m}^{3}$ increase in PM2.5 leads to a $9.4 \%$ increase in our error measure.

\subsubsection{Effect heterogeneity with Respect to Time Pressure}

The time-control regulations of the tournament rules induce time pressure, requiring players to make the first 40 moves within 110 minutes of the game; otherwise, they lose the game. In this section, we estimate equation 5.2 for four different subsamples of move intervals within games, namely, $15-20$ (24\% of the sample), 21-30 (34\%), 31-40 (22\%), and >40 moves (20\%). Decisions taken within the range of 31-40 moves can be assumed to be taken under relative time pressure, compared to the other categories given the low expected time left to execute the required 40 moves to stay in the game. In our sample, $44.4 \%$ percent of the games last more than 40 moves.

Figure 5.5 shows the estimated parameters with respect to the probability of making a 
Table 5.2: Impact of indoor environmental quality on performance of chess players
(1)
$(2)$
(3)
$(4)$
(5)

\begin{tabular}{|c|c|c|c|c|c|}
\hline CO2 (in 100 ppm) & $\begin{array}{c}0.000 \\
(0.001)\end{array}$ & $\begin{array}{l}0.003^{*} \\
(0.001)\end{array}$ & $\begin{array}{l}0.003^{* *} \\
(0.001)\end{array}$ & $\begin{array}{c}0.002 \\
(0.003)\end{array}$ & $\begin{array}{c}0.001 \\
(0.003)\end{array}$ \\
\hline Temperature & $\begin{array}{c}0.003 \\
(0.003)\end{array}$ & $\begin{array}{c}-0.006^{* *} \\
(0.003)\end{array}$ & $\begin{array}{c}-0.008^{* *} \\
(0.003)\end{array}$ & $\begin{array}{l}-0.006 \\
(0.005)\end{array}$ & $\begin{array}{l}-0.005 \\
(0.005)\end{array}$ \\
\hline PM2.5 (in $10 \mu g / m 3$ ) & $\begin{array}{c}0.004 \\
(0.005)\end{array}$ & $\begin{array}{c}0.011^{* *} \\
(0.004)\end{array}$ & $\begin{array}{l}0.011^{* *} \\
(0.004)\end{array}$ & $\begin{array}{c}0.013^{* * *} \\
(0.005)\end{array}$ & $\begin{array}{c}0.015^{* * *} \\
(0.005)\end{array}$ \\
\hline Observations & 20,408 & 20,408 & 20,408 & 20,408 & 20,408 \\
\hline Adj. R-squared & 0.009 & 0.018 & 0.018 & 0.019 & 0.037 \\
\hline \multicolumn{6}{|l|}{ Panel B: Ln(error) } \\
\hline CO2 (in 100 ppm) & $\begin{array}{l}-0.011 \\
(0.013)\end{array}$ & $\begin{array}{c}0.006 \\
(0.012)\end{array}$ & $\begin{array}{c}0.008 \\
(0.012)\end{array}$ & $\begin{array}{c}0.016 \\
(0.021)\end{array}$ & $\begin{array}{l}-0.001 \\
(0.022)\end{array}$ \\
\hline Temperature & $\begin{array}{l}0.045^{*} \\
(0.025)\end{array}$ & $\begin{array}{l}-0.015 \\
(0.024)\end{array}$ & $\begin{array}{l}-0.029 \\
(0.026)\end{array}$ & $\begin{array}{l}-0.043 \\
(0.041)\end{array}$ & $\begin{array}{l}-0.022 \\
(0.043)\end{array}$ \\
\hline PM2.5 (in $10 \mu g / m 3$ ) & $\begin{array}{c}0.011 \\
(0.044)\end{array}$ & $\begin{array}{c}0.051 \\
(0.036)\end{array}$ & $\begin{array}{c}0.054 \\
(0.036)\end{array}$ & $\begin{array}{l}0.073^{*} \\
(0.042)\end{array}$ & $\begin{array}{c}0.094^{* *} \\
(0.045)\end{array}$ \\
\hline Observations & 8,600 & 8,600 & 8,600 & 8,600 & 8,589 \\
\hline Adj. R-squared & 0.024 & 0.050 & 0.050 & 0.051 & 0.113 \\
\hline Player FE & NO & YES & YES & YES & YES \\
\hline Tournament FE & NO & NO & YES & YES & YES \\
\hline Round FE & $\mathrm{NO}$ & NO & NO & YES & YES \\
\hline Move FE & NO & NO & NO & NO & YES \\
\hline
\end{tabular}

meaningful error (Panel A) and the magnitude of the error (Panel B). All regressions contain individual, year, round, and move fixed effects, all environmental measures, and the full set of control variables. The dots represent point estimates and the black (gray) bars show the $90 \%$ (95\%) confidence intervals based on standard errors clustered at the game level. 
Figure 5.5: Impact of indoor environmental quality on performance of chess players by move level

CO2 concentration (in 100 ppm)
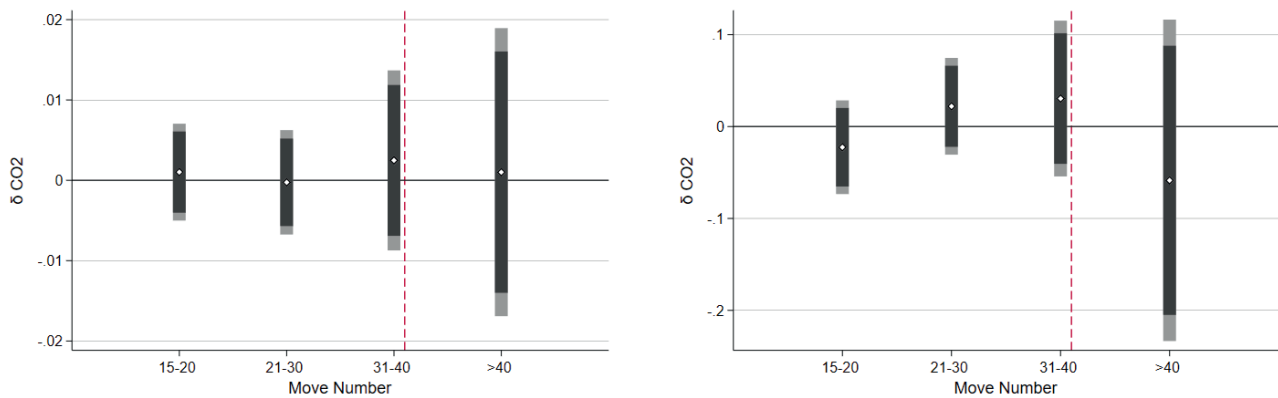

Temperature
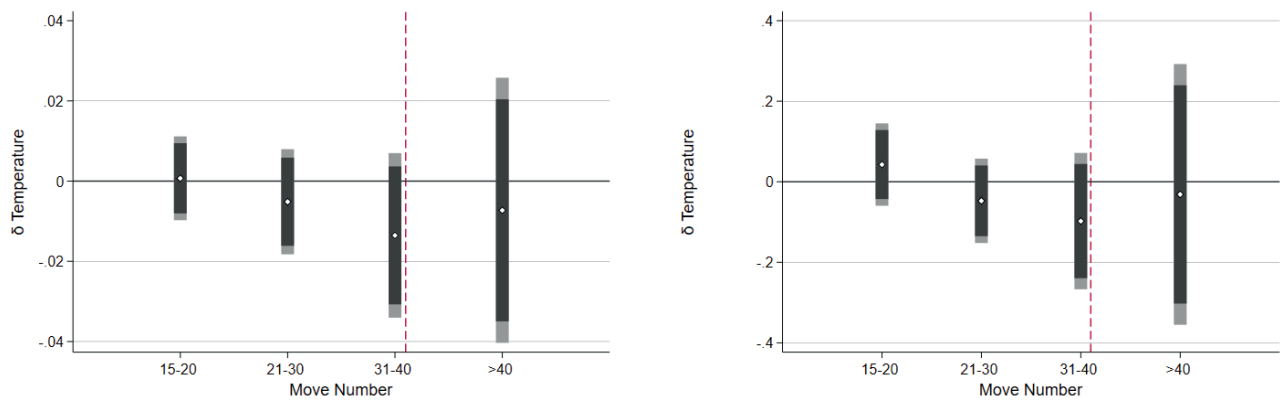

PM2.5 (in $10 \mu \mathrm{g} / \mathrm{m} 3$ )
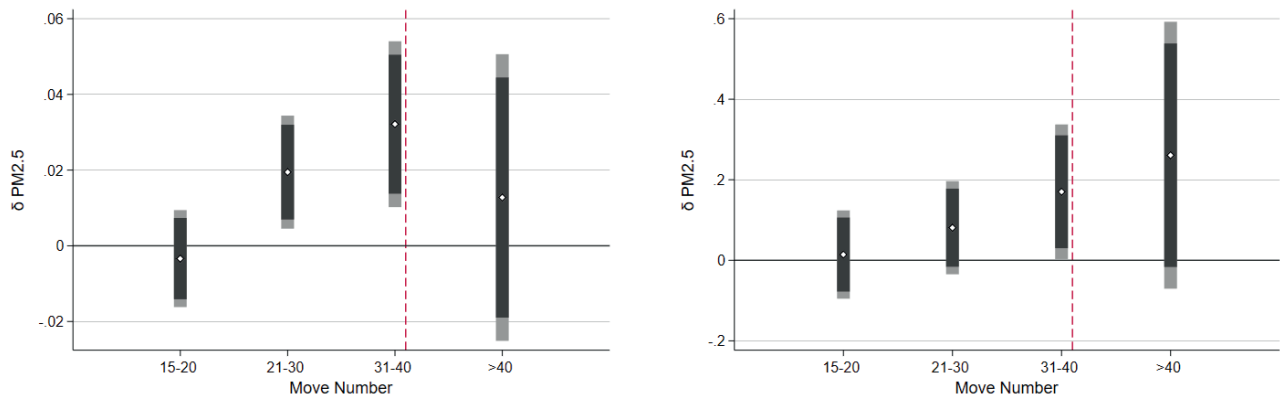

Note: The figure shows the estimated coefficient of joint regressions including all the environmental measures. We divided the total sample of moves into subsamples with respect to the number of moves within a game (horizontal axis). The vertical, dashed red line indicates the occurrence of the time restriction during the game. Each panel presents the regression on different outcomes. The binary outcome variable "meaningful error" takes the value of 1 if the move is marked as a meaningful error by the chess engine, and zero otherwise. Dots represent point estimates. Black (gray) bars show the $90 \%$ (95\%) confidence intervals based on standard errors clustered at the game level. All regressions include individual, year, round, and move fixed effects, as well as the full set of control variables: (i) difference in the $E L O$ rating score between the player and the opponent (as well as its squared term), (ii) the number of points achieved during the tournament, and (iii) the actual status of the game before the move, namely., the pawn metric of the previous move by the opponent $\left(C_{j t r m-1}^{\text {opponent }}\right)$. 
First, we focus on the results concerning the effect of environmental conditions on the probability of making a meaningful error (Panel A in Figure 5.5). In line with the results of the pooled regression, the results indicate $\mathrm{CO} 2$ and temperature have no effect on the probability of making a meaningful error at any stage of the game. However, we detect a clear pattern for the case of PM2.5. The estimated coefficients increase in size and significance the closer the game gets to the 40th move. This finding suggests that the effects as displayed in Table 5.2 are entirely driven by the moves close to move 40 , when the time control takes place. Focusing on the move category $31-40$, we find a $10 \mu \mathrm{g} / \mathrm{m}^{3}$ increase in the levels of PM2.5 in the room leads to an increase in the probability of making a meaningful error by 3.2 percentage points. This effect is equivalent to a $29.6 \%$ increase given the average probability of making a meaningful error in our sample (10.8\% for moves in this range).

Second, we focus on the impact of environmental conditions on the magnitude of the error. Panel B in Figure 5.5 shows the estimated coefficient $\hat{\delta}$ of equation 5.2 using $\ln$ (error) as the outcome variable. Again, we observe no evidence of a detrimental effect of $\mathrm{CO} 2$ concentration or temperature on the magnitude of the error. However, the estimates associated with PM2.5 show a positive and significant impact immediately before the time control at move 40 . In particular, we find that when games are in the move interval between 30 and 40 , an increase in $10 \mu \mathrm{g} / \mathrm{m}^{3}$ is associated with a $17.3 \%$ increase of the error. In earlier phases of the game before move 30 , the existing variation in environmental conditions in our sample does not yield any impact on the performance of the chess players.

In sum, we find the negative impact of fine particles on the performance of chess players is exacerbated by time pressure. The level of particles affect both, the probability of making meaningful errors during the game and the magnitude of errors. In our preferred specification, including the full set of fixed effects, the results from the pooled regression indicates an increase in $10 \mu \mathrm{g} / \mathrm{m}^{3}$ (similar to one standard deviation in our sample) leads to an increase of 1.5 percentage points in the probability of making a meaningful error and $9.4 \%$ larger errors (relative to the average error). When we estimate the parameters for the move interval before the time control (move 30-40), the estimated coefficients double.

\subsubsection{Effect Heterogeneity with Respect to Individual And Game Charac- teristics}

In a final step, we analysis potential effect heterogeneity with respect to individuals' age, as well as their absolute skill level as measured by the Elo rating score and the difference in the Elo score to the opponent (reflecting the tightness of a game). Table 5.3 shows the estimated parameters within each subsample (defined by terciles of the underlying distribution) with respect to the probability of making a meaningful error (column 1 and 2) and the magnitude of the error 
(column 3 and 4). Thereby, we focus on the effect of PM2.5 and show the results for both the pooled sample (in column 1 and 3) and the subsample containing only the moves within the move category 31-40 moves (column 2 and 4). All regressions contain individual, year, round, and move fixed effects, all environmental measures, and the full set of control variables.

With respect to age, the effects are strongest for the middle age category (50-60 years). Similar to the analysis above, the effects double once players have to take decisions under time pressure. Regarding the initial skill level of players, it seems that the weakest players make slightly more meaningful mistakes (column 1 and 2) in polluted days, while the strongest players tend to make larger errors, in particular under time pressure (ln(error)). Considering the tightness of the game, the impact of pollution becomes more pronounced when players playing against stronger or similar players in terms of the Elo rating score. Similar to the results on time pressure, this suggests that players' performance is particularly sensitive to air pollution if they have to act under certain pressure. Air pollution does not affect the players' performance when playing against a significant weaker opponent.

\subsubsection{Discussion of Results in Context of Previous Findings}

Previous studies find a negative effect of $\mathrm{CO} 2$ on the cognitive performance of adults (e.g. Allen et al. 2016); however, the level at which $\mathrm{CO} 2$ impairs cognitive performance and the exact mechanisms for cognitive impairments remains unclear. In a lab experiment, Allen et al. (2016) shows that levels beyond 1,500 ppm have a detrimental effect on the performance of 24 adults in a simulated management task, using $500 \mathrm{ppm}$ as a baseline. Zhang et al. (2015) reduce the air supply in the chamber to let subjects be exposed to 3,000 ppm of CO2. The authors find a cognitive impairment in the subjects at 3,000 ppm. The distribution of values of $\mathrm{CO} 2$ observed in our study differs from the distributions in lab experiments. Our baseline $(\operatorname{minCO} 2=1,179$ $\mathrm{ppm}$ ) is twice the $500 \mathrm{ppm}$ value commonly used in the literature as the reference CO2 level. We find no evidence that higher levels of $\mathrm{CO} 2$ are correlated with a higher presence of errors or the magnitude of the errors within the range of values considered in the analysis.

A number of studies show significant drops in the cognitive performance of humans under heat stress. In their meta-review of lab studies, Seppänen et al. (2006) find an average loss in cognitive performance of workers beyond 24 degrees Celsius - relative to the temperatures between 22 and 24 degrees Celsius. In their field study, Graff Zivin et al. (2018) find a significant drop in cognitive performance of subjects taking math tests while temperatures are above 26 degrees Celsius, using 22 degrees Celsius as the reference category. Our study spans temperatures between 22 and 29 degrees Celsius (72 and 84 Fahrenheit), with 40 percent of the rounds with average temperatures beyond 24 degrees Celsius and $27 \%$ of days beyond 26 degrees Celsius. We find no effects of temperature in a joint regression with $\mathrm{CO} 2$ and pollution (measured at the 
Table 5.3: Effect heterogeneity with respect to individual and game characteristics

\begin{tabular}{|c|c|c|c|c|}
\hline & $\begin{array}{c}\text { (1) } \\
\text { Meaningful Error } \\
\text { Pool sample }\end{array}$ & $\begin{array}{c}(2) \\
\text { Meaningful Error } \\
\text { Moves } 30-40\end{array}$ & $\begin{array}{c}(3) \\
\text { Ln(error) } \\
\text { Pool sample }\end{array}$ & $\begin{array}{c}(4) \\
\operatorname{Ln}(\text { error }) \\
\text { Moves } 30-40\end{array}$ \\
\hline \multicolumn{5}{|l|}{ Age 18-50 } \\
\hline PM2.5 (in $10 \mu \mathrm{g} / \mathrm{m} 3$ ) & $\begin{array}{c}0.003 \\
(0.007)\end{array}$ & $\begin{array}{c}0.013 \\
(0.015)\end{array}$ & $\begin{array}{c}0.045 \\
(0.064)\end{array}$ & $\begin{array}{c}0.081 \\
(0.138)\end{array}$ \\
\hline Observations & 7,165 & 1,536 & 2,787 & 638 \\
\hline \multicolumn{5}{|l|}{ Age 51-62 } \\
\hline PM2.5 (in $10 \mu g / m 3$ ) & $\begin{array}{c}0.025^{* * *} \\
(0.010)\end{array}$ & $\begin{array}{c}0.054^{* *} \\
(0.023)\end{array}$ & $\begin{array}{c}0.140^{* *} \\
(0.067)\end{array}$ & $\begin{array}{c}0.339 * * \\
(0.137)\end{array}$ \\
\hline Observations & 6,810 & 1,524 & 2,966 & 661 \\
\hline \multicolumn{5}{|l|}{ Age $>62$} \\
\hline PM2.5 (in $10 \mu g / m 3$ ) & $\begin{array}{c}0.010 \\
(0.009)\end{array}$ & $\begin{array}{c}0.024 \\
(0.017)\end{array}$ & $\begin{array}{c}0.076 \\
(0.068)\end{array}$ & $\begin{array}{c}0.080 \\
(0.126)\end{array}$ \\
\hline Observations & 6,418 & 1,451 & 2,820 & 620 \\
\hline Adjusted R-squared & 0.044 & 0.044 & 0.119 & 0.095 \\
\hline \multicolumn{5}{|l|}{ ELO $<1527$} \\
\hline PM2.5 (in $10 \mu g / m 3$ ) & $\begin{array}{c}0.020^{* *} \\
(0.010)\end{array}$ & $\begin{array}{c}0.035^{* *} \\
(0.016)\end{array}$ & $\begin{array}{l}0.122^{*} \\
(0.063)\end{array}$ & $\begin{array}{c}0.044 \\
(0.096)\end{array}$ \\
\hline Observations & 6,870 & 1,572 & 3,263 & 732 \\
\hline \multicolumn{5}{|l|}{ ELO 1528-1900 } \\
\hline PM2.5 (in $10 \mu g / m 3$ ) & $\begin{array}{c}0.008 \\
(0.008)\end{array}$ & $\begin{array}{l}0.032 * \\
(0.019)\end{array}$ & $\begin{array}{l}-0.029 \\
(0.061)\end{array}$ & $\begin{array}{c}0.081 \\
(0.133)\end{array}$ \\
\hline Observations & 6,454 & 1,443 & 2,721 & 608 \\
\hline Adjusted R-squared & 0.032 & 0.054 & 0.099 & 0.143 \\
\hline \multicolumn{5}{|l|}{ ELO 1910-2325 } \\
\hline PM2.5 (in $10 \mu g / m 3$ ) & $\begin{array}{c}0.016^{* *} \\
(0.006)\end{array}$ & $\begin{array}{c}0.021 \\
(0.014)\end{array}$ & $\begin{array}{c}0.192^{* * *} \\
(0.069)\end{array}$ & $\begin{array}{c}0.521^{* * * *} \\
(0.168)\end{array}$ \\
\hline Observations & 7,083 & 1,496 & 2,593 & 579 \\
\hline Adjusted R-squared & 0.049 & 0.026 & 0.145 & 0.119 \\
\hline \multicolumn{5}{|l|}{ Diff ELO $<-268$} \\
\hline PM2.5 (in $10 \mu g / m 3$ ) & $\begin{array}{c}0.015 \\
(0.012)\end{array}$ & $\begin{array}{c}0.096^{* * *} \\
(0.023)\end{array}$ & $\begin{array}{c}0.075 \\
(0.068)\end{array}$ & $\begin{array}{c}0.324^{* *} \\
(0.161)\end{array}$ \\
\hline Observations & 5,077 & 1,107 & 2,393 & 529 \\
\hline $\begin{array}{l}\text { Adjusted R-squared } \\
\text { Diff ELO -268- }+\mathbf{2 6 8}\end{array}$ & 0.049 & 0.169 & 0.138 & 0.204 \\
\hline PM2.5 (in $10 \mu g / m 3$ ) & $\begin{array}{c}0.026 \\
(0.030)\end{array}$ & $\begin{array}{c}0.142^{* *} \\
(0.065)\end{array}$ & $\begin{array}{c}0.312 \\
(0.235)\end{array}$ & $\begin{array}{c}1.410^{* * *} \\
(0.521)\end{array}$ \\
\hline Observations & 10,171 & 2,279 & 4,238 & 956 \\
\hline \multicolumn{5}{|l|}{ Diff ELO > 268} \\
\hline PM2.5 (in $10 \mu g / m 3$ ) & $\begin{array}{l}-0.001 \\
(0.006)\end{array}$ & $\begin{array}{c}0.004 \\
(0.019)\end{array}$ & $\begin{array}{c}0.049 \\
(0.068)\end{array}$ & $\begin{array}{c}0.059 \\
(0.198)\end{array}$ \\
\hline Observations & 5,073 & 1,102 & 1,899 & 413 \\
\hline Adjusted R-squared & 0.053 & 0.035 & 0.179 & 0.208 \\
\hline Player FE & YES & YES & YES & YES \\
\hline Tournament FE & YES & YES & YES & YES \\
\hline Round FE & YES & YES & YES & YES \\
\hline Move FE & YES & YES & YES & YES \\
\hline
\end{tabular}

Note: $* / * * / * * *$ indicate statistical significance at the $10 \% / 5 \% / 1 \%$ levels. Standard errors are in parentheses and clustered at the game level. Each panel presents the regression on different outcomes. The binary outcome variable "meaningful error" takes the value of 1 if the move is marked as a meaningful error by the chess engine and zero otherwise. For each panel, each column displays the results of a separate regression with the combination of fixed effects specified at the bottom of the table. All regressions presented in the table include all the environmental parameters and the full set of control variables. 
exact tournament time) on the quality of decisions of highly incentivized subjects.

Evidence on the impact of air pollution on cognitive performance of adults is increasing. Ebenstein et al. (2016) find that a 10-unit increase in daily PM2.5 (AQI) leads to an increase of 2 percentage points in the probability of failing a high-stakes exam. In our pooled sample, we find comparable effects with $10 \mu \mathrm{g} / \mathrm{m}^{3}$ increase resulting in a 1.5 percentage points increase in the probability of making a meaningful error. Importantly, when looking at the move interval before the time control, we find the impact of PM2.5 doubles. An increase of $10 \mu \mathrm{g} / \mathrm{m}^{3}$ in PM2.5 leads to a 3.2-percentage points increase in the probability of making meaningful errors. When looking at continuous variables of performance, we see heterogeneity in the elasticities of pollution on performance 19 Among manual workers, the highest elasticity is 0.260 , estimated in a US sample of agriculture workers (Graff Zivin and Neidell, 2012). For China, Kahn and Li (2019) estimate the elasticity of PM2.5 in a sample of highly skilled public workers, finding elasticities between 0.179 and 0.243 . In our pooled sample, we find a 0.267 elasticity associated with PM2.5. When restricting the sample to the move interval before the time control, we observe that the elasticity increases to 0.484 , suggesting the effect of PM2.5 on cognitive performance is exacerbated under time pressure.

In sum, we find no impact of $\mathrm{CO} 2$ and temperature during the tournament rounds on the quality of tasks of our subjects. The estimated impact of PM2.5 in the full sample of moves suggests the existence of significant impairments of cognition, at a magnitude similar to the estimates of the literature. The estimates double in the sample of moves just before the time control. This observation suggests that when the time available for the execution of the cognitive tasks is limited, the impact of pollution increases substantially.

\subsection{Sensitivity Analysis}

In this section, we present a number of sensitivity tests to check the robustness of our significant results on pollution (PM2.5) ${ }^{20}$ In particular, we reestimate the linear probability model as shown in equation (5.2), introducing the following modifications: (i) We use the daily maximum instead of mean value of the environmental parameters during the tournament rounds. (ii) We restrict the sample by removing games with less than 40 moves, and (iii) use data on outdoor pollution PM10 and ozone stemming from the closest air-quality stations. (iv) Finally, we additionally include pollution measurements the day before and after the tournaments rounds. While lagged pollution values test for lagged health channels driving our performance measure, the inclusion

\footnotetext{
${ }^{19} \mathrm{See}$ Kahn and Li $(2019)$ for an excellent overview of the elasticities found in previous studies.

${ }^{20} \mathrm{We}$ provide the results of the sensitivity analysis for temperature and CO2 in Figures 5.13 and 5.14 in the appendix, but refrain from discussing them here because we do not find any significant effects on these measures in the main analysis.
} 
of lead values provides a falsification test.

Figure 5.6: Robustness of the effect on PM2.5

$\underline{\text { Meaningful error }}$

$\underline{\operatorname{Ln}(\text { error })}$

Panel A: Daily maximum value of air quality as treatment
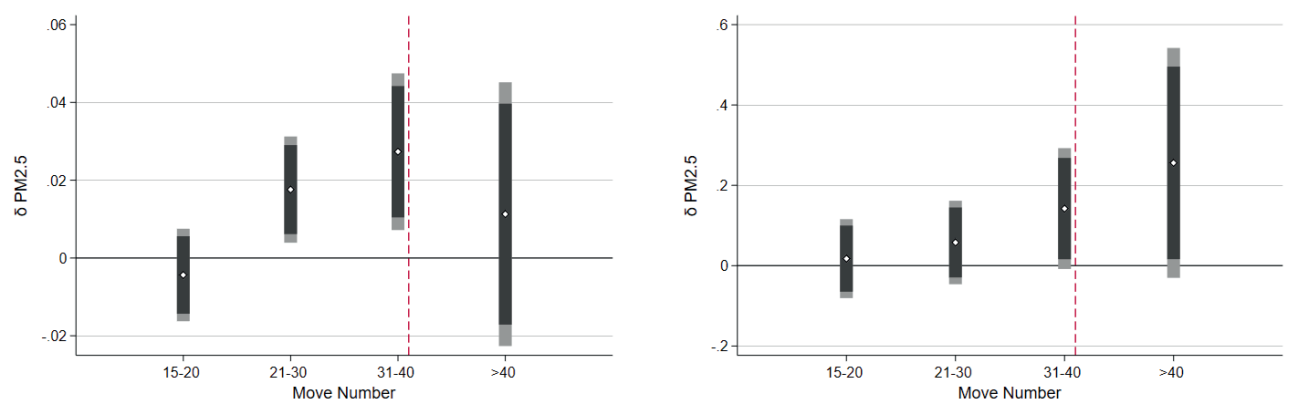

Panel B: Only games with $\geq 40$ moves per player
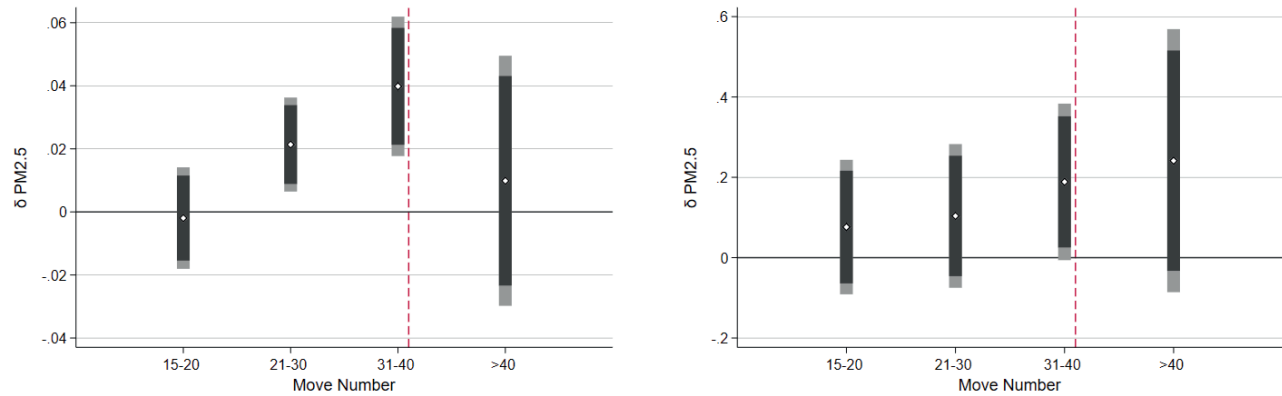

Panel C: Outdoor PM10 (in $10 \mu \mathrm{g} / \mathrm{m3}$ )
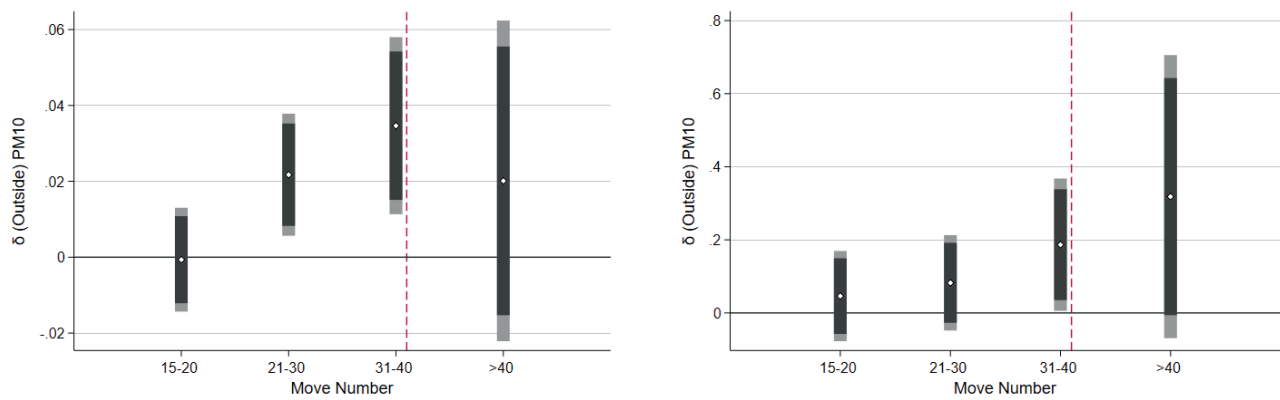

Note: The figure shows the results of the sensitivity analysis testing the robustness of the effect on PM2.5. We show the estimated coefficient of joint regressions including all the environmental measures. We divided the total sample of moves into subsamples with respect to the number of moves within a game (horizontal axis). The vertical, dashed red line indicates the occurrence of the time restriction during the game. Each panel presents the regression on different outcomes. The binary outcome variable "meaningful error" takes the value of 1 if the move is marked as a meaningful error by the chess engine, and zero otherwise. Dots represent point estimates. Black (gray) bars show the 90\% (95\%) confidence intervals based on standard errors clustered at the game level. All regressions include individual, year, round, and move fixed effects, as well as the full set of control variables: (i) difference in the ELO rating score between the player and the opponent (as well as its squared term), (ii) the number of points achieved during the tournament, and (iii) the actual status of the game before the move, namely, the pawn metric of the previous move by the opponent $\left(C_{j t r m-1}^{\text {opponent }}\right)$. 
Figures 5.6 and 5.7 summarizes the findings with respect to sensitivity checks (i) - (iii) and show the estimated coefficients on the pollution parameter. Figure 5.8 shows the results of the specification test with respect to lagged and lead pollution values. All specifications include the $\mathrm{CO} 2$ and temperature levels, the full set of fixed effects, and control variables as regressors.

\subsubsection{Maximum Values}

We first test the sensitivity of the results with respect to measurement of the environmental conditions by using the maximum instead of the mean value of the air-quality measures and temperature as the treatment. Panel A in Figure 5.6 presents the results, which are consistent with our main estimates. The coefficients associated with PM2.5 remain significant and of a similar magnitude to those presented in the results section (see Figure 5.5.

\subsubsection{Attrition}

In our sample, a number of games do not get to the 40th move, when the time control takes place. Those games are likely to display differences in the number of errors in the earlier stages of the games that might lead to the early defeat of one of the players. These games might mislead our interpretation of the results, which might well be driven by those games finishing before the 40th move, and not by the time pressure induced by the time control per se. In this subsection, we present the estimation results restricting our sample to those games that reach the 40th move.

Panel B in Figure 5.6 presents the estimation results of the main equations for the sample of games lasting at least 40 moves. The results suggest that the main findings from section 5.4 are not driven by the games that finish before the time control is implemented. The estimates associated with PM2.5 do not change and even slightly increase in magnitude. In the move interval between 30 and 40 moves, a $10 \mu \mathrm{g} / \mathrm{m}^{3}$ increase in the levels of PM2.5 in the room is associated with a $4 \%$-points increase in the probability of making a meaningful error and $18.9 \%$ larger errors, compared to 3.2 percentage points and $17 \%$ in our unrestricted sample (see section 5.4 .2 .

\subsubsection{Outdoor Values}

The existing studies in the field of environmental economics predominantly rely on outdoor measures of the environment (except for Roth, 2018)). Thus, the existing studies tend to use data from weather stations (e.g., Park, 2018) or local air-quality stations (e.g., Ebenstein et al., 2016) to measure the exposure of individuals to certain temperatures or air pollution. In this subsection, we follow the traditional approach in the literature and replace our main regressors with outdoor measures. In particular, we replace the temperature and pollution treatments with 
the corresponding measures retrieved from an air quality and a weather station close to the tournament venue (about 3.8 kilometers). The outdoor measures are measured during the same time interval as the indoor measures, namely, during the second hour of the tournament rounds. However, for pollution, we have to rely on PM10 because PM2.5 is not available for the outdoor measurement 21

Panel C in Figure 5.6 shows the results when we use the outdoor measure of PM10 instead of the indoor measure of PM2.5 as the treatment. We find an identical pattern for the coefficients on outdoor PM10, compared to our main results using indoor PM2.5 (see Figure 5.5). Within the category 31-40 moves, the magnitude and significance of the effects do not change. This finding is mostly attributable to the high correlation between the two pollution measures of 0.76 in our sample.

\subsubsection{Other Pollutants}

Finally, we test whether the effect is due to general pollution or is specific to PM2.5. We include the average level of ozone in the area during the tournament rounds in the main empirical model, together with PM2.5 and the rest of the environmental measures (equation (5.2)). Figure 5.7 shows the estimated coefficients associated with outdoor levels of PM10 and ozone. Although the coefficient associated with PM10 remains unchanged, ozone never has a significant effect in our sample. This finding supports the hypothesis that the estimated impacts of air pollution are mainly driven by the level of particles.

\subsubsection{Lagged And Lead Pollution Values}

Our analysis so far has focused on the effects at the time of the tournament rounds. In this subsection, we present the results of a specification test in which we estimate the relationship between the error measures and average pollution at times other than during the actual tournament rounds. In particular, we estimate a modified version of equation 5.2, from the pollution levels on days leading up to and following the tournament round.

We generate this mis-assigned pollution using the levels of PM10 corresponding to the second hour of the tournament rounds (7:00pm-8:00pm) in the two preceding $(t-2$ and $t-1)$ and two following days $(t+1$ and $t+2)$. ${ }^{22}$ In addition, we include the pollution levels in the early morning (6:00am-9:00am) of the same day of the tournament round.

Figure 5.8 shows the results of seven separate regressions (including the pollution during the time of the tournament round). As anticipated, the observed positive relationship between the

\footnotetext{
${ }^{21}$ Unfortunately, the outdoor measurement of PM2.5 is only available as the daily mean for every second day, so we decided to rely on the PM10 measurement instead.

${ }^{22}$ Given the lack of indoor measurements on the days before and after the tournament rounds, we rely on PM10 levels from the same air-quality station used in section 5.5.3 (3.8 kilometers away from the tournament venue).
} 
Figure 5.7: Robustness check: Inclusion of ozone
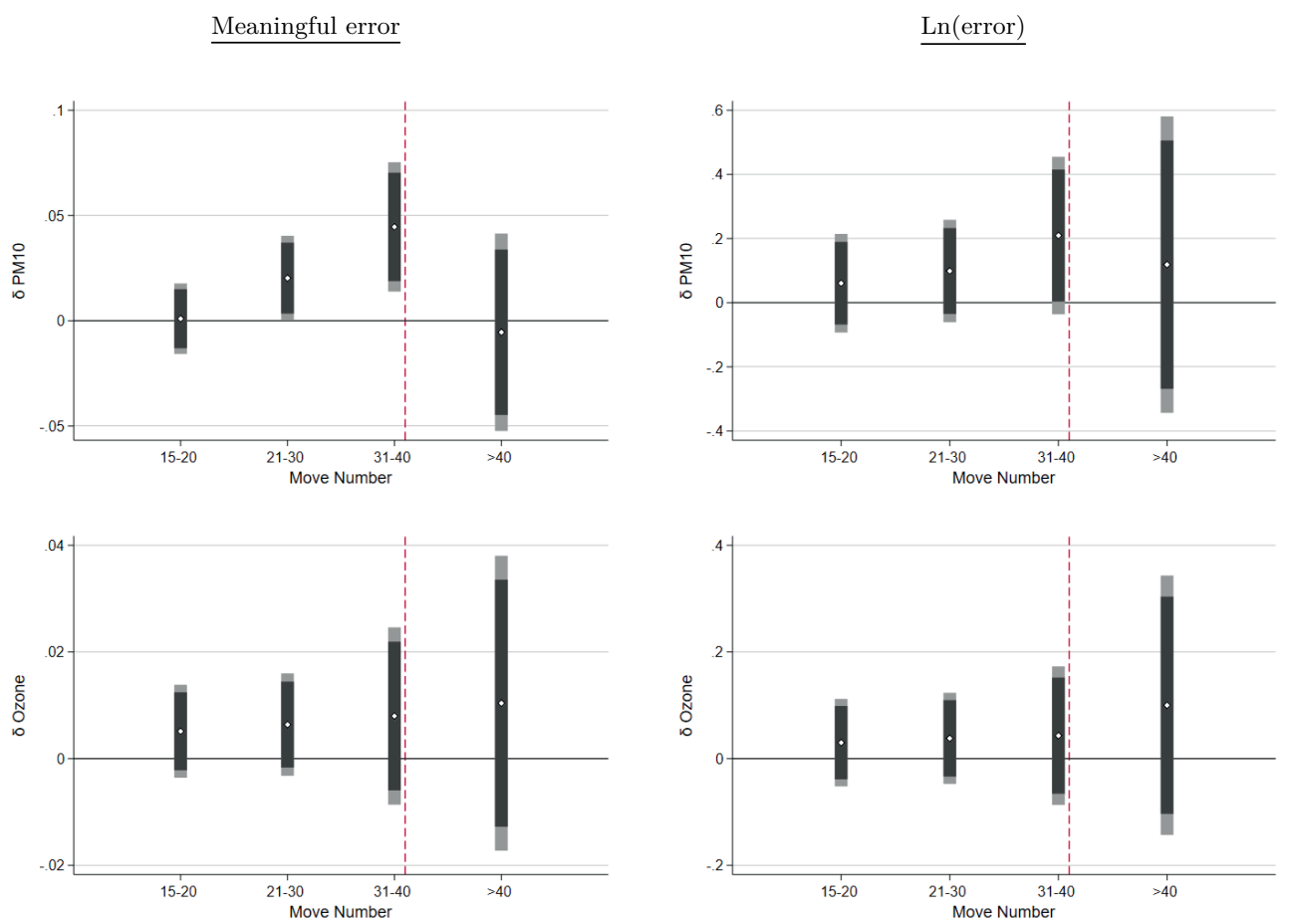

Note: We show the estimated coefficient of joint regressions including all the environmental measures. We divided the total sample of moves into subsamples with respect to the number of moves within a game (horizontal axis). The vertical, dashed red line indicates the occurrence of the time restriction during the game. Each panel presents the regression on different outcomes. The binary outcome variable "meaningful error" takes the value of 1 if the move is marked as a meaningful error by the chess engine, and zero otherwise. Dots represent point estimates. Black (gray) bars show the $90 \%$ (95\%) confidence intervals based on standard errors clustered at the game level. All regressions include individual, year, round, and move fixed effects, as well as the full set of control variables: (i) difference in the ELO rating score between the player and the opponent (as well as its squared term), (ii) the number of points achieved during the tournament, and (iii) the actual status of the game before the move, namely, the pawn metric of the previous move by the opponent $\left(C_{j \text { trm }-1}^{\text {oppont }}\right)$.

level of pollution and the error measures is strongest when we use the PM10 at the exact time of the tournament. The rest of the coefficients are not significantly different from zero. This finding is supportive evidence that our results on the probability and magnitude of errors are driven by the transitory effect of pollution, rather than by other explanations. The lack of effects of the lag PM10 indicates an absence of lagged health channels driving our performance measures. The absence of an effect for lead pollution offers further confirmation that our results are not driven by unobserved confounding factors. 
Figure 5.8: Robustness check: Lagged and lead pollution values

Meaningful error
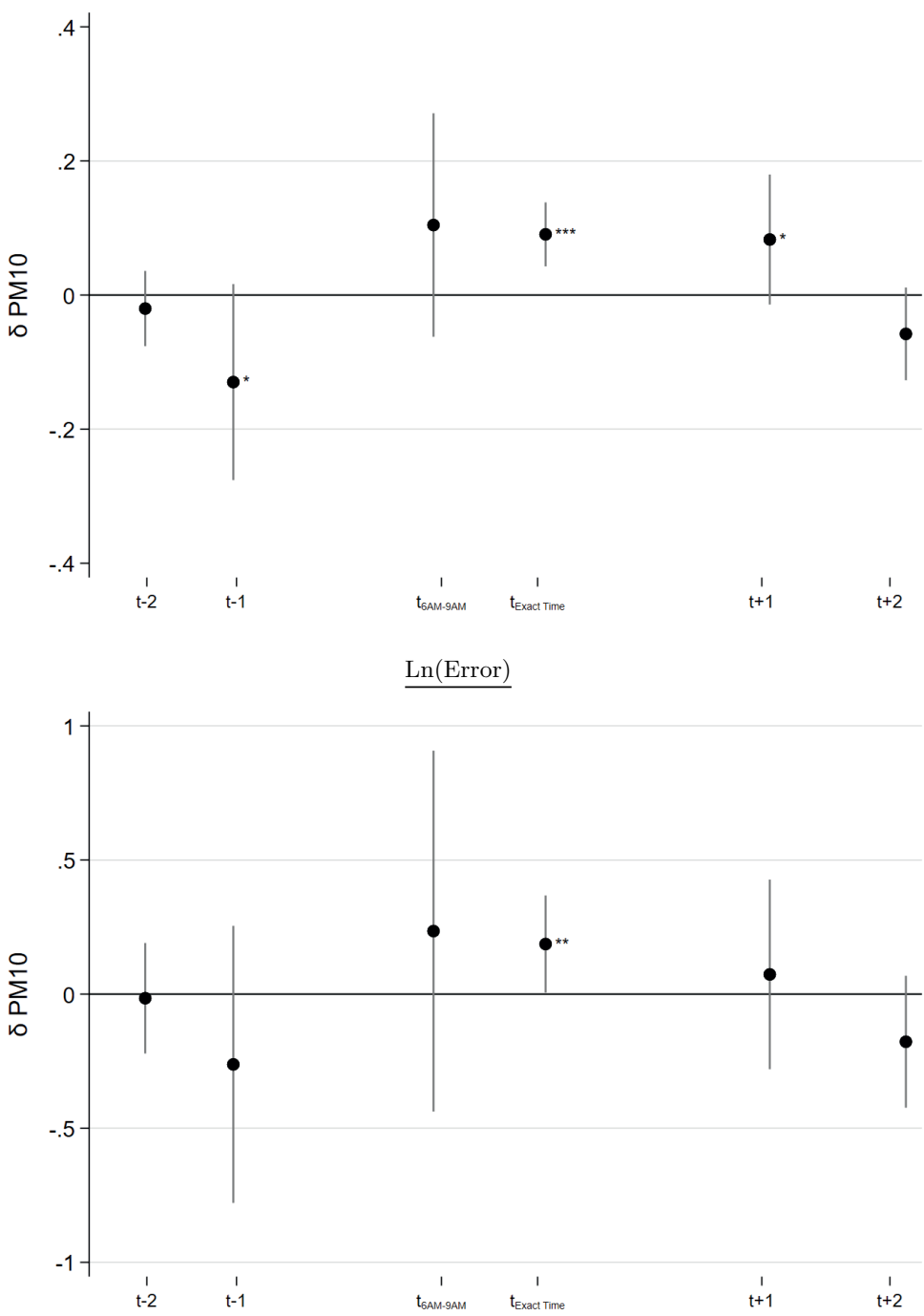

Note: $* / * * / * *$ indicate statistical significance at the $10 \% / 5 \% / 1 \%$ levels. We show the estimated coefficient of separate regressions. We divided the total sample of moves into subsamples with respect to the number of moves within a game (horizontal axis). The binary outcome variable "meaningful error" takes the value of 1 if the move is marked as a meaningful error by the chess engine and zero otherwise. Dots represent point estimates. Gray bars show the $95 \%$ confidence intervals based on standard errors clustered at the game level. All regressions include individual, year, round, and move fixed effects, as well as the full set of control variables: (i) difference in the $E L O$ rating score between the player and the opponent (as well as its squared term), (ii) the number of points achieved during the tournament, and (iii) the actual status of the game before the move, namely, the pawn metric of the previous move by the opponent $\left(C_{j t r m-1}^{\text {opponent }}\right)$. 


\subsection{Conclusion}

In this paper, we investigate the impact of environmental conditions on human cognition by examining the performance of chess players at tournaments under different levels of air quality and temperature. Chess requires players to use their cognitive skills intensively and to decide strategically. Due to the computational nature of the game of chess, the cognitive performance of players can be measured very objectively by comparing the quality of a player's actual moves with those moves proposed by chess computer. In addition, chess players at tournament have a strong intrinsic as well as extrinsic motivation to exert high effort. By using this setting, we contribute to the existing literature on the effects of environmental conditions on human productivity, which so far have relied on using simulated office tasks in lab settings, and field studies focusing on routine manual occupations or workers' availability to execute tasks (or uptime) in non-routine cognitive occupations.

In addition, most studies are based on outdoor measurements of the environment that are likely to deviate from the actual environmental conditions (office) workers are exposed to during the working day. In our study, we were able to install measurement sensors recording the indoor environmental quality (CO2 concentration, temperature, and PM2.5) to which the players were exposed during the tournaments.

Our study is based on detailed move-level information collected at two chess tournaments in Germany. In total, we observe 102 players making 20,408 moves over a maximum of 14 matches (7 matches per tournament). Based on move-level information, we calculate our main outcome variable - the move-specific error rate - as the difference between the quality score of the actual move and the "optimal" move as proposed by a chess engine. To estimate the effect of indoor environmental conditions on the players' performance, we regress the error rate on the environmental conditions in the tournament round as well as individual, year, round, and move fixed effects. Further, we control for the difference in initial skill levels between the player and her opponent as measured by the $E L O$ rating score, the number of points achieved during the tournament, and the actual status of the game before the move.

The results consistently indicate pollution harms the players' performance in cognitive tasks, whereas we find no effects for temperature and $\mathrm{CO} 2$ concentration. The estimation results show a $10 \mu \mathrm{g} / \mathrm{m}^{3}$ increase in PM2.5 results in a 1.5-percentage-point increase in the probability of a player making a meaningful error, with $9.4 \%$ larger errors. The results on pollution are similar in magnitude to existing estimates within the literature. However, the effects double if decisions are taken under time pressure. We identify the different phases of the game by exploiting a tournament rule stating that the first 40 moves have to be completed within a total time limit of 110 minutes. We find a clear pattern showing the performance of players becomes even more 
sensitive to pollution when approaching move 40, when the time control takes place and the time budget is at its minimum. For the closest move category, 31-40 moves, we find a $10 \mu \mathrm{g} / \mathrm{m}^{3}$ increase in the levels of PM2.5 in the room leads to a 3.2-percentage-point increase in the probability of making a meaningful error, and $17.3 \%$ larger errors.

Given that our measures of indoor environmental conditions are within a moderate range, resembling normal conditions humans are usually exposed to during their daily life, we argue that our findings can be extrapolated to different setups where individuals are required to make complex decisions or execute cognitive tasks under time pressure. For the labor market, given the type of cognitive task chess players have to perform (and which we actually measure with our outcome variable), our results likely have strong implications for the productivity of highskilled office workers, in particular, for those executing non-routine cognitive tasks requiring problem-solving skills. Due to the technological change, the role of these tasks is steadily rising in developed labor markets and is represented in professional, managerial, technical, and creative occupations (Autor and Price, 2013). 


\section{Appendix 5A: Supplementary material}

Figure 5.9: Timing and setting of the chess tournaments

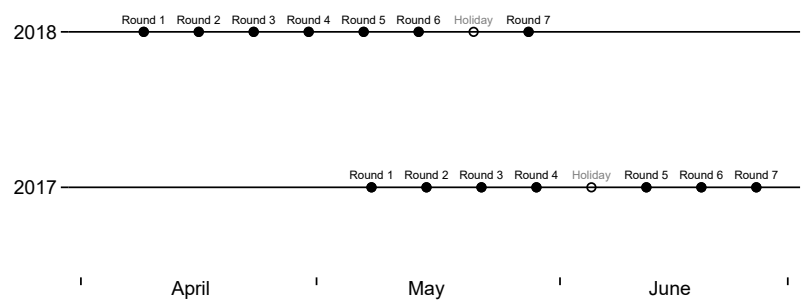

Note: This diagram illustrates the timing and setting of the observed tournaments. Each tournament consists of seven rounds, played every Monday, 6:00pm (local time). 
Figure 5.10: Example of players' hand-written game notation

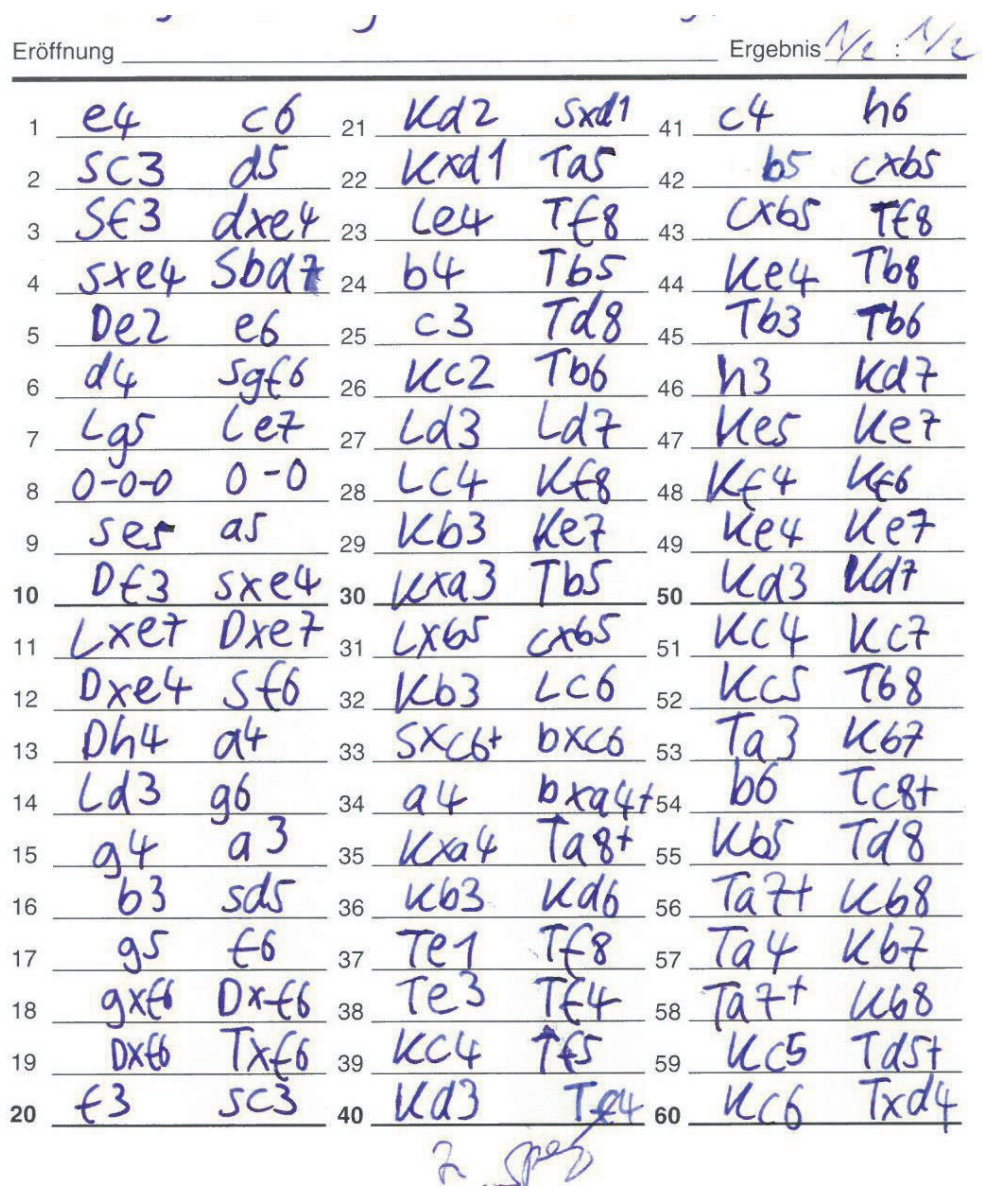

Note: This picture shows an example of the hand-written documentation as filled in during each game within the chess tournament. The documentation has been digitized by the tournament organizers. 
Figure 5.11: Example for sensor location

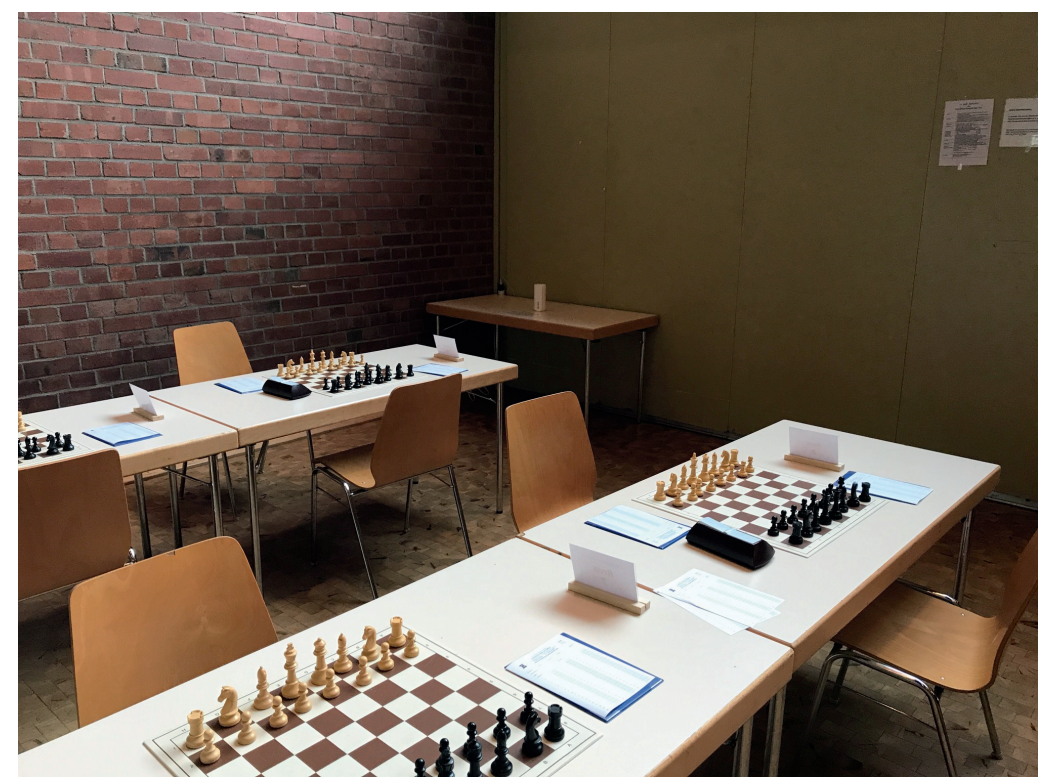

Note: This picture illustrates the placement of one sensor measuring the indoor environmental quality. In total, three sensors were placed across the room on separate tables. 
Figure 5.12: Distribution of indoor-environmental-quality measures during the tournament rounds
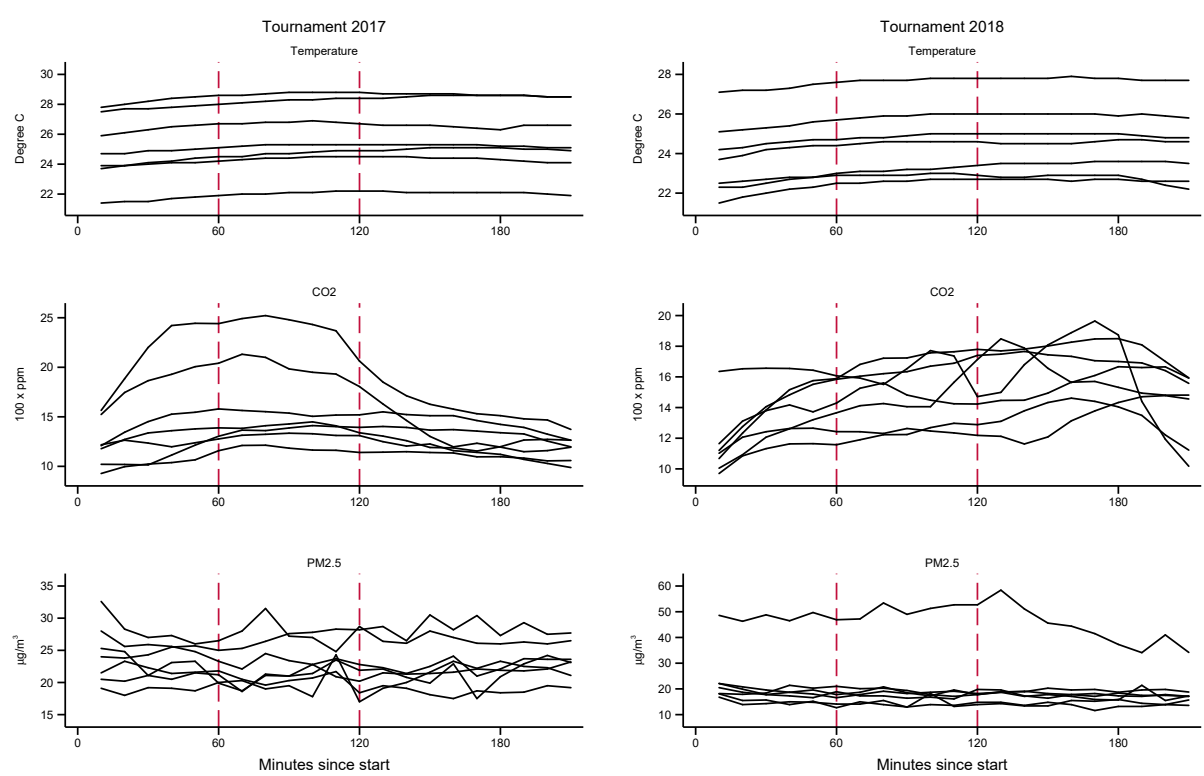

Note: The solid black lines indicate the distribution of the environmental measures during the seven rounds within a tournament. The calculation of the mean values of the environmental measures as used in the regression analysis are calculated based on observations during the second hour of the tournament rounds, as indicated by the dashed lines. 


\section{Appendix 5B: Extra estimations}

Figure 5.13: Robustness of the effect on temperature

Meaningful error

$\underline{\operatorname{Ln}(\text { error })}$

Panel A: Daily maximum value of temperature and air quality as treatment
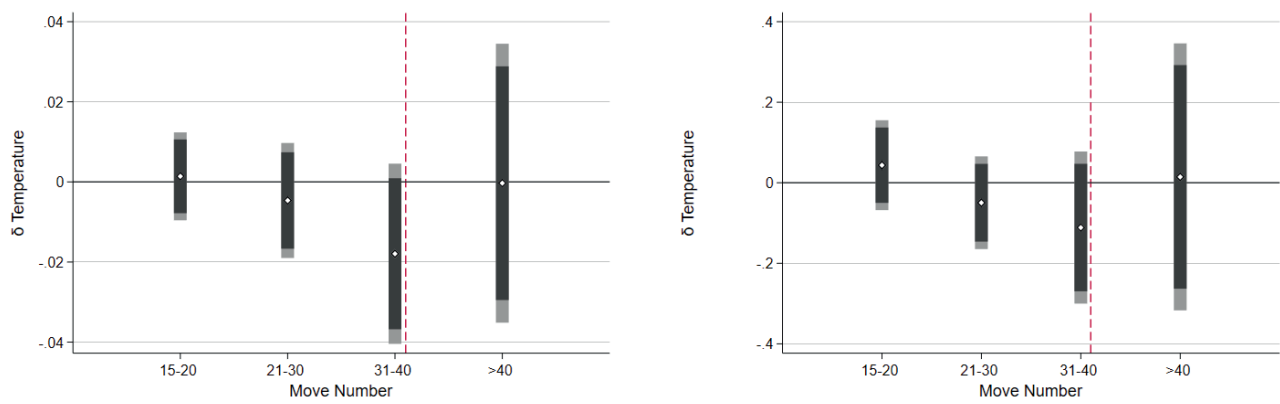

Panel B: Only games with $>40$ moves per player
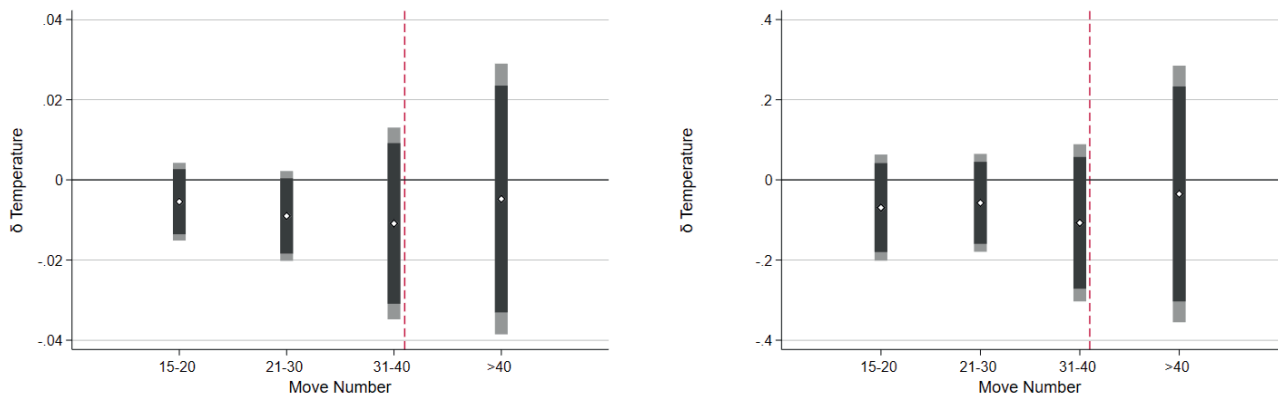

Note: The figure shows the results of the sensitivity analysis testing the robustness of the effect on PM2.5. We show the estimated coefficient of joint regressions including all the environmental measures. We divided the total sample of moves into subsamples with respect to the number of moves within a game (horizontal axis). The vertical, dashed red line indicates the occurrence of the time restriction during the game. Each panel presents the regression on different outcomes. The binary outcome variable "meaningful error" takes the value of 1 if the move is marked as a meaningful error by the chess engine, and zero otherwise. Dots represent point estimates. Black (gray) bars show the $90 \%$ (95\%) confidence intervals based on standard errors clustered at the game level. All regressions include individual, year, round, and move fixed effects, as well as the full set of control variables: (i) difference in the $E L O$ rating score between the player and the opponent (as well as its squared term), (ii) the number of points achieved during the tournament, and (iii) the actual status of the game before the move, namely, the pawn metric of the previous move by the opponent $\left(C_{j t r m-1}^{\text {opponent }}\right)$. 
Figure 5.14: Robustness of the effect on $\mathrm{CO} 2$

Meaningful error

$\operatorname{Ln}($ error $)$

Panel A: Daily maximum value of temperature and air quality as treatment
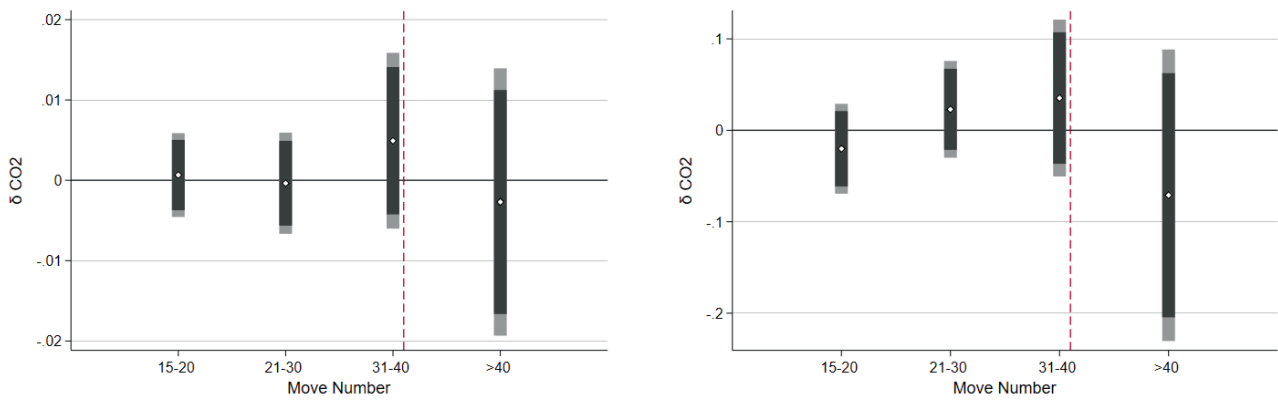

Panel B: Only games with $\geq 40$ moves per player
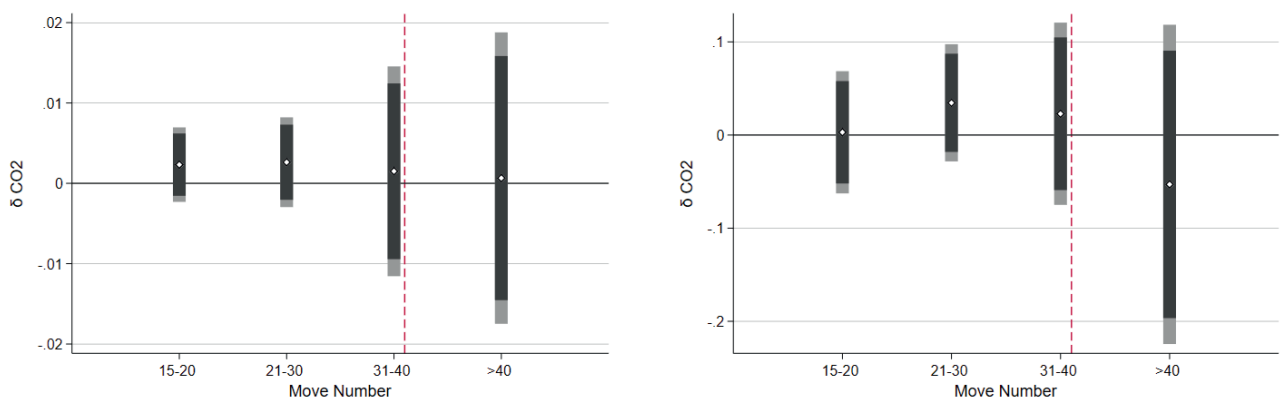

Note: The figure shows the results of the sensitivity analysis testing the robustness of the effect on PM2.5. We show the estimated coefficient of joint regressions including all the environmental measures. We divided the total sample of moves into subsamples with respect to the number of moves within a game (horizontal axis). The vertical, dashed red line indicates the occurrence of the time restriction during the game. Each panel presents the regression on different outcomes. The binary outcome variable "meaningful error" takes of the value of 1 if the move is marked as a meaningful error by the chess engine, and zero otherwise. Dots represent point estimates. Black (gray) bars show the $90 \%$ (95\%) confidence intervals based on standard errors clustered at the game level. All regressions include individual, year, round, and move fixed effects, as well as the full set of control variables: (i) difference in the ELO rating score between the player and the opponent (as well as its squared term), (ii) the number of points achieved during the tournament, and (iii) the actual status of the game before the move, namely., the pawn metric of the previous move by the opponent $\left(C_{j t r m-1}^{\text {opponent }}\right)$. 


\section{Chapter 6}

\section{Classroom Environment and Pupil

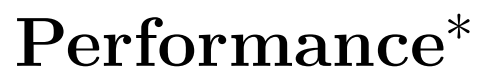

Exposure to poor environmental conditions has been associated with deterioration of physical health, mental health, and cognitive performance (Brunekreef and Holgate, 2002). However, most evidence relies on outdoor measurements and is based on samples of the adult population. There is a dearth of reliable and accurate evidence on the impact and distribution of indoor environmental conditions on human performance in general, and children's cognitive development in particular. Children are especially vulnerable to poor environmental conditions, and these conditions might well be a significant determinant of outcomes in later life.

Children in developed countries spend an average of 7,450 hours in school buildings during their primary and lower secondary education (OECD, 2016). After their home, schools are the most frequented place for children on any given weekday. Schools are also a major consumer of public funds. The U.S. alone invested USD49 billion per year in school facilities from 2011 to 2013. Yet, a recent study reports that 53 percent of U.S. public schools are in urgent need of repairs, renovation and/or modernizations (U.S. Department of Education, 2014), providing some indication that indoor conditions may be suboptimal in many schools. Understanding better the relationship between the variation in indoor environmental conditions and cognitive performance of children may thus have important implications for academia and society alike.

In this paper, we present an overview of studies that address the impact of environmental conditions on children's health and performance. We then present the design of the prospective study. We also discuss the results from a pilot study, describing the variation of environmental conditions across classrooms.

\footnotetext{
${ }^{*}$ This chapter is co-authored with Piet Eichholtz (Maastricht University), Nils Kok (Maastricht University) and Maartje Willeboordse (Maastricht University)
} 


\subsection{Literature}

\subsubsection{The Effects of Ambient Environment on Health And Cognitive Func- tioning}

There is extensive evidence in the health science literature on the damaging effects of ambient environmental stressors, such as extreme temperatures or air pollution, on physical and mental health of individuals. For instance, heat waves or the presence of air pollutants, such as ozone or fine particles both have been associated with respiratory or cardiovascular diseases in humans Brunekreef and Holgate (2002); Nimon and Oswald (2013). More recently, empirical evidence shows that air pollution can also cause serious damage to human nervous systems, impairing proper cognitive functioning of people. In particular, research in the field of neuroscience suggests that exposure to air pollution is related to ischemic stroke risk, depression and mood disorders in adult populations (Calderon-Garciduenas et al., 2015, Taylor et al. 2015).

These hazards are expected to create even more severe damage among infants and young children, as the immune systems, central nervous systems, and respiratory systems are not yet fully developed at a young age (Makri et al. 2004). Quasi-experimental evidence shows that moderate levels of pollution in developed countries are associated with significant drops in birth weight, increases in school absences, and infant mortality and morbidity (Currie, 2013). Furthermore, children's behavioral responses to environmental hazards differ from adults, since children have limited decision power on how and where they spend their time. Exogenous shocks in environmental conditions might well have detrimental consequences for individual human capital accumulation and labor outcomes later in life.

\section{Air Quality}

Recent evidence suggests that the impact of air pollution on human performance goes beyond direct health channels. A recent study of 39 schools in Southern Europe finds strong associations between the level of traffic-related pollution (i.e. fine particles) and slower cognitive development among children (Dadvand et al., 2015; Sunyer et al., 2015). Similarly, Ebenstein et al. (2016) show that air pollution may also lead to immediate impairment of cognitive performance of individuals. The authors link a longitudinal dataset of 400,000 high-stake test examinations in Israel to ambient levels of pollution on the test day, documenting that a student taking an exam on a day with high pollution (measured by levels of fine particles) scores, on average, 2.3 percent lower.

Indoor air quality (AIQ) is not purely a by-product of outdoor air pollution, or purely generated by outdoor sources alone. Rather, it is the result of a complex process affected by building conditions and occupant-related factors (Madureira et al., 2016). The most commonly 
used indicator of IAQ is the concentration of $\mathrm{CO} 2$, a colorless, odorless gas that is metabolically produced by humans. $\mathrm{CO} 2$ is also used as a metric to evaluate the performance of ventilation systems in buildings. The inhalation of high levels of $\mathrm{CO} 2$ has been associated with respiratory and cardiovascular problems in humans (Seppänen and Fisk, 2004, Stankovic et al., 2016; Sundell et al. (2011). The health science literature documents multiple physiological symptoms related to poor ventilation in rooms, such as fatigue, headaches, and prevalence of asthma episodes (Annesi-Maesano et al., 2013). These health issues, ultimately, have also been associated with an increase in absence from work and school for adults and children, respectively (Mendell et al. 2013; Shendell et al., 2004).

Studies in the field of epidemiology and neuroscience show significant impairments in cognitive performance associated with poorly ventilated rooms (i.e. high levels of CO2). Experimental evidence from functional magnetic resonance imaging (fMRI) in the field of neuroscience documents reduction in brain activity following inhalation of $5 \%(50,000 \mathrm{ppm}) \mathrm{CO} 2$ (Xu et al. 2011).

Recent lab evidence suggests significant effects of moderate CO2 concentrations on the cognitive performance of individuals beyond the aforementioned health channels. These studies typically evaluate the performance of healthy adults on different cognitive tasks in rooms where CO2 levels have been manipulated. Zhang et al. (2017a) show significant reductions in the speed of addition, increased response time in a redirection task, and an increase in the number of errors made by adults when undertaking those tasks in rooms with a CO2 level of 3,000 ppm (relative to $500 \mathrm{ppm}$ ). Satish et al. (2012) find that, relative to a baseline of $600 \mathrm{ppm}$ of CO2 (close to outdoor levels), healthy adults exposed to 2,500 ppm of $\mathrm{CO} 2$ for 2.5 hours scored 44 to 94 percent lower along different cognitive dimensions, such as crisis response, or information usage. Using a similar study design, Allen et al. (2016) document a 50 percent reduction in cognitive performance after being exposed for 6 hours to $\mathrm{CO} 2$ levels of 1,400 ppm (relative to $550 \mathrm{ppm}$ ).

\section{Temperature}

The literature also highlights the role of temperature in affecting human health and performance. In particular, strong links have been found between extreme temperatures and morbidity and mortality in developed and developing countries (Patz et al., 2005). In addition, there is increasing evidence from quasi-experimental field studies concerning the health and cognitive implications of sharp variations in day-to-day temperatures (Hancock et al., 2007). Park (2018) studies the effects of outdoor temperature during exam days on student performance, using 4.6 million high school exit tests in New York. The author finds that students taking an exam on a day with temperatures higher than $32{ }^{\circ} \mathrm{C}$ score up to 15 percent lower. Cho (2017) explores the effect of temperature on student learning. In a cohort study including 1,729 high schools 
in Korea (some 1.6 million students during 5 years) the author explores the changes in student test scores within schools associated with heat waves during the academic year. The estimates show a drop in math and English tests of 0.0042 and 0.0064 standard deviations for days with a maximum daily temperature above $34{ }^{\circ} \mathrm{C}$, relative to days with a maximum daily temperature between $28{ }^{\circ} \mathrm{C}$ and $30{ }^{\circ} \mathrm{C}$.

Lab experiments equally show the detrimental effects of passive heat on stress and human cognitive function. These studies experimentally manipulate the exposure to high temperatures $\left(50{ }^{\circ} \mathrm{C}, 50 \%\right.$ r.h.) over short periods (45 mins) and look at changes in performance on cognitive tasks. The results indicate that individuals under heat stress perform worse in complex tasks such as working memory or executive function (Gaoua et al., 2011; Taylor et al., 2015). Studies in the area of neuroscience suggest that these drops might be a consequence of alterations in blood flow and brain activity associated with heat stress (Taylor et al., 2015). The effects of extreme temperatures on performance and health are likely to be even more damaging when coinciding with other environmental factors, such as high relative humidity (Barreca, 2012) or air pollutants such as ozone (Breitner et al. 2014).

\subsubsection{Existing Studies on Indoor Environmental Quality in Schools}

Schools are commonly regarded to have poor indoor air quality, resulting from a combination of high occupancy and poorly ventilated spaces. Numerous studies show that $\mathrm{CO} 2$ concentrations in schools frequently go beyond the levels that facilitate proper cognitive functioning of occupants. These thresholds have been defined by the American Society of Heating, Refrigerating and Air-Conditioning Engineers (ASHRAE) and are typically used as cut-offs in academic research, including the studies in epidemiology or neuroscience discussed in the previous section (Fisk, 2017). However, the evidence on the implications of deficient environmental conditions in classrooms for learning outcomes is still scant, and the magnitude and distribution of the impact of indoor environmental quality (IEQ) on children's school performance remains an open question.

The most recent review of the literature identified 27 studies exploring the link between ventilation rates and CO2 on children's academic achievement or health (Fisk, 2017). The current analyses tend to focus on one unique measure of environmental conditions (e.g. average temperature in a classroom or average $\mathrm{CO} 2$ over the measurement period) as main explanatory variable. Most studies are therefore not able to differentiate between the effects of indoor climate on learning and testing performance. This differentiation is critical for the interpretation of results and policy implications of any study.

The current evidence on indoor environmental conditions in schools and student perfor- 
mance mostly relies on between-subject comparisons and do not contain information on health outcomes at the individual level. The limited number of students in the typical sample, the use of classroom-aggregated variables and the lack of background information about students hinder examination of channels or heterogeneous effects of climate on student achievement. The lack of availability of testing measures for younger children makes all of the available studies, with one exception (Gaihre et al. 2014), rely on samples of pupils at the end of their primary/elementary education (age 10-12). The systematic exclusion of younger children from studies might well have important consequences for the estimated effects of poor environmental conditions. Children's developing bodies experience significant changes in respiratory, immune and neurological systems. In addition, learning goals and challenges differ between the age of 4-5 and the age of 10-12, impeding the direct extrapolation of findings from older children to younger children.

Examining the relationship between air quality or temperature and cognitive performance or health is a challenging task, as there are many confounding factors. The presence of unobserved school or classroom characteristics that are potentially correlated with indoor conditions is likely to pollute any estimate on the effect of indoor air quality on health or academic outcomes. Thus, it is necessary to measure indoor environmental conditions for a large number of classrooms over multiple years to let participants be exposed to different indoor environmental conditions while undertaking comparable tasks. The current literature often highlights the lack of statistical power in tests due to the low number of observations in their analysis. This is the result of a small number of individuals in the sample (typically less than 2,500 individuals) and the collection of one testing outcome per child and subject (e.g. Madureira et al., 2016). The low number of observations leads to wide confidence intervals, often resulting in a failure to reject the null hypothesis of deficient climate conditions affecting academic achievement.

Finally, the current literature lacks data on individual health profiles and socio-demographic characteristics of children. Most studies have access to absence days or gender ratios at the grade or classroom level only (e.g. Mendell et al., 2015). The lack of individual characteristics in the analysis hinders the examination of potential heterogeneous effects of climate conditions on children's academic achievements. This is critical for the policy recommendations of a study, since it allows for the identification of specific target groups (e.g. asthmatic kids) and ultimately advice on more effective interventions or investments (e.g. ventilation system versus heating system).

For a graphic overview of the existing literature, and to provide a comparison with the research setup of our study, we collected information on the number of measurement days and number of individuals in all current studies investigating the effects of indoor school environment on health and/or academic performance (figure 1). Operational limitations typically make researchers face a tradeoff between measurement time and sample size (i.e. the number of class- 
rooms monitored). Over 90 percent of the studies rely on short term measurements (less than 10 days) and not a single study performs analyses on measurement periods longer than 30 days. Stability in occupancy rates and usage of classrooms within the academic year tend to reduce variance in environmental conditions in classrooms. However, the changes in ambient conditions (outdoor climate or pollution) and in the built environment (i.e. building modification or depreciation) create meaningful deviations in environmental conditions over time. Each dot in figure 1 represents one study, distinguishing between studies that focus on health, academic performance, or both. For comparison, our own study is depicted in the larger blue dot in the upper right corner. We note that, since the graph depicts observations days per school year, whereas our study will cover four consecutive school years, it understates the difference between our study and the existing literature.

Figure 6.1: Current studies on IEQ and cognitive performance in children.

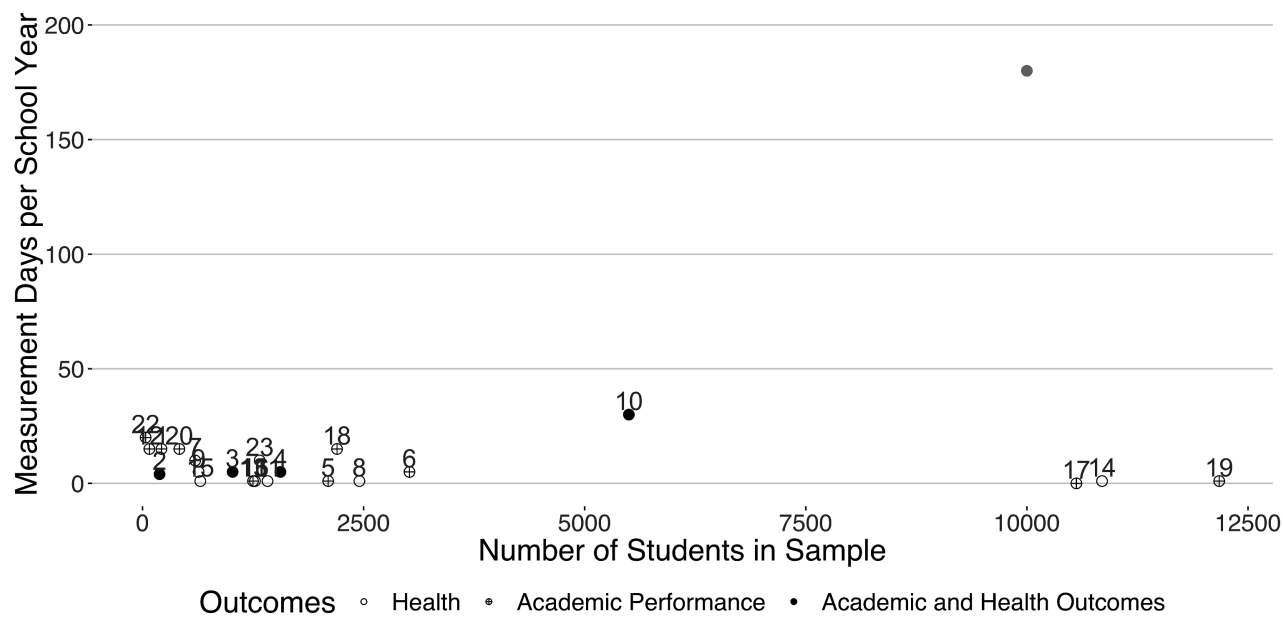

Note: The references of the studies included the graphs are [1] (Bakó-Biró et al. 2012, [2] (Dorizas et al. 2015, [3] (Ferreira and Cardoso 2014), [4] (Gaihre et al. 2014), [5] (Haverinen-Shaughnessy et al. 2011), [6] Haverinen-Shaughnessy et al. (2015), [7] (Hutter et al. 2013), [8] (Kim et al. 2011), [9] (Kolarik et al. 2016), [10] (Mendell et al. 2013, 2015), [11] (Mi et al. 2006), [12] (Petersen et al. 2016), [13] (Shaughnessy et al. 2006), [14] (Shendell et al. 2004), [15] (Simoni et al. 2010), [16] , [17] (Stafford 2015), [18] (Toftum et al. 2015), [19] (Toftum et al. 2015), [20] (Twardella et al. 2012), [21] (Wang et al. 2015), [22] (Wargocki and Wyon 2007), [23] (Zhang et al. 2014). For the studies whom the number of students in the sample are reported (Shaughnessy et al. 2006 Shendell et al. 2004) we consider the average class size to be 25 pupils. The blue dot represents the study design presented in this paper.

\subsection{Methods}

\subsubsection{The Elementary Education System in The Netherlands}

In a typical Dutch elementary school, children attend class from 8:30am until 3:15pm. Children have the option to consume their lunch at home during the one-hour lunch break or eat their 
self-brought lunch at school. The amount of time that children spend in the classroom is second only to the time they spend in their bedroom, and it generally increases as children progress in elementary school.

The elementary education in the Netherlands consists of 8 years, from the age of 4 to the age of 12 , being compulsory from the age of 5 only. The education system is ruled under the principle of "freedom of education", where elementary schools are granted a high degree of autonomy, giving the right to any natural or legal person to set up a school and to organize its teaching program. At the same time, the central government sets learning objectives and quality standards that apply to all schools, monitoring school quality and compliance with central rules and regulations. Nearly all schools participate in the well-developed nationally standardized assessment system, the Leerling Volg Systeem (LVS), a longitudinal student tracking system comprised of multiple tests per grade, covering the main knowledge areas and developed by the Central Institute for Test Development (Centraal Instituut voor Toetsontwikkeling, Cito). The tests take place throughout the academic year, with clear testing peaks in January, February and June. By the end of the primary education, in the 8th grade, Cito's Entreetoets supports elementary schools in their recommendations regarding the level of high school education most suitable for each student.

\subsubsection{Study Sample And Study Design}

Our study is designed to monitor the indoor environmental conditions and learning outcomes in approximately 280 classrooms, covering about 10,000 pupils. The levels of CO2, particles, temperature, relative humidity, background noise and light intensity of each classroom, as well as student performance in the sample will be continuously monitored for four consecutive academic years, starting September 2018.

The 23 schools involved represent a random sample of the schools belonging to an educational board with 47 schools under management, in the South of the Netherlands. All schools are situated in an area that is economically slightly deprived, with a rather large proportion of inhabitants that have a low socioeconomic status. Relatively few children achieve an adequate starting qualification for the labor market, and a large number of children leave high school without a certificate (Frontczak et al., 2012). All schools in the sample teach the full range of grades (i.e. grades 1-8) in their education program. The average amount of classes per school is 11 . The sample is quite heterogeneous with regards to building characteristics. The average school building in the sample was built in 1987, and the date of construction ranges from 1932 to 2016. All classrooms have internet connection and multimedia boards for teaching practices. The buildings are also heterogeneous in terms of ventilation system. Approximately half of the buildings have a ventilation system (52 percent), and 23 percent of the school buildings have a 
ventilation system that was installed in the last 5 years.

\subsubsection{Monitoring Environmental Conditions in Classrooms}

Environmental conditions in each classroom will be monitored using the Aclima measurement system (Aclima Inc., San Francisco, CA). Spatially and temporally resolved indoor data is collected using a sensor network consisting of individual wall-mounted stationary nodes, all equipped with a number of individual sensor modules. For this study, the nodes will measure CO2 (ppm), coarse particles (counts/L), temperature (C), relative humidity, light intensity (lux), and sound $(\mathrm{dBA})$. The node captures and transmits all data to a cloud-based server, where the data is processed, analysed, and stored. See Table 1 for the sensor performance characteristics. The frequency of raw data collection ranges from 1 to 30 seconds. However, we implement a smoothing protocol that aggregates all measures at the 1-minute level, using moving averages. With the exception of coarse particle counts, that will be aggregated at 15-minute intervals.

Table 6.1: Sensor characteristics

\begin{tabular}{lcccc}
\hline \hline & \multicolumn{1}{c}{$\begin{array}{c}\text { Sensing } \\
\text { method }\end{array}$} & Accuracy & Resolution & $\begin{array}{c}\text { Sample } \\
\text { frequency }\end{array}$ \\
\hline $\begin{array}{l}\text { Carbon Dioxide } \\
\left(\mathrm{CO}_{2}\right)\end{array}$ & $\begin{array}{c}\text { Non-dispersive } \\
\text { infrared }\end{array}$ & $50 \mathrm{ppm}+3 \%$ & $10 \mathrm{ppm}$ & $17 \mathrm{sec}$ \\
$\begin{array}{l}\text { Coarse Particles } \\
(\mathrm{PM})\end{array}$ & $\begin{array}{c}\text { Optical, } \\
\text { scattered light }\end{array}$ & $250 \mathrm{count} / \mathrm{L}+20 \%$ & $250 \mathrm{count} / \mathrm{L}$ & $30 \mathrm{sec}$ \\
$\begin{array}{l}\text { Relative Humidity } \\
(\text { rh })\end{array}$ & $\begin{array}{c}\text { Complementary metal } \\
\text { oxide semiconductor } \\
\text { Light }\end{array}$ & 0,04 & $0.3 \%$ & $5 \mathrm{sec}$ \\
$\begin{array}{l}\text { (lux }) \\
\text { Temperature }\end{array}$ & $\begin{array}{l}\text { Photodiode } \\
(\mathrm{C})\end{array}$ & $3 \mathrm{lux}$ & & $1 \mathrm{sec}$ \\
Sound $(\mathrm{dB})$ & $\begin{array}{l}\text { Solid state } \\
\text { integrated circuit }\end{array}$ & $1 \mathrm{C}$ & $0.2 \mathrm{C}$ & $1 \mathrm{sec}$ \\
\hline \hline
\end{tabular}

An important channel for indoor environmental quality on place and occupant performance is the perceived quality of the environment. To explore the level of comfort at different schools and classrooms, we assess (1) teachers and (2) students by using annual questionnaires. For teachers, we use the Occupant Indoor Environmental Quality Survey developed by the Center for the Built Environment at the University of California, Berkeley (Madureira et al., 2016). The questionnaire includes questions about thermal comfort, perceived air quality, and noise. For students, we ask a cohort of 1,000 pupils, starting at age 10 (all pupils in group 6 in the sample), to report annually on their perceptions of odor intensity and acceptability by using a series of visual scales, previously validated in the literature (see Madureira et al., 2016). 
In addition, we also retrieve daily information ambient temperature from the Global Historical Climatology Network (GHCN) of the National Oceanic and Atmospheric Administration (NOAA) and outdoor levels or air pollution from the Dutch National Air Quality Monitoring Network (LML).

\subsubsection{Student Performance}

We exploit an existing infrastructure that tracks student performance, based on standardized tests (the LVS tracking system), regular evaluations by the teachers, the Cito final test, student and teacher attendance, student socio-demographics and their attitudes toward the school (see Table 2 for an overview of the data). This dataset is part of OnderwijsMonitor Limburg (OML) within the Educational Agenda Limburg that monitors educational development and teacher quality (See Borghans et al. (2015ba) and Willeboordse et al. (2016) for previous studies using this data).

In our sample of schools, the dataset contains a total of approximately 36,000 standardized tests per year (6 tests per child). Each child takes an average of 2 tests per year per subject. The tests comprise a wide variation of educational areas, such as reading, math, language and foreign language tasks (English). The dataset includes individual identifiers for each child in the dataset, allowing to follow children over the entire study period, and to explore changes in the test scores of a child. The panel structure of the dataset also allows for the exploitation of variation in environmental conditions, linking it to test scores at the individual level. In addition, the final dataset will include accurate information of the time and place of each of the tests in the sample, enabling differentiation between contemporaneous effects (i.e. at the time of testing) and permanent effects (learning).

Table 6.2: Student performance assessments

\begin{tabular}{lll}
\hline \hline National tests & School tests & Study tests \\
\hline $\begin{array}{l}\text { Cito LVS tracking tests } \\
\text { groups } 3-8\end{array}$ & Grades (four times/year) & Self-efficacy pupils \\
Cito final test group 7 & $\begin{array}{l}\text { School advice on secondary } \\
\text { education }\end{array}$ & $\begin{array}{l}\text { Strengths and difficulties } \\
\text { questionnaire }\end{array}$ \\
& Actual ongoing education & \\
\hline \hline
\end{tabular}

\subsubsection{Individual Characteristics}

\section{Individual Health Outcomes}

We gather data on health outcomes for children in the sample from multiple sources. Annual absence days of children will be collected by OML and the registration records by the 
educational board. For students enrolled in five sample schools, we will complement information on the student profile with general health measures of the child, combining multiple sources. All health outcome measures originate from an already existing longitudinal study on health and lifestyle of pupils. See Willeboordse et al. (2016) for a detailed description of all general health measures. Information on general health outcomes will be derived from an online parental questionnaire covering: disease status since birth, hospital admissions (number and duration), healthcare visits (number), and medication use in the previous 12 months (See Appendix A, B and $\mathrm{C}$ for the English translation of the exact questions in the questionnaire.). Anthropometric measurements, including height, weight, hip, and weight circumference will be objectively and separately collected for all children. Information on birth weight and additional information on disease status will be collected via the Regional Public Health Services (GGD).

Table 6.3: Health outcomes

\begin{tabular}{ll}
\hline \hline Health Measure & Source \\
\hline Birthweight (subsample of 5 schools) & Regional public health services (GGD) \\
Disease status, hospital admissions, medicine & Parental questionnaire and GGD \\
use, healthcare visits (subsample of 5 schools) & \\
Anthropometrics (subsample of 5 schools) & Objective measurement in children \\
Absence days & Onderwijs Monitor Limburg (OML) \\
Frequency of pupil absence and sick leave & Educational board \\
\hline \hline
\end{tabular}

\section{Household socio-economic characteristics}

In addition to academic and health outcomes, we gather a complete profile of household socio-economic characteristics of the pupil. These factors have been shown to be important mediators on the link between pupil health and academic achievement (Currie, 2009). This information is available for every pupil in the dataset and contains information on parental income, occupational status, education, and parental health.

\subsubsection{Medical Ethical Approval}

This study has been submitted for medical ethical approval, but the board of the ethical commission has provided a written statement that medical ethical approval is not required for this type of study. In addition, data on student performance and health stem from an already existing data infrastructure that is granted with ethical approval by the Ethical Review Committee Inner City faculties (ERCIC). Health data is obtained from the 'The Healthy primary School of the Future' (HPSF) project. Medical Ethical Approval for HPSF was waived by the Medical Ethical Committee of Zuyderland, Heerlen (METC 14-N-142). Data collection from GGD-ZL is executed by researchers of HPSF, this procedure has been fully approved by the Medical Ethical Committee of Zuyderland. The questionnaires on level of comfort will be filled in anonymously 
by students and teachers. All data records will be assured anonymized and confidential according to the Dutch data protection law.

\subsection{Pilot Study}

In this section, we present the results of a pilot study, carried out in multiple classrooms in two schools, for a complete academic year (2016-2017). The aim of the pilot study is to test the spatial and time series variation of indoor environmental conditions in schools. We first describe the characteristics of the schools selected for the pilot, and we then present a pilot test on the number of sensors per classroom needed to accurately measure indoor environment accurately. In the second pilot test, the cross-classroom variation in indoor environmental conditions is tested over the course of an academic year.

Two schools with heterogenous physical characteristics were selected for the pilot, with the aim to maximize differences in environmental conditions. Pilot School 1 represents a relatively new school, with a modern ventilation system in a rural area. Pilot School 2 is a school built over 20 years ago, with a mechanical ventilation system that initially did not cover the classrooms, but that was redesigned to do so during our pilot study. This school is located in an urban area. The location and building characteristics of the schools are thus expected to generate differences in indoor environmental parameters. In the pilot schools none of the teachers have control over the temperature in their classrooms.

Table 6.4: Student performance assessments

\begin{tabular}{lcc}
\hline \hline & Pilot School 1 & Pilot School 2 \\
\hline Construction Year & 2010 & 1992 \\
Ventilation in classrooms & Yes & No \\
Area Characteristics & Rural & Urban \\
Control Over Temperature & No & No \\
\hline \hline
\end{tabular}

\subsubsection{Pilot Test 1: Differences in Environmental Conditions Within and Across Classrooms}

The first phase of the pilot study is aimed at exploring the differences in environmental conditions within classrooms. For this purpose, we deployed 3 sensors in four classrooms (12 sensors in total) monitored for a period of 5 months (August 2016-January 2017). The sensors were deployed at the same height (1.50 meters) and in three separate locations covering the perimeter of the classrooms. $2^{2}$ The height was chosen following current guidelines for air quality monitoring at schools (WHO, 2011). In one of the classrooms at Pilot School 2, we further investigated the

\footnotetext{
${ }^{2}$ Photos of sampling locations in the classrooms of the pilot schools are shown in Appendix.
} 
differences in measurements at different heights (1.50 versus 2.00 meters) and the results show high correlations between the measurements of the sensor mounted at 2 meters versus the other two sensors installed in the same classroom.

Figure 2 presents the Pearson correlation coefficients between the sensors and respectively $\mathrm{CO} 2$, coarse particles and temperature for the first phase of the pilot study. The results indicate that the correlations for $\mathrm{CO} 2$, coarse particles and temperature between the three sensors within one classroom are on all occasions very high (over 0.98). Correlations of indoor environmental metrics are always higher between the sensors within a classroom than with sensor measurements in different classrooms in a school. Especially the variation in indoor temperature and CO2 levels is highly heterogenous between classrooms, as can be observed from figure 2. The correlation between sensors in different classrooms in the same schools is higher in Pilot School 1, the newly constructed school with a mechanical ventilation system, suggesting a higher degree of homogeneity in the school.

These graphs provide important information on the heterogeneity of indoor environmental conditions within a room, and the heterogeneity across rooms. From a measurement perspective the results suggest that there is unique information to obtain from each node, thus reinforcing the need to measure each room individually. However, deploying more than one sensor per room seems to be redundant.

Figure 6.2: Correlation in $\mathrm{CO}_{2}$, coarse particles and temperature within and across classrooms.
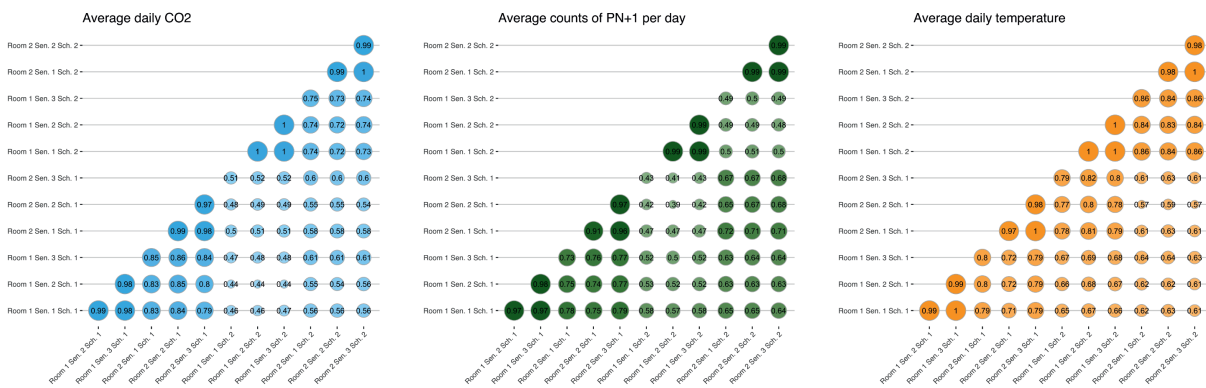

Note: The figure presents the Pearson correlation matrixes of the daily average of temperature, coarse particles (PN) and peaks of $\mathrm{CO} 2$, measured at different locations within 4 classrooms: 2 classrooms in a relatively new school ("School 1") and 2 classrooms in an older one ("School 2").

\subsubsection{Pilot Test 2: Time-Series Variation of Sensors over The Academic Year}

The second part of the pilot study aims to test the variation in indoor environmental conditions in the selected sample of classrooms over the period of one academic year. For this study, 12 sensors were placed in 10 classrooms and one computer room, divided over the two pilot schools described above. Figure 3 shows the variation in indoor temperature and $\mathrm{CO} 2$ levels over the 
course of a year for a classroom in Pilot School 1, along with the ambient temperature in the area of the school. The outdoor temperatures were gathered from the U.S. National Oceanic and Atmospheric Administration (NOAA) and correspond to the average daily temperatures measured at the nearby Maastricht Airport weather station. The average daily temperature in the classroom during learning hours ranges from $19 \mathrm{C}$ to $30 \mathrm{C}$, with an average of $22 \mathrm{C}$. The daily peaks of $\mathrm{CO} 2$ increase when the ambient temperature drops, fluctuating around 1,300 ppm in the cold season and around 1,000 ppm in the warm season.

Figure 6.3: Temperature and $\mathrm{CO}_{2}$ levels over the 2015-2016 academic year in classroom 1 of School 1 (with mechanical ventilation).

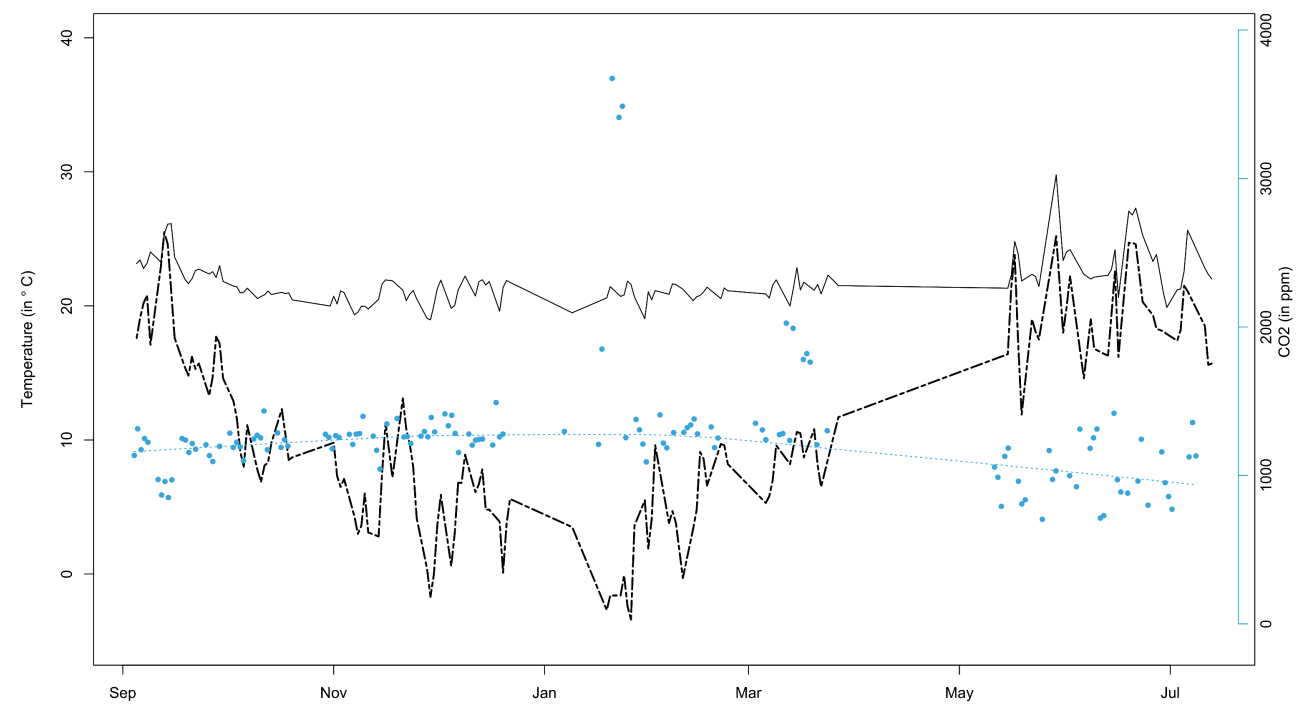

Compared to Pilot School 1, the variation in indoor temperature and CO2 levels over the course of a year in Pilot School 2 is quite high, as figure 4 illustrates. The figure highlights that the average daily temperature in the classroom during learning hours ranges from $19 \mathrm{C}$ to $28 \mathrm{C}$, with an average of $21 \mathrm{C}$. The daily peaks of $\mathrm{CO} 2$ again increase when the ambient temperature drops, fluctuating around 2,000 ppm in the cold season and around 1,000 ppm in the warm season.

There are significant differences in the levels of $\mathrm{CO} 2$ in the cold season, when teachers close the windows to keep the temperature in the classroom within acceptable levels for teaching. In the school with a ventilation system (figure 3) the daily peaks of $\mathrm{CO} 2$ are on average $700 \mathrm{ppm}$ lower than in the school without a ventilation system (figure 4). The difference becomes less pronounced during the warm season, when teachers in the naturally ventilated school frequently 
Figure 6.4: Temperature and $\mathrm{CO}_{2}$ levels over the 2015-2016 academic year in classroom 1 of School 2 (without mechanical ventilation).

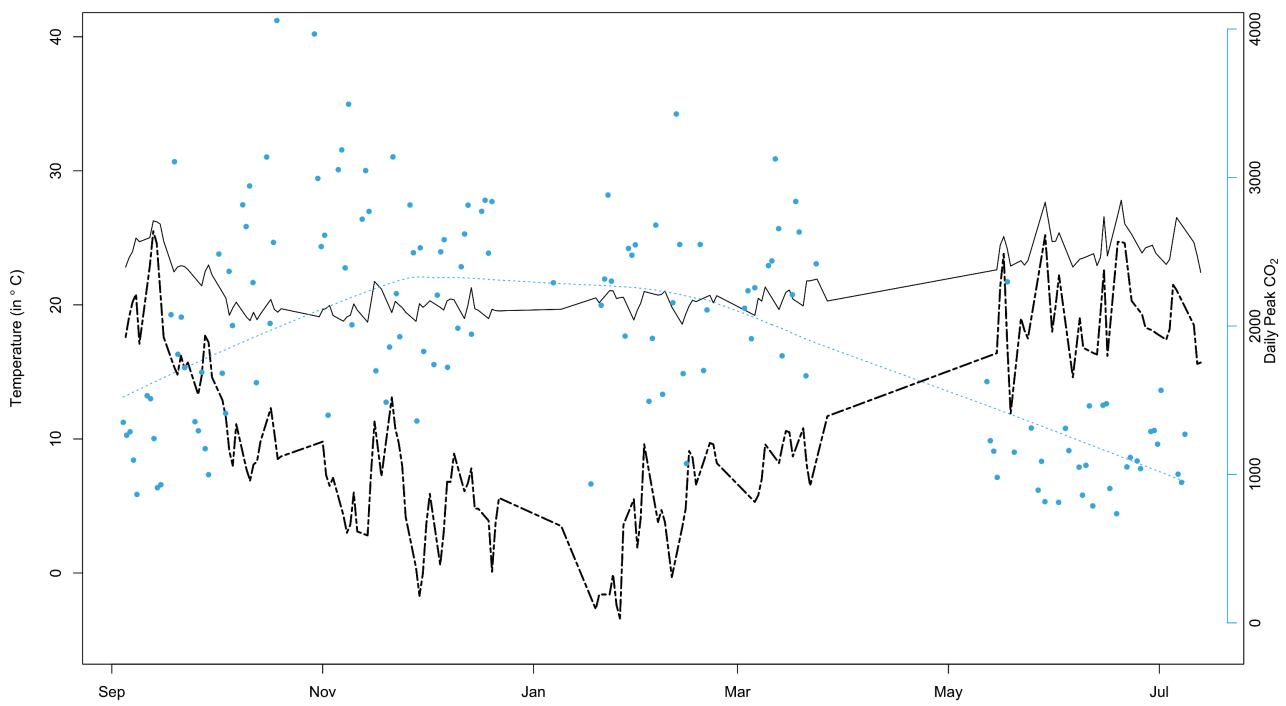

open the windows. The influence of ambient temperature on indoor temperature is higher in the summer period for both schools, when the lack of air conditioning even exposes pupils to temperatures surpassing the (already high) outdoor temperature.

During the academic year, it became apparent that indoor environmental quality is strongly associated with the status of building conditions and the status of the mechanical ventilation system. This is illustrated by the effects of a breakdown and modification of a ventilation system (figures 5 and 6). In January 2017, the ventilation system in Pilot School 1 had to be switched off for a week due to problems with the engines. In March 2017, half of the engines in the ventilation system were not working, so the ventilation system worked at half capacity for seven school days. As a result, the levels of $\mathrm{CO} 2$ increased by 50 to 70 percent, and tripled during the days where the ventilation system was not functioning at all.

We also observed a strong impact of modification of the ventilation system on classroom CO2 levels. In January 2017, the ventilation system in Pilot School 2 was modified to increase its coverage of the classrooms. The distribution of $\mathrm{CO} 2$ levels after the modification was significantly lower than the distribution before the change, reducing the exposure of children to high levels of $\mathrm{CO} 2$ (figure 6). We did not observe any systematic change in the distribution of the other IEQ characteristics collected by the sensor (see Appendix C for distribution of coarse particles and temperature before and after the modification). 
Figure 6.5: Distribution of daily CO2 peaks over the 20162017 academic year in Pilot School 1 for three scenarios in the ventilation system conditions.

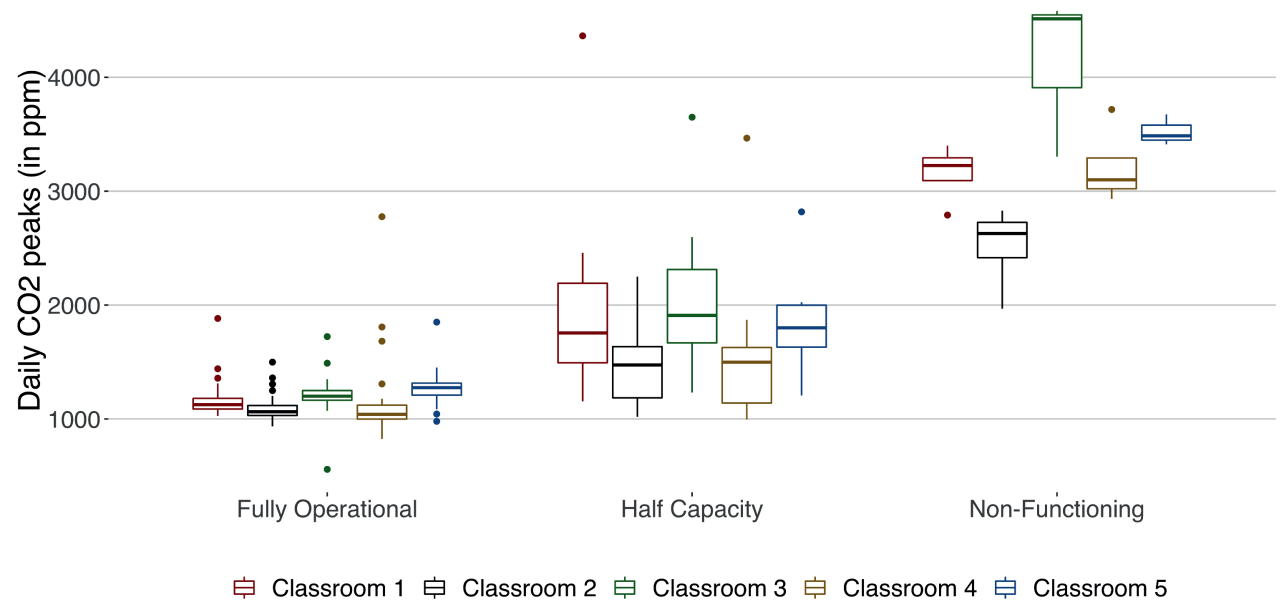

\footnotetext{
Note: The ventilation breakdown period took place in January 2017 and the "Half-Operational" period took place in March 2017. The fully operational block is computed using the CO2 peaks in January, February, March and April excluding the days where the ventilation system was not working properly.
}

Figure 6.6: Distribution of daily CO2 peaks in Classroom 1 and Classroom 2 of Pilot School 2 before and after modification in ventilation system.

\section{Classroom 1, School 2}

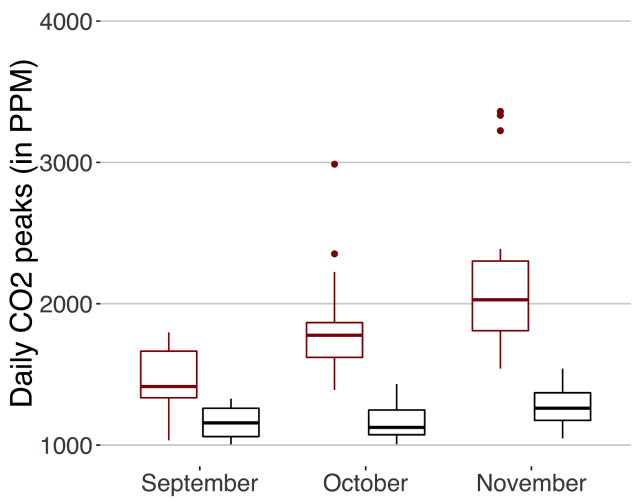

追 2016 帛 2017

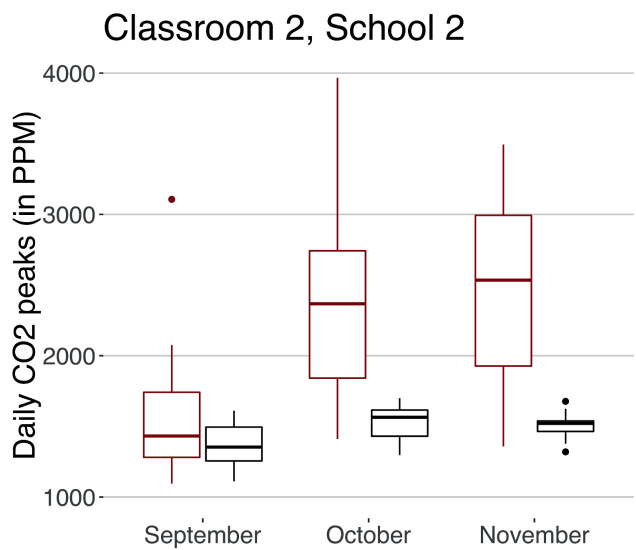

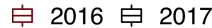

\subsection{Conclusions}

There is extensive evidence that exposure to poor environmental conditions is associated with deteriorations in physical health, mental health, and cognitive performance. However, most of the studies rely on outdoor measurements of environmental conditions and on samples of the adult population. Scientific evidence on the relationship between indoor environmental condi- 
tions and cognitive performance is scant, particularly for children, which arguably have most to lose from exposure to detrimental condition. From a methodological perspective, the literature is constrained by small samples, relying on between-subject comparisons rather than withinsubject comparisons, making it hard to establish causality. This paper describes the design of a longitudinal study in which the environmental conditions of more than 10,000 children will be monitored during four academic years and will be related to individual measures of academic performance and health. The study has a robust design to measure indoor environmental quality in a school setting, using state-of-the-art sensor technology to objectively measure the environmental conditions at high frequency.

From the first pilot study, we conclude that the exact placement of sensors in a classroom does not affect the ability of the sensor to accurately measure indoor environmental conditions. The additional information content from installing multiple sensors, relative to a singular sensor, to accurately measure indoor environmental quality within a classroom is low. Placement of one sensor at briefing height provides robust measurements of the indoor environment in a classroom setting. At the same time, indoor climate conditions differ considerably across classrooms, indicating that sensors need to be installed in each individual classroom in a school.

The second pilot study shows that the variation of various indoor environmental quality characteristics over the course of one academic school year is high. Due to the high variation of IEQ during the school year, a longitudinal design of at least one academic year is necessary to robustly measure the impact of indoor environmental quality on health and academic outcomes.

The proposed study will clarify to which degree different environmental characteristics influence cognitive performance, taking into account the health of pupils. The correct placement of sensors, the longitudinal design, and the large number of pupils included in the study will add valuable knowledge to the current literature. If it turns out that indoor environmental quality is indeed salient for the performance of young children, the next stage will be to design field experiments. By optimizing air, light and sound in classrooms, cognitive performance can possibly be improved. As changes in indoor environment are often low-cost and easily implementable, the direct societal and scientific importance of the findings in this study may be substantial. Indirectly, this study may affect how school buildings are built, managed, and maintained, both in the Netherlands and across the globe. 


\section{Appendix 6A: Respiratory diseases}

Table 6.5: Disease prevalence of children

\begin{tabular}{lcccc}
\hline \hline & $\begin{array}{c}\text { Child suffered } \\
\text { this before } \\
\text { primary school }\end{array}$ & $\begin{array}{c}\text { Child suffered } \\
\text { this during } \\
\text { primary school }\end{array}$ & $\begin{array}{c}\text { My child } \\
\text { currently has } \\
\text { this disease }\end{array}$ & $\begin{array}{c}\text { It has been } \\
\text { diagnosed by } \\
\text { a doctor }\end{array}$ \\
\hline $\begin{array}{l}\text { Asthma or chronic bronchitis } \\
\text { Hay fever or allergy to dust / } \\
\text { animals / medicines }\end{array}$ & Yes/No & Yes/No & Yes/No & Yes/No \\
Throat, nose or ear infections & Yes/No & Yes/No & Yes/No & Yes/No \\
$\begin{array}{l}\text { Pneumonia } \\
\text { Allergy for certain foods } \\
\text { (eg. gluten, lactose) }\end{array}$ & Yes/No & Yes/No & Yes/No & Yes/No \\
$\begin{array}{l}\text { Eczema or other skin } \\
\text { conditions }\end{array}$ & Yes/No & Yes/No & Yes/No & Yes/No \\
\hline \hline
\end{tabular}




\section{Appendix 6B: Medicine Use}

Did your child regularly used medicines for the past 12 months?

- Yes

- No

- I'd rather not fill in

If yes: What medication does your child use and what? If necessary, include the package. Homeopathic remedies do not need to be filled in here. Example: Ventolin, 2 times a month, $100 \mathrm{mg}$, 2 months used, used for asthma.

Table 6.6: Medicine usage of children

\begin{tabular}{l|l|l|l|l}
\hline \hline $\begin{array}{l}\text { What medicine } \\
\text { did your } \\
\text { child use? }\end{array}$ & $\begin{array}{c}\text { How often } \\
\text { per day / month? }\end{array}$ & Dose & $\begin{array}{c}\text { How many months } \\
\text { did your child use } \\
\text { this medicine during } \\
\text { the previous year? }\end{array}$ & $\begin{array}{l}\text { What did your } \\
\text { child use these } \\
\text { medicines for? }\end{array}$ \\
\hline Medicine 1: & & & & \\
\hline Medicine 2: & & & & \\
\hline Medicine 3: & & & & \\
\hline
\end{tabular}




\section{Appendix 6C: Current treatments}

Has your child been treated by organizations and/or doctors mentioned below during the last 12 months? You can check multiple options. If you have not been in contact with one of the organizations, you can check 'no'.

Table 6.7: Current treatments

\begin{tabular}{|c|c|c|}
\hline $\begin{array}{l}\text { Organizations / } \\
\text { Assistants }\end{array}$ & $\begin{array}{l}\text { Number of contacts } \\
\text { in the last } 12 \text { months }\end{array}$ & $\begin{array}{l}\text { What was/were the } \\
\text { reason(s) for treatment? }\end{array}$ \\
\hline General Practitioner & $\ldots$ times & \\
\hline Medical specialist: Pediatrician & $\ldots$ times & \\
\hline Medical specialist: Ophthalmologist & ... times & \\
\hline Medical specialist: E.N.T. Specialist & $\ldots$ times & \\
\hline Medical specialist: Orthopedist & ... times & \\
\hline Other medical specialist in the hospital. & ... times & \\
\hline \multicolumn{3}{|l|}{ Please specify: } \\
\hline Speech therapist & ... times & \\
\hline Youth Care Office & ... times & \\
\hline Youth care or child protection & ... times & \\
\hline \multicolumn{3}{|l|}{ No } \\
\hline Youth psychologist or psychiatrist & ... times & \\
\hline Other, please specify: & $\ldots$ times & \\
\hline \multicolumn{3}{|l|}{ 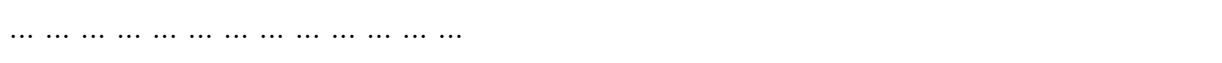 } \\
\hline \multicolumn{3}{|l|}{ 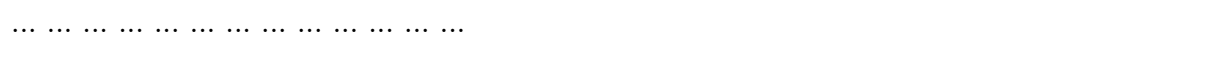 } \\
\hline \multicolumn{3}{|l|}{ 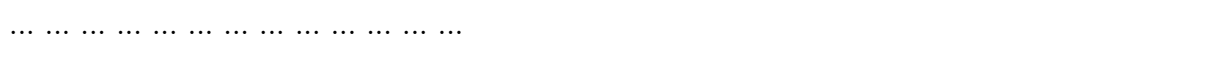 } \\
\hline No, I would rather not fill in & & \\
\hline
\end{tabular}


Appendix 6D: Pictures Deployment Pilot Study

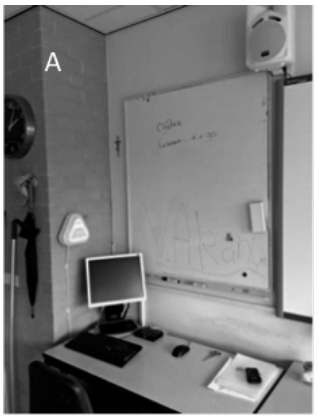

Sensor 1 Pilot School 1

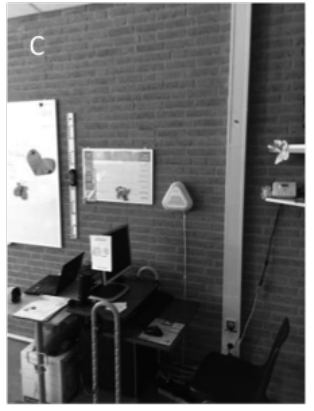

Sensor 1 Pilot School 2

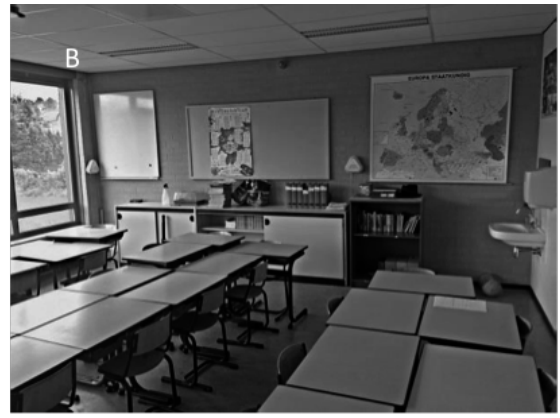

Sensor 2 and 3 Pilot School 1

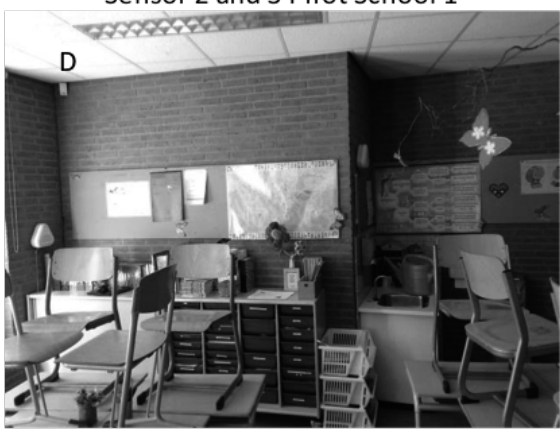

Sensor 2 and 3 Pilot School 2 


\section{Appendix 6E: Modification Ventilation System Pilot School 2}

Figure 6.7: Average daily counts of Coarse Particles (count/L) in Classroom 1 and Classroom 2 at Pilot School 2 over the fall of the academic year 2016-2017 before and after the ventilation system is modified (January 2017).

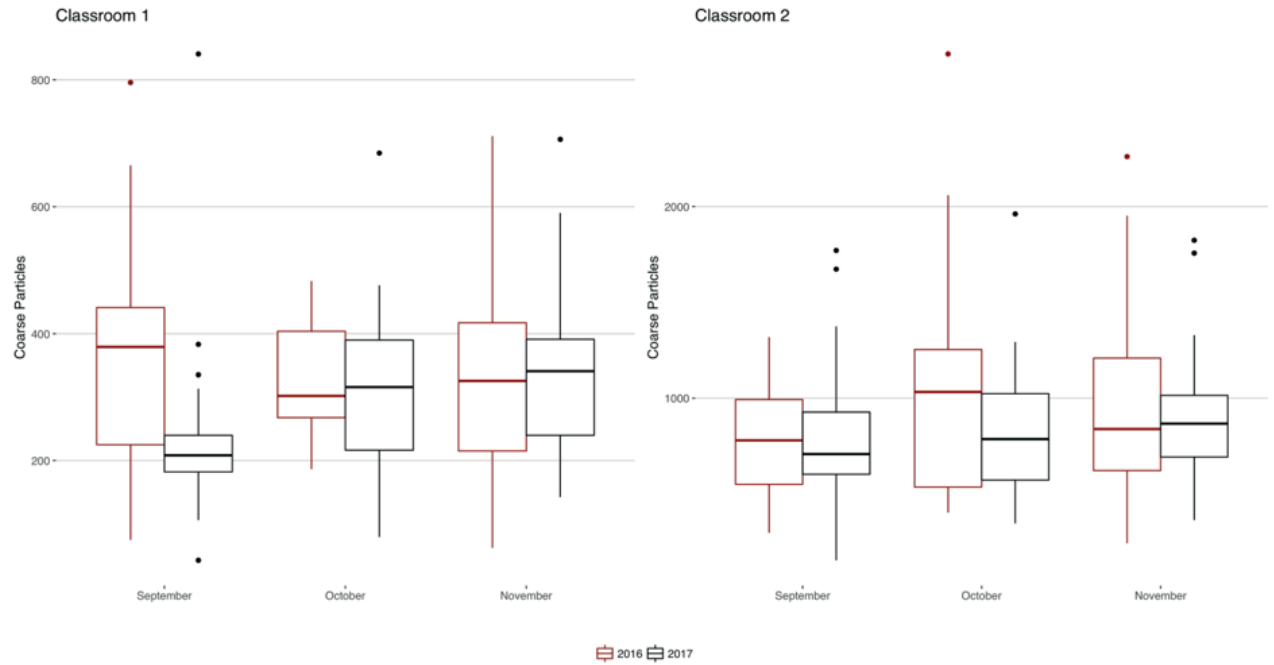

Figure 6.8: Average daily Temperature (in C) in Classroom 1 and Classroom 2 at Pilot School 2 over the fall of the academic year 2016-2017 before and after the ventilation system is modified (January 2017).

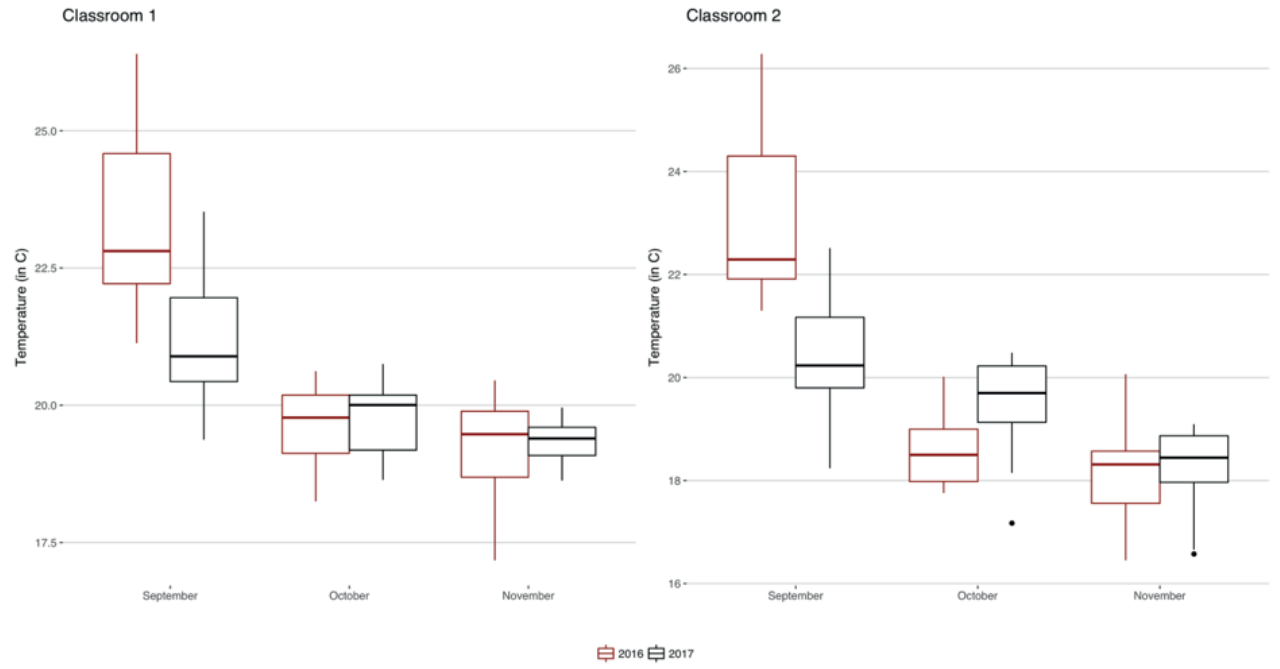





\section{Chapter 7}

\section{Conclusion}

This dissertation presents a series of studies exploring whether and to what extent environmental conditions inside buildings impact their occupants. The dissertation builds on the extensive literature in health science documenting the societal harm of outdoor environmental risk factors, like air pollution and extreme temperatures. Over the past decade, a new strand of literature has emerged, complementing the health science literature by analyzing the impact of the outdoor environment on human capital formation, productivity and economic development of nations. Economists have shown how individuals do not remain passive to these outdoor hazards, but undertake a series of actions to reduce the impact on their health and well-being (chapter 1).

Individuals in Western societies spend the overwhelming majority of their time indoors, giving buildings a crucial role in shaping the environmental conditions that we are ultimately exposed to, and in protecting us against environmental hazards. A good example is the widespread adoption of air conditioning in residential buildings in the US, which has been the main cause of the drop in heat-wave related mortality over the past decades.

Most of our current understanding of how indoor environmental conditions affect the health and performance of citizens of developed countries is currently based on lab studies. The traditional lab study locks a set of participants in a room where the air quality or temperature is experimentally manipulated, and asks them to undertake certain tasks. After a predefined exposure time, researchers collect a set of performance or health measures and compare the outcomes of the individuals in the treated condition with the outcomes of the individuals in the control condition 1

However, individuals in modern societies do not generally take as given the indoor environmental conditions that they are exposed to, and tend to have certain capacity to select the places where they live and work, and to transform these places to accommodate their preferences. Chapter 4 provides an example of the existence of such heterogeneous preferences for

\footnotetext{
${ }^{1}$ In within-subject studies, participants are exposed to both environmental conditions and the comparisons are made within individuals.
} 
environmental conditions. While both men and women in our treatment sample are moved to a new building designed to provide enhanced environmental conditions at the workplace, only men show an increase in satisfaction with the relocation to the new workplace. The influence of individuals on the spaces where they live and work challenges proper empirical identification of the impact of environmental conditions on occupants, where these conditions, at least to a certain extent, can be shaped by individuals.

The studies presented in this thesis are designed to ensure that the environmental conditions that humans are exposed are largely uninfluenced by themselves. Chapter 2 and 3 investigate the impact of housing conditions on occupant health, exploiting the variation in housing conditions over time for individuals that live in dwellings where an external party is in charge of the maintenance or renovations of the house. Chapter 2 explores the changes in tenant's health associated with changes in maintenance status of a house maintained by the landlord. Chapter 3 uses the upgrades in housing conditions triggered by a national renovation program in Germany that covers the entire region of Eastern Germany, where the individuals in our sample have no opportunity to decide on the timing and the type of renovation executed in the building. In both chapters, I find that changes in housing conditions have consequences for the health of the occupants.

The use of quasi-experimental methods in the field allows me to access larger samples than those generally used in the lab studies, allowing to test for heterogeneity in dose response functions that generally interest policy makers. For example, chapters 2 and 3 show that the changes in housing conditions have differential effects across age (chapter 2) and gender (chapter 3). In addition, the access to longitudinal data in the field allows me to test whether the estimated benefits of building upgrades are only transitory or are also present in the long term. The difference-in-difference estimates provided in chapter 4 show that the health benefits associated with the upgrade in the office environment persisted for more than 2 years after the upgrade.

The incentives that subjects face in lab experiments are generally designed by researchers. Those incentives, typically based on a monetary compensation, try to resemble the working conditions of individuals in an occupation of interest. So far, the standard approach of lab studies focusing on the effects of indoor environmental conditions is to compensate subjects with a showup fee, not rewarding their performance during the tasks (Zhang et al., 2017b; Seppänen et al. 2006, see, for example). Thus, poor performance in proposed tasks has no direct consequences for participants. The lack of incentives or stakes might thus encourage individuals to reduce effort in situations where participants are asked to perform tasks in a room that is unusually hot or poorly ventilated, to avoid fatigue or any other unpleasant consequences of undertaking tasks in suboptimal environmental conditions. Against this background, the final decrease in performance will therefore be a combination of a drop in the actual ability of the individual to 
execute the task under environmental stress and the decrease in the effort put in the task.

In real life settings, individuals tend to face a set of extrinsic and intrinsic incentives at work or school that rewards good performance and therefore makes it costly not to exert high effort. Chapters 5 and 6 in this thesis investigate the impact of indoor environmental conditions on performance in settings were individuals face incentives to exert high effort. In chapter 5 subjects are chess players for whom each game in the sample is part of an official tournament and therefore counts for their position in the national ranking. Chapter 6 examines the impact of environmental conditions in classrooms where primary school kids are learning or undertaking high-stake tests.

Chapter 5 indicates that the behavioral conditions under which the tasks are executed exacerbate the impact of environmental factors. In particular, time pressure magnifies the harm of pollution (PM2.5) on the performance of players in cognitive demanding tasks. In addition, further results from heterogeneity analysis in chapter 5 indicate that players are mainly affected by air pollution when playing games against players with a similar skill level, based on their ratings. Thus, the interaction between the environment and behavioral factors suggest that researchers should take into account the conditions and extrinsic motivation under which the tasks are executed when extrapolating the results.

Taken together, the studies presented in this dissertation investigate the role of environmental conditions, inside buildings, in shaping occupant health and performance, focusing on population-representative samples in settings where individuals are facing real-life incentives. Chapters 2 and 3 show how variations in housing conditions translate into changes in health care demand or health status. The sensitivity towards housing conditions differs across population groups, being larger for women and older adults. Chapter 4 examines the role of environmental conditions in workplaces on the health status of office workers. The results indicate that environmental conditions at work also generate significant and sustained changes in health status of individuals. Chapter 5 shows the detrimental impact of indoor air pollution (PM2.5) on the cognitive performance of highly motivated and highly skilled individuals. Finally, 6 presents a prospect field study were environmental conditions will be linked to the performance of thousands of kids over multiple years.

This dissertation provides initial estimates for policy makers and real estate market participants to justify future investments in the built environment on the grounds of occupant health and performance. The first part of the dissertation provides the evidence for the consideration of housing as a public health policy instrument, which may alleviate the increasing demand for healthcare services due to the aging of population in developed countries. The second part of the thesis provides insights towards the consideration of environmental conditions in the workplace as an additional factor shaping the performance of occupants executing cognitive tasks. 



\section{Chapter 8}

\section{Research Impact}

Investments in improving poor building conditions have long been proposed as instruments for health improvement (Thomson et al. 2009). However, most of today's rules and regulations guiding construction and renovation of buildings are based on grounds of minimizing energy consumption and environmental impact. Indeed, over the last decades the building industry has made remarkable progress in the design and standardization of assessment methods to measure energy performance of existing buildings. But when it comes to the indoor environmental conditions, the current Energy Performance Buildings Directive (2010/31/EU) by the European Parliament simply asks that the measures 'to improve further the energy performance of buildings should take into account climatic and local conditions as well as indoor climate environment and cost-effectiveness'. In addition, enhancing indoor environmental conditions of buildings is mostly focused on compliance with regulation preventing the exposure of citizens to extreme environmental risk factors, such as mold, lead paint or radon. So far, real estate markets have limited understanding of and appreciation for the benefits of investing in the improvement of indoor environmental conditions beyond extreme cases, where the health of occupants is at immediate risk.

The studies presented in this dissertation contribute to our understanding of the implications of improving indoor environments beyond extreme conditions. The results presented in chapters 2, 3 and 4 show how environmental conditions have consequences for occupant health in working and living places, for the average individual in a Western country. The chapters provide estimates of health costs associated with deficient building conditions (chapter 2), and health benefits linked to building upgrades (chapter 3 and 4). The sample of buildings and individuals in these studies are representative of the average building in developed countries.

To date, policy makers have been constrained by the lack of availability and access to tools to evaluate the indoor climate in buildings at scale, hindering the consideration of indoor climate when purchasing or leasing commercial or residential buildings. In the last decades, the sensor industry has made significant progress in the production of affordable tools to assess the indoor 
climate of our buildings (Kumar et al., 2015). Only in the commercial real estate sector, the number of sensors deployed in buildings is expected to reach in 1.6 billion in 2020 (Kejriwal and Mahajan, 2016). The widespread adoption of that technology will facilitate the access to information for market participants and policy makers, and ultimately allow for the incorporation of indoor environmental factors into guidelines, rules, regulations, construction projects and investment decisions.

The sensor revolution provides a wealth of information on environmental conditions at an unprecedented level of granularity and frequency, requiring a new set of techniques to obtain useful, new insights. Chapters 5 and 6 describe two innovative study designs of how to connect the data from this new generation of sensors to the performance and health of occupants in a noninvasive way. Chapter 5 connects the readings from environmental sensors to the performance of highly skilled individuals in cognitive demanding tasks, showing the detrimental impact of air pollutants on the cognitive abilities of individuals.

Chapter [ uses large sensor networks to investigate the impacts of environmental conditions in some of the most relevant buildings in modern societies, primary schools. Children in developed countries spend an average of 7,450 hours in school buildings during their primary and lower secondary education (OECD, 2016). Schools are also a major consumer of public funds. The U.S. alone invested USD49 billion per year in school facilities from 2011 to 2013 . Yet, a recent study reports that 53 percent of U.S. public schools are in urgent need of repairs, renovation and/or modernizations (U.S. Department of Education, 2014). The Dutch schools are no exception, a recent report on Dutch classrooms describes the learning environments as often poorly ventilated with potential harm for the learning outcomes of kids (Health Council of the Netherlands, 2010). However, the current shortage of field studies providing robust evidence about how environmental deficiencies at schools impair learning abilities of pupils prevents policy makers from a clear understanding of the exact costs of unhealthy classroom environments. Chapter 6 attempts to bridge this gap by describing a prospective study using a large scale sensor network and 10,000 kids to improve our understanding about how the environmental conditions during learning and testing affects academic performance outcomes. The unprecedented scale of the study will provide insights into how the kids are affected by environmental conditions in the learning and testing phases of the time spent at school.

Taken together, the advent of the sensor revolution provides researchers and policy makers with unprecedented opportunities to evaluate the human impact of investments in the built environment. The findings and methods described in the chapters of this dissertation provide the first insights for policy makers to assess and understand the impact of the conditions in buildings on the well-being, health and performance of their occupants. 


\section{Bibliography}

Adams, P., M. Hurd, D. McFadden, A. Merrill, and T. Ribeiro (2003): "Healthy, wealthy, and wise? Tests for direct causal paths between health and socioeconomic status," Journal of Econometrics, 112, 3-56.

Allen, J. G., P. Macnaughton, U. Satish, S. Santanam, J. Vallarino, and J. D. SPENGLER (2016): "Associations of cognitive function scores with carbon dioxide, ventilation, and volatile organic compound exposures in office workers: A controlled exposure study of green and conventional office environments," Environmental Health Perspectives, 124, 805812.

Altomonte, S. And S. Schiavon (2013): "Occupant satisfaction in LEED and non-LEED certified buildings," Building and Environment, 68, 66-76.

Andersen, H., A. Mühlbacher, M. Nübling, J. Schupp, and G. Wagner (2007): "Computation of standard values for physical and mental health scale scores using the SOEP version of SF12v2," Journal of Applied Social Science Studies (Schmollers Jahrbuch), 127, 171-182.

Angrist, J. D. And A. B. Krueger (1991): "Does Compulsory School Attendance Affect Schooling and Earnings?" The Quarterly Journal of Economics, 106, 979-1014.

Annesi-Maesano, I., N. Baiz, S. Banerjee, P. Rudnai, S. Rive, and SinPhonie Group (2013): "Indoor air quality and sources in schools and related health effects." Journal of toxicology and environmental health. Part B, Critical reviews, 16, 491-550.

Aragón, F. M., J. Jose, And P. Oliva (2017): "Particulate matter and labor supply : The role of caregiving," Journal of Environmental Economics and Management, 86, 295-309.

Archsmith, J., A. Heyes, And S. Saberian (2018): "Air Quality and Error Quantity : Pollution and Performance in a High-Skilled , Quality-Focused Occupation," Journal of the Association of Environmental and Resource Economists, 5.

Autor, D. And B. Price (2013): "The Changing Task Composition of the US Labor Market: An Update of Autor, Levy, and Murnane (2003)," MIT Working Paper.

Backhus, P., M. Cubel, M. Guid, S. Sánchez-Pages, and E. Lopez Manas (2016): "Gender, Competition and Performance: Evidence from Real Tournaments," IEB Working Paper.

Bakó-Biró, Z., D. Clements-Croome, N. Kochhar, H. Awbi, and M. Williams (2012): "Ventilation rates in schools and pupils' performance," Building and Environment, 48, 215223.

Banzhaf, S., L. Ma, And C. Timmins (2019): "Environmental Justice: The Economics of Race, Place, and Pollution," Journal of Economic Perspectives, 33, 185-208.

Barreca, A., K. Clay, O. Deschênes, M. Greenstone, and J. S. Shapiro (2016): "Adapting to Climate Change: The Remarkable Decline in the US Temperature-Mortality Relationship over the 20th Century," Journal of Political Economy, 124, 105-159.

BARRECA, A. I. (2012): "Climate change, humidity, and mortality in the United States," Journal of Environmental Economics and Management, 63, 19-34.

BARron, M. AND M. Torero (2017): "Household electrification and indoor air pollution," Journal of Environmental Economics and Management, 86, 81-92. 
Bernstein, J. A., N. Alexis, C. Barnes, I. L. Bernstein, J. A. Bernstein, A. Nel, D. Peden, D. Diaz-Sanchez, S. M. Tarlo, and P. B. Williams (2004): "Health effects of air pollution," Journal of Allergy and Clinical Immunology, 114, 1116-1123.

Bhatnagar, A. (2006): "Environmental cardiology: Studying mechanistic links between pollution and heart disease," Circulation Research, 99, 692-705.

BiLger, M. AND V. CARRIERI (2013): "Health in the cities: When the neighborhood matters more than income," Journal of Health Economics, 32, 1-11.

Billings, S. B. And K. T. Schnepel (2017): "The value of a healthy home: Lead paint remediation and housing values," Journal of Public Economics, 153, 69-81.

Bind, M., A. Peters, P. Koutrakis, B. Coull, P. Vokonas, and J. Schwartz (2016): "Quantile regression analysis of the distributional effects of air pollution on blood pressure, heart rate variability, blood lipids, and biomarkers of inflammation in elderly american men: The normative aging study," Environmental Health Perspectives, 124, 1189-1198.

Böckerman, P. And P. Ilmakunnas (2012): "The job satisfaction-productivity nexus: A study using matched survey and register data," Industrial and Labor Relations Review, 65, 244-262.

Borghans, L., B. H. H. Golsteyn, and U. Zölitz (2015a): "Parental preferences for primary school characteristics," B.E. Journal of Economic Analysis and Policy, 15, 85-117.

(2015b): "School quality and the development of cognitive skills between age four and six," PLoS ONE, 10, 1-20.

Breitner, S., K. Wolf, R. B. Devlin, D. Diaz-Sanchez, A. Peters, and A. Schneider (2014): "Short-term effects of air temperature on mortality and effect modification by air pollution in three cities of Bavaria, Germany: A time-series analysis," Science of the Total Environment, 485-486, 49-61.

Brunekreef, B. And S. T. Holgate (2002): "Air pollution and health," Lancet, 360, 12331242 .

Burda, M. C. (1993): "The Determinants of East-West German Migration: Some First Results,," European Economic Review, 37, 452-461.

Burgoyne, A. P., G. Sala, F. Gobet, B. N. Macnamara, G. Campitelli, and D. Z. HAMBRICK (2016): "The relationship between cognitive ability and chess skill: A comprehensive meta-analysis," Intelligence, 59, 72-83.

Burks, S. V., J. P. Carpenter, L. Goette, and A. Rustichini (2009): "Cognitive skills affect economic preferences, strategic behavior, and job attachment." Proceedings of the National Academy of Sciences of the United States of America, 106, 7745-50.

Calderon-Garciduenas, L., A. Calderon-Garciduenas, R. Torres-Jardon, J. AvilaRamirez, R. J. Kulesza, AND A. D. Angiulli (2015): "Air pollution and your brain: what do you need to know right now," Primary Health Care Research and Development, 16, 329345 .

Cattaneo, M. D., S. Galiani, P. J. Gertler, and S. Martinez (2009): "Housing, health, and happiness," American Economic Journal: Economic Policy, 1, 75-105.

Cedeño Laurent, J. G., A. Williams, Y. Oulhote, A. Zanobetti, J. G. Allen, and J. D. Spengler (2018): "Reduced cognitive function during a heat wave among residents of non-air-conditioned buildings: An observational study of young adults in the summer of 2016," PLoS Medicine, 15, 1-20.

Cedeño-laurent, J., A. Williams, P. Macnaughton, X. Cao, E. Eitland, J. SpenGLeR, AND J. Allen (2018): "Building Evidence for Health: Green Buildings, Current Science, and Future Challenges," Annual Review of Public Health, 39, annurev-publhealth031816-044420.

Chang, T., J. G. Zivin, T. Gross, And M. Neidell (2016): "Particulate pollution and the productivity of pear packers," American Economic Journal: Economic Policy, 8, 141-169. 
Chang, T. Y., J. Graff Zivin, T. Gross, and M. Neidell (2019): "The Effect of Pollution on Worker Productivity: Evidence from Call Center Workers in China," American Economic Journal: Applied Economics, 11, 151-172.

Chang, T. Y. AND A. K. ID (2019): "Battle for the thermostat : Gender and the effect of temperature on cognitive performance," PLoS ONE, 15, 1-10.

Charness, N. (1992): "The impact of chess research on cognitive science," Psychological Research, 54, 4-9.

Chay, K. And M. Greenstone (2003): "The Impact of Air Pollution on Infant Mortality: Evidence From Geographic Variation in Pollution Shocks Induced by a Recession," The Quarterly Journal of Economics, 118, 1121-1167.

Chay, K. Y. And M. Greenstone (2005): "Does air quality matter? Evidence from the housing market," Journal of Political Economy, 113, 376-424.

CHо, H. (2017): "The effects of summer heat on academic achievement: A cohort analysis," Journal of Environmental Economics and Management, 83, 185-196.

Cohen, A. J., M. Brauer, R. Burnett, H. R. Anderson, J. Frostad, K. Estep, K. Balakrishnan, B. Brunekreef, L. Dandona, R. Dandona, V. Feigin, G. Freedman, B. Hubbell, A. Jobling, H. Kan, L. Knibbs, Y. Liu, R. Martin, L. Morawska, C. A. Pope, H. Shin, K. Straif, G. Shaddick, M. Thomas, R. van Dingenen, A. van DonkelaAR, T. Vos, C. J. Murray, and M. H. Forouzanfar (2017): "Estimates and 25-year trends of the global burden of disease attributable to ambient air pollution: an analysis of data from the Global Burden of Diseases Study 2015," The Lancet, 389, 1907-1918.

Contoyannis, P., A. M. Jones, And N. Rice (2004): "The dynamics of health in the British Household Panel Survey," Journal of Applied Econometrics, 19, 473-503.

CucE, E. (2016): "Thermal regulation impact of green walls: An experimental and numerical investigation," Applied Energy, 194, 247-254.

Curl, A. And A. Kearns (2015): "Can housing improvements cure or prevent the onset of health conditions over time in deprived areas?" BMC public health, 15, 1191.

Currie, J. (2009): "Healthy, wealthy, and wise: Socioeconomic status, poor health in childhood, and human capital development," Journal of Economic Literature, 47, 87-122.

(2013): "Pollution and Infant Health," Child Development Perspectives, 7, 237-242.

Currie, J., L. Davis, M. Greenstone, and R. Walker (2015): "Environmental health risks and housing values: Evidence from 1,600 toxic plant openings and closings," American Economic Review, 105, 678-709.

Currie, J., E. A. Hanushek, E. M. Kahn, M. Neidell, and S. G. Rivkin (2009): "Does pollution increase school absences?" Review of Economics and Statistics, 91, 682-694.

Currie, J. AND B. C. MAdrian (1999): "Health, health insurance and the labor market," Handbook of Labor Economics, 3, 3309-3416.

Currie, J. And M. Neidell (2005): "Air Pollution and Infant Health: What Can We Learn From California's Recent Experience?" Quarterly Journal of Economics, 120, 1003-1030.

Cutler, D. and E. Glaeser (2005): "What explains differences in smoking, drinking, and other behaviors?" American Economic Review, 95, 238-242.

Dadvand, P., M. J. Nieumenhuijsen, M. Esnaola, J. Forns, X. Basagaña, M. Alvarez-Pedrerol, I. Rivas, M. López-Vicente, M. De Castro Pascual, J. Su, M. Jerrett, X. Querol, And J. Sunyer (2015): "Green spaces and cognitive development in primary schoolchildren," Proceedings of the National Academy of Sciences of the United States of America, 112, 7937-7942.

D'Angiulli, A. (2018): "Severe Urban Outdoor Air Pollution and Children's Structural and Functional Brain Development, From Evidence to Precautionary Strategic Action," Frontiers in Public Health, 6, 1-7. 
Dean, J. T. (2017): "Noise, Cognitive Function, and Worker Productivity," .

Deschenes, O. (2014): "Temperature, human health, and adaptation: A review of the empirical literature," Energy Economics, 46, 606-619.

Deschênes, O. And M. Greenstone (2011): "Climate change, mortality, and adaptation: Evidence from annual fluctuations in weather in the US," American Economic Journal: Applied Economics, 3, 152-185.

Deschenes, O. And E. Moretti (2009): "Extreme weather events, mortality, and migration," The Review of Economics and Statistics, 91, 659-681.

Deschênes, Olivier, Greenstone, Michael, \& Guryan, J. (2017): "American Economic Association Climate Change and Birth Weight Author," The American Economic Review, 99, 211-217.

Devoto, B. F., E. Duflo, P. Dupas, W. Pariente, and V. Pons (2012): "Happiness on Tap : Piped Water Adoption in Urban Morocco," American Economic Journal: Economic Policy, 4 .

Dieleman, J., M. Campbell, A. Chapin, E. Eldrenkamp, V. Fan, A. Haakenstad, Z. Kates, J., Li, T. Matyasz, A. Micah, And A. Reynolds (2017): "Future and potential spending on health 2015-40: Development assistance for health, and government, prepaid private, and out-of-pocket health spending in 184 countries," The Lancet, 389, 2005-2030.

Dorizas, P. V., M.-N. Assimakopoulos, and M. Santamouris (2015): "A holistic approach for the assessment of the indoor environmental quality, student productivity, and energy consumption in primary schools," Environmental Monitoring and Assessment, 187, 259 .

Ebenstein, A., M. Fan, M. Greenstone, G. He, and M. Zhou (2017): "New Evidence on the Impact of Sustained Exposure to Air Pollution on Life Expectancy from China's Huai," Proceedings of the National Academy of Sciences.

Ebenstein, A., V. Lavy, And S. Roth (2016): "The Long Run Economic Consequences of High-Stakes Examinations : Evidence from Transitory Variation in Pollution," American Economic Journal: Applied Economics, 8, 36-65.

Edmans, A. (2012): "The Link Between Job Satisfaction and Firm Value," Academy of Management Perspectives, 1-19.

EEA (2018): "Air quality in Europe," Tech. rep.

(2019): "Global and European Temperature," Tech. rep.

EIBICH, P. (2015): "Understanding the effect of retirement on health: Mechanisms and heterogeneity," Journal of Health Economics, 43, 1-12.

Eurostat (2017): "Consumption of energy," Tech. rep.

Federal Ministry of Transport, B. And Housing (2000): "10 Jahre KfW-Programm zur Wohnraummodernisierung in den neuen Bundeslandern," KfW Beitrage zur Mittelstands- und Strukturpolitik, 17.

Ferreira, A. M. D. C. AND M. CARdoso (2014): "Indoor air quality and health in schools." Jornal brasileiro de pneumologia : publicacao oficial da Sociedade Brasileira de Pneumologia e Tisilogia, 40, 259-68.

FIsk, W. J. (2017): "The ventilation problem in schools: literature review," Indoor Air, 27, $1039-1051$.

Fisk, W. J., A. G. Mirer, AND M. J. Mendell (2009): "Quantitative relationship of sick building syndrome symptoms with ventilation rates," Indoor Air, 19, 159-165.

Frijters, P., J. P. Haisken-DeNew, And M. A. Shields (2005): "The causal effect of income on health: Evidence from German reunification," Journal of Health Economics, 24, 997-1017. 
Frontczak, M., S. Schiavon, J. Goins, E. Arens, H. Zhang, and P. Wargocki (2012): "Quantitative relationships between occupant satisfaction and satisfaction aspects of indoor environmental quality and building design," Indoor Air, 22, 119-131.

Fu, S., V. B. Viard, AND P. Zhang (2017): "Air Pollution and Manufacturing Firm Productivity: Nationwide Estimates for China," .

Gaihre, S., S. Semple, J. Miller, S. Fielding, and S. Turner (2014): "Classroom carbon dioxide concentration, school attendance, and educational attainment." The Journal of school health, 84, 569-74.

Galiani, S., P. J. Gertler, And R. Undurraga (2018): "The half-life of happiness: Hedonic adaptation in the subjective well-being of poor slum dwellers to the satisfaction of basic housing needs," Journal of the European Economic Association, 16, 1189-1233.

Galiani, S., P. J. Gertler, R. Undurraga, R. Cooper, S. Martínez, and A. Ross (2017): "Shelter from the storm: Upgrading housing infrastructure in Latin American slums," Journal of Urban Economics, 98, 187-213.

Gaoua, N., S. Racinais, J. Grantham, and F. El Massioui (2011): "Alterations in cognitive performance during passive hyperthermia are task dependent," International Journal of Hyperthermia, 27, 1-9.

Gasparrini, A., Y. Guo, M. Hashizume, E. Lavigne, A. Zanobetti, J. Schwartz, A. Tobias, S. Tong, J. Rocklöv, S. Paulo, and S. Paulo (2015): "Mortality risk attributable to high and low ambient temperature : a multicountry observational study," Lancet, 386, 369-375.

GDW (1990): "Daten und Fakten der unternehmerischen Wohnungswirtschaft in den neuen Bundeslandern," Gesamtverband der Wohnungswirtschaft.

_ (1999): "Daten und Fakten 1998/1999 der unternehmerischen Wohnungswirtschaft in den neuen Landern," Gesamtverband der Wohnungswirtschaft.

Gerdes, C. And P. Gränsmark (2010): "Strategic behavior across gender: A comparison of female and male expert chess players," Labour Economics, 17, 766-775.

German Federal Statistical Office (2003): "Einkommens- und Verbrauchsstichprobe: Haus- und Grundbesitz sowie Wohnsituation privater Haushalte," Wirtschaftsrechnungen. Wirtschaftsrechnungen: Fachserie 15, Sonderheft 1.

Ghaffarianhoseini, A., H. AlWaer, H. Omrany, A. Ghaffarianhoseini, C. Alalouch, D. Clements-Croome, And J. Tookey (2018): "Sick building syndrome: are we doing enough?" Architectural Science Review, 61, 99-121.

Gill, D. And V. Prowse (2016): "Cognitive Ability, Character Skills, and Learning to Play Equilibrium: A Level-k Analysis," Journal of Political Economy, 124, 1619-1676.

Goodman, J., M. Hurwitz, J. Park, And J. Smith (2018): "Heat and Learning," NBER Working Paper.

Graff Zivin, J., S. M. Hsiang, And M. Neidell (2018): "Temperature and Human Capital in the Short and Long Run," Journal of the Association of Environmental and Resource Economists, 5, 77-105.

Graff Zivin, J. AND M. Neidell (2009): "Days of haze: Environmental information disclosure and intertemporal avoidance behavior," Journal of Environmental Economics and Management, 58, 119-128.

(2012): "The impact of pollution on worker productivity," American Economic Review, $102,3652-3673$. 689-730.

(2013): "Environment, health, and human capital," Journal of Economic Literature, 51,

(2014): "Temperature and the allocation of time: Implications for climate change," Journal of Labor Economics, 32, 1-26. 
(2018): "Air pollution's hidden impacts," Science, 359, 39-40.

Grossman, M. (1972): "On the concept of health capital and the demand for health," Journal of Political Economy, 80, 223-255.

Hancock, P. A., J. M. Ross, And J. L. Szalma (2007): "A meta-analysis of performance response under thermal stressors." Human factors, 49, 851-877.

Hanna, R., E. Duflo, and M. Greenstone (2016): "Up in smoke The influence of household behavior on the long-run impact of improved cooking stoves," American Economic Journal: Economic Policy, 8, 80-114.

Hanna, R. And P. Oliva (2015): "The effect of pollution on labor supply: Evidence from a natural experiment in Mexico City," Journal of Public Economics, 122, 68-79.

HARRIS, L. (1998): "Wiederaufbau, Welt und Wende. 50 Jahre Kreditanstalt fur Wiederaufbau - eine Bank mit öffentlichen Auftrag." .

Haverinen-Shaughnessy, U., D. J. Moschandreas, and R. J. Shaughnessy (2011): "Association between substandard classroom ventilation rates and students' academic achievement," Indoor Air, 21, 121-131.

Haverinen-Shaughnessy, U., R. J. Shaughnessy, E. C. Cole, O. Toyinbo, and D. J. MoschandREas (2015): "An assessment of indoor environmental quality in schools and its association with health and performance," Building and Environment, 93, 35-40.

He, J., N. Gouveia, And A. Salvo (2018): "External Effects of Diesel Trucks Circulating Inside the São Paulo Megacity," Journal of the European Economic Association, jvy015, 143.

HeAl, G. AND J. PARK (2016): "Reflections-temperature stress and the direct impact of climate change: A review of an emerging literature," Review of Environmental Economics and Policy, $10,347-362$.

Health Council of the Netherlands (2010): "Indoor air quality in primary schools," .

Hemp, P. (2004): "Presenteeism: At Work, But Out of It," Harvard Business Review.

Herrmann, F. R., C. Griffiths, H. Van Oyen, J.-M. Robine, S. L. K. Cheung, J.-P. Michel, AND S. Le Roy (2008): "Death toll exceeded 70,000 in Europe during the summer of 2003," Comptes Rendus Biologies, 331, 171-178.

Hutter, H. P., D. Haluza, K. Piegler, P. Hohenblum, M. Fröhlich, S. Scharf, M. Uhl, B. DAmberger, P. TAppler, M. Kundi, P. Wallner, and H. Moshammer (2013): "Semivolatile compounds in schools and their influence on cognitive performance of children," International Journal of Occupational Medicine and Environmental Health, 26, 628-635.

ImELDA (2018): "Indoor Air Pollution and Infant Mortality: A New Approach," American Economic Association Papers and Proceedings, 108, 416-21.

Isen, A., M. Rossin-Slater, AND R. WAlker (2017a): "Relationship between season of birth, temperature exposure, and later life wellbeing," Proceedings of the National Academy of Sciences, 114, 13447-13452.

Isen, A., M. Rossin Slater, And W. R. Walker (2017b): "Every Breath You Take Every Dollar You'll Make: The Long-Term Consequences of the Clean Air Act of 1970," Journal of Political Economy, 125, 848-902.

Kahn, M. E. AND P. LI (2019): "The effect of pollution and heat on high skill public sector worker productivity in China," NBER Working Paper.

Kahneman, D. And A. Deaton (2010): "High income improves evaluation of life but not emotional well-being," Proceedings of the National Academy of Sciences, 107, 16489-16493.

KARJALAinen, S. (2012): "Thermal comfort and gender: A literature review," Indoor Air, 22, 96-109. 
KeJRiwal, S. And S. Mahajan (2016): "Smart buildings: How IoT technology aims to add value for real estate companies," Deloitte University Press, 34-45.

KIm, J. AND R. DE DeAR (2013): "Workspace satisfaction: The privacy-communication tradeoff inopen-plan offices," Journal of Environmental Psychology, 36, 18-26.

Kim, J. L., L. Elfman, G. Wieslander, M. Ferm, K. Torén, and D. Norbäck (2011): "Respiratory health among Korean pupils in relation to home, school and outdoor environment," Journal of Korean Medical Science, 26, 166-173.

Kingma, B. and W. VAn Marken Lichtenbelt (2015): "Energy consumption in buildings and female thermal demand," Nature Climate Change, 5, 1054-1056.

Klepeis, N. E., W. C. Nelson, W. R. Ott, J. P. Robinson, A. M. Tsang, P. Switzer, J. V. Behar, S. C. Hern, and W. H. Engelmann (2001): "The National Human Activity Pattern Survey (NHAPS): A resource for assessing exposure to environmental pollutants." Journal of Exposure Analysis and Environmental Epidemiology, 11, 231-252.

Kolarik, B., Z. J. Andersen, T. Ibfelt, E. H. Engelund, E. Møller, and E. V. BRÄUNER (2016): "Ventilation in day care centers and sick leave among nursery children," Indoor Air, 26, 157-167.

Kumar, A. (2018): "Editorial: Neuroinflammation and Cognition," Frontiers in Aging Neuroscience, 10.

Kumar, P., L. Morawska, C. Martani, G. Biskos, M. Neophytou, S. Di Sabatino, M. Bell, L. Norford, AND R. BRITTER (2015): "The rise of low-cost sensing for managing air pollution in cities," Environment International, 75, 199-205.

KünN-Nelen, A. (2016): "Does commuting affect health?" Health Economics, 25, 984-1004.

Lafortune, J., J. Rothstein, And D. W. Schanzenbach (2016): "School Finance Reform and the Distribution of Student Achievement," 10, 1-26.

LAN, L., P. WARGOCKI, AND Z. LiAn (2011): "Quantitative measurement of productivity loss due to thermal discomfort," Energy and Buildings, 43, 1057-1062.

Landrigan, P. J., R. Fuller, N. J. R. Acosta, O. Adeyi, R. Arnold, N. N. Basu, A. B. Baldé, R. Bertollini, V. Fuster, M. Greenstone, A. Haines, D. Hanrahan, D. Hunter, M. Khare, A. Krupnick, B. Lanphear, B. Lohani, K. Martin, K. V. Mathiasen, M. A. Mcteer, C. J. L. Murray, J. D. Ndahimananjara, F. Perera, J. Potočnik, A. S. Preker, J. Ramesh, J. Rockström, C. Salinas, L. D. Samson, K. Sandilya, P. D. Sly, K. R. Smith, and A. Steiner (2018): "The Lancet Commission on pollution and health," Lancet, 391, 462-512.

Levitt, S. D., J. A. List, S. E. Sadoff, S. The, A. Economic, N. April, B. S. D. LevitT, J. A. List, ANd S. E. SAdoff (2011): "Checkmate : Exploring Backward Induction among Chess Players," American Economic Review, 101, 975-990.

Li, T., Y. Zhang, J. Wang, D. Xu, Z. Yin, H. Chen, Y. Lv, J. Luo, Y. Zeng, Y. Liu, P. L. KinneY, AND X. SHI (2018): "All-cause mortality risk associated with long-term exposure to ambient PM 2.5 in China: a cohort study," The Lancet Public Health, 3, 470-477.

Lichter, A., N. Pestel, ANd E. Sommer (2017): "Productivity effects of air pollution: Evidence from professional soccer," Labour Economics, 48, 54-66.

Liu, C., R. Chen, F. Sera, A. M. Vicedo-Cabrera, Y. Guo, S. Tong, M. S. Coelho, P. H. Saldiva, E. Lavigne, P. Matus, N. Valdes Ortega, S. Osorio Garcia, M. PasCal, M. Stafoggia, M. Scortichini, M. Hashizume, Y. Honda, M. Hurtado-Díaz, J. Cruz, B. Nunes, J. P. Teixeira, H. Kim, A. Tobias, C. Íñiguez, B. Forsberg, C. Åström, M. S. Ragettli, Y.-L. Guo, B.-Y. Chen, M. L. Bell, C. Y. Wright, N. Scovronick, R. M. Garland, A. Milojevic, J. Kyselý, A. Urban, H. Orru, E. Indermitte, J. J. JaAkkola, N. R. Ryti, K. Katsouyanni, A. Analitis, A. Zanobetti, J. Schwartz, J. Chen, T. Wu, A. Cohen, A. Gasparrini, and H. Kan (2019): "Ambient Particulate Air Pollution and Daily Mortality in 652 Cities," New England Journal of Medicine, 381, 705-715. 
Liu, F., S. Beirle, Q. Zhang, S. Dörner, K. He, and T. Wagner (2016): "NOxlifetimes and emissions of cities and power plants in polluted background estimated by satellite observations," Atmospheric Chemistry and Physics, 16, 5283-5298.

Liu, K., G. Sun, B. Li, Q. Jiang, X. Yang, M. Li, L. Li, S. Qian, L. Zhao, Z. Zhou, K. M. von DENEEn, AND Y. LiU (2013): "The impact of passive hyperthermia on human attention networks: An fMRI study," Behavioural Brain Research, 243, 220-230.

Loewenstein, G. And P. A. Ubel (2008): "Hedonic adaptation and the role of decision and experience utility in public policy," Journal of Public Economics, 92, 1795-1810.

Ludwig, J., G. J. Duncan, L. A. Gennetian, L. F. Katz, R. C. Kessler, J. R. Kling, AND L. SANBonmatsu (2012): "Neighborhood effects on the long-term well-being of low income adults," Science, 337, 1505-1510.

Luechinger, S. (2009): "Valuing air quality using the life satisfaction approach," The Economic Journal, 119, 482-515.

Macnaughton, P., J. Pegues, U. Satish, S. Santanam, J. Spengler, and J. Allen (2015): "Economic, Environmental and Health Implications of Enhanced Ventilation in Office Buildings," International Journal of Environmental Research and Public Health, 12, 1470914722 .

Macnaughton, P., U. Satish, J. G. C. Laurent, S. Flanigan, J. Vallarino, B. Coull, J. D. Spengler, And J. G. Allen (2016): "The impact of working in a green certified building on cognitive function and health," Building and Environment, 114, 178-186.

Madureira, J., I. Paciência, C. Pereira, J. P. Teixeira, and E. D. O. Fernandes (2016): "Indoor air quality in Portuguese schools: levels and sources of pollutants," Indoor Air, 26, 526-537.

Makri, A., M. Goveia, J. Balbus, And R. Parkin (2004): "Children's susceptibility to chemicals: a review by developmental stage," Journal of Toxicology and Environmental Health, $\underline{\text { Part B }, 7,417-435 . ~}$

Marcus, J. (2013): "The effect of unemployment on the mental health of spouses - Evidence from plant closures in Germany," Journal of Health Economics, 32, 546-558.

Mendell, E. Eliseeva, M. M. Davies, M. Spears, A. Lobscheid, W. J. Fisk, and M. G. APTE (2013): "Association of classroom ventilation with reduced illness absence: a prospective study in California elementary schools," Indoor air, 23, 515-528.

Mendell, M. J., E. A. Eliseeva, M. M. Davies, And A. Lobscheid (2015): "Do classroom ventilation rates in California elementary schools influence standardized test scores? Results from a prospective study," Indoor Air, n/a-n/a.

Meyer, S. And M. Pagel (2017): "Fresh Air Eases Work, The Effect of Air Quality on Individual Investor Activity," NBER Working Paper Series.

Mi, Y. H., D. Norbëck, J. TaO, Y. L. Mi, and M. Ferm (2006): "Current asthma and respiratory symptoms among pupils in Shanghai, China: Influence of building ventilation, nitrogen dioxide, ozone, and formaldehyde in classrooms," Indoor Air, 16, 454-464.

Mitchell, T. R., B. C. Holtom, T. W. Lee, C. J. Sablynski, and M. Erez (2001): "Why People Stay : Using Job Embeddedness to Predict Voluntary Turnover," Academy of Management Journal, 44, 1102-1121.

NAYHA, S. (2002): "Cold and the risk of cardiovascular diseases. A review." International journal of circumpolar health, $373-380$.

NeIDELl, M. (2009): "Information, avoidance behavior, and health. The effect of ozone on asthma hospitalizations," The Journal of Human Resources, 44, 450-478.

Nimon, K. F. And F. L. Oswald (2013): "Understanding the Results of Multiple Linear Regression: Beyond Standardized Regression Coefficients," Organizational Research Methods, $16,650-674$.

OECD (2016): Education at a Glance 2016: OECD Indicators, OECD Publishing, Paris. 
Oswald, A. J., E. Proto, And D. Sgroi (2015): "Happiness and Productivity," Journal of Labor Economics, 33, 789-822.

Palacios-Huerta, I. And O. Volij (2009): "Field centipedes," American Economic Review, 99, 1619-1635.

PArk, J. (2018): "Hot Temperature and High Stakes Cognitive Assessments," .

Patz, J. A., D. Campbell-lendrum, T. Holloway, J. A. Foley, and E. Nin (2005): "Impact of regional climate change on human health," Nature, 438, 310-317.

Perini, K. And P. Rosasco (2013): "Cost-benefit analysis for green façades and living wall systems," Building and Environment, 70, 110-121.

Petersen, S., K. L. Jensen, A. L. Pedersen, and H. S. Rasmussen (2016): "The effect of increased classroom ventilation rate indicated by reduced $\mathrm{CO} 2$ concentration on the performance of schoolwork by children," Indoor Air, 26, 366-379.

POHLMEIER, W. AND V. UlRich (1995): "An econometric model of the two-part decisionmaking process in the demand for health care," The Journal of Human Resources, 30, 339.

Pollack, C. E., K. O. Von Dem, And J. Siegrist (2004): "Housing and health in Germany." Journal of Epidemiology and Community Health, 58, 216-222.

Pope, C. A., R. T. Burnett, G. D. Thurston, M. J. Thun, E. E. Calle, D. Krewski, AND J. J. Godleski (2004): "Cardiovascular Mortality and Long-Term Exposure to Particulate Air Pollution: Epidemiological Evidence of General Pathophysiological Pathways of Disease," Circulation, 109, 71-77.

Power, M. C., S. D. Adar, J. D. Yanosky, and J. Weuve (2016): "Exposure to air pollution as a potential contributor to cognitive function, cognitive decline, brain imaging, and dementia: A systematic review of epidemiologic research," NeuroToxicology, 56, 235-253.

REICH, H. W. (2000): "Ein Schritt voran," KfW-Beitrage zur Mittelstands- und Strukturpolitik, 17.

REINHOLD, S. AND H. JÜrges (2010): "Secondary school fees and the causal effect of schooling on health behavior," Health Economics, 19, 994-1001.

Rosen, G. (2015): A history of public health, JHU Press.

Roth (2018): "The Contemporaneous Effect of Indoor Air Pollution on Cognitive Performance: Evidence from the UK," Mimeo, 1-32.

Rückerl, R., A. Schneider, S. Breitner, J. Cyrys, And A. Peters (2011): "Health effects of particulate air pollution: A review of epidemiological evidence," Inhalation Toxicology, 23, $555-592$.

Russo, S., A. Dosio, P. Barbosa, and J. Vogt (2014): "Extreme heat waves in present climate and their projection in a warming Mediterranean region," Journal of Geophysical Research: Atmospheres, 16, 2014.

Rustichini, A. (2015): "The role of intelligence in economic decision making," Current Opinion in Behavioral Sciences, 5, 32-36.

Santos Silva, J. M. And F. Windmeijer (2001): "Two-part multiple spell models for health care demand," Journal of Econometrics, 104, 67-89.

Satish, U., M. J. Mendell, K. Shekhar, T. Hotchi, D. Sullivan, S. Streufert, and W. J. FISK (2012): "Is CO2 an indoor pollutant? Direct effects of low-to-moderate CO2 concentrations on human decision-making performance." Environmental health perspectives, $120,1671-7$.

Schiele, V. AND H. Schmitz (2016): "Quantile treatment effects of job loss on health," Journal of Health Economics, 49, 59-69.

SChlenkeR, W. AND W. R. WAlker (2016): "Airports, air pollution, and contemporaneous health," The Review of Economic Studies, 83, 768-809. 
Seppänen, O., W. Fisk, And Q. Lei (2006): "Effect of Temperature on Task Performance in Office Environment," Lawrence Berkeley National Laboratory, 11.

Seppänen, O. A. And W. J. Fisk (2004): "Summary of human responses to ventilation," Indoor Air, 14, 102-118.

Shaughnessy, R. J., U. Haverinen-Shaughnessy, A. Nevalainen, and D. MoschanDREAS (2006): "A preliminary study on the association between ventilation rates in classrooms and student performance," Indoor Air, 16, 465-468.

SHAw, M. (2004): "Housing and public health." Annual Review of Public Health, 25, 397-418.

Shendell, D. G., R. Prill, W. J. Fisk, M. G. Apte, D. Blake, and D. Faulkner (2004): "Associations between classroom $\mathrm{CO} 2$ concentrations and student attendance in Washington and Idaho," Indoor Air, 14, 333-341.

Simoni, M., I. Annesi-Maesano, T. Sigsgaard, D. Norback, G. Wieslander, W. Nystad, M. Cancianie, P. Sestini, And G. Viegi (2010): "School air quality related to dry cough, rhinitis and nasal patency in children," European Respiratory Journal, 35, 742-749.

Singh, A., M. Syal, S. C. Grady, And S. Korkmaz (2010): "Effects of green buildings on employee health and productivity," American Journal of Public Health, 100, 1665-1668.

Sinn, H.-W. (1993): "Privatization in East Germany," NBER Working Paper Series.

(2000): "German's economic unification: An assessment after 10 years," NBER Working Paper Series.

Smith-Sivertsen, T., E. Díaz, D. Pope, R. T. Lie, A. Díaz, J. McCracken, P. Bakke, B. Arana, K. R. Smith, and N. Bruce (2009): "Effect of reducing indoor air pollution on women's respiratory symptoms and lung function: The RESPIRE Randomized Trial, Guatemala," American Journal of Epidemiology, 170, 211-220.

StAFFord, T. M. (2015): "Indoor air quality and academic performance," Journal of Environmental Economics and Management, 70, 34-50.

Stankovic, A., D. Alexander, C. M. Oman, And J. Schneiderman (2016): "A Review of Cognitive and Behavioral Effects of Increased Carbon Dioxide Exposure in Humans," NASA/TM-2016-219277, 1-24.

Stephens, M. And N. Desmond Toohey (2018): "The Impact of Health on Labor Market Outcomes: Experimental Evidence from MRFIT," Nber Working Paper Series.

Stewart, W., J. Ricci, E. Chee, D. Morganstein, and R. Lipton (2003): "Lost Productive Time and Cost Due to Common Pain Conditions in the US Workforce," Journal of the American Medical Association, 290, 2443-2454.

Sundell, J., H. Levin, W. W. Nazaroff, W. S. Cain, W. J. Fisk, D. T. Grimsrud, F. Gyntelberg, Y. Li, A. K. Persily, A. C. Pickering, J. M. Samet, J. D. Spengler, S. T. TAYLOR, AND C. J. WESChlER (2011): "Ventilation rates and health: Multidisciplinary review of the scientific literature," Indoor Air, 21, 191-204.

Sunyer, J., M. Esnaola, M. Alvarez-Pedrerol, J. Forns, I. Rivas, M. L??PezVicente, E. SuAdes-Gonz??LEZ, M. Foraster, R. Garcia-Esteban, X. Basaga??A, M. Viana, M. Cirach, T. Moreno, A. Alastuey, N. Sebastian-Galles, M. NieuwenhuiJsen, And X. Querol (2015): "Association between Traffic-Related Air Pollution in Schools and Cognitive Development in Primary School Children: A Prospective Cohort Study," PLoS Medicine, 12, 1-24.

Taylor, L., S. L. Watkins, H. Marshall, B. J. Dascombe, and J. Foster (2015): "The Impact of Different Environmental Conditions on Cognitive Function: A Focused Review," Front Physiol, 6, 372 .

Thomson, H., S. Thomas, E. Sellstrom, and M. Petticrew (2009): "The health impacts of housing improvement: a systematic review of intervention studies from 1887 to 2007," American Journal of Public Health, 99, S681-S692. 
Toftum, J., B. U. Kjeldsen, P. Wargocki, H. R. MenÅ, E. M. Hansen, and G. Clausen (2015): "Association between classroom ventilation mode and learning outcome in Danish schools," Building and Environment, 92, 494-503.

Twardella, D., W. Matzen, T. Lahrz, R. Burghardt, H. Spegel, L. Hendrowarsito, A. C. Frenzel, and H. Fromme (2012): "Effect of classroom air quality on students' concentration: results of a cluster-randomized cross-over experimental study," Indoor Air, 22, $378-387$.

Underwood, E. (2017): "The polluted brain," Science, 355, 342-345.

U.S. Department of Education (2014): "Condition of America's Public School Facilities : 2012-13," Washington, DC: National Center for Education Statistics.

U.S. Environmental Protection Agency (1985): "The total exposure assessment methodology (TEAM) study: Summary and analysis," Tech. rep., Washington, DC.

Wagner, G., J. Frick, And J. Schupp (2007): "The German Socio-Economic Panel Study (SOEP) - Scope, Evolution and Enhancements," Journal of Applied Social Science Studies, 127, 139-169.

Wang, M., U. Gehring, G. Hoek, M. Keuken, S. Jonkers, R. Beelen, M. Eeftens, D. S. Postma, and B. Brunekreef (2015): "Air pollution and lung function in Dutch children: A comparison of exposure estimates and associations based on Land Use Regression and dispersion exposure modeling approaches," Environmental Health Perspectives, 123, 847851.

Wargocki, P. AND D. P. Wyon (2007): "The Effects of Outdoor Air Supply Rate and Supply Air Filter Condition in Classrooms on the Performance of Schoolwork by Children (RP-1257)," HVAC\&R Research, 13, 165-191.

WHO (1983): "Indoor Air Pollutants: Exposure and Health Effects," EURO Reports and Studies, 78, 1-42.

Tech. rep.

(2007): "Large analysis and review of European housing and health Status (LARES),"

(2009): "Global health risks. Mortality and burden of disease attributable to selected major risks." WHO Library Cataloguing-in-Publication Data Global.

(2011): "Methods for monitoring indoor air quality in schools Methods for monitoring indoor air quality in schools," .

(2016): "Burning Opportunity: Clean Household Energy for Health, Sustainable Development, and Wellbeing of Women and Children." Who, 113.

Willeboordse, M., M. W. Jansen, S. N. van den Heijkant, A. Simons, B. Winkens, R. De Groot, N. Bartelink, S. P. Kremers, P. van Assema, H. H. Savelberg, E. De Neubourg, L. Borghans, T. Schils, K. M. Coppens, R. Dietvorst, R. ten Hoopen, F. Coomans, S. Klosse, M. Conjaerts, M. Oosterhoff, M. A. Joore, I. Ferreira, P. Muris, H. Bosma, H. L. Toppenberg, and C. P. van Schayck (2016): "The Healthy Primary School of the Future: study protocol of a quasi-experimental study," BMC Public Health, 16, 639.

Winkelmann, R. (2004): "Health care reform and the number of doctor visits - An econometric analysis," Journal of Applied Econometrics, 19, 455-472.

World Health Organization (2018): "WHO Housing and health guidelines," Tech. rep., Geneva.

Xiaofang, Y., W. Rodney, Y. Weiwei, V. Pavla, P. Xiaochuan, and T. Shilu (2012): "Ambient temperature and morbidity: A review of epidemiological evidence," Environmental Health Perspectives, 120, 19-28.

Xu, F., J. Uh, M. R. Brier, J. Hart, U. S. Yezhuvath, H. Gu, Y. Yang, and H. Lu (2011): "The influence of carbon dioxide on brain activity and metabolism in conscious humans," Journal of Cerebral Blood Flow and Metabolism, 31, 58-67. 
Zagreus, L., C. Huizenga, E. Arens, And D. Lehrer (2004): "Listening to the occupants: a Web-based indoor environmental quality survey." Indoor air, 14 Suppl 8, 65-74.

ZhANG, J. AND Q. MU (2018): "Air pollution and defensive expenditures: Evidence from particulate-filtering facemasks," Journal of Environmental Economics and Management, 92, $517-536$.

Zhang, Q., X. Jiang, D. Tong, S. J. Davis, H. Zhao, and G. Geng (2017a): "Transboundary health impacts of transported global air pollution and international trade," Nature, 543, 705-709.

Zhang, X., X. Chen, And X. Zhang (2018): "The impact of exposure to air pollution on cognitive performance," Proceedings of the National Academy of Sciences, 115, 9193-9197.

Zhang, X., F. Li, L. Zhang, Z. ZhaO, And D. Norback (2014): "A longitudinal study of sick building syndrome (SBS) among Pupils in Relation to SO2, NO2, O3 and PM10 in schools in China," PLoS ONE, 9.

Zhang, X., P. Wargocki, and Z. Lian (2015): "Effects of Exposure to Carbon Dioxide and Human Bioeffluents on Cognitive Performance," Procedia Engineering, 121, 138-142.

Zhang, X., P. Wargocki, Z. Lian, and C. Thyregod (2017b): "Effects of exposure to carbon dioxide and bioeffluents on perceived air quality, self-assessed acute health symptoms, and cognitive performance," Indoor Air, 27, 47-64.

Zhang, Xin, Xi Chen And X. Zhang (2018): "The impact of exposure to air pollution on cognitive performance," Proceedings of the National Academy of Sciences, 115, 9193-9197.

Zheng, S. And M. E. KAhn (2013): "Understanding China's Urban Pollution Dynamics," Journal of Economic Literature, 51, 731-772. 
